Florida International University FIU Digital Commons

$10-27-2016$

\title{
Qualitative Analysis for the Characterization and Discrimination of Printing Inks
}

Rhett J. Williamson

Florida International University, rwill166@fiu.edu

DOI: $10.25148 /$ etd.FIDC001179

Follow this and additional works at: https://digitalcommons.fiu.edu/etd

Part of the Analytical Chemistry Commons

\section{Recommended Citation}

Williamson, Rhett J., "Qualitative Analysis for the Characterization and Discrimination of Printing Inks" (2016). FIU Electronic Theses and Dissertations. 3055.

https://digitalcommons.fiu.edu/etd/3055

This work is brought to you for free and open access by the University Graduate School at FIU Digital Commons. It has been accepted for inclusion in FIU Electronic Theses and Dissertations by an authorized administrator of FIU Digital Commons. For more information, please contact dcc@fiu.edu. 


\title{
FLORIDA INTERNATIONAL UNIVERSITY
}

Miami, Florida

\section{QUALITATIVE ANALYSIS FOR THE CHARACTERIZATION AND DISCRIMINATION OF PRINTING INKS}

\author{
A dissertation submitted in partial fulfillment of \\ the requirements for the degree of \\ DOCTOR OF PHILOSOPHY \\ in \\ CHEMISTRY \\ by
}

Rhett Williamson

2016 
To: Dean Michael R. Heithaus

College of Arts, Sciences and Education

This dissertation, written by Rhett Williamson, and entitled Qualitative Analysis for the Characterization and Discrimination of Printing Inks, having been approved in respect to style and intellectual content, is referred to you for judgment.

We have read this dissertation and recommend that it be approved.

Piero R. Gardinali

James M. Quirke

Sneh Gulati

Antonio A. Cantú

José R. Almirall, Major Professor

Date of Defense: October 27, 2016

The dissertation of Rhett Williamson is approved.

Dean Michael R. Heithaus

College of Arts, Sciences and Education

Andrés G. Gil

Vice President for Research and Economic Development and Dean of the University Graduate School

Florida International University, 2016 
C Copyright 2016 by Rhett Williamson

All rights reserved. 


\section{DEDICATION}

To my family, who have supported me since day one and pushed me to work towards my dreams. To my friends and loved ones who have stuck with me through the ups and downs, and for being understanding during my time in graduate school- I would not have been able to do this without you, and for helping me learn that: "We are made to persist. That's how we find out who we really are."- Tobias Wolff 


\section{ACKNOWLEDGMENTS}

First, I'd like to acknowledge and thank Dr. José R. Almirall for providing me with the opportunity to be a part of his research group, for his guidance, insight, and for pushing me to excel. I would also like to thank my dissertation committee Dr. Piero Gardinali, Dr. Martin Quirke, Dr. Sneh Gulati, and Dr. Antonio Cantú for being an active part of my graduate school experience, their time and guidance. A special thank you to Dr. Cantú for generously agreeing to be a part of my dissertation committee from Virginia and then Texas. His wealth of knowledge and willingness to provide technical and life advice have been invaluable.

I would like to acknowledge the University Graduate School for the Dissertation Year Fellowship and the Graduate and Professional Student Committee for providing travel funds for research and conference travel multiple times throughout my graduate school career.

I would also like to acknowledge Dr. Luis Arroyo for technical support and advice, and use of instruments in the Forensic Toxicology and Analytical Facility at FIU. Dr. Floyd Russell at Florida Atlantic University is acknowledged for use of the MALDITOF-MS instrument. The U.S. Homeland Security Investigation Forensic Laboratory is acknowledged for providing inks samples, data, and technical advice. Dr. Mario Gomez is acknowledged for technical support in analyzing samples for MALDI-MS analysis at the Advanced Mass Spectrometry Facility at Florida International University. Many thanks to Dr. Tatiana Trejos for endless amounts of guidance and support both professionally and personally. 
ABSTRACT OF THE DISSERTATION

QUALITATIVE ANALYSIS FOR THE CHARACTERIZATION AND

DISCRIMINATION OF PRINTING INKS

by

Rhett Williamson

Florida International University, 2016

Miami, Florida

Professor José R. Almirall, Major Professor

Improvements in printing technology and the wide accessibility of advanced printers has resulted in an increase in counterfeiting. Of particular interest to forensic document examiners, ink analysis of security documents has emerged as an important tool for the analysis, comparison, and association of inks to a potential production source. In this study, methods were developed for Py-GC/MS, ATR-FTIR, DART-MS, and MALDI-MS analyses of printing inks of four classes: 78 inkjet inks, 76 toners, 79 offset inks, and 86 intaglio inks in order to generate information on the organic chemical characterization of the inks to determine the ability to associate and discriminate the inks for uses in security document examinations. The suite of analytical techniques evaluated in the study focused on having the following analytical characteristics: 1) rapid analysis time, 2) little-to-no sample preparation, 3) minimal destructiveness to the sample, 4) allow for association of inks with the same source of origin as well as discrimination of inks originating from different sources. As a result of this study, a novel searchable library database of inks was developed for use with each analytical chemical method that allows for data fusion. 
Py-GC/MS analysis was used to achieve $>63 \%$ discrimination of toner inks on the basis of the characterization of polymer degradation products. The combination of a protocol implementing first ATR-FTIR and subsequently DART-MS analysis resulted in $>96 \%$ discrimination for toners, $95 \%$ for inkjet, $>92 \%$ for offset, and $>54 \%$ for intaglio. In addition, a case study was performed using DART-MS to illustrate its utility as a tool for ink analysis in document examination. The results of MALDI-MS analyses from two different instruments resulted in $>90 \%$ discrimination of a subset of all inks by characterizing the colorant molecules present in ink formulations. A study characterizing luminescent compounds present in the formulation of inks in crossed-line intersections was performed using a combination of MALDI-MS, LC-MS, and TLC. Overall, it was shown that the combination of analytical techniques included within this dissertation can provide information on the organic chemical composition of four classes of printing inks, which is useful for the future of document examination. 


\section{TABLE OF CONTENTS}

CHAPTER

PAGE

CHAPTER 1. INTRODUCTION ....................................................................... 1

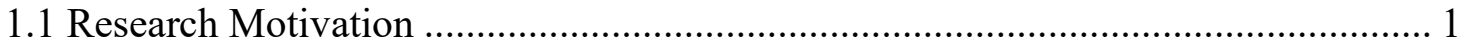

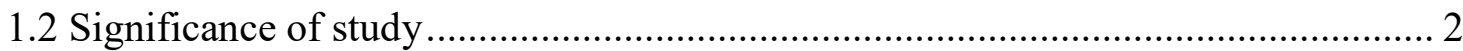

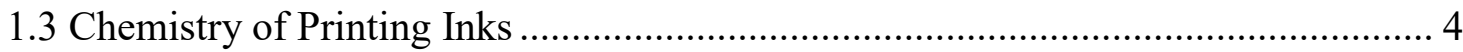

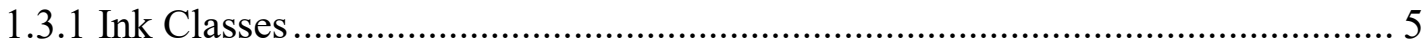

1.3.2 Analytes of interest in the organic analysis and characterization of inks.......... 6

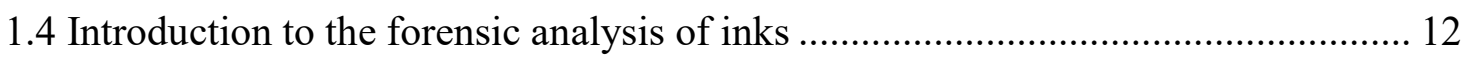

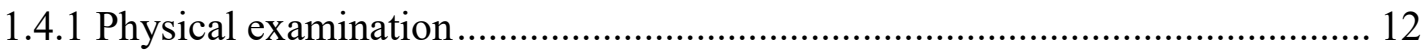

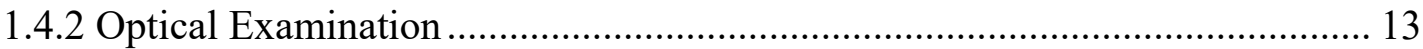

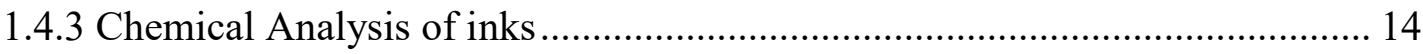

1.5 Previously Reported chemical techniques for the analysis of inks ....................... 15

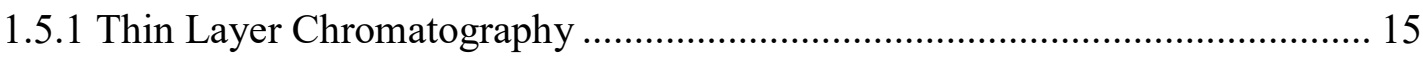

1.5.2 Pyrolysis Gas Chromatography_Mass Spectrometry ................................ 16

1.5.3 Attenuated Total Reflectance_-Fourier Transform Infrared Spectroscopy ..... 17

1.5.4 Direct Analysis in Real Time-Mass Spectrometry .................................... 18

1.5.5 Matrix —Assisted Laser Desorption Ionization-Mass Spectrometry ............. 19

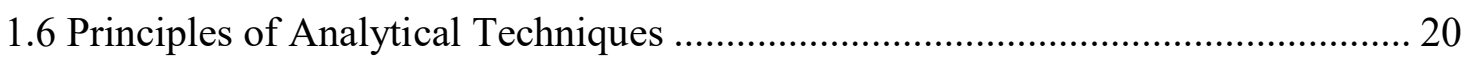

1.6.1 Pyrolysis Gas Chromatography-Mass Spectrometry …............................. 20

1.6.2 Attenuated Total Reflectance-Fourier Transform Infrared Spectroscopy ..... 20

1.6.3 Direct Analysis in Real Time-Mass Spectrometry .................................... 22

1.6.4 Matrix - Assisted Laser Desorption Ionization-Mass Spectrometry …......... 24

CHAPTER 2. MATERIALS AND METHODS ....................................................... 26

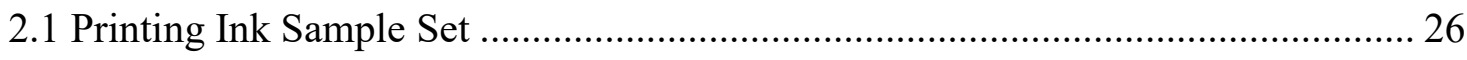

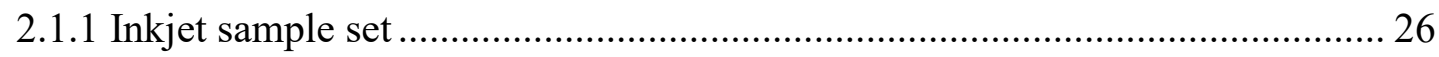

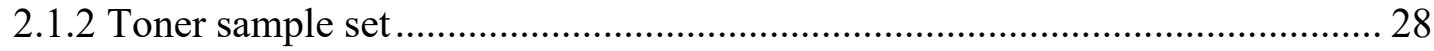

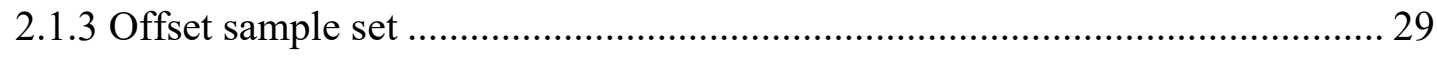

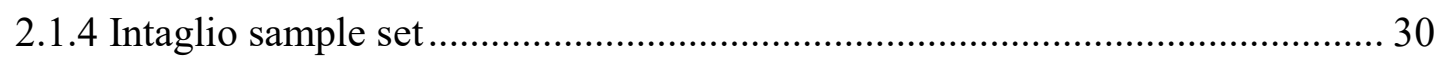

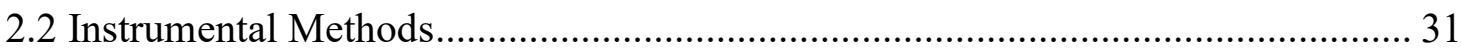




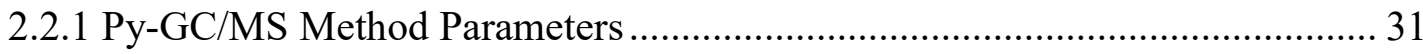

2.2.3 ATR-FTIR Method Parameters ..................................................................... 32

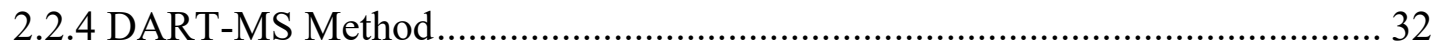

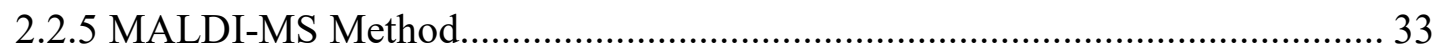

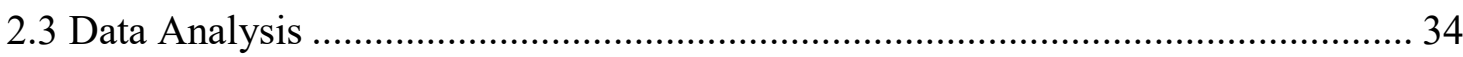

CHAPTER 3. ANALYSIS OF PRINTING INKS BY PY-GC/MS …………………....... 36

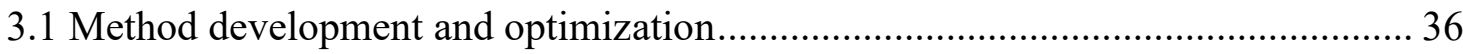

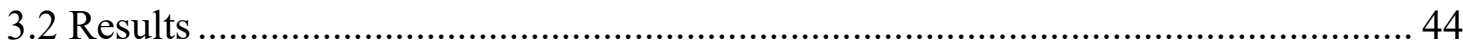

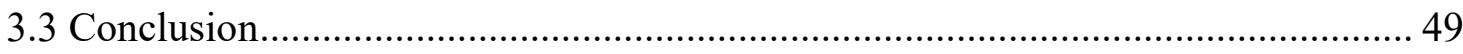

CHAPTER 4. ANALYSIS OF PRINTING INKS USING ATR-FTIR ………………....51

4.1 Method development and optimization................................................................. 51

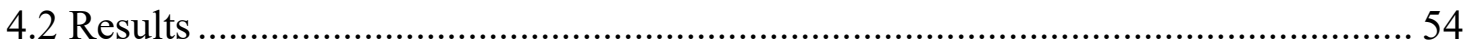

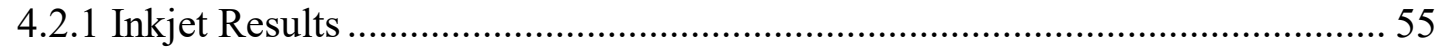

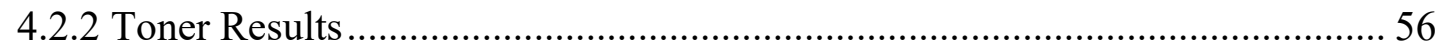

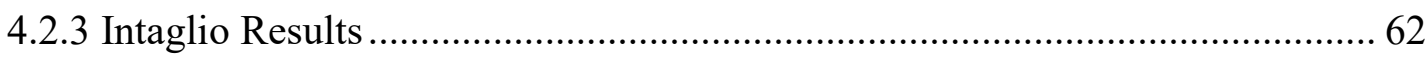

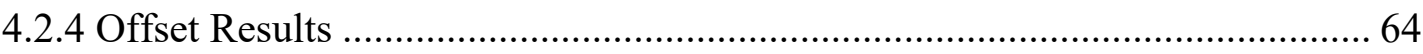

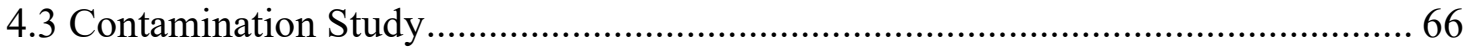

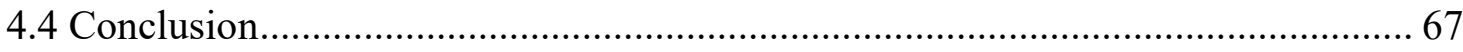

CHAPTER 5. ANALYSIS OF PRINTING INKS USING DART-MS ........................... 70

5.1 Method Development and Optimization .................................................................. 70

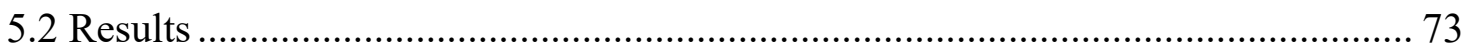

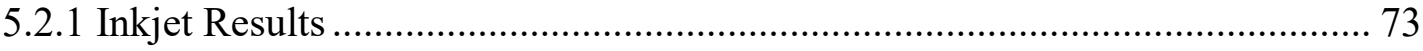

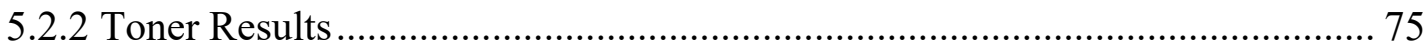

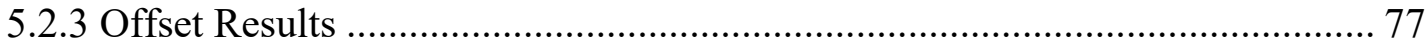

5.2.4 Intaglio Results .................................................................................... 78

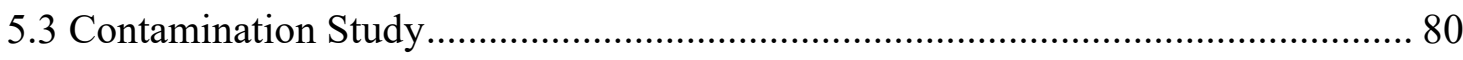

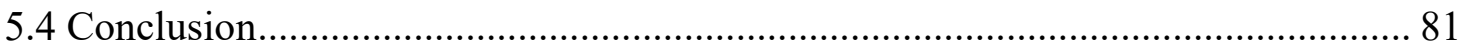

CHAPTER 6. ANALYSIS OF PRINTING INKS USING MALDI-MS .......................... 83

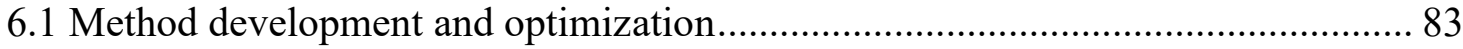


6.2 Results 86

6.2.1 Comparison between Voyager DE PRO and Bruker AutoFlex II

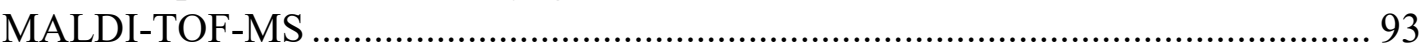

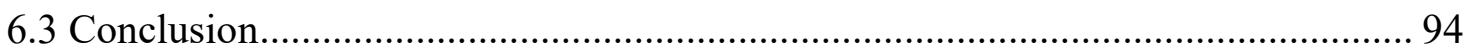

CHAPTER 7. PHYSICAL CHEMISTRY OF CROSSED-LINE INTERSECTIONS: CHEMICAL ANALYSIS OF INK COMPONENTS.................................................... 97

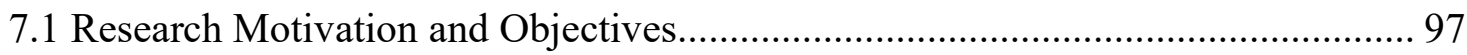

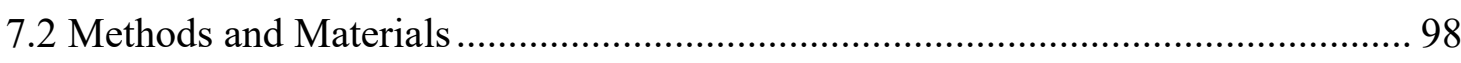

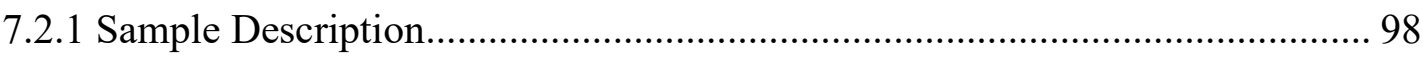

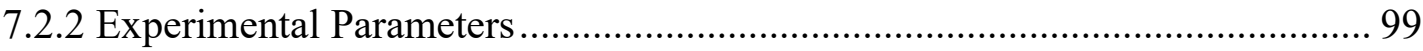

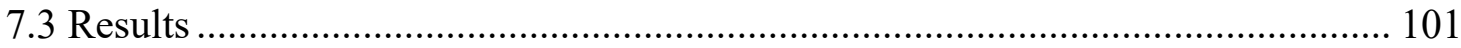

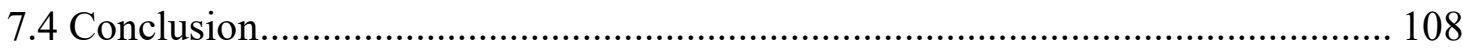

CHAPTER 8. POSSIBLE ALTERATION OF A CHEMISTRY EXAM: A CASE STUDY USING DART-MS ............................................................................... 111

8.1 Background and reasoning for chemical analysis .................................................. 111

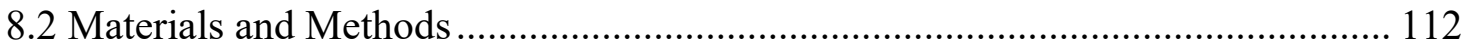

8.2.1 Experimental method and sample description............................................. 113

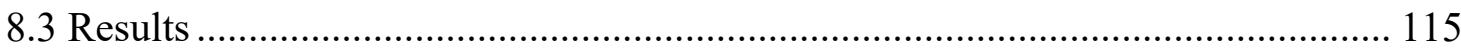

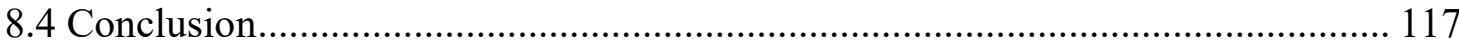

CHAPTER 9. UTILITY OF COMBINING CHEMICAL METHODS FOR THE

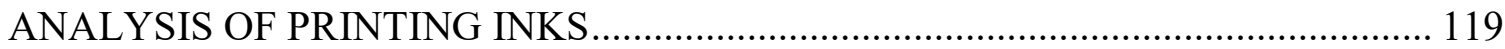

9.1 Combined ATR-FTIR and DART-MS analysis of printing inks ........................... 119

9.2 Complementarity of DART-MS and MALDI-MS ............................................... 122

CHAPTER 10. DEVELOPMENT OF A SEARCHABLE DATABASE FOR THE COMPARISON OF PRINTING INK EVIDENCE …………………...................... 125

10.1 Background and Research Motivation .......................................................... 125

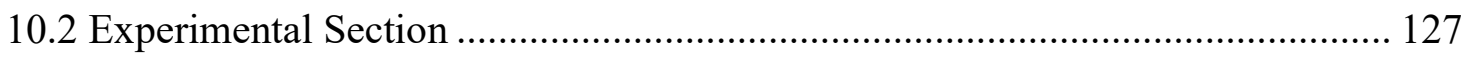

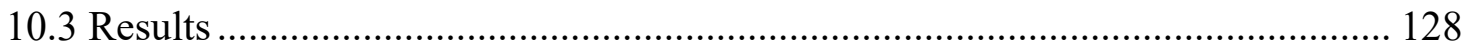

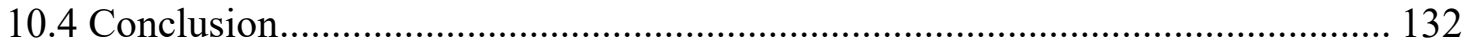

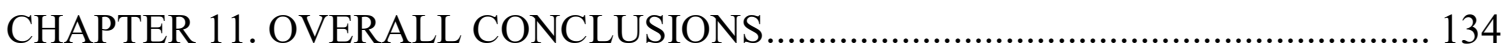




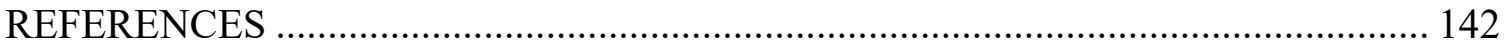

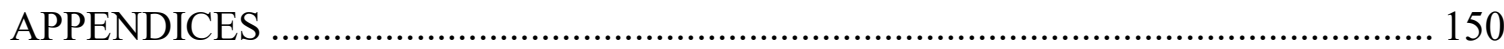

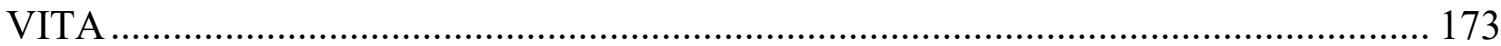




\section{LIST OF TABLES}

TABLE

PAGE

Table 1- Examples of molecules found in the formulation of printing inks 9

Table 2- Comparison of figures of merit for diamond and germanium

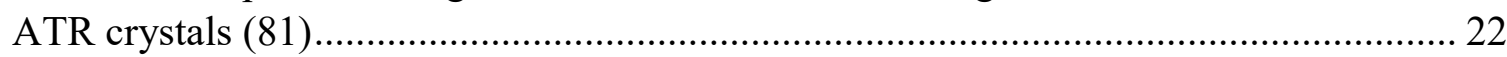

Table 3. Optimized parameters for Py-GC-MS analysis.................................................. 37

Table 4. Tentative identification of compounds in HSI Laboratory toner sample ........... 43

Table 5. Compounds used for grouping of Py-GC/MS data for toners. ........................... 46

Table 6- Grouping of toner ink samples by Py-GC/MS analysis based on presence and absence of compounds used for classification .......................................................... 47

Table 7- Discrimination capability of Py-GC/MS for toner inks based on color (CMYK)

Table 8. Optimized ATR-FTIR method parameters for printing ink analysis.................. 52

Table 9. Groupings of toner samples based on characteristic FTIR peaks (in

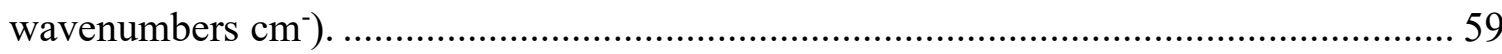

Table 10- Discrimination capability of ATR-FTIR for toners based on color .................. 62

Table 11. Summary of discrimination by ATR-FTIR based on ink type. ........................ 69

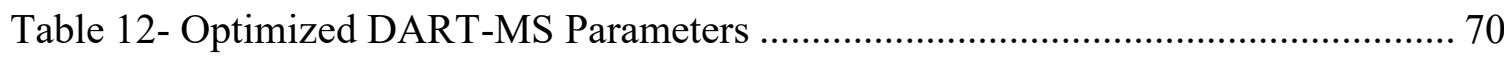

Table 13- Summary of DART-MS discrimination capability for each ink type ...............80

Table 14- Comparison of MALDI-MS discrimination capability of two different instruments Voyager DE PRO MALDI-TOF-MS and Bruker AutoFlex II

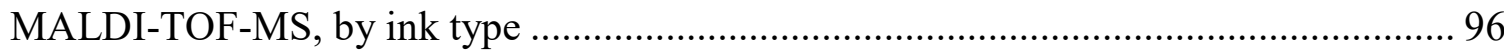

Table 15- Comparison of ATR-FTIR and DART-MS discrimination capabilities

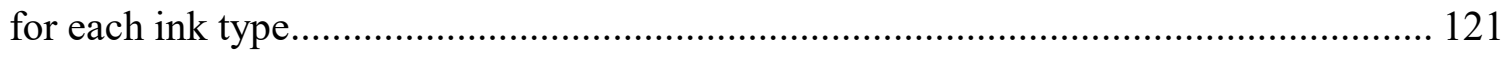

Table 16- Comparison of ATR-FTIR and DART-MS analyses ..................................... 121

Table 17- Comparison of match criteria for ATR-FTIR and DART-MS for association of duplicate controls, using database algorithms 
Table 18-Comparison of analytical techniques included within this dissertation as well as discrimination capability for each ink class . 


\section{LIST OF FIGURES}

FIGURE

PAGE

Figure 1- Mechanism of ATR sampling for FTIR analysis ........................................ 22

Figure 2- Schematic of DART ionization source ....................................................... 23

Figure 3- Distribution of inkjet ink samples by brand ............................................ 27

Figure 4- Distribution of toner ink samples by brand .............................................. 28

Figure 5- Distribution of offset ink samples by source.......................................... 30

Figure 6- Distribution of intaglio ink samples by country of origin............................ 31

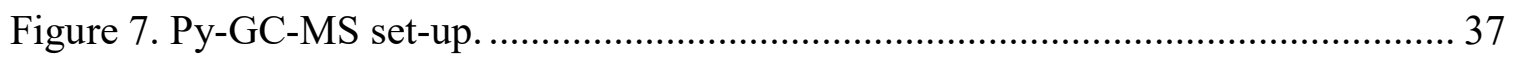

Figure 8. Sample preparation for Py-GC-MS. .......................................................... 38

Figure 9. Chromatogram for inkjet sample (0077IJ0101PYR). .................................. 38

Figure 10. Py-GC-MS data for inkjet sample 0005IJ0101PYR (top) and probe blank

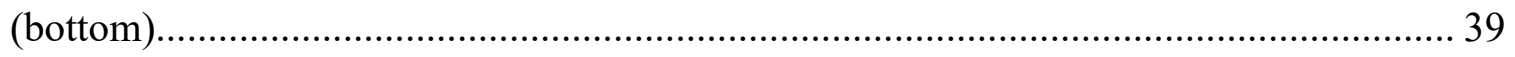

Figure 11- Comparison between pyrogram obtained for the same inkjet ink sample when (top) printed, and (bottom) deposited on whatman paper ................................. 40

Figure 12. Py-GC-MS data for the toner sample (0038TN0101) ................................ 41

Figure 13. Py-GC-MS data for HSI Laboratory toner sample (HSI Lab ID 320)........... 42

Figure 14. Py-GC-MS data for the same toner sample (0037TN) obtained one month

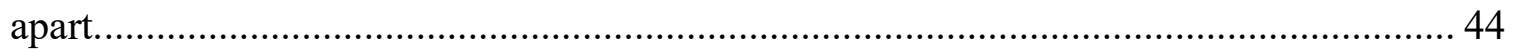

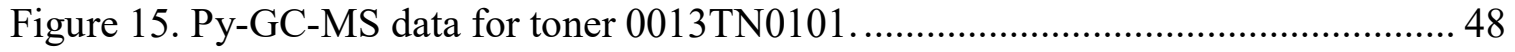

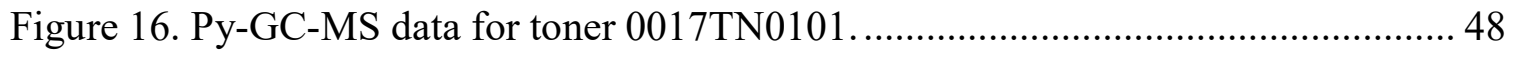

Figure 17- (left) PCA of toner samples showing distinct grouping between HP samples (red) and non-HP samples (blue) note: circles are hand-drawn; and (right) hierarchial cluster analysis of toner samples also showing distinct grouping between HP samples (red) and non-HP samples (blue)

Figure 18. (a.) Close-up of FTIR instrument and ATR accessory (b.) Close-up of ATR pressure knob and crystal (c.) Entire instrumental set-up. 
Figure 19. Method Validation with Sample provided by HSI Laboratory. 53

Figure 20. Inter- and intra-day reproducibility validation.

53

Figure 21- Inter- and intra-day reproducibility of ATR-FTIR spectra for toner sample 37 , illustrating association of common spectra to one another.

Figure 22. ATR-FTIR spectra of inkjet inks and blank paper background, illustrating presence of diamond ATR crystal artifact.

Figure 23- CMYK toner samples from same printer illustrating qualitative similarity with exception of diamond absorption artifact.

Figure 24- Three cyan toners belonging to different groups based on presence/absence of different absorption bands.

Figure 25. Toner ink samples grouped based on presence/absence of absorption bands by ATR-FTIR analysis.

Figure 26- Decision tree for grouping of toners based on presence and absence of absorption bands in ATR-FTIR spectra.

Figure 27. ATR-FTIR of intaglio inks illustrating limited discrimination capability.

Figure 28- Intaglio samples from three different countries showing domination of cellulose peaks.

Figure 29. ATR-FTIR spectra of offset inks illustrating variability in sample type and information obtained for discrimination (top) samples of different colors from same manufacturer discriminated based on differences in ATR spectra and (bottom) lack of useful information for discrimination of offset samples from security documents due to domination of cellulose band

Figure 30- qualitative differences between orange and dark orange offset inks from same manufacturer

Figure 31-ATR-FTIR spectra of sample 0021TN0101 under different conditions: control, fingerprints, and sweat, with the most noticeable additional contaminant absorption bands present in the sweat sample

Figure 32- image of (left) preparation and size of ink samples for DART-MS analysis and (right) DART-MS sampling procedure for ink samples

Figure 33- DART-MS spectra of PEG 600 internal standard (top) and inkjet sample (bottom) 
Figure 34- Inter-day reproducibility of inkjet sample and example of indistinguishable DART-MS spectra.

Figure 35- Two spectra of inkjets discriminated based on different combinations of PEG distributions present 75

Figure 36- DART-MS Spectra of toner samples exhibiting PEG distributions (top) and PPG distributions (bottom) 76

Figure 37- DART-MS spectra of offset samples containing portions of PEG distributions allowing for discrimination. 78

Figure 38- DART-MS Spectra of intaglio samples containing PEG distributions (top) and Cocaine contaminant and common phthalate (bottom)

Figure 39- DART-MS spectra of 0021TN01 under different conditions: (top) no contamination, (middle) fingerprints, (bottom) sweat, showing the contaminant peak at $\mathrm{m} / \mathrm{z} 206.14$ present in fingerprint and sweat samples but absent from control.

Figure 40- Comparison of MALDI-MS spectra of the same inkjet sample with (top) addition of matrix 9-aminoacridine and (bottom) with no matrix added.

Figure 41- MALDI-MS spectra of the same inkjet sample (top) in pure liquid form and (bottom) on paper substrate.

Figure 42- MALDI-MS spectra of same cyan inkjet sample in (top) negative mode containing sulfonated molecular ions and (bottom) in positive mode, where sulfonated molecular ions are absent

Figure 43- Replicate MALDI-MS spectra of the same toner sample (top) acquired on different days and (middle, bottom) on the same day.

Figure 44- MALDI-MS spectra of two inkjet inks of different colors from the same printer cartridge showing different colorant molecular ions present (top) magenta and (bottom) yellow

Figure 45- MALDI-MS spectra of two toner inks of different colors from the same printer cartridge showing different colorant molecular ions present (top) cyan and (bottom) magenta

Figure 46- MALDI-MS spectra of two offset inks from the same manufacturer that are indistinguishable to the naked eye but contain different colorant molecules (top) magenta and (bottom) red 
Figure 47- Instrumental comparison of same ink sample analyzed by (top)

Voyager DE PRO and (bottom) Bruker Autoflex III exhibiting same molecular ions .... 95

Figure 48- Photos of different ink samples (left) Instrument Y Pilot BPA-10F pen ink (middle) Instrument Z Shachihata SGN-40 stamp ink, and (right) crossed-line intersections of stamp and pen ink.

Figure 49- Cross-line intersections of writing instruments $\mathrm{Y}$ and $\mathrm{Z}$ visualized in VSC exhibiting invisible migration (colorless) under spot light source (480-620nm) (left) color, (right) black and white image.

Figure 50- Positive mode MALDI-MS spectrum of pen ink Instrument Y containing Crystal Violet

Figure 51- Negative mode MALDI-MS spectrum of pen ink Instrument Y containing Acid Violet 49

Figure 52- (top) Positive mode and (bottom) negative mode MALDI-MS spectra of stamp ink Instrument $Z$ containing sulfonated Copper Phthalocyanine

Figure 53-Positive mode MALDI-MS spectra of crossed-line intersections containing pen and stamp ink

Figure 54- Negative mode MALDI-MS spectra of crossed-line intersections containing pen and stamp ink

Figure 55- Liquid chromatogram and Positive mode LC-MS spectrum of writing instrument $Y$ pen ink exhibiting three distinct molecules tetramethyl p-rosaniline, methyl violet and crystal violet.

Figure 56- DART-MS spectrum of writing instrument $\mathrm{Y}$ exhibiting series of mass fragments that correspond to polyethylene glycol (PEG) at m/z 610, 654, 698 which are 44 units apart and polypropylene glycol (PPG) at m/z 384, 442, 500 which are 58 units apart.

Figure 57- (left) image of questioned exam 1 and (right, top) red pen markings analyzed via DART-MS from exam 1 and (right, bottom) blue pen markings analyzed via DART-MS from exam 2

Figure 58- DART-MS spectra of red pen markings from Exam 1: (top) Known Document 1 K1, (middle) Known Document 2 K2, and (bottom) Questioned Document 1 (Q1) 
Figure 59- DART-MS spectra of blue pen markings from Exam 2: (top) Known Document 3 K3, (middle) Known Document 4 K4, and (bottom) Questioned Document 2 Q2

Figure 60- (top) MALDI-MS spectrum and (bottom) DART-MS spectrum of same toner ink sample illustrating complimentary information acquired via protocol including both analytical techniques

Figure 61-Comparison, similarities, and differences between DART-MS and MALDI-MS, illustrating the complementarity of the two techniques.....

Figure 62- visualization of PLSDA output for ATR-FTIR data using a comparison sample as a duplicate toner ink (sample 57). The bars represent the PLSDA output magnitude for each replicate for each of the 76 inks in the reference database. The large similarity scores for sample 57 indicates the comparison sample (duplicate control) is correctly associated with the same sample in the reference database.

Figure 63- Database output for a comparison of DART-MS data for an inkjet sample against the reference databased illustrating the PLSDA top 5 most likely classes, the PLSDA visualization output, KNN spectral comparison, and the KNN top 10 most similar spectra 


\section{CHAPTER 1. INTRODUCTION}

\subsection{Research Motivation}

Counterfeiting, or the production of falsified documents and currency, has existed in one form or another for the past 2,000 years (1). With the improvement in printing technology and wide accessibility of advanced printers, there has been an increase in counterfeiting in recent history $(2,3)$. Interest in the forensic analysis of questioned documents and inks has also increased over the past two decades as a result of this expansion in technology, which calls for improved methodology for the analysis, comparison, and eventual tracing of counterfeit inks to the production source $(4,5)$. The analysis of inks in a forensic context, in particular, can be traced back to the $1800 \mathrm{~s}$ in the U.S. A review of inks and the analysis of inks published in 1904 highlights the same goal of ink analysis today: to derive information as to the chemical composition of a questioned ink in order to make comparison to an ink or inks of known composition (6). The continued importance of improving chemical methods for the analysis of inks can be highlighted in the INTERPOL International Forensic Science Symposium Review Papers, which are released every three years. As of the last printing, the amount of published research focusing on questioned document analysis and the chemical analysis of inks stood at 275 papers published from 2010-2013 on the topic of chemical analysis of inks (7). Additionally, the National Academy of Sciences (NAS) Report of 2009 and the President's Council of Advisors on Science and Technology (PCAST) report of September 2016 identifies a need to develop and validate chemical methods applied to the analysis of inks in questioned document examination $(8,9)$. 
In practice, chemical analysis of inks in questioned document examination usually occurs after the document in question has been thoroughly examined visually, microscopically, and with non-contact/non-destructive methodologies that allow for differences between a questioned and known specimen to be revealed (10). However, the need to develop robust analytical chemical methodology for the analysis of inks has been highlighted in the literature $(5,11)$.

\subsection{Significance of study}

The study performed within the scope of this dissertation will address the need to develop chemical methods applied to inks and add to the collective knowledge of analytical instrumental techniques that can be applied to characterization and analysis of printing inks for possible implementation in forensic document examination. The dissertation will focus on developing and improving analytical chemical methods for the organic chemical characterization of printing inks for use in forensic document examination. Inks are complex mixtures that can contain dozens of distinct compounds, and many of those compounds are carbon-containing, allowing for organic molecular chemical characterization to provide useful information for associating inks from common sources and distinguishing inks from different sources, which is in line with the overall goals for questioned document examination.

In this study, methods for Pyrolysis Gas Chromatography—Mass Spectrometry (Py-GC/MS), Attenuated Total Reflectance Fourier Transform Infrared Spectroscopy (ATR-FTIR), Direct Analysis in Real Time Mass Spectrometry (DART-MS), and Matrix-Assisted Laser Desorption Ionization Mass Spectrometry (MALDI-MS) analysis 
of printing inks of four classes: inkjet, toner, offset, and intaglio were developed in order to provide information on the organic chemical characterization, association, and discrimination of these inks for uses in questioned document examination. The suite of analytical techniques developed in the study focused on having the following qualities: 1) rapid analysis time, 2) little-to-no sample preparation, 3) minimal destructiveness to the sample, 4) allow for association of common inks as well as discrimination of inks from different sources. Sources, as defined within this dissertation refers to different printers and/or cartridges.

The ink classes that were included in this study are inkjet, toner, offset, and intaglio. Inkjet and toner inks are used in personal printers used in homes and workplaces and are increasingly used in the production of fraudulent documents and currency $(4,5)$. Offset and intaglio inks are used in the production of security documents and currency, and developing protocols for the characterization of such inks is very useful for national security and intelligence purposes.

The ultimate goal is to evaluate the forensic utility of each of the instrumental techniques included in this study, the complementarity of these techniques, and make recommendations as to a suite of complimentary analytical chemical techniques that can be implemented in forensic document examination of printing inks. The combination of the instrumental techniques included in this dissertation is novel and will provide insight into the advantages of using each, or a combination of two or more in a protocol for the chemical analysis of four classes of printing inks: inkjet, toner, offset, and intaglio. As a result of this study, a novel searchable library database of inks was developed for use 
with the analytical chemical methods that allows for data fusion. The database, along with the instrumental methodology, provides increased information for use in forensic document examination.

In addition, the research conducted as a part of this dissertation is the first to apply the suite of analytical techniques used here: Py-GC/MS, ATR-FTIR, DART-MS, and MALDI-MS to a comprehensive sample set of printing inks including inkjets, toners, offset, and intaglio inks. The data fusion conducted as a result of these analyses provides novel information regarding the chemical composition of printing inks to allow for improved association of inks from common sources and discrimination of inks from different sources. The generation of a novel ink database is also a result of these analyses.

\subsection{Chemistry of Printing Inks}

The classes of printing inks described here are by no means completely inclusive of all varieties of printing inks. Rather, these are the classes of printing inks that are most commonly observed in document examination. They are included in all the analyses completed within the scope of this dissertation. Inks can be distinguished by class in terms of both printing process (e.g., movement of ink from printer to paper/substrate) and composition, which is highly dependent on the printing process. Therefore, each of the ink classes described differs in the process through which they are printed and the composition of said ink.

The use of printing inks, or implementing tools for reproduction of printed materials can be traced back to $\mathrm{AD} 250$ in eastern Asia (12). In the millennia that 
follows, printing processes have seen incredible development, but since the establishment of oil-based printing inks in the $17^{\text {th }}$ century, little change has been made to printing ink composition in the 300 years since (12).

\subsubsection{Ink Classes}

Inkjet is a non-impact printing process, implementing a liquid ink with low viscosity and consists of a solvent, colorant, binder, and additives. It is relatively new form of printing technology that is the most increasingly popular printer classes for both personal and professional use $(4,12)$. The two most commonly employed methods of inkjet technology fall into either continuous inkjet printing or drop-on-demand printing. In continuous inkjets, a stream of continuous ink is delivered to the substrate via a piezoelectric crystal that ejects drops that are then charged and deflected at the substrate. In drop on demand printers, ink drops are only dispersed when needed via a thermal, piezo, or electrostatic process (12).

Toner inks are fine powders which are electrostatically charged and are mostly comprised of a resin (up to $90 \%$ composition) and pigment. Toner printers are driven via an electrostatic process to deposit the particles onto the substrate. Different methods include electrophotography, ion deposition, magnetographic, and electrographic. The electrographic method is the most commonly employed in laser and photocopier printers, which uses a drum to homogenously deposit the ink onto the substrate (12).

Offset inks are those used in the lithographic printing process, which are those most commonly implemented in industrial printing, security document and currency production. The process is planographic, which employs the use of a plate and chemical 
characteristics of the ink to ensure that the ink adheres to specific regions and not others, to create the printed image. Offset inks are usually viscous and contain a high pigment content, and are deposited upon the substrate in thin films. The drying process may be expedited through a light transfer process such as ultraviolet curing (12).

The intaglio or recess printing process is most commonly used in the production of bank notes, and involves the deposition of the ink onto the substrate via a metal plate or cylinder, which creates a raised film of ink off the surface of the substrate. These inks have high viscosity and contain many additives to ensure proper film formation upon deposition (12).

1.3.2 Analytes of interest in the organic analysis and characterization of inks

\subsubsection{Pigments/dyes/colorants}

Inks are complex matrices that include a wide variety of compounds for different purposes, which can include, but are not limited to, colorants: pigments/dyes, oils, resins, solvents, plasticizers, waxes, driers, curing components, and miscellaneous additives. Each of these components avails itself to characterization and can provide possible chemical information that can be used for intelligence, association, and discrimination of inks in questioned document analysis.

The colorant is the portion of the ink that gives it color. Most common in printing inks are cartridges that are separated into black $(\mathrm{K})$, cyan $(\mathrm{C})$, yellow $(\mathrm{Y})$, and magenta (M) from which other colors are printed via mixtures of the aforementioned colors. Each of these primary colors is achieved via a dye or pigment molecule. The percent composition of the colorant molecule varies depending on the class of the ink, ranging 
from very trace concentrations $(2 \%)$ such as those in inkjet inks, to higher percent composition in those such as offset inks (4). Characterizing the colorant molecule can be very useful in document examination as two inks of the same color can be formulated with different colorant molecules, even similar molecules with different substitutions that can be used as a point of distinction. The distinction between molecules classified as dyes and those considered to be pigments is determined by solubility in water. Pigments are generally insoluble, which increases resistance to degradation. Pigments can exist as organic, inorganic, or organometallic compounds. Because of the unique properties of these molecules, a variety of techniques have been applied to gain information on the chemical behavior of colorants, which is useful in characterizing the overall ink for association and discrimination purposes. The color that the molecules give to the inks depends on the ability of these molecules to absorb light in the ultraviolet and visible regions of the electromagnetic spectrum. These molecules are made up of complex systems of chromophores which are pi electronic systems of conjugated double bonds, which are responsible for the absorption of visible light and cause the phenomenon we observe as color (13). Therefore, it is incredibly useful to characterize the organic molecular components of inks using optical, spectroscopic and mass spectrometric methods. Optical methods such as fluorescence, infrared luminescence, and spectroscopic methods such as Fourier transform infrared spectroscopy and UV/Vis spectroscopy rely on these properties, from which useful information is derived. In addition, chromatographic, spectroscopic, and mass spectrometric techniques such as High Performance Liquid Chromatography (HPLC), Gas Chromatography (GC), paper chromatography, nuclear magnetic resonance (NMR) spectroscopy, and liquid 
chromatography mass spectrometry (LC-MS), and gas chromatography mass spectrometry (GC/MS) have been applied to analysis of dyes and pigments over the past 100 years (14). The vast array of molecules used as colorants also lends itself well to analysis via thin layer chromatography (TLC) which has been one of the most widely used and established methodologies for ink analysis (15).

Phthalocyanines are an interesting subcategory of pigments that are organometallic compounds consisting of a metal chelate, most commonly copper, to tetrabenzene ligands. As a consequence of the unique characteristics of these complex molecules, they have been mass produced for the past 100 years in wide variety of industries including plastics, paints, and most significantly inks, with production in millions of tons a year (16). They are also the most produced subclass of pigments in production (13). In their most generic form, they exist as insoluble pigments with extreme heat stability and sublime at $\sim 550^{\circ} \mathrm{C}(13)$. To improve solubility of these molecules, they are often sulfonated, to form sulfonic acid derivatives. In a single ink, there are mixtures of phthalocyanines, with multiple molecules existing in the formulation with differing numbers of sulfonic acid group substitutions $(16,17)$. The unique ability of these molecules to exist with differing number of substitutions provides very useful information in document examination and the analysis described within this dissertation provides evidence of this phenomenon. 
Table 1- Examples of molecules found in the formulation of printing inks

\begin{tabular}{llll}
\hline & Organometallic pigment, \\
\hline
\end{tabular}




\subsubsection{Other Ink Components}

As a consequence of the insolubility of many industrially used pigments, additive components are used in ink formulation such as solvents, vehicles, stabilizers, and plasticizers to improve overall ink quality $(5,16)$.

Oils have been incorporated into printing inks since their first production and are used as drying agents, stabilizers, and plasticizers. They can be saturated or unsaturated (containing conjugated or unconjugated systems) and can exist in polymer form within the composition as well. There are many classes of oils that are incorporated in ink manufacturing, including natural and synthetic oils. Most are polymers of methylene groups with alternating single and double bonds, ending in carbonyl groups. Various oils are incorporated including linseed oils, mineral oils, bean oils, castor oils, and vegetable oils (12).

Resins are typically used in ink manufacturing as binders for insoluble pigments. They also contribute to various desired properties of inks such as hardness, glossiness, and flexibility. These are most commonly found in toner, offset, and intaglio inks. Resins also exist in both natural and synthetic variants. Natural resins include rosin, ester gums, and maleic resins, which are polymers bearing carboxylic acid substitutions. There is much more variation in synthetic resins, which include phenols, alkyds, polystyrene, terpene, ureic formaldehyde, melamines, polyamides, vinyl, acrylates, epoxides, polyurethanes, and cellulose (12).

The definition of the solvent within the ink depends on the percent composition of the individual component, but the solvent component is typically implemented to ensure 
suspension and transfer of the ink from cartridge to final substrate. Solvents may include hydrocarbon oils, alcohols, glycols, ketones, and esters (12). Inkjet inks in particular contain a high concentration of solvents, most typically alcohols and glycols.

Plasticizers function as a means of increasing flexibility of inks, so that degradation and cracking does not occur after deposition to the substrate. Usually the plasticizer is a viscous liquid, but solids are being implanted in both solid inks like toners but also in suspension in liquid inks to improve overall heat resistance. There are many classes of plasticizers that may include phthalates, polyesters, polyol esters, benzoates, sulphonamides, and stearates (12).

Waxes are typically used in offset and intaglio inks to improve resistance and hydrophobic properties of the ink. These may exist in the formulation by being added with the colorant or introduced through a dispersion. Some commonly employed classes of wax include polyethene, fatty acid amides, petroleum, and paraffins (12).

Driers are used to ensure efficient drying of the ink upon deposition and are typically metal salts of organic fatty acids and include cobalt, manganese, cerium, zirconium, lithium, calcium, zinc, and iron (12).

Understanding the wide variety of molecules that are used in the formulation of printing inks is incredibly useful in determining which instrumental chemical methodologies are most applicable for ink analysis, and what possible information can be derived, in the form of a chemical profile, based on the formulation. 


\subsection{Introduction to the forensic analysis of inks}

When examining inks or a document for questioned document examination or forensic analysis, there is always a comparison between a questioned and known document. The goal of questioned document analysis usually incorporates the following: determining whether a questioned document was printed from a known printer, associating two or more documents to a common source, discriminating documents originating from different sources, and identifying possible manufacture and authenticity of documents $(4,18)$. Another facet of ink analysis involves dating and determination of inks, which is not within the scope of the work described here.

\subsubsection{Physical examination}

Physical examination of documents involves looking for minute differences, irregularities, qualitative differences that may provide points of association or distinction between two inks. Artifacts left on the document as a result of the physical printing process may be characteristic of a class of printers, inks, or era of printing technology and useful for intelligence purposes (5). Defects present in copied or counterfeit documents also allow analysts to derive points of distinction for authenticity and intelligence purpose (19). However, these determinations require a skilled analyst and are often subjective. Additionally, with the vast array of printers available in today's market, relying on physical examination on its own is not especially informative for association or discrimination purposes. Up until the 1950s, non-invasive physical examination and photographic examination were the primary methods of choice for document examiners, as a result of the lack of research into chemical methodologies applied to the analysis of inks $(20,21)$. 


\subsubsection{Optical Examination}

In addition to physical examination, document examiners typically use a Video Spectral Comparator (VSC) or similar technology to conduct an optical examination of a document and inks (5). The VSC contains multiple light sources in the infrared, visible, and ultraviolet range of the electromagnetic spectrum. Different light sources can be illuminated, without contact to the specimen under observation, to detect fluorescence and also measure absorbance by the substrate. This examination may give insight into different inks being used on one document, and may even allow for discrimination between different inks. However, the utility of this method is severely limited by the paper, since the paper can inhibit/quench fluorescence and/or absorbance of an ink (4, 22). Optical examination has also been referred to as filtered light examination (FLE) and is reported to be the most popular initial method via which inks are first examined (23).

For the past 50 years, optically examining documents and inks with visible light sources to detect infrared luminescent properties has been well established and readily used for the comparison of inks (24). However, the limitations of solely relying on optical examination has been repeatedly reported in the literature. The majority opinion deems that additional examinations and testing be performed before any conclusion is made (20). Thus, luminescence observation has been readily combined with other techniques such as Thin Layer Chromatography (TLC) to improve the amount of chemical information obtained $(25,26)$. The biggest obstacle for the utility of optical and luminescence examination for inks is that a majority of inks are mixtures of components, some of which are luminescent and others that are not, and the non-luminescent 
components have a masking effect and therefore inhibit overall luminescence (27).

Therefore, it is most useful to employ optical examination as a preliminary step in the analysis of inks, and to combine it with other techniques that can provide complimentary information (28) .

\subsubsection{Chemical Analysis of inks}

As the complexity of ink and printing technology has increased over the past decades, so has the rate of counterfeiting involving inks and questioned documents. Thus there has been a great need to develop chemical methods to characterize inks for association and discrimination purposes $(5,14)$. A variety of analytical chemical methods have been applied to the analysis of inks and more specifically, printing inks, each with their own advantages and disadvantages. No single technique has been demonstrated to be the golden standard for ink analysis, and thus new methodologies continue to be developed, focusing on combinations of two or more techniques that provide comprehensive chemical information. It is the goal of the present dissertation to show that the suite of analytical techniques included here provides such useful information on the organic chemical composition of printing inks for use in questioned document analysis. Chemical analysis is most typically employed to derive a point of comparison between two or more inks. During chemical analysis, the similarities and differences between chemical profiles of two inks are compared. Any differences must be considered carefully as to whether they arise from differences in chemical composition of the inks, are a product of instrument fluctuation, or because of other external or environmental factors which may have affected the ink in question (29). 
1.5 Previously Reported chemical techniques for the analysis of inks

\subsubsection{Thin Layer Chromatography}

Thin Layer Chromatography (TLC) is a mature technique and has been readily applied to ink analysis for at least the past 40 years and has been used to separate inks and as a method for dye/pigment identification and differentiation (14). The first documented application of TLC to ink analysis was reported in 1960, and showed the ability to separate dyes in writing inks for comparison purposes (30). Prior to that, the most similar technique to be applied to ink analysis was paper chromatography (31). TLC has been most successful in the analysis of writing inks, and the US Secret Service has one of the largest TLC ink libraries in the world, and TLC is routinely performed for writing inks in documentation in that laboratory (11). TLC has also been applied to the analysis of inkjet inks, and more limitedly to toner inks $(5,32)$. However, TLC is limited because it requires an extraction of the ink from the substrate, is limited by solvent compatibility, and is somewhat subjective as to the skill of the analyst performing the separation.

TLC has been compared in terms of utility to microscopic and optical techniques, and shown to provide beneficial information in terms of comparison for association and discrimination $(23,33)$. Historically, TLC had been readily applied to the analysis of writing inks, because of the ease by which these inks could be extracted from paper and separated. However, TLC has also been used to analyze inkjet inks and this information has allowed for the discrimination of inkjet inks from different brands and even different printers from the same brand (32). As part of the U.S. Secret Service ink library, which 
houses thousands of writing inks, inkjet and toner printing inks, among others, also has thousands of inks preserved in a separated form via $\operatorname{TLC}(29,34)$.

TLC has been instituted as part of laboratory protocols for the examination of inks for the past 40 years, in tandem with physical, optical, and spectroscopic methodologies (35). Typically, inks are first observed microscopically, and then irradiated with a number of light sources to gain any useful information as to the characteristics of the inks. The ink must then be removed from the document and extracted to be analyzed with TLC. Subsequent spectrophotometric analyses of the separated components then give insight as to the colorant component of the ink $(14,35)$. TLC was also a suggested protocol in the American Society of the International Association for Testing and Materials (ASTM) Standard Guide for Test Methods for Forensic Writing Ink Comparison for over 30 years (36-38). As early as 1976, TLC had been established in federal forensic laboratories for the routine analysis of inks (39). As time progressed, TLC had been applied to a variety of inks including ball point pens, stamp inks from passports, typewriter inks, felt tipped pens, and inkjet inks, in combination with luminescence and spectrophotometry $(15,18,40-45)$. TLC has also been used in combination with mass spectrometric methods such as GC/MS and LDI/MALDI-MS as a sample preparation method for separating ink components $(17,46-48)$.

\subsubsection{Pyrolysis Gas Chromatography—Mass Spectrometry}

Py-GC-MS is especially effective in the analysis of polymeric matrices, some of which are present in inks, and has been applied to the analysis of insoluble and nonvolatile inks for at least the past thirty years (49). Py-GC-MS is an established method 
for the analysis of toners and characterization of pyrolysis polymer products in toners has been carried out (50). It has shown to be useful for grouping toners by the presence and absence of polymer pyrolyzates and/or pyrolysis products (51). Combining Py-GC/MS with complimentary analytical techniques has allowed for improved characterization of printing inks $(51,52)$ Py-GC-MS has been limitedly applied to inkjets as a method for the thermal desorption of volatile organic compounds present in the inkjet formulation (53). However, the time consuming nature and total destructiveness of the analyzed sample severely limit its evolution and increased application in the chemical analysis of inks for questioned document examination $(54,55)$.

\subsubsection{Attenuated Total Reflectance-Fourier Transform Infrared Spectroscopy}

Since the early 1980s, Fourier Transform Infrared Spectroscopy has been applied to the analysis of inks, starting out with primarily writing inks $(40,56)$. It was found to be a very complimentary technique to TLC, as it allows for the characterization of insoluble ink components such as resins $(57,58)$. Many different FTIR techniques including diffuse reflection (DRIFTS) and reflection absorbance (R-A) have been used to characterize toners, although these techniques require the physical removal or transfer of the toner ink from the paper substrate $(50,59)$. FTIR techniques have been used in combination with other techniques such as Py-GC/MS to provide improved characterization of toner inks (60). The ATR method of infrared spectroscopy specifically has been limitedly applied to the analysis of toners but is an attractive method because of its ability to produce a chemical profile without removal of the toner from the paper substrate, no sample preparation, and the nondestructive nature of the technique, which allows for repeated analysis $(50,61)$. The resins present in toners produce 
characteristic IR spectra that can be used to differentiate toners into groups on the basis of the presence or lack thereof certain polymer bands $(60,62)$. ATR-FTIR has been applied to offset inks to determine penetration of ink into paper substrate. Resin and dye/pigment content was observed in offset analysis (63). Discrimination between authentic and counterfeit currency, which encompasses the analysis of intaglio inks, has been carried out via ATR-FTIR and allowed for qualitative measurements used to differentiate currency (64).

\subsubsection{Direct Analysis in Real Time—-Mass Spectrometry}

Direct Analysis in Real Time Mass Spectrometry (DART-MS) is a recently evolved technique that has seen great implementation in drug analysis, as well as other applications such as food testing and explosives monitoring, and more recently ink and paper analysis (65). Its first documentation in the literature was in 2005 and along with Desorption Electrospray Ionization (DESI) brought about the advent of ambient ionization techniques for mass spectrometry (66). DART-MS has shown to be a rapid, minimally destructive method for the analysis and differentiation of paper, writing inks, and printing inks $(62,67-71)$ as a result of its ability to characterize the semi-volatile components of inks, which can be useful for the association of inks from common sources and discrimination of inks from different sources.

DART-MS, as applied to writing pen inks, has allowed for the rapid, semidestructive characterization of volatile additives such as phthalates, and also polar, volatile colorant components of the inks $(68,69)$. Inkjet inks have also been successfully analyzed via DART-MS, which provides information as to the composition of the semi- 
volatile polymeric vehicle content of the ink, most specifically different length polyethylene glycol (PEG) polymers present in the inkjet formulations (70).

\subsubsection{Matrix—Assisted Laser Desorption Ionization—Mass Spectrometry}

Matrix-assisted laser desorption ionization mass spectrometry (MALDI-MS) and laser desorption ionization mass spectrometry (LDI-MS) are mature analytical techniques that differ only in the addition of a matrix to promote desorption and ionization in MALDI-MS as compared to LDI. In 2001 Grim et al. applied LDI-MS to the analysis of writing and inkjet inks on paper (72). Their proof of concept investigation set the way for further research in the area of LDI and MALDI to the analysis of inks on paper (73). Previous to the ink studies implementing laser desorption methods, there are studies in which dyes and pigments in different forms, not always originating from inks, have been analyzed via MALDI-MS $(74,75)$. Many studies have shown the complementarity of LDI versus MALDI in that, for example, molecules, namely dyes, which contain multiple charges in their ground state require the use of a matrix to effectively desorb and ionize the molecules $(76,77)$. Laser desorption is a very attractive method of ionization for mass spectrometric ink analysis in that it is considered a soft ionization technique which allows for the ionization of intact molecular ions with limited fragmentation as compared to traditional electron impact ionization $(76,78,79)$. In recent years, laser desorption has been applied to the analysis of inkjet printing inks, with success in characterizing both the dye, pigment, and more limitedly the polymeric content of the inks on paper in combination with other techniques such as TLC and Raman spectroscopy $(17,79)$. 


\subsection{Principles of Analytical Techniques}

\subsubsection{Pyrolysis Gas Chromatography_Mass Spectrometry}

In pyrolysis, a small amount of a sample (usually $10-100 \mu \mathrm{g}$ ) is heated in the absence of oxygen instantaneously at $250-1000{ }^{\circ} \mathrm{C}$ to cause fragmentation and vaporization of polymers, producing fragments referred to as pyrolysis products or pyrolytes. Decomposition products are carried out to the GC column via helium where they are separated and then detected using the MS detector (80). Pyrolysis products are complex mixtures with many compounds and it can be difficult to elucidate the exact mass of the original compound(s) from its decomposition products. However, these fragments usually provide enough information to identify the original polymer. Although Py-GC-MS is quite often used for the analysis of printing inks, it has some disadvantages which include the destructiveness of analysis and long analysis times ( $80 \mathrm{~min} / \mathrm{sample})$. For inks, the sample must be physically cut from the substrate and/or transferred to a heat resistant substrate such as aluminum foil. Once the samples are pyrolyzed, it cannot be reanalyzed as it is destroyed upon pyrolysis.

\subsubsection{Attenuated Total Reflectance-Fourier Transform Infrared Spectroscopy}

Attenuated Total Reflectance Fourier Transform Infrared Spectroscopy (ATRFTIR) allows for the rapid non-destructive analysis of solid and liquid sample with little to no sample preparation. ATR functions by measuring the changes in an internally reflected infrared beam that comes into contact with a sample and the mechanism has been described previously $(50,81)$. The beam is directed onto a crystal with a high refractive index at a certain angle, and an evanescent wave is created that passes beyond 
the crystal into the sample (81). For a sample to be compatible with ATR-FTIR analysis, the critical angle of the ATR crystal must be exceeded. The critical angle depends on the composition of the crystal. The resultant angle is calculated using the refractive index of the crystal material and the refractive index of the of the material, as seen in equation $1(81)$

$$
\theta_{c}=\sin ^{-}\left(\frac{n_{2}}{n_{1}}\right)
$$

Where $\mathrm{n}_{2}$ is the refractive index of the material being analyzed and $\mathrm{n}_{1}$ is the refractive index of the ATR crystal. Therefore, the refractive index of the material to be analyzed cannot exceed the refractive index of the ATR crystal. Germanium crystals have high refractive indices, but a low penetration depth, and therefore diamond crystals are more commonly utilized and have sufficient refractive indices to analyze most materials. A comparison between diamond and germanium crystals can be seen in Table 2. If the sample absorbs energy in regions of the infrared spectrum, then the evanescent wave will be altered and this will be illustrated in the resultant spectra output. It is an ideal method for the analysis of inks of interest to forensic document examiners in that it is completely non-destructive to the overall integrity of the document. 
Table 2- Comparison of figures of merit for diamond and germanium ATR crystals (81)

\begin{tabular}{|l|l|l|l|l|}
\hline Crystal & Refractive & Critical Angle, & Penetration & Spectral \\
& Index, $\mathbf{n}_{1}$ & $\boldsymbol{\theta}_{\mathbf{c}}$ & depth, $\mathbf{d}_{\mathbf{p}, \boldsymbol{\mu}}$ & range, $\mathbf{c m}^{-1}$ \\
\hline Diamond & 2.4 & $38.7^{\circ}$ & 2.01 & $4000-525$ \\
\hline Germanium & 4.0 & $22.0^{\circ}$ & 0.66 & $4000-570$ \\
\hline
\end{tabular}

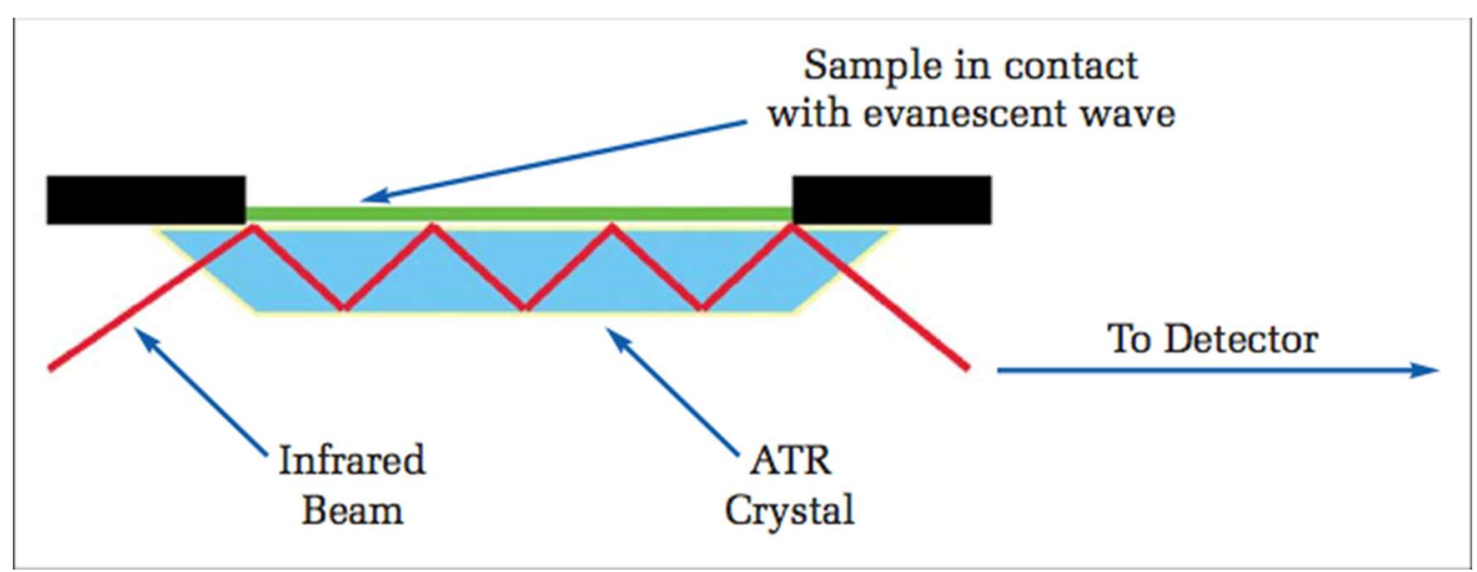

Figure 1- Mechanism of ATR sampling for FTIR analysis

\subsubsection{Direct Analysis in Real Time-Mass Spectrometry}

Direct analysis in real time (DART) is an ambient soft ionization technique for mass spectrometric analysis. Its ionization mechanism has been described previously (66, $69,70)$. An illustration of the ion source is illustrated in Figure 2. An inert gas, most typically either Helium, Argon, or Nitrogen, is guided into the source where it is exposed to a corona discharge of up to $4000 \mathrm{~V}$, which produces a glow discharge of ions, electrons and neutral, excited state metastable species. The resultant plasma is then 
passed through an additional charged field to filter any charged species, leaving the metastables from the inert gas. It is then heated and filtered once again to remove any charged species. Once the metastable species reach the atmosphere, they immediately interact with gas molecules in the air, which are believed to drive the primary mechanism of ionization of the analytes.
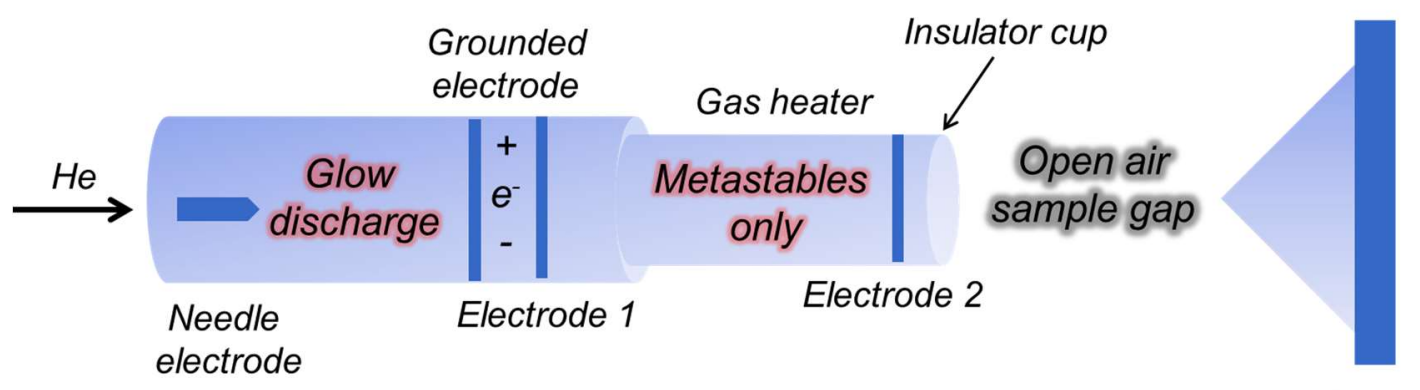

MS inlet

Figure 2- Schematic of DART ionization source

In positive ion mode, the mechanism of ionization is hypothesized to be (66)

$$
\begin{gathered}
\mathrm{He}\left(2^{3} \mathrm{~S}\right)+n \mathrm{H}_{2} \mathrm{O} \rightarrow\left[\left(\mathrm{H}_{2} \mathrm{O}\right)_{n}+\mathrm{H}\right]^{+}+\mathrm{OH}+\mathrm{He}\left(1^{1} \mathrm{~S}\right) \\
{\left[\left(\mathrm{H}_{2} \mathrm{O}\right)_{n}+\mathrm{H}\right]^{+}+\mathrm{M} \rightarrow[\mathrm{M}+\mathrm{H}]^{+}+n \mathrm{H}_{2} \mathrm{O}}
\end{gathered}
$$

Where water molecules in the atmosphere are first ionized by the metastable helium species and the protonated analyte molecule $[\mathrm{M}+\mathrm{H}]^{+}$is formed via proton transfer if the analyte has a higher proton affinity than the ionized water clusters. In the negative mode, Penning ionization occurs as energy is transferred from the metastable helium species to atmospheric nitrogen, and thermal electrons are produced. Atmospheric oxygen then captures these electrons and produces negatively charged oxygen anion radicals that may serve as reagent ions, forming adducts with analyte molecules, or are directly captured by the analyte molecules to form radical anions, as illustrated in equation (66) 


$$
\begin{gathered}
H e^{*}+N_{2} \rightarrow H e+N_{2}^{+.}+e^{-} \\
O_{2}+e^{-} \rightarrow O_{2}^{-} \cdot \\
O_{2}^{-.}+M \rightarrow\left[M+O_{2}\right]^{-.}
\end{gathered}
$$

These mechanisms rely on the ability of the analyte molecules to be desorbed into a gaseous form, where the ionization process occurs. Therefore, for a target analyte to be ionized via DART, it must be able to be thermally desorbed by the heated reagent gas, which in the Ionsense source has a maximum temperature of $500{ }^{\circ} \mathrm{C}$ in source (which results in $\sim 350-400^{\circ} \mathrm{C}$ once the stream comes into contact with atmospheric temperature). However, DART allows for direct analysis of samples in liquid, solid, or even gaseous form with little-to-no sample preparation and surface analysis.

\subsubsection{Matrix—Assisted Laser Desorption Ionization—Mass Spectrometry}

The exact mechanism through which MALDI-MS achieves ionization of analyte molecules is not universally agreed upon or understood, however, it is generally believed to occur in a two-step process (82-84). The first step involves the analyte compound to be dissolved or completely imbedded within a matrix solution containing organic molecules that have a strong absorption at the wavelength of the laser. Before irradiation with the laser, the sample and matrix are dried to ensure removal of the matrix solvent, leaving only the matrix crystals. The second step involves irradiation of the sample by a laser under vacuum. During the laser irradiation process, bulk portions of the sample are physically ablated, and rapid heating of the matrix crystal occurs, which in turn causes sublimation of the crystal and analyte molecules. During the desorption process, ionization is occurring simultaneously and can be achieved through a number of 
mechanisms including gas phase photoionization, proton transfer, and ion-molecule interactions. The most widely agreed upon mechanism is that of proton transfer since MALDI-MS spectra are dominated by $[\mathrm{M}+\mathrm{H}]^{+}$molecular ionic species. The ionic species are then accelerated electrostatically to the detector (83). If no matrix solution is used, the process is referred to as laser desorption ionization (LD) and it is believed that the analyte molecules undergo the same processes to achieve ionization, but this often results in fragmentation and incomplete ionization, depending on the analyte molecules (76). MALDI instruments tend to be exclusively time-of-flight (TOF) mass spectrometers as a result of the pulsed nature of the MALDI sampling/ionization. An electrostatic reflector or reflectron is commonly used to improve resolution in MALDITOF instruments. The reflectron creates a retarding field, or ion mirror, for the ions and deflects them back through the flight tube, which corrects any kinetic energy dispersion of ions with the same $\mathrm{m} / \mathrm{z}$ value, and thus increases mass resolution of the resultant spectra (83). Introduction of samples into MALDI-MS involves the deposition of solid or liquid samples on a well plate, and in the case of ink samples on paper, these samples can be adhered to the surface with double-sided tape. 


\section{CHAPTER 2. MATERIALS AND METHODS}

\subsection{Printing Ink Sample Set}

The complete list of printing ink samples analyzed as a part of this dissertation can be seen in Appendix 1. The entire ink sample collection consisted of 319 distinct ink samples representing the four major classes of printing inks included within the scope of this work. Each of these inks originated from a different source meaning different ink type, brand, model, and/or cartridge/batch. Making up this sample set are 78 inkjet inks, 76 toners, 79 offset inks, and 86 intaglio inks. The goal in collecting a diverse sample set was to represent as much as possible a large variety of inks that are available in the market and/or used in the production of currency and security documents.

\subsubsection{Inkjet sample set}

The inkjet sample set consists of 78 samples from 9 different brands, each being either cyan, magenta, yellow, or black. All printer cartridges were purchased from original manufacturing sources. $31 \%$ of the inkjets are Hewlett Packard brand, which is one of the world's largest provider of printing ink cartridges and has a large variety of models within the same brand. Other brands include Canon, Epson, and Lexmark. The distribution of brands can be seen in Figure 3. Most of the samples are black because it occurs more frequently in the market than other colors. $42 \%$ of the inkjet samples were black, with between $15-22 \%$ of the samples being cyan, magenta, or yellow. Some samples were labeled light cyan or light magenta, but were grouped within the main color category. 


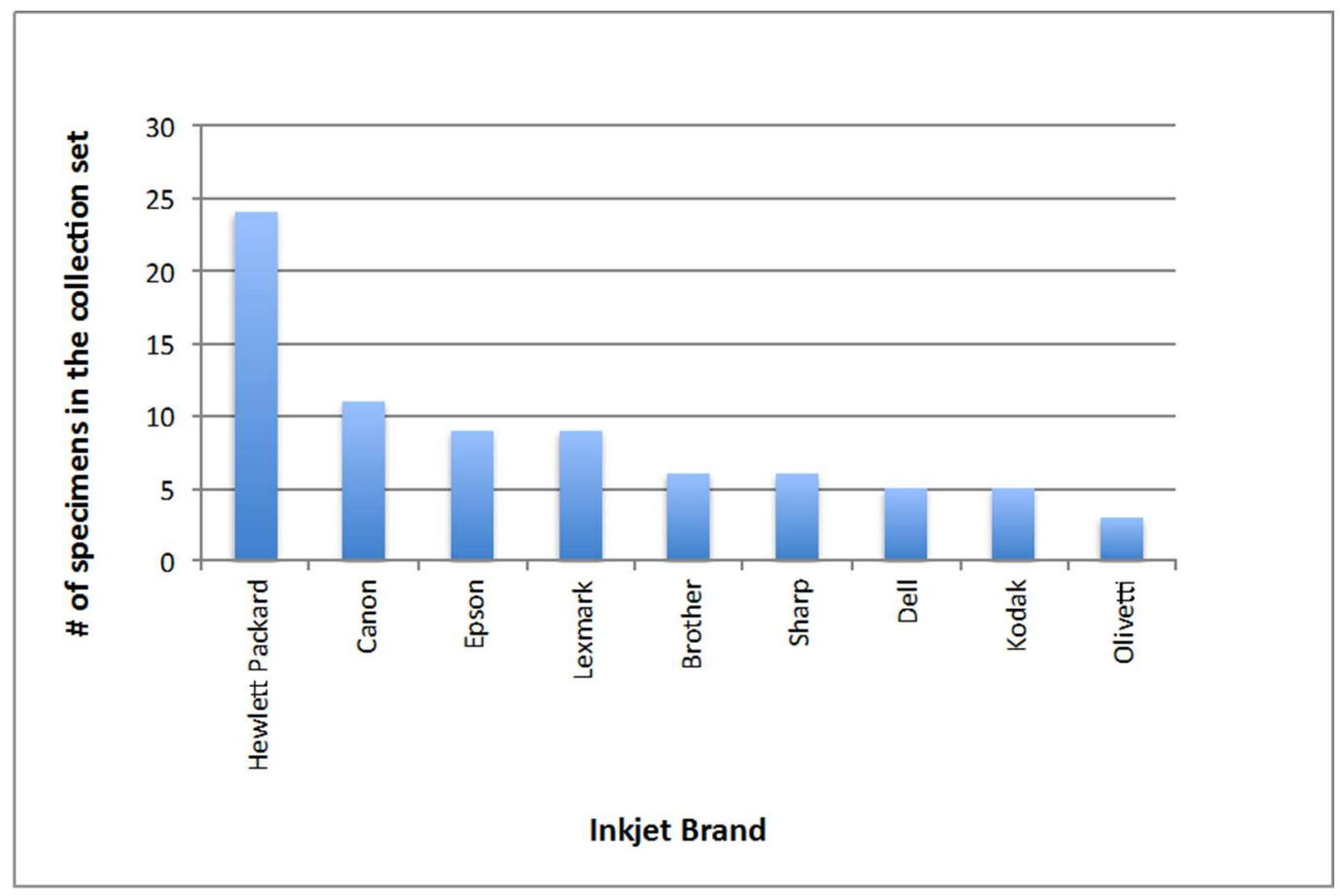

Figure 3- Distribution of inkjet ink samples by brand

Whatman Grade 42 white paper (Whatman Ltd., Piscataway, New Jersey) was used as the substrate for all inkjet samples. If the printer was available for use, a printout consisting of either a) a word document template comprising several numbers and letters in Times New Roman size 12 font or b) the default test page of the printer. All printouts were verified to be pure colors $(\mathrm{C}, \mathrm{M}, \mathrm{Y}, \mathrm{K})$. If the printer was not available, the ink was manually deposited onto the Whatman paper by extracting the ink from the cartridge and depositing an aliquot of $5 \mu \mathrm{L}$ and drying at room temperature.

The inkjet inks in the sample set were readily embedded and absorbed into the paper substrate. The ink samples from the printouts penetrated anywhere from $60-95 \mu \mathrm{m}$ into the paper substrate. The manually deposited ink samples penetrate further into the paper substrate $(\sim 200-250 \mu \mathrm{m})$. 


\subsubsection{Toner sample set}

The toner sample set consists of 76 samples originating from 15 different brands from the four colors cyan, magenta, yellow, and black. Similarly, to the inkjet sample set, all cartridges were purchased from original manufacturing sources. A majority of the samples were Hewlett Packard, making up about $34 \%$ of the total samples. Other brands include OKI, Canon, Xerox, and RICOH. The distribution of toner ink samples by brand can be seen in Figure 4. Black colored samples were also the highest color represented because of their proliferation. $50 \%$ of the toners were black, with the other $50 \%$ being cyan, magenta, or yellow.

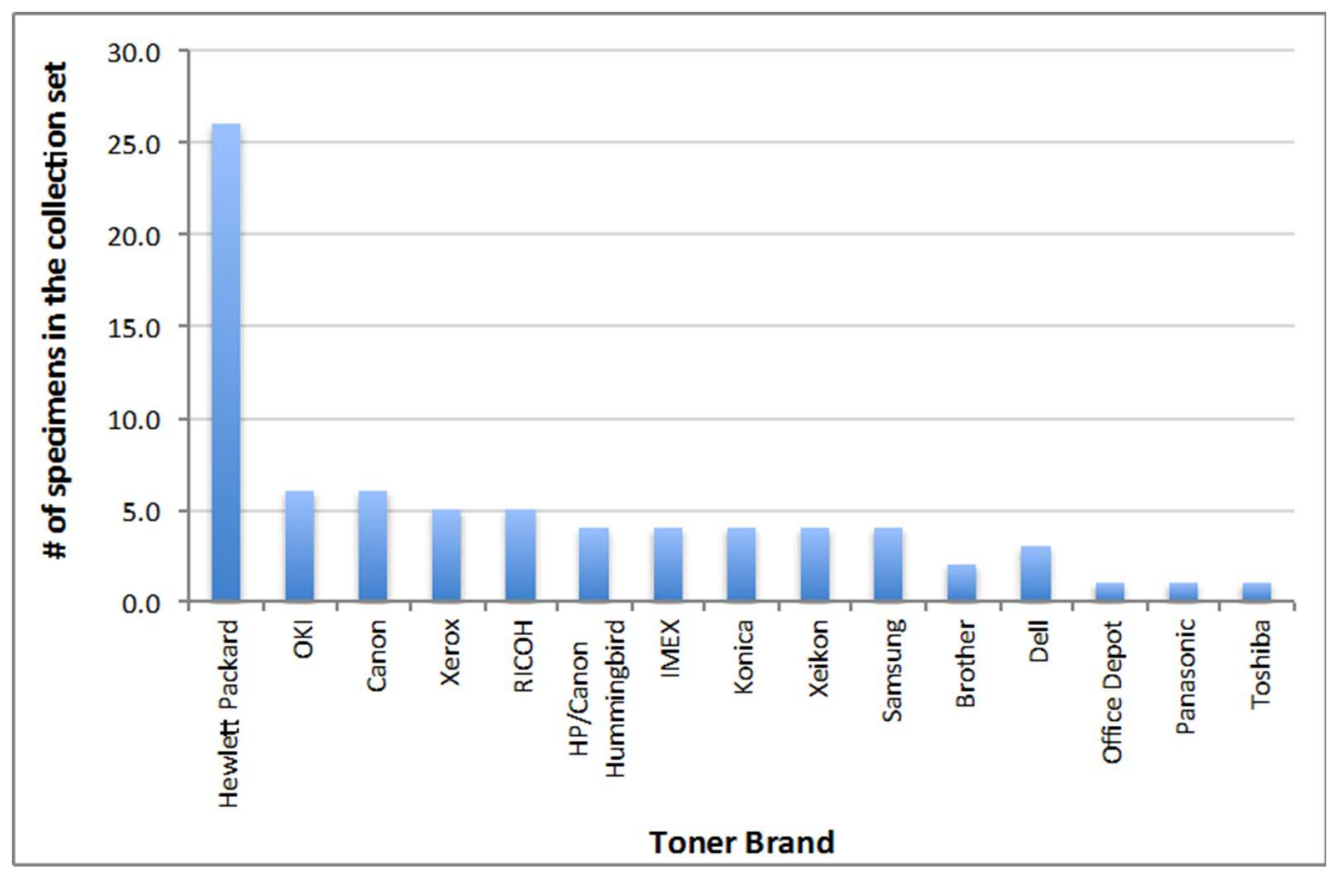

Figure 4- Distribution of toner ink samples by brand

Whatman Grade 42 white paper was used as the substrate for all toner samples. If the printer was available, a printout was made consisting of a word document template comprised of letters and numbers in Times New Roman size 12 font and printing the same layer one and ten times. All printouts consisted of pure CMYK colors. If the 
printer was not available, a manual deposition method was developed to simulate the printing process. The process involved creating a smooth film of the toner on Whatman 42 paper by rolling $\sim 0.1 \mathrm{~g}$ of toner powder on the paper substrate which had been preheated to $\sim 140-180^{\circ} \mathrm{C}$. The rolling and heating process creates a layer of ink on the paper $\sim 70-90 \mu \mathrm{m}$ thick which is equivalent to toner inks printed by a printer. The toner ink samples formed a thin film of particles above the surface of the paper between 20-95 $\mu \mathrm{m}$ thick.

\subsubsection{Offset sample set}

The offset sample set consists of 79 samples consisting of 39 print-outs from five manufacturers, 16 raw paste samples from two manufacturers, eight ink samples from U.S. Lincoln Visas, 15 ink samples from U.S. passports, and one sample from a training business card. The distribution of offset ink samples by source can be seen in Figure 5 . These samples consist of inks of 21 different colors. The raw paste samples were homogenized with a vortex before being deposited on Whatman 42 paper, smoothed into a thin layer, and let dry at room temperature. The offset inks in this sample set created a thin layer that was partially embedded into the paper substrate, $4-23 \mu \mathrm{m}$ in thickness. 


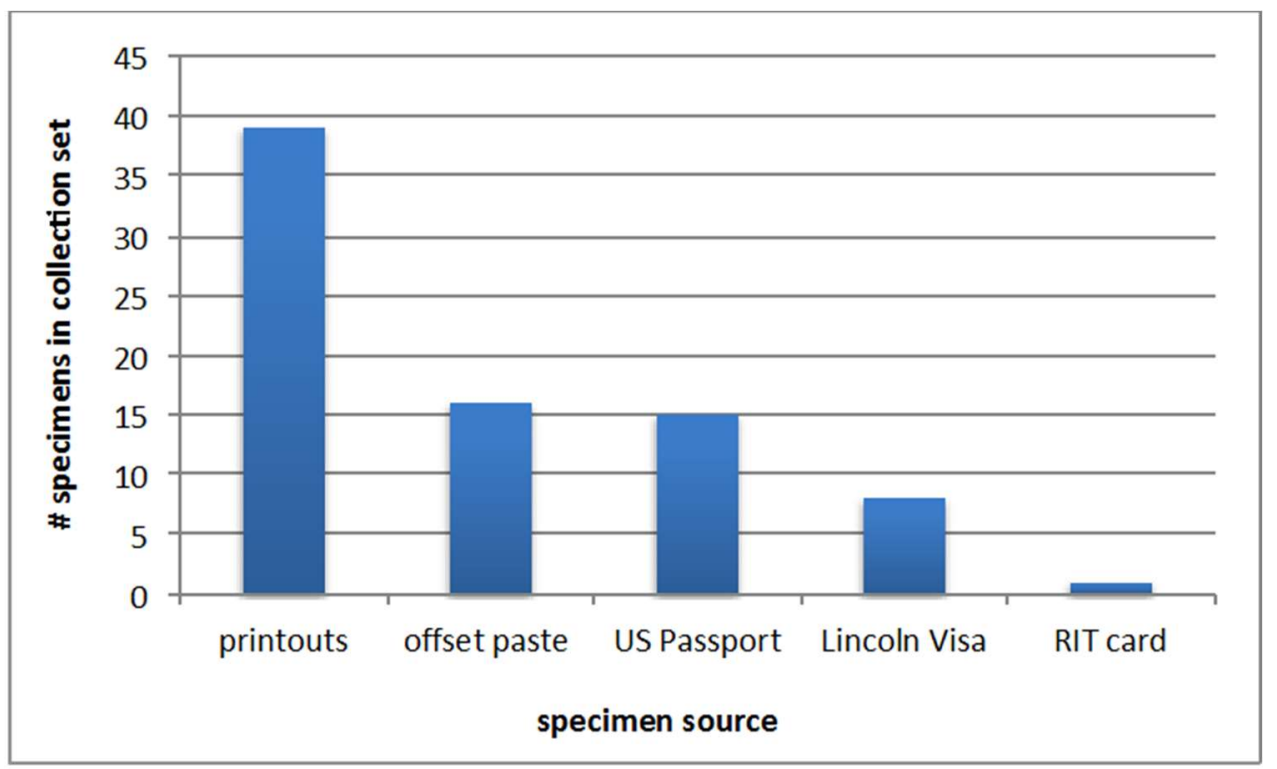

Figure 5- Distribution of offset ink samples by source

\subsubsection{Intaglio sample set}

The intaglio sample set consists of 86 samples originating from U.S. banknotes and banknotes from 24 different countries, a training business card, and U.S. Lincoln Visas. The distribution of intaglio ink samples by country of origin can be seen in Figure 6. The areas of intaglio ink on the Lincoln Visas were identified via physical and visual inspection under a microscope. Keesing Documentchecker (Keesing reference systems Inc., Netherlands) was used to identify the area on each banknote where intaglio ink was printed and then verified under a microscope. The intaglio ink in the samples were raised above the paper ranging from $19-45 \mu \mathrm{m}$ in thickness. 


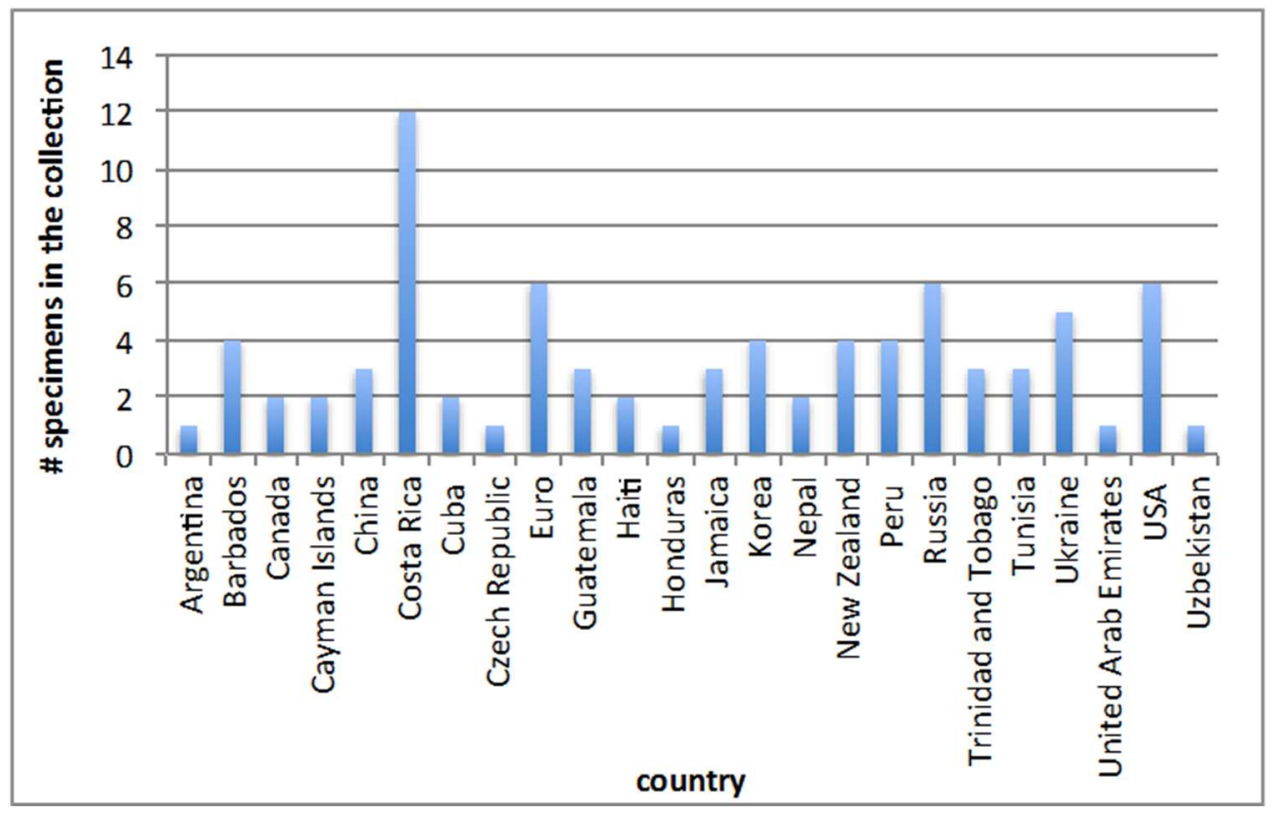

Figure 6- Distribution of intaglio ink samples by country of origin

2.2 Instrumental Methods

\subsubsection{Py-GC/MS Method Parameters}

The Py-GC/MS analyses were conducted using a CDS Analytical Pyroprobe 2000 (CDS Analytical: Oxford, PA, US) with CDS Analytical 1500 GC interface (CDS Analytical: Oxford, PA, US) coupled to Agilent 7980 GC with 5975 MS detector (Agilent, Santa Clara, CA). Pyroprobe parameters, for toners: interface $300^{\circ} \mathrm{C}$, probe 750 ${ }^{\circ} \mathrm{C}$ (initial temperature $50{ }^{\circ} \mathrm{C}$, final temperature $750{ }^{\circ} \mathrm{C}$ for $15 \mathrm{~s}$, heating rate $10^{\circ} \mathrm{C} / \mathrm{min}$ ), probe heating rate $10^{\circ} \mathrm{C} / \mathrm{min}$; for inkjet: interface $250^{\circ} \mathrm{C}$, probe $250^{\circ} \mathrm{C}$ (initial temperature $50{ }^{\circ} \mathrm{C}$, final temperature $250{ }^{\circ} \mathrm{C}$ for $15 \mathrm{~s}$, heating rate $10{ }^{\circ} \mathrm{C} / \mathrm{min}$ ), probe heating rate $10{ }^{\circ} \mathrm{C} / \mathrm{min}$. Gas chromatography parameters were: Oven Program: $40{ }^{\circ} \mathrm{C}$ for $2 \mathrm{~min}$ to $300^{\circ} \mathrm{C}$ at $8^{\circ} \mathrm{C} / \mathrm{min}, 5.5 \mathrm{~min}$ hold, Injection port at the same temperature as probe 
interface Solvent delay was 4 min for both inkjets and toners, split 300:1. Mass spectrometer parameters were $\mathrm{EI}, 70 \mathrm{eV}$; MS source at $230{ }^{\circ} \mathrm{C}$, MS quadrupole at $150{ }^{\circ} \mathrm{C}$.

\subsubsection{ATR-FTIR Method Parameters}

The ATR-FTIR analyses were conducted using a Spectrum One FTIR (Perkin Elmer, Waltham, MA) coupled to a GladiATR accessory (PIKE Technologies, Madison, WI) with single bounce diamond crystal (area: 770x590 $\mu \mathrm{m}$; sample spot size: $50 \mu \mathrm{m}$ ) and imaging capabilities. Perkin Elmer Spectrum software (v 10.03.06.0100) was used for elucidation and analysis of IR spectra obtained. Videology Image Capture Software (v 2.1.105) was used to ensure proper contact between sample and ATR crystal. The parameters for all analyses conducted include a resolution of $4 \mathrm{~cm}^{-}$, spectral range of 4000-600 $\mathrm{cm}^{-}$, and 4 scans per sample.

\subsubsection{DART-MS Method}

The DART-MS analyses were conducted using a 6530 Q-TOF MS (Agilent, Santa Clara, CA) coupled to a DART SVP (IonSense, Saugus, MA) ambient ionization source. DART ion source control was achieved through the DART SVP software (v 3.0.x). Mass spectra and Q-TOF data acquisition was achieved using MassHunter Workstation Software LC/MS Data Acquisition for the 6200 series TOF/6500 series QTOF (v B.05.00). Analyses of spectra were carried out using MassHunter Workstation Software Qualitative Analysis (B.05.00). All analyses were conducted in positive mode with a DART helium gas at $350{ }^{\circ} \mathrm{C}$, Q-TOF heater gas (helium) at $350{ }^{\circ} \mathrm{C}$, drying gas flow at $0.2 \mathrm{~L} / \mathrm{min}$, fragmentor voltage of $175 \mathrm{~V}$, skimmer voltage $65 \mathrm{~V}$, and a mass range of 100-1000 amu. A 5ppm solution of polyethylene glycol (PEG) 600 (Emerald 
Biosystems, Bainbridge Island, WA) in 50:50 water:methanol (Thermo Fisher Scientific, Waltham, MA) was used as a daily performance standard and internal mass calibrant for the DART ionization source.

\subsubsection{MALDI-MS Method}

The MALDI-MS analyses were first conducted on a Voyager DE Pro TOF mass spectrometer (Applied Biosystems: Carlsbad, CA USA). A subset of the original $\sim 300$ printing ink samples was used in the MALDI-MS portion of the dissertation. Sample preparation involved cutting a $\sim 2 \times 2 \mathrm{~mm}$ portion of the ink on paper and attached to a 100 well stainless steel target (JBI Scientific: Huntsville, TX). The matrix used was 9aminoacridine (9AA: Aldrich) dissolved in 70\% methanol:water $(5 \mathrm{mg} / \mathrm{mL})$. A $0.5 \mathrm{uL}$ aliquot of the matrix solution was spotted on top of the sample on the target. Instrumental parameters were as follows: $337 \mathrm{~nm}$ Nitrogen laser, $3 \mathrm{~ns}$ pulses, $2 \mathrm{~Hz}, 50$ shots per sample, negative and positive mode, mass range m/z 100-1000.

Another subset of inks was analyzed using a Bruker AutoFlex II MALDI-TOFMS. Sample preparation was similar with the exception of samples being affixed to an ITO-coated (indium tin-oxide) glass slide (Bruker Daltonics, Bremen, Germany). All analyses were conducted in negative mode and a mass spectrum dominated by a molecular ion that could be attributed to a colorant molecule was acquired for all samples. Negative mode calibration was achieved using Angiotensin II, 9-AA, and Acid Red 52 at $\mathrm{m} / \mathrm{z} 193.076,501.079,557.142$, and 1044.527. Instrumental parameters were as follows: $355 \mathrm{~nm}$ Nitrogen laser, $5-7 \mathrm{~ns}$ pulses, $100 \mathrm{~Hz}, 400$ shots per sample, negative 
mode, mass range $\mathrm{m} / \mathrm{z}$ 100-1000. Imaging of each sample was also performed with a minimum of 5 replicate spectra per sample spot.

\subsection{Data Analysis}

The focus of this dissertation was to evaluate the capability of the aforementioned analytical techniques to discriminate inks known to originate from different sources, while correctly associating inks known to originate from the same source. The term source, within the scope of this dissertation, refers to the association and discrimination of a questioned or test sample to the correct sample source. For example, there were 76 toner samples analyzed in this study, meaning 76 distinct sources. The comparison between spectra was performed by overlaying the spectra using Plot software (v.0.997) and noting qualitative differences in spectra. The replicate spectra were first compared to one another, and then the composite spectrum including the three spectra of the one sample were compared to all other samples. To evaluate the discrimination capability of each method for each ink type, the percent discrimination power (DP) was calculated, adapted from Trejos et al. (85) Sources, as defined within this dissertation, refers to different printers and/or cartridges. The DP was calculated using the following relationship:

$$
\% \mathrm{DP}=100 *[1-(\mathrm{IP} / \mathrm{CP})]
$$

Where IP is the number of indistinguishable pairs from different sources and CP is the total number of possible comparison pairs between samples and calculated as 


$$
\mathrm{CP}=[\mathrm{n}(\mathrm{n}-1) / 2]
$$

where $\mathrm{n}$ is the number of samples originating from different sources.

The false inclusion rate was then estimated and defined as the percent of ink samples originating from different sources but were indistinguishable given the spectra obtained from the individual analytical technique. The false inclusion value was calculated using the following formula:

$$
\% \text { false inclusions }=100-\% \mathrm{DP} \quad \text { [9] }
$$




\section{CHAPTER 3. ANALYSIS OF PRINTING INKS BY PY-GC/MS}

\subsection{Method development and optimization}

The Py-GC-MS system used in this work was the CDS Analytical Pyroprobe 2000 with 1500 GC interface coupled to Agilent 7890 GC with 5975 MS detector (Figure

7). Parameters that were used for Py-GC-MS analysis are listed in Table 3. Prior to analysis, ink samples were cut into $1 \mathrm{~mm}$ x $10 \mathrm{~mm}$ strips (Figure 8, left), placed in quartz tubes (Figure 8, right) and analyzed via Py-GC/MS. Method development samples and data for toner inks were provided by the U.S. Homeland Security Investigation Forensic Laboratory (HSIFL).

Inkjet samples were analyzed directly on paper via Py-GC-MS. In contrast to toners, inkjet inks are analyzed at lower pyrolysis temperature. In fact, instead of true pyrolysis, inkjet samples underwent thermal desorption, and at this temperature, only the volatile components of the inks were characterized. At a pyrolysis temperature of $375{ }^{\circ} \mathrm{C}$, burning of the paper was observed and carry over contamination was present in multiple blanks after the sample. For that reason, it was decided to use a lower temperature, as compared to the toner analysis temperature. Optimum results (no burning and relatively high peak abundances) were observed when the probe temperature was set to $250{ }^{\circ} \mathrm{C}$ (Figure 9). The same temperature was used for the interface and injection port (Table 3) to ensure that there was no cooling of the sample as it moved towards the GC/MS analyzer. When inkjet samples printed on paper were analyzed, the recorded signal was identical to the one for a probe blank (Figure 10). A comparison between a deposited inkjet and printed inkjet can also be seen in Figure 11. 


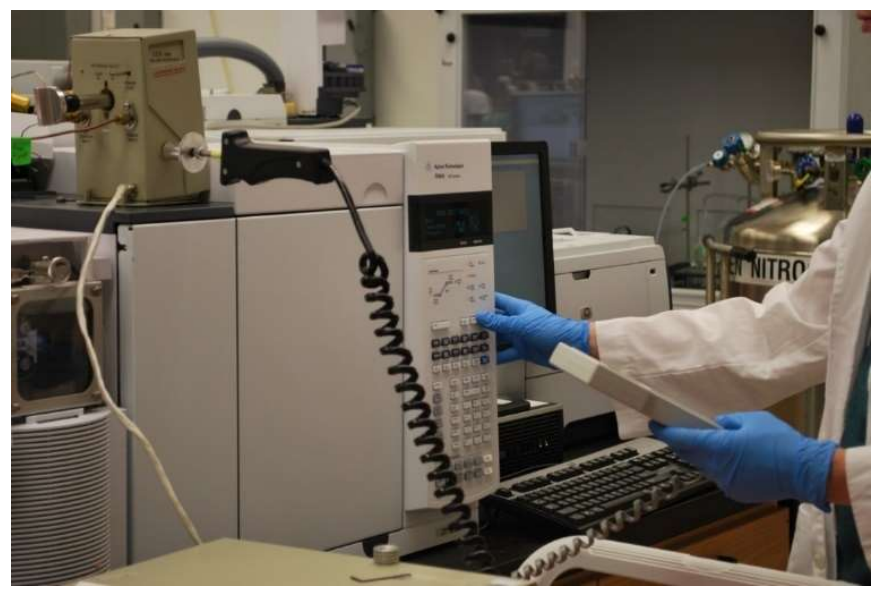

Figure 7. Py-GC-MS set-up.

Table 3. Optimized parameters for Py-GC-MS analysis.

\begin{tabular}{|c|c|c|}
\hline & Toner & Inkjet \\
\hline Pyroprobe Parameters & $\begin{array}{l}\text { interface } 300{ }^{\circ} \mathrm{C} \text {, probe } 750{ }^{\circ} \mathrm{C} \\
\text { (initial temperature } 50{ }^{\circ} \mathrm{C} \text {, final } \\
\text { temperature } 750{ }^{\circ} \mathrm{C} \text { for } 15 \mathrm{~s} \text {, } \\
\text { heating rate } 10^{\circ} \mathrm{C} / \mathrm{min} \text { ), probe } \\
\text { heating rate } 10^{\circ} \mathrm{C} / \mathrm{min}\end{array}$ & $\begin{array}{l}\text { interface } 250{ }^{\circ} \mathrm{C} \text {, probe } 250 \\
{ }^{\circ} \mathrm{C} \text { (initial temperature } 50{ }^{\circ} \mathrm{C} \text {, } \\
\text { final temperature } 250^{\circ} \mathrm{C} \text { for } \\
15 \mathrm{~s} \text {, heating rate } 10^{\circ} \mathrm{C} / \mathrm{min} \text { ), } \\
\text { probe heating rate } 10^{\circ} \mathrm{C} / \mathrm{min}\end{array}$ \\
\hline GC Parameters & \multicolumn{2}{|c|}{$\begin{array}{l}\text { Oven Program: } 40^{\circ} \mathrm{C} \text { for } 2 \mathrm{~min} \text { to } 300^{\circ} \mathrm{C} \text { at } 8^{\circ} \mathrm{C} / \mathrm{min}, 5.5 \mathrm{~min} \\
\text { hold } \\
\text { Injection port at the same temperature as probe interface } \\
\text { Solvent delay was } 4 \text { min for both inkjets and toners } \\
\text { Split 300:1 }\end{array}$} \\
\hline MS Parameters & \multicolumn{2}{|c|}{ EI, $70 \mathrm{eV} ; \mathrm{MS}$ source at $230^{\circ} \mathrm{C}$, MS quad at $150^{\circ} \mathrm{C}$} \\
\hline
\end{tabular}



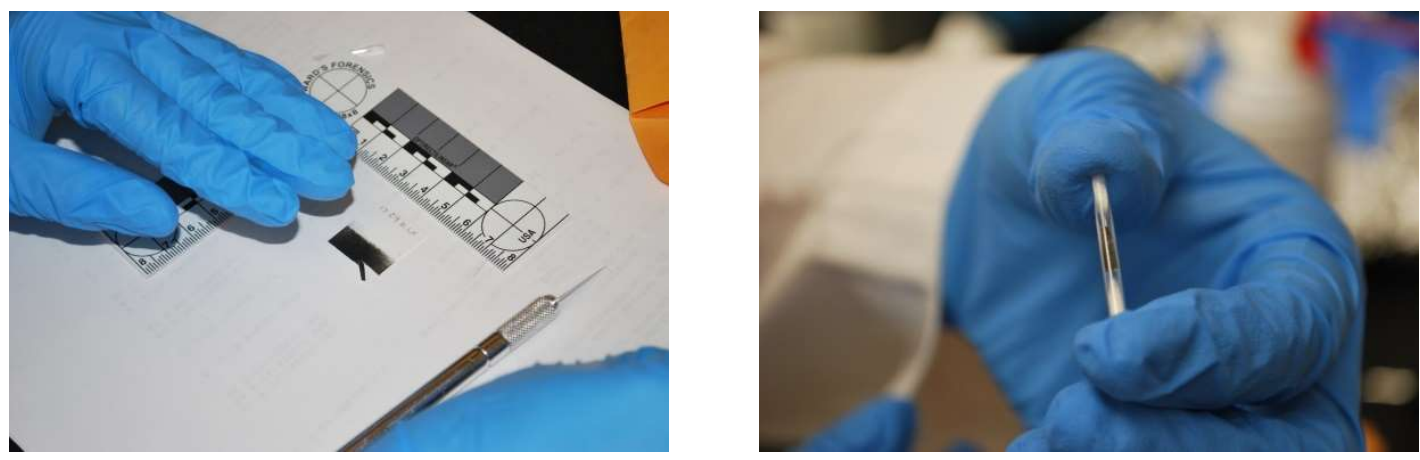

Figure 8. Sample preparation for Py-GC-MS.

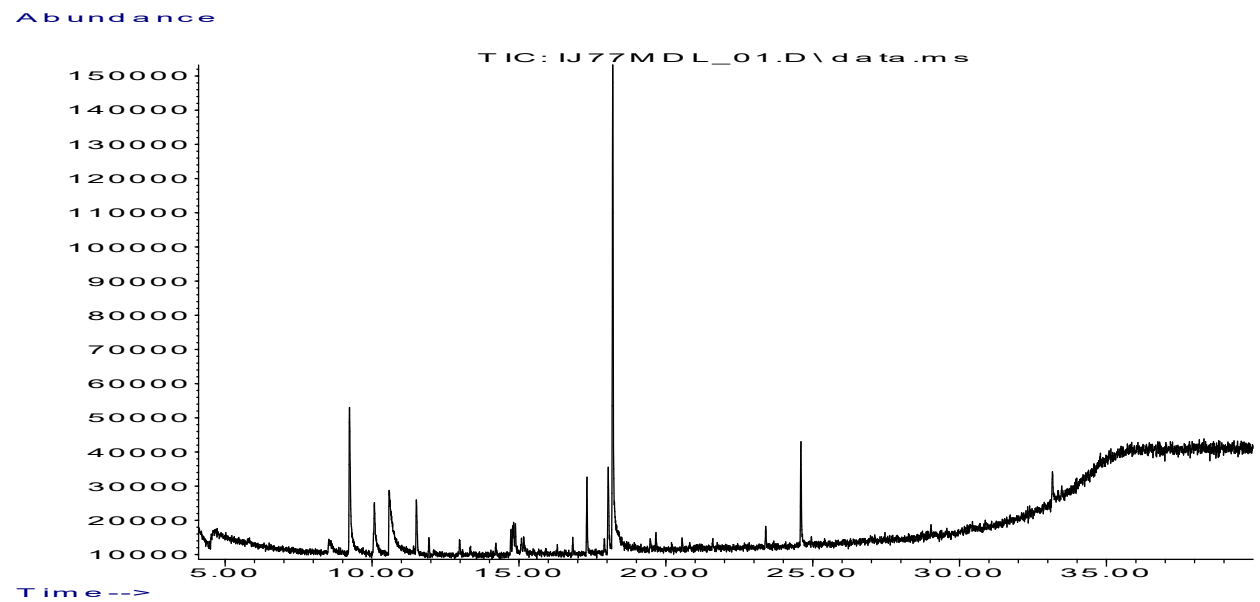

Figure 9. Chromatogram for inkjet sample (0077IJ0101PYR). 


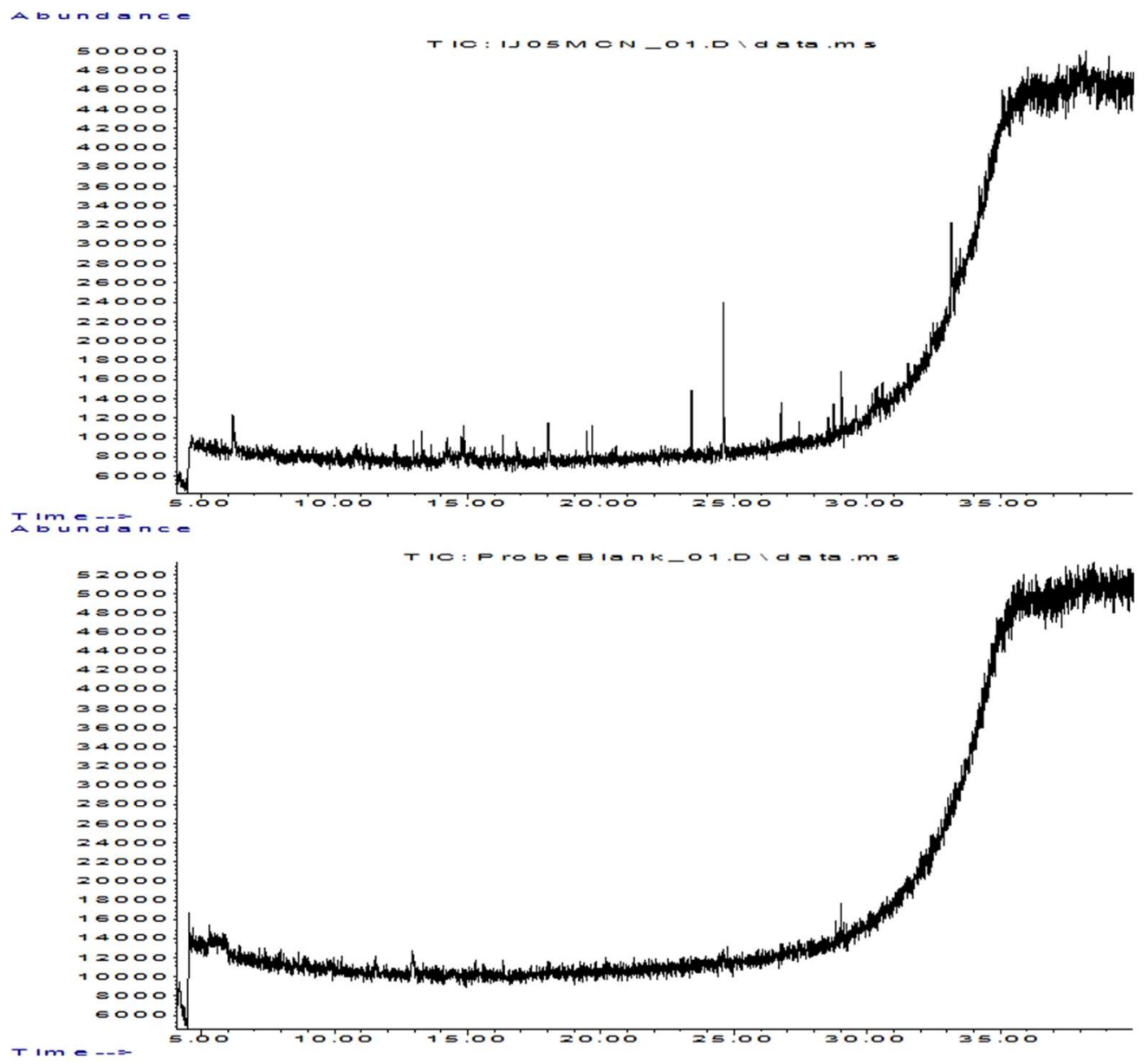

Figure 10. Py-GC-MS data for inkjet sample 0005IJ0101PYR (top) and probe blank (bottom). 


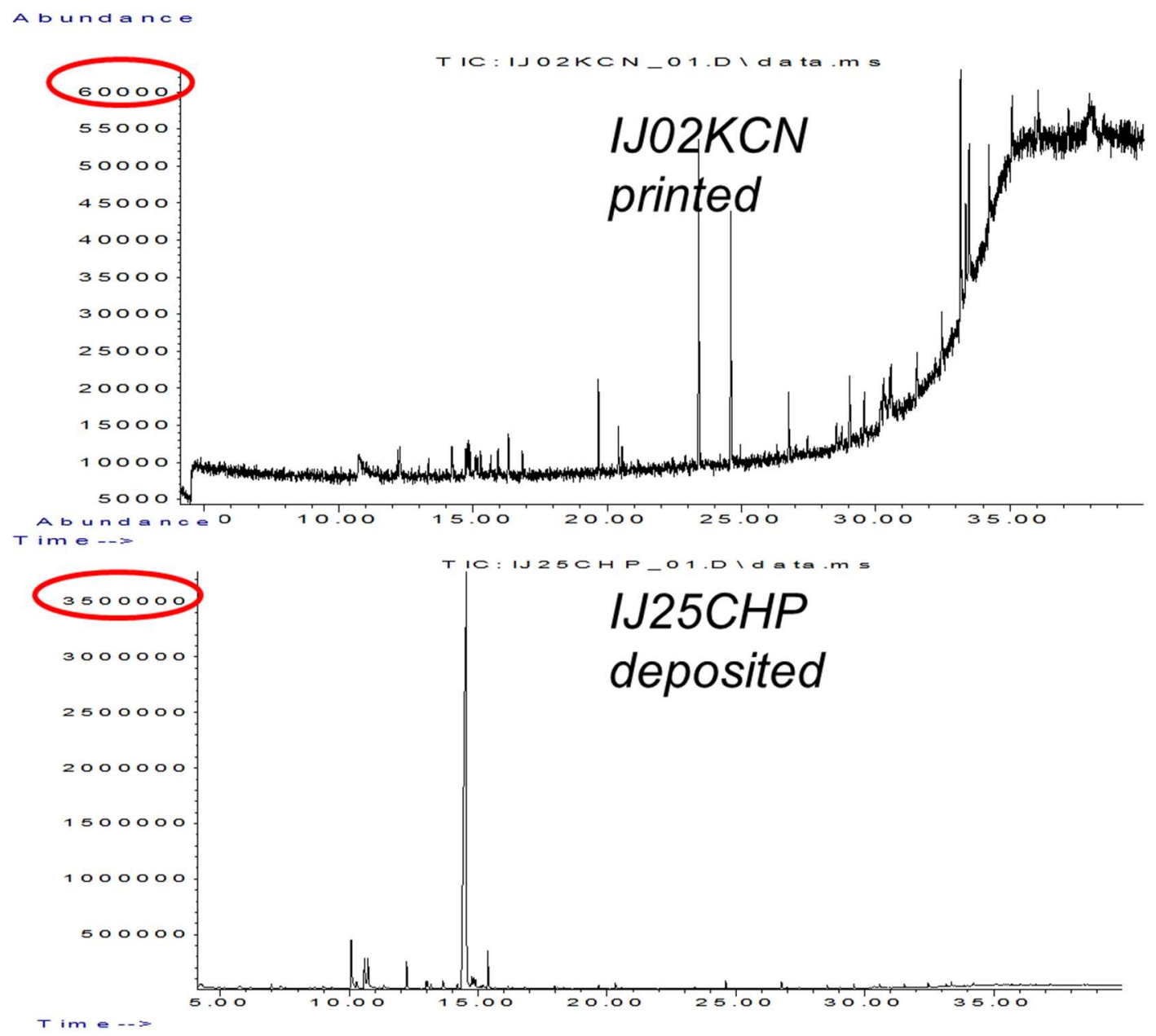

Figure 11- Comparison between pyrogram obtained for the same inkjet ink sample when (top) printed, and (bottom) deposited on whatman paper

At first, it was attempted to analyze toners at the same low temperature, thus performing thermal desorption. However, the chromatograms obtained were identical to the probe blank, and it was determined that a higher temperature was necessary. Because the paper burned and dominated the chromatogram at a higher temperature than was used for inkjet analysis, it was determined that the toner samples needed to be transferred to a different substrate that is temperature resistant. The substrate of choice was aluminum foil, as it has been repeatedly reported in the literature and was also a part of the procedure for routine toner analysis in the HSI laboratory. Toner samples were 
transferred from paper to foil using a modification of procedure described by Egan et al. (51). Instead of using a soldering iron described in that procedure, a digestion hot block was used. Temperature programs for the probe as well as GC-MS analysis conditions were adopted from the work of Shaffer et al. (61). These conditions are listed in Table 3. The GC-MS conditions were the same for toners and inkjets with the exception of injection port temperature which was kept the same as the interface temperature. An example pyrogram (i.e., chromatogram of pyrolysis products) for a toner sample is shown in Figure 12.

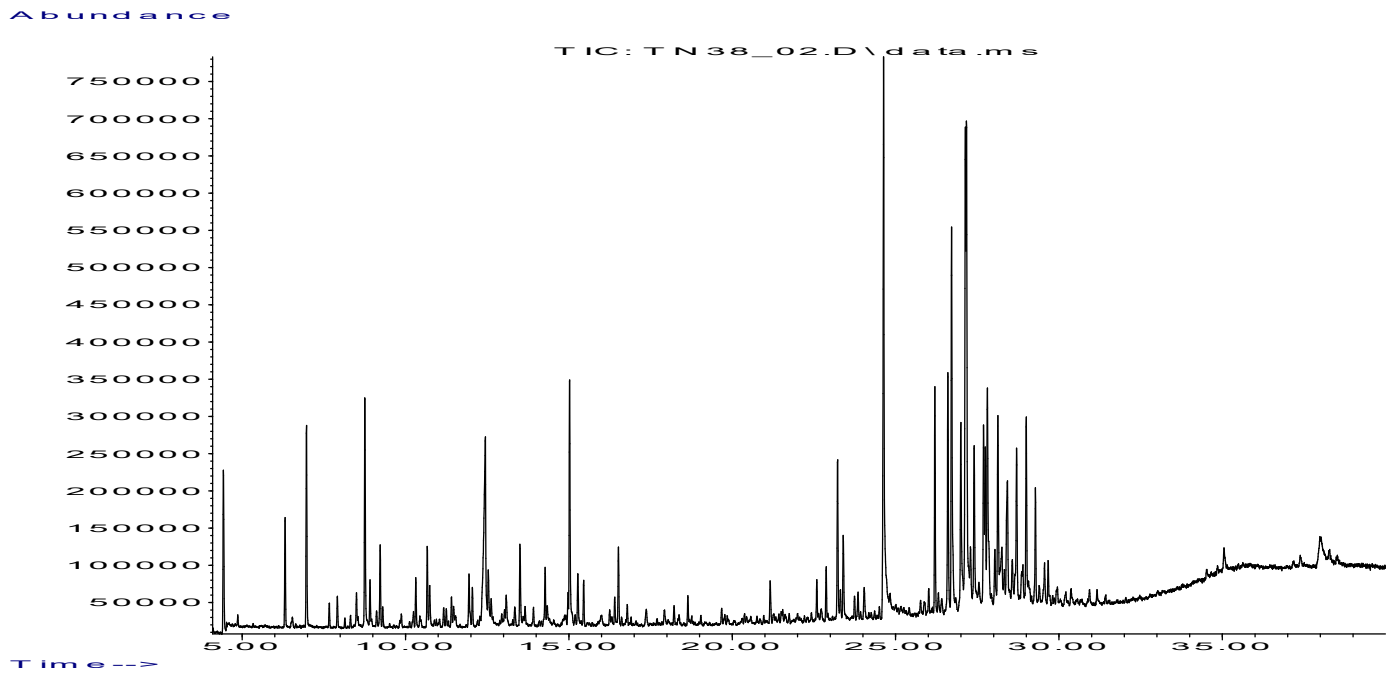

Figure 12. Py-GC-MS data for the toner sample (0038TN0101).

The main difference in toner and inkjet analysis by Py-GC-MS was that in toners we targeted resins whereas in inkjets we targeted volatile solvents and vehicles which are much more volatile than resins and can be desorbed at low temperature $\left(250{ }^{\circ} \mathrm{C}\right.$ vs. 750 $\left.{ }^{\circ} \mathrm{C}\right)$. This is a result of the temperature settings of the pyroprobe in that only thermal desorption was occurring for inkjet samples while pyrolysis of the toner samples was being performed. 
Some preliminary experiments were conducted for offset and intaglio samples. In the case of intaglio samples, it was not possible to determine if the observed compounds came from the banknotes themselves or contaminants. Due to the complex nature of PyGC-MS data, the decision was made not to analyze offset and intaglio samples further.

Method validation was conducted by analyzing the sample (toner) supplied by the HSI Laboratory.

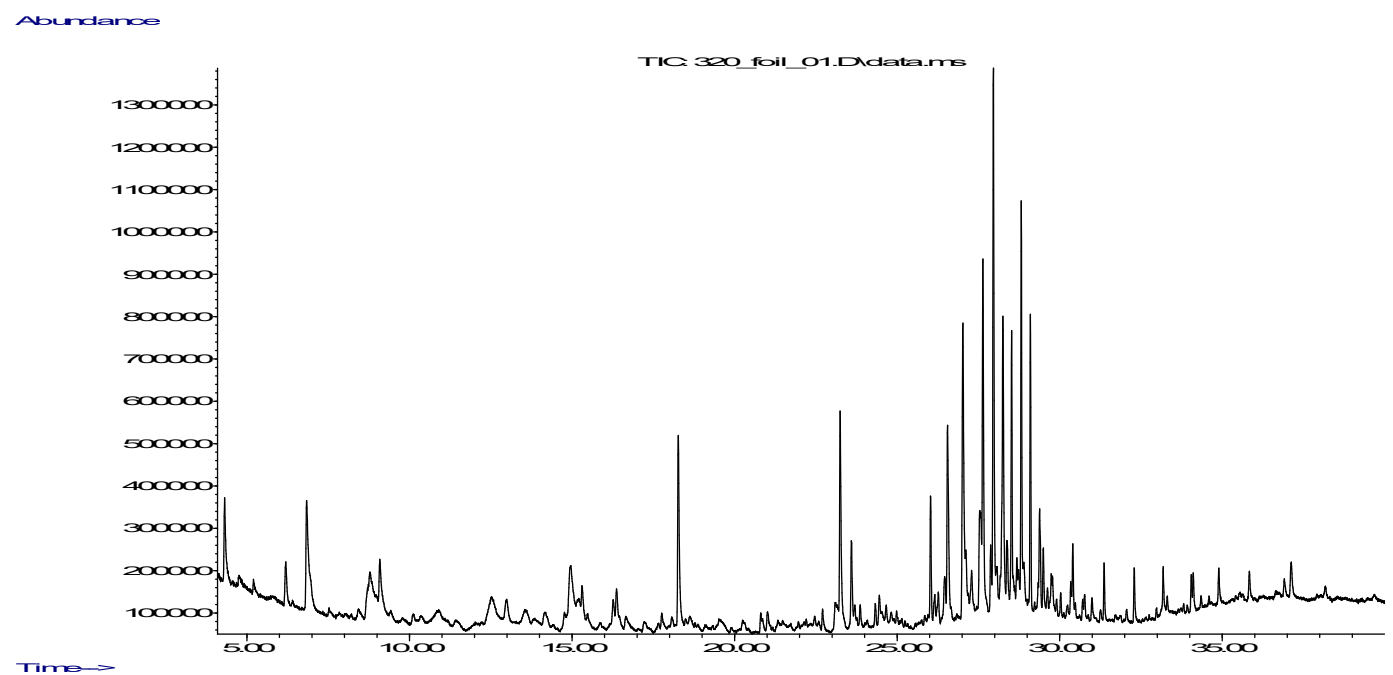

Figure 13. Py-GC-MS data for HSI Laboratory toner sample (HSI Lab ID 320).

Identification of compounds present in spectra was conducted by comparing their spectra to NIST library spectra. The results achieved here corroborate with data provided by the HSI laboratory. The list of the compounds is given in Table 4 . 
Table 4. Tentative identification of compounds in HSI Laboratory toner sample

\begin{tabular}{|c|c|}
\hline Compound & Retention time (RT) \\
\hline Styrene & $6.9 \mathrm{~min}$ \\
\hline Benzofuran & $9.1 \mathrm{~min}$ \\
\hline Tetramethyl benzene & $14.9 \mathrm{~min}$ \\
\hline Bis-dimethylethyl phenol & $18.3 \mathrm{~min}$ \\
\hline Pthalic Acid ester & $23.3 \mathrm{~min}$ \\
\hline Methylethylidene bisphenol & $27.0 \mathrm{~min}$ \\
\hline Fumaric acid & $27.9 \mathrm{~min}$ \\
\hline Methylethylidene bisbenzene & $29.1 \mathrm{~min}$ \\
\hline
\end{tabular}

Replicate measurements were also conducted for inkjet and toners. Inter-day reproducibility data for a toner sample $(0037 \mathrm{TN})$ are shown in Figure 14 . These pyrograms were acquired one month apart. Although the abundance (Y axis) value changes depending on the amount of sample introduced into Py-GC-MS, the positions of the peak did not change. The Py-GC-MS data obtained in this study provide qualitative rather than quantitative information about sample composition. 


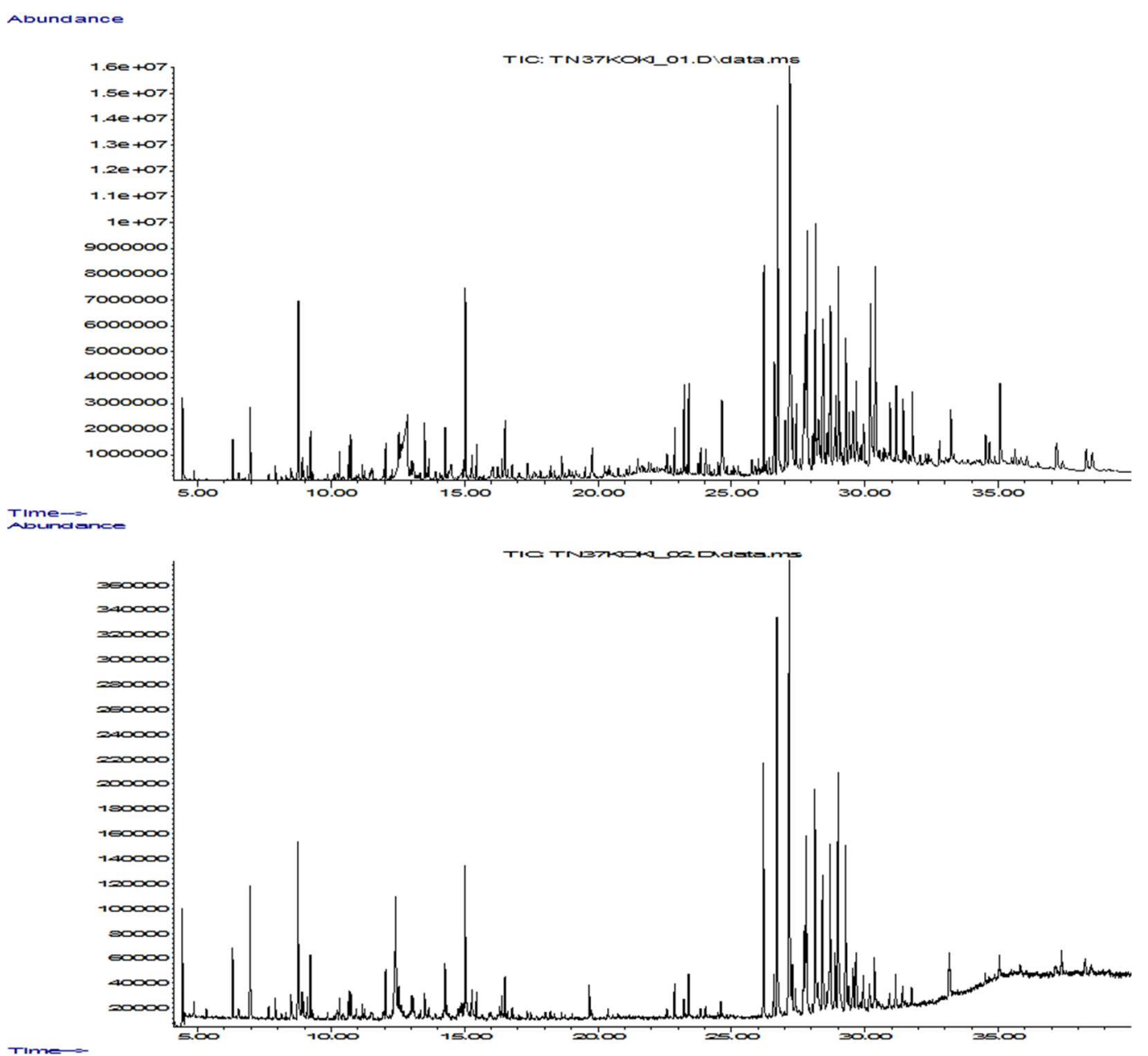

Figure 14. Py-GC-MS data for the same toner sample (0037TN) obtained one month apart.

\subsection{Results}

Overall, more than 200 compounds were detected in 77 toner samples. Ten compounds for classification and differentiation of toner were identified (Table 5). These compounds include toluene, ethyl benzene, 1,3,5,7-cyclooctatetraene, styrene, butyl methacrylate, phenol, benzofuran, p-Isopropenylphenol, bibenzyl and bisphenol A. The retention time (abbreviated as RT) for these compounds are listed in Table 5. On the basis of the presence or absence of these compounds, all toners were grouped into seven groups, which can be seen in Table 6. Toners from groups 1 and 4 (two toner samples per 
group) are shown in Table 5. In both groups, toner samples from the same brand but different color were chosen. Numeric values shown in the table represent areas of these compounds normalized to styrene area. Toners from the same brand show good sampleto-sample reproducibility in normalized areas. As it was mentioned before, although PyGC-MS data are not quantitative, they can be used for semi-quantitative analysis and for sample comparisons. Chromatograms of samples from different groups are shown in Figure 15 and Figure 16. The highest peak in both chromatograms correspond to styrene $(\mathrm{RT}=6.98 \mathrm{~min})$. In the case of toner 0017TN0101, a group of peaks in between 27 and 30 min was observed. These peaks are characteristic of bisphenol A $(\mathrm{RT}=27.17 \mathrm{~min})$. On the basis of the presence and absence of the compounds listed in Table 5, all toners were grouped into seven groups and discrimination percent was calculated based on the grouping. It was found to be $64 \%$. The discrimination capability of Py-GC/MS for toners by color (CMYK) was also calculated and can be seen in Table 7. To gain more insight into the spread of the data, principle component analysis (PCA) and cluster analysis were performed on the toner results using the 10 compounds of interest as variables. Using these statistical tools, it was shown that the toner samples could be grouped by brand, namely toners from the Hewlett Packard (HP) brand were similarly classified using these variables, with all other brands being classified differently than the HP brands. Both the PCA and cluster analysis exhibited this separation by HP and non-HP brands. The results of the PCA and cluster analyses can be seen in Figure 17. 
Table 5. Compounds used for grouping of Py-GC/MS data for toners.

\begin{tabular}{|c|c|c|c|c|c|}
\hline & & \multicolumn{2}{|c|}{ Group 1} & \multicolumn{2}{|c|}{ Group 4} \\
\hline $\mathrm{RT}$, min & Compound & $\begin{array}{c}0002 \mathrm{TN} 0101 \\
\text { K HPCN }\end{array}$ & $\begin{array}{c}0005 \mathrm{TN} 0101 \\
\text { Y HPCN }\end{array}$ & $\begin{array}{c}\text { 0030TN0101 } \\
\text { M IMX }\end{array}$ & $\begin{array}{l}0031 \mathrm{TN} 010 \\
\text { 1YIMX }\end{array}$ \\
\hline 4.437 & Toluene & 0.033 & 0.039 & 1.01 & 0.75 \\
\hline 6.329 & Ethyl benzene & 0.015 & 0.020 & 0.39 & 0.39 \\
\hline 6.659 & $\begin{array}{c}1,3,5,7- \\
\text { Cyclooctatetra } \\
\text { ene }\end{array}$ & 0 & 0 & 0 & 0 \\
\hline 6.977 & Styrene & 1 & 1 & 1 & 1 \\
\hline 7.08 & $\begin{array}{c}\text { Butyl } \\
\text { methacrylate }\end{array}$ & 0.024 & 0.022 & 0 & 0 \\
\hline 8.765 & Phenol & 0 & 0 & 1.71 & 1.27 \\
\hline 9.225 & benzofuran & 0 & 0 & 0.61 & 0.57 \\
\hline 15.03 & $\begin{array}{c}\text { p- } \\
\text { Isopropenylph } \\
\text { enol }\end{array}$ & 0 & 0 & 1.078 & 0.91 \\
\hline 18.769 & Bibenzyl & 0.025 & 0.021 & 0 & 0 \\
\hline 27.173 & Bisphenol A & 0 & 0 & 2.47 & 2.23 \\
\hline
\end{tabular}


Table 6- Grouping of toner ink samples by Py-GC/MS analysis based on presence and absence of compounds used for classification

\begin{tabular}{|l|l|l|l|l|l|l|}
\hline Group 1 & Group 2 & Group 3 & Group 4 & Group 5 & Group 6 & Group 7 \\
\hline TN01KBR & TN15KHP & TN21KHP & TN29CIMX & TN36KOD & TN51KXR & TN12KHP \\
\hline TN02KHPCN & TN17KHP & TN22CHP & TN30MIMX & & & TN06KHP \\
\hline TN03CHPCN & & TN23CHP & TN31YIMX & & & TN14KHP \\
\hline $\begin{array}{l}\text { TN04MHPC } \\
\text { N }\end{array}$ & & TN24MHP & TN50KBR & & & TN16KHP \\
\hline TN05YHPCN & & TN25MHP & TN37KOD & & & TN28KIM \\
\hline TN07KHP & & TN26YHP & TN38KOKI & & & TN43CXR \\
\hline TN08KHP & & TN27YHP & TN39COKI & & & TN70CRC \\
\hline TN09KHP & & & TN40MOKI & & & TN71MRC \\
\hline TN10KHP & & & TN41YOKI & & & TN72YRC \\
\hline TN11KHP & & & TN61YOKI & & & \\
\hline TN13KHP & & & TN42KXR & & & \\
\hline TN18KHP & & & TN44MXR & & & \\
\hline TN19KHP & & & TN45YXR & & & \\
\hline TN20KHP & & & TN46KXK & & & \\
\hline TN32KKN & & & TN47CXK & & & \\
\hline TN33CKN & & & TN48MXK & & & \\
\hline TN34MKN & & & TN49YXK & & & \\
\hline TN35YKN & & & TN52KRS & & & \\
\hline TN54KHP & & & TN53KRC & & & \\
\hline TN55YHP & & & TN57KTS & & & \\
\hline TN56KHP & & & TN60KCN & & & \\
\hline TN58KCN & & & TN62KCN & & & \\
\hline TN63CCN & & & TN67CDL & & & \\
\hline TN64MCN & & & & TN68MDL & & \\
\hline TN65YCN & & & & & & \\
\hline TN74CSM & & & & & & \\
\hline TN75MSM & & & & & & \\
\hline & & & & & & \\
\hline
\end{tabular}




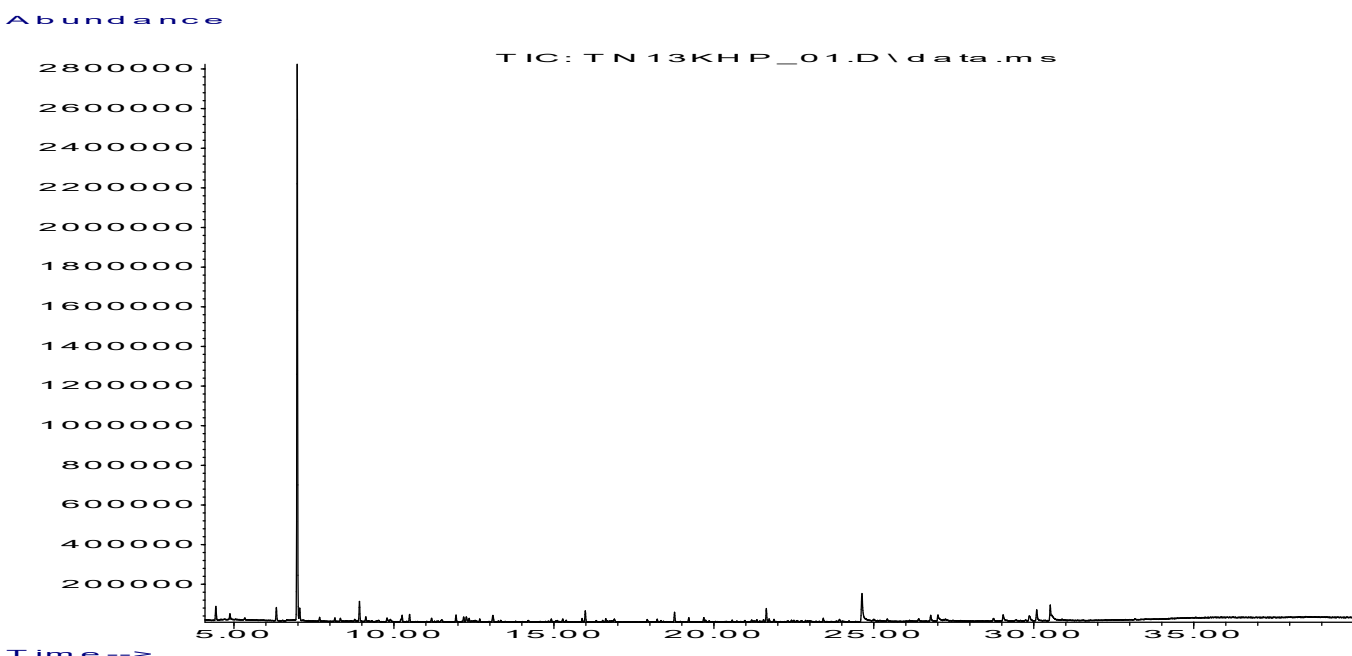

Figure 15. Py-GC-MS data for toner 0013TN0101.

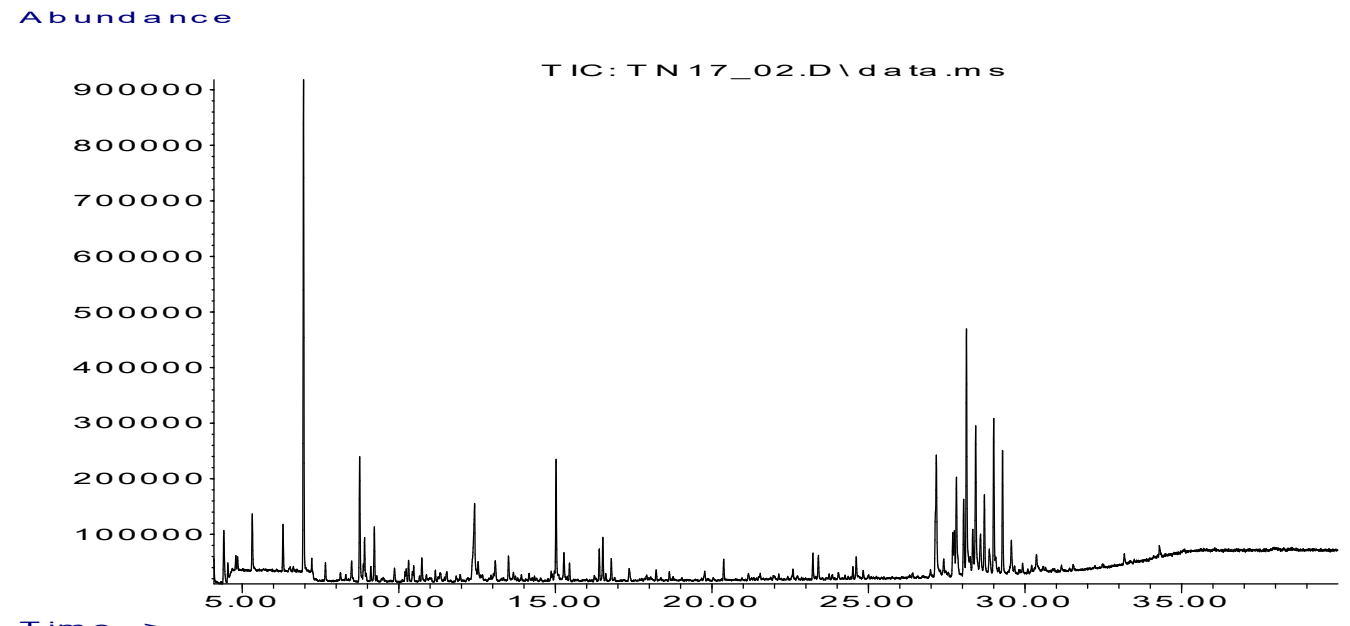

Figure 16. Py-GC-MS data for toner 0017TN0101. 

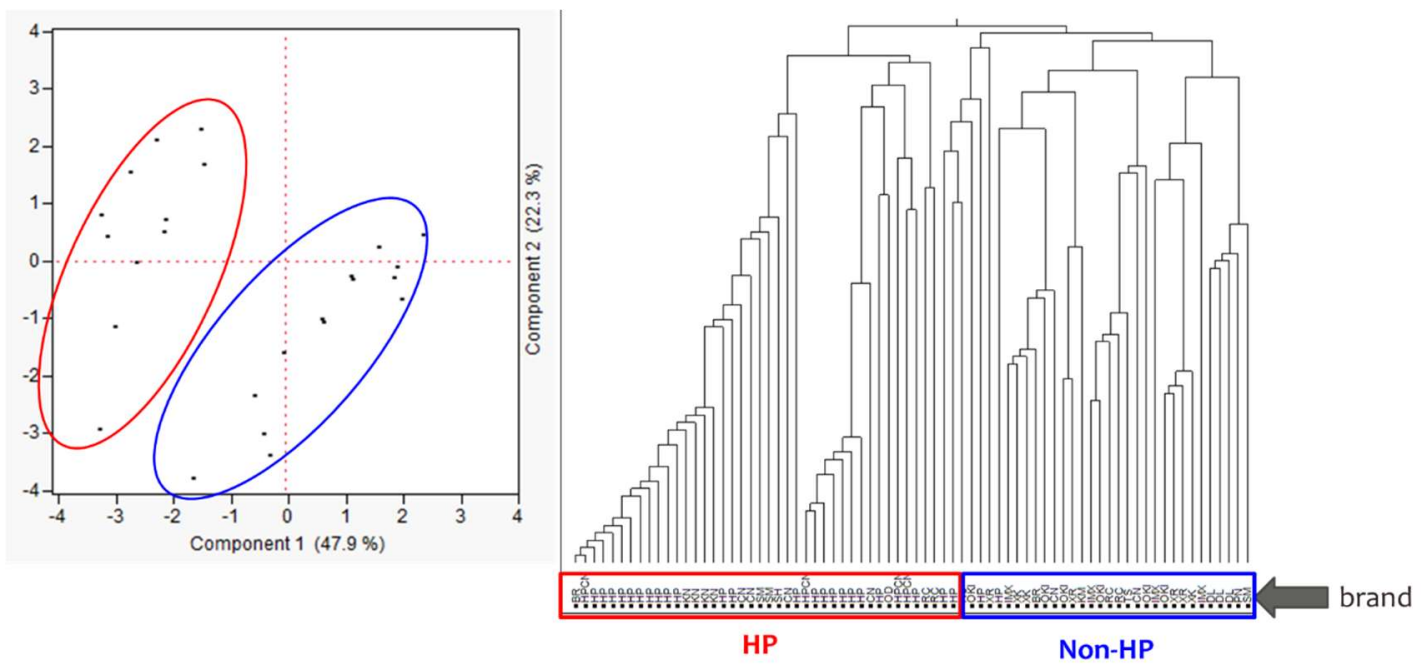

Figure 17- (left) PCA of toner samples showing distinct grouping between HP samples (red) and non-HP samples (blue) note: circles are hand-drawn; and (right) hierarchical cluster analysis of toner samples also showing distinct grouping between HP samples (red) and non-HP samples (blue)

Table 7- Discrimination capability of Py-GC/MS for toner inks based on color (CMYK)

\begin{tabular}{|c|c|}
\hline Color & DP, $\%$ \\
\hline $\mathrm{K}$ & 65 \\
\hline $\mathrm{C}$ & 71 \\
\hline $\mathrm{M}$ & 69 \\
\hline $\mathrm{Y}$ & 67 \\
\hline
\end{tabular}

\subsection{Conclusion}

Given that Py-GC/MS is a mature technique for the analysis of inks, particularly toner inks, it is not rapid, non-destructive, reproducible, nor does it provide as comprehensive chemical information as the other instrumental techniques included in this dissertation. The need for the sample to be physically cut and is destroyed subsequent to 
analysis excludes it from being considered non or semi-destructive in nature. The analysis time required to gain useful chemical information and the need to run a method blank in between samples analyses severely handicaps a rapid analysis. Therefore, this technique does not qualify to be useful for routine analysis of printing inks in a forensic setting due to the destructive nature, long analysis time, and limited chemical information it provides. In conclusion, all toner samples were transferred to foil analyzed via Py-GCMS with pyrolysis temperature $750{ }^{\circ} \mathrm{C}$. Inkjet samples were analyzed directly on paper with pyrolysis temperature $250{ }^{\circ} \mathrm{C}$. Only deposited inkjet samples were analyzed via PyGC-MS whereas for printed samples not enough sample was present to be detected via Py-GC-MS. In toners, mainly break down products of resins were detected whereas in inkjets volatile solvents and vehicles were detected. The method was not useful for the analysis of offset or intaglio samples. On the basis of the presence and absence of 10 compounds of interest, all toners were classified into 7 groups and discrimination percent was found to be $64 \%$. As a result of the low discrimination capabilities and destructiveness of this technique, it is recommended that this technique to be used as a last resort in the analysis of printing inks. However, Py-GC-MS can be useful on the case by case basis, especially for toner inks. 


\section{CHAPTER 4. ANALYSIS OF PRINTING INKS USING ATR-FTIR}

Portions of this chapter were published in the Journal of Forensic Sciences, May 2016, Volume 61, Number 3, Pages 706-714 Copyright (C) John Wiley and Sons

\subsection{Method development and optimization}

A Perkin Elmer Spectrum One FTIR with PIKE Technologies GladiATR accessory was used for analysis. The instrument is shown in Figure 18. The same optimized method parameters were used for all ink samples and are listed in

Table 8. Initial method parameters were adapted from Shaffer and recommendations from PIKE Technologies manufacturer specifications. The method was validated by analyzing samples provided by the HSI Laboratory. The results were confirmed by data provided by HSI. The resulting spectra are illustrated in

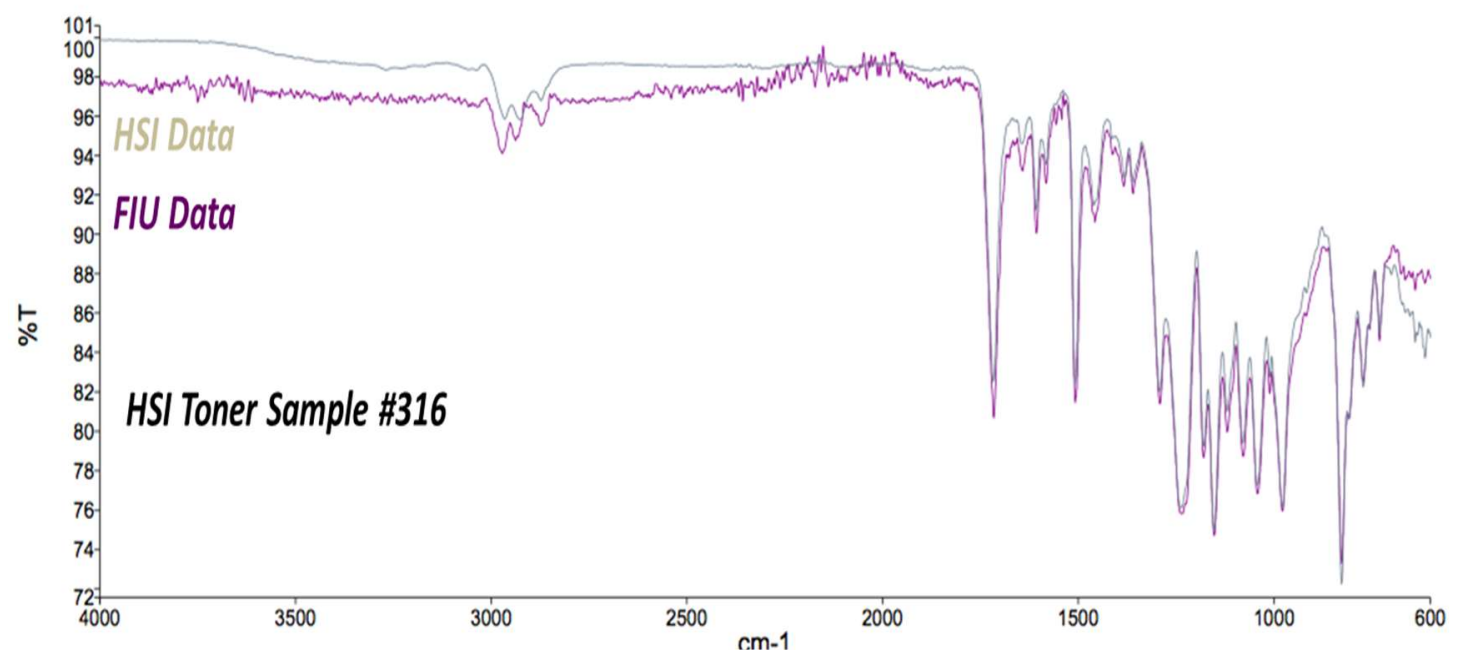

Figure 19. Reproducibility of the technique was also validated with replicate spectra of the same sample taken on the same day and on different days. The results show that the ATR-FTIR method has a high degree of reproducibility as illustrated in Figure 20. 


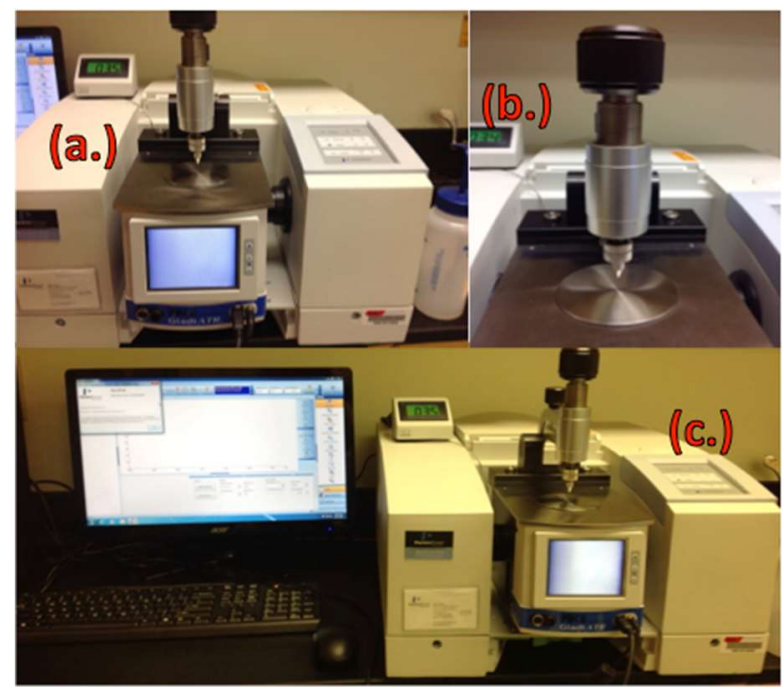

Figure 18. (a.) Close-up of FTIR instrument and ATR accessory (b.) Close-up of ATR pressure knob and crystal (c.) Entire instrumental set-up.

Table 8. Optimized ATR-FTIR method parameters for printing ink analysis.

\begin{tabular}{|c|c|}
\hline \multicolumn{2}{|c|}{ Perkin Elmer Spectrum One FTIR } \\
\hline \multicolumn{2}{|c|}{ PIKE Technologies GladiATR } \\
\hline \multicolumn{2}{|c|}{ Diamond Crystal, single bounce } \\
\hline Resolution & $4 \mathrm{~cm}^{-}$ \\
\hline Spectral range & $4000-600 \mathrm{~cm}^{-}$ \\
\hline Scans per sample & 4 \\
\hline Crystal area & $770 \times 590 \mathrm{microns}$ \\
\hline Sampling spot size & $50 \mu \mathrm{m}$ \\
\hline
\end{tabular}




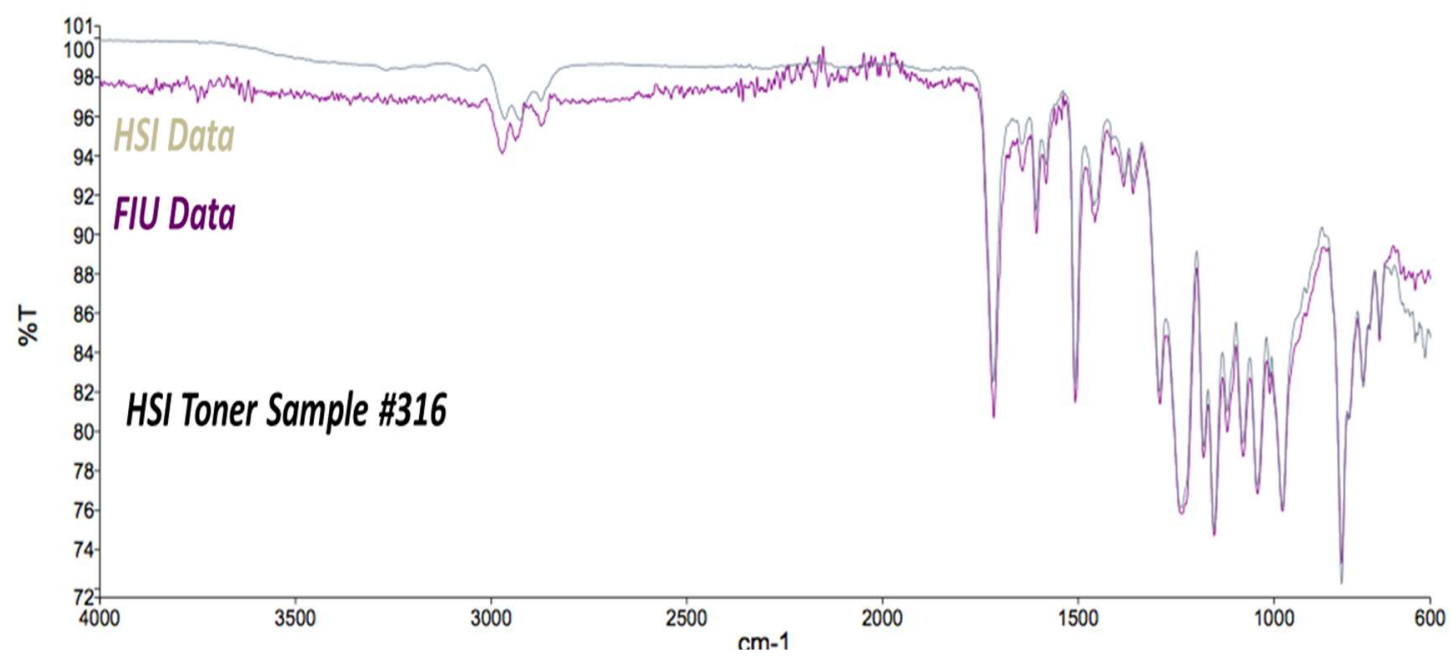

Figure 19. Method Validation with Sample provided by HSI Laboratory.

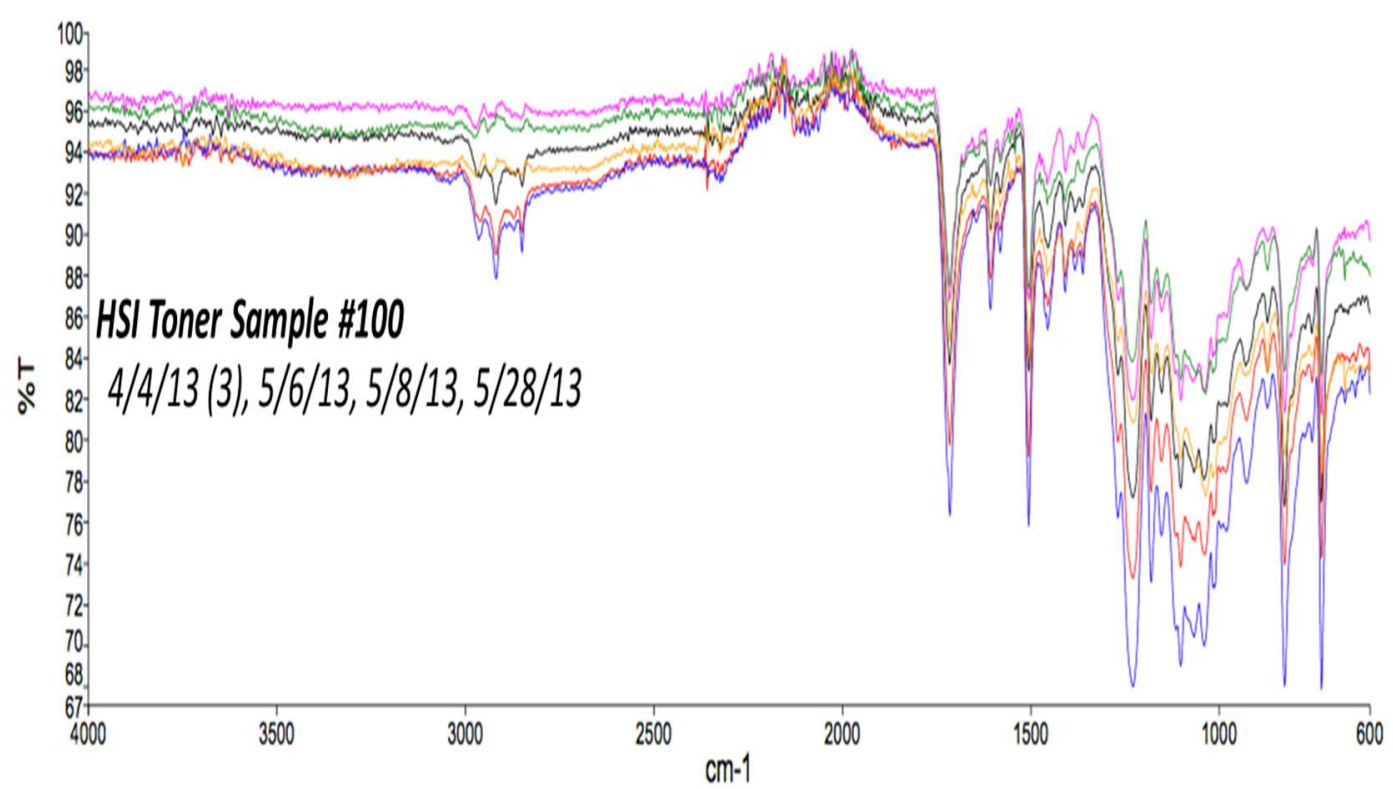

Figure 20. Inter- and intra-day reproducibility validation.

Sample TN37 was used as a daily performance standard. Inter-day and Intra-day variation was accounted for, as is illustrated in Figure 21. The only differences in the spectra were in the $\% \mathrm{~T}$ for the absorption bands. The position, relative intensity, and 
shape of the absorption peaks are identical for the same sample analyzed at different times, at different positions on the sample, and even with different pressures applied with the ATR accessory. For this study, differences between spectra were accounted for in the presence and/or absence of absorption peaks, discounting any differences in $\% \mathrm{~T}$. Figure 21 illustrates the identical position of absorption peaks and differences in $\% \mathrm{~T}$ that would qualify for the association of common inks.

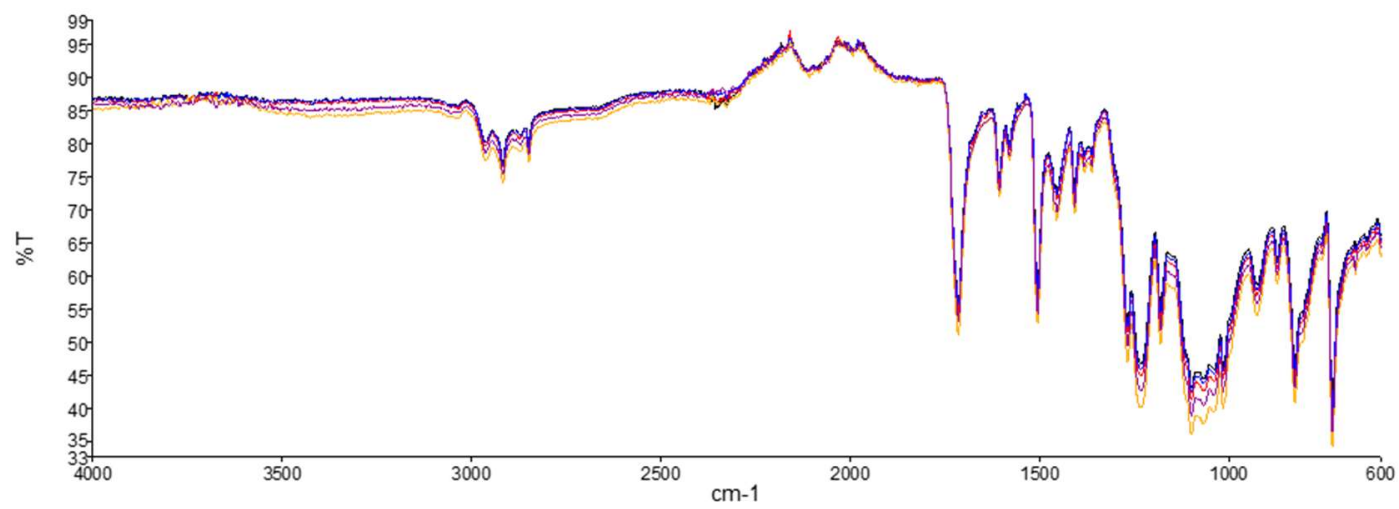

Figure 21- Inter- and intra-day reproducibility of ATR-FTIR spectra for toner sample 37, illustrating association of common spectra to one another.

\subsection{Results}

For each class of ink analyzed, the most abundant component of the ink contributes to and dominates the IR spectra obtained. For toners, the primary constituent is a polymer resin, for offsets, it is a pigment and/or resin, for inkjets, a solvent, and for intaglio, a resin and/or pigment. The differences in composition of these inks is the determining factor in the effective utility of ATR-FTIR as an analytical tool in producing a chemical profile for use in associating common inks and discriminating inks from different sources. 
After qualitatively comparing the spectra acquired, inks from each class were separated into groups based on characteristic absorption bands present in IR spectra. Within each group, the position, relative intensity, and shape of the absorption bands are identical, only differing in overall \%T. Inks in the same group could not be discriminated from one another based on information provided by FTIR analysis alone. Figure 23 illustrates inks from different sources belonging to the same group based on IR spectra. Inks belonging to different groups could be discriminated based on the presence and/or absence of absorption bands. Figure 24 illustrates inks from different sources belonging to different groups that can be discriminated based on qualitative differences in IR spectra.

\subsubsection{Inkjet Results}

The analysis of inkjet inks did not provide useful information for discrimination purposes. The deep penetration of the inkjet ink into the paper substrate fibers caused the spectra obtained to be dominated by cellulose peaks identical to a spectra acquired of blank Whatman paper. The only feature observed in the spectra of inkjets was the contribution of the ATR diamond crystal absorption at $\sim 2000 \mathrm{~cm}^{-}$in black (K) ink samples, which is illustrated in Figure 22. Inkjet inks were also analyzed in pure liquid form, but the spectra were dominated by bands due to the alcohol solvent of the inks, and all spectra for pure inkjet inks were identical, providing evidence that the only contributing factor to the IR spectrum is in fact the common alcohol solvent, which is not useful for discrimination purposes. The only reported successful analysis of inkjet inks for discrimination purposes using FTIR employed a photoacoustic apparatus, which is 
sensitive enough to characterize the trace components of the inkjets, such as pigments and/or dyes.

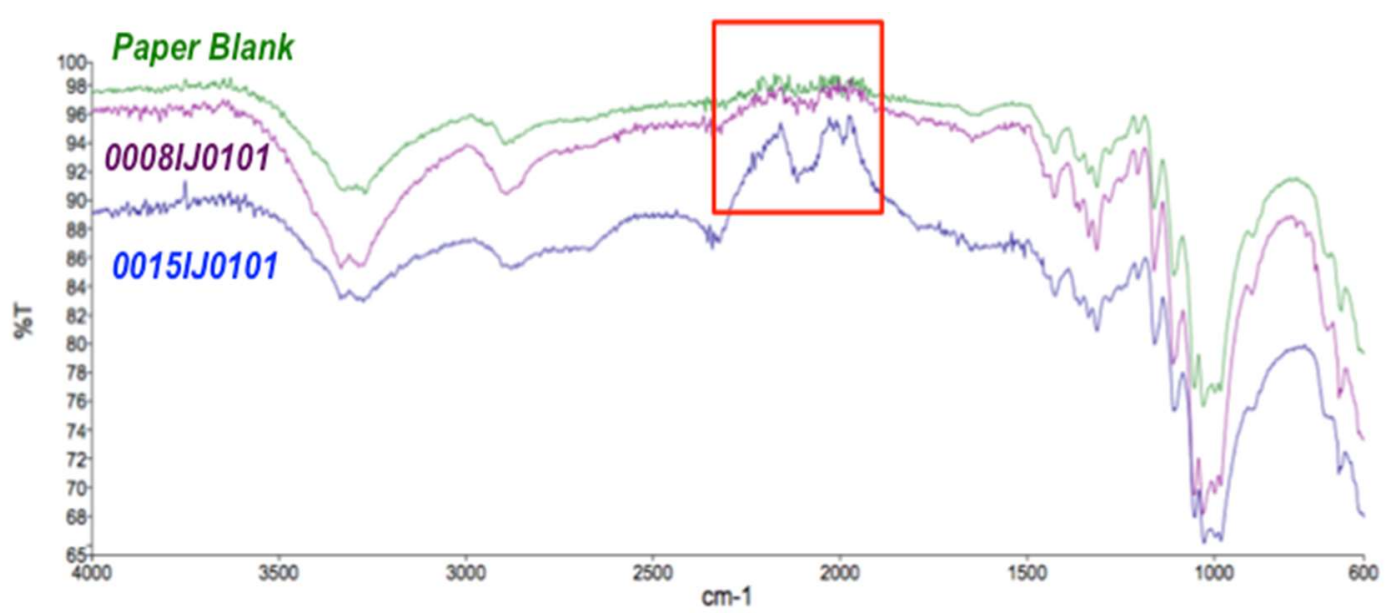

Figure 22. ATR-FTIR spectra of inkjet inks and blank paper background, illustrating presence of diamond ATR crystal artifact.

\subsubsection{Toner Results}

The spectra obtained from the analysis of toner samples were dominated by contribution from the polymer resin content of the toners. A combination of the presence and absence of polystyrene, acrylate, epoxy, and polyester resins were present in the samples, as has been previously reported in the analysis of toners. Many of the samples contained an absorption peak around $2000 \mathrm{~cm}^{-}$due to the diamond crystal. This absorption band was not present in all samples analyzed and was therefore included when associating common toners and discriminating different toners. The CMY inks originating from the same printer produced identical IR spectra, differing only in overall $\% \mathrm{~T}$, which is also observed between replicate measurements of the same sample. The black $(\mathrm{K})$ colored toner from the same cartridge differed only from the CMY in the 
presence of the diamond crystal absorption artifact at $\sim 2000 \mathrm{~cm}^{-}$, as is illustrated in Figure 23. This provides evidence that the polymeric content of toners dominates the spectra in ATR-FTIR analysis, and not dye/pigments, due to polymers being the major component of toners. An illustration of the characteristic peaks used to differentiate toners into groups can be viewed in Table 9. A decision tree was made based on presence and/or absence of characteristic absorption peaks for classification of a toner ink sample into one of the twelve groups differentiating toners by class (Figure 26). For toner samples, out of 2850 possible comparison pairs, 391 were indistinguishable, giving a discrimination percent of $86.3 \%$, defining the percent of toners from different sources that ATR-FTIR differentiated correctly. The percent false inclusion was $13.7 \%$, defining the percent of toners from different sources that were incorrectly associated with one another.

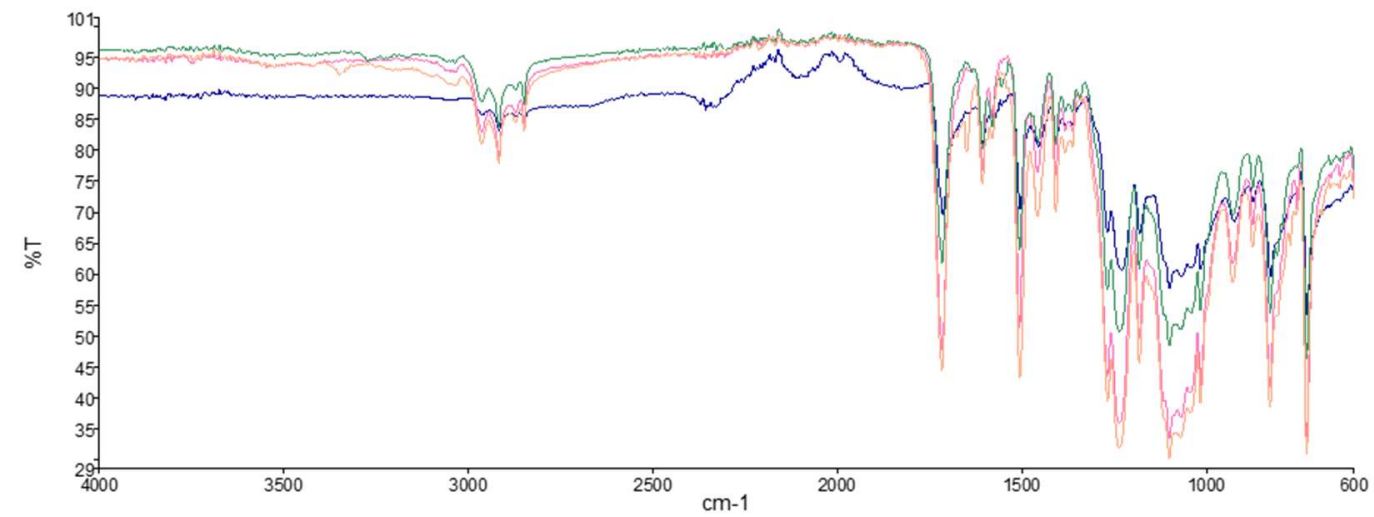

Figure 23-CMYK toner samples from same printer illustrating qualitative similarity with exception of diamond absorption artifact. 


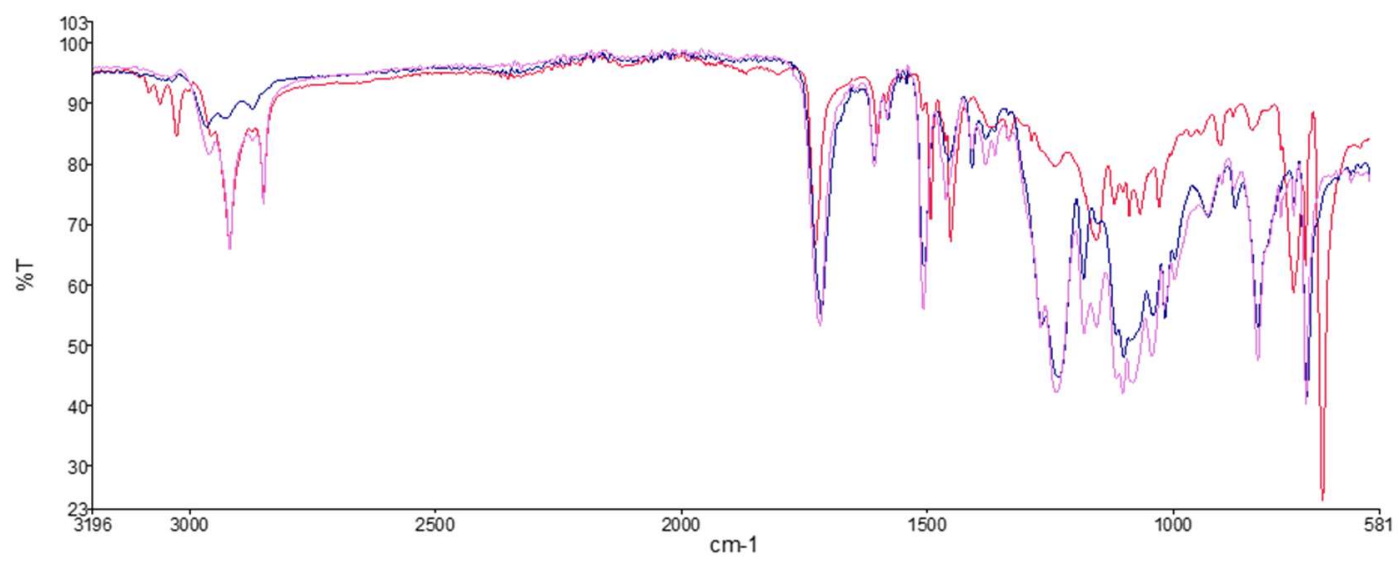

Figure 24- Three cyan toners belonging to different groups based on presence/absence of different absorption bands. 
Table 9. Groupings of toner samples based on characteristic FTIR peaks (in wavenumbers $\mathrm{cm}^{-}$).

\begin{tabular}{|c|c|c|c|c|c|c|c|}
\hline Group 1 & Group 2 & $\underline{\text { Group } 2 K}$ & Group 3 & $\underline{\text { Group } 3 K}$ & Group 4 & $\underline{\text { Group } 4 K}$ & Group 5 \\
\hline $\begin{array}{l}\text { Polystyrene } \\
\text { co-acrylate } \\
\text { Above 3000, } \\
700 \text { \& } 760\end{array}$ & $\begin{array}{l}\text { Polystyrene } \\
\text { co-acrylate } \\
\text { Above 3000, } \\
700 \text { \& } 760\end{array}$ & $\begin{array}{l}\text { Polystyrene } \\
\text { co-acrylate } \\
\text { Above 3000, } \\
700 \text { \& } 760\end{array}$ & $\begin{array}{l}\text { Epoxy } \\
1600-1000\end{array}$ & Eроху1600-1000 & Ероху1600-1000 & Epoxy 1600-1000 & $\begin{array}{l}\text { Polyethylene } \\
3000\end{array}$ \\
\hline \multirow[t]{4}{*}{$\begin{array}{l}\text { Diamond } \\
\text { Absorption } \\
2400-1800\end{array}$} & $\begin{array}{l}\text { Polyethylene } \\
3000\end{array}$ & $\begin{array}{l}\text { Polyethylene } \\
3000\end{array}$ & $\begin{array}{l}\text { Acrylate } \\
1730 \& 1130\end{array}$ & $\begin{array}{l}\text { Acrylate1730 \& } \\
1130\end{array}$ & Polyethylene3000 & Polyethylene3000 & $\begin{array}{l}\text { Group 6 } \\
\text { Paper } \\
\text { Contribution }\end{array}$ \\
\hline & & $\begin{array}{l}\text { Diamond } \\
\text { Absorption } \\
\text { 2400-1800 }\end{array}$ & & $\begin{array}{l}\text { Diamond } \\
\text { Absorption2400- } \\
1800\end{array}$ & $\begin{array}{l}\text { Acrylate1730 \& } \\
1130\end{array}$ & $\begin{array}{l}\text { Acrylate1730 \& } \\
1130\end{array}$ & $\frac{\text { Group } 7}{\text { TN70CRC }}$ \\
\hline & & & & & & $\begin{array}{l}\text { Diamond } \\
\text { Absorption2400- } \\
1800\end{array}$ & $\frac{\text { Group } 8}{\text { TN71MRC }}$ \\
\hline & & & & & & & $\frac{\text { Group } 9}{\text { TN72YRC }}$ \\
\hline
\end{tabular}



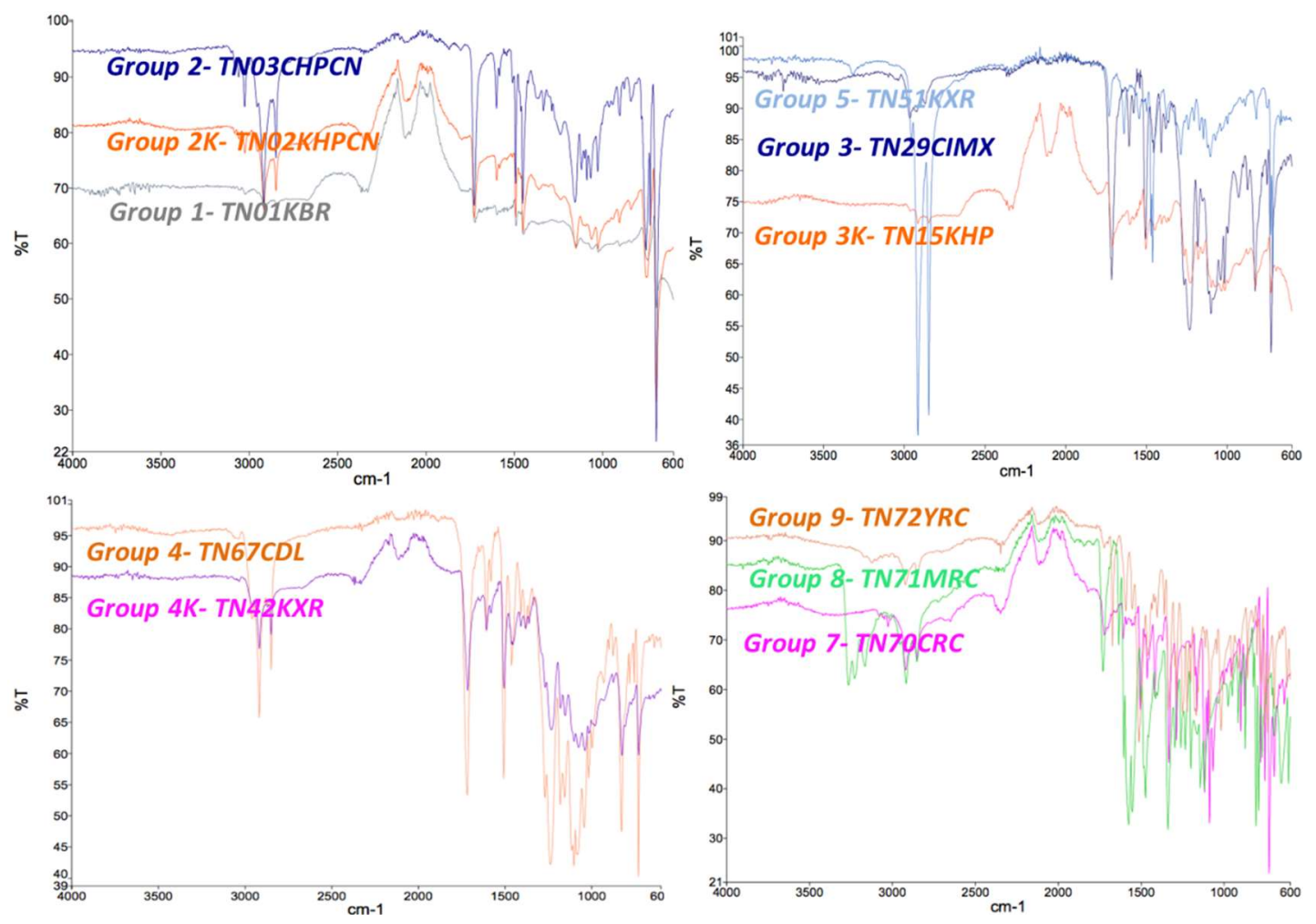

Figure 25. Toner ink samples grouped based on presence/absence of absorption bands by ATR-FTIR analysis. 


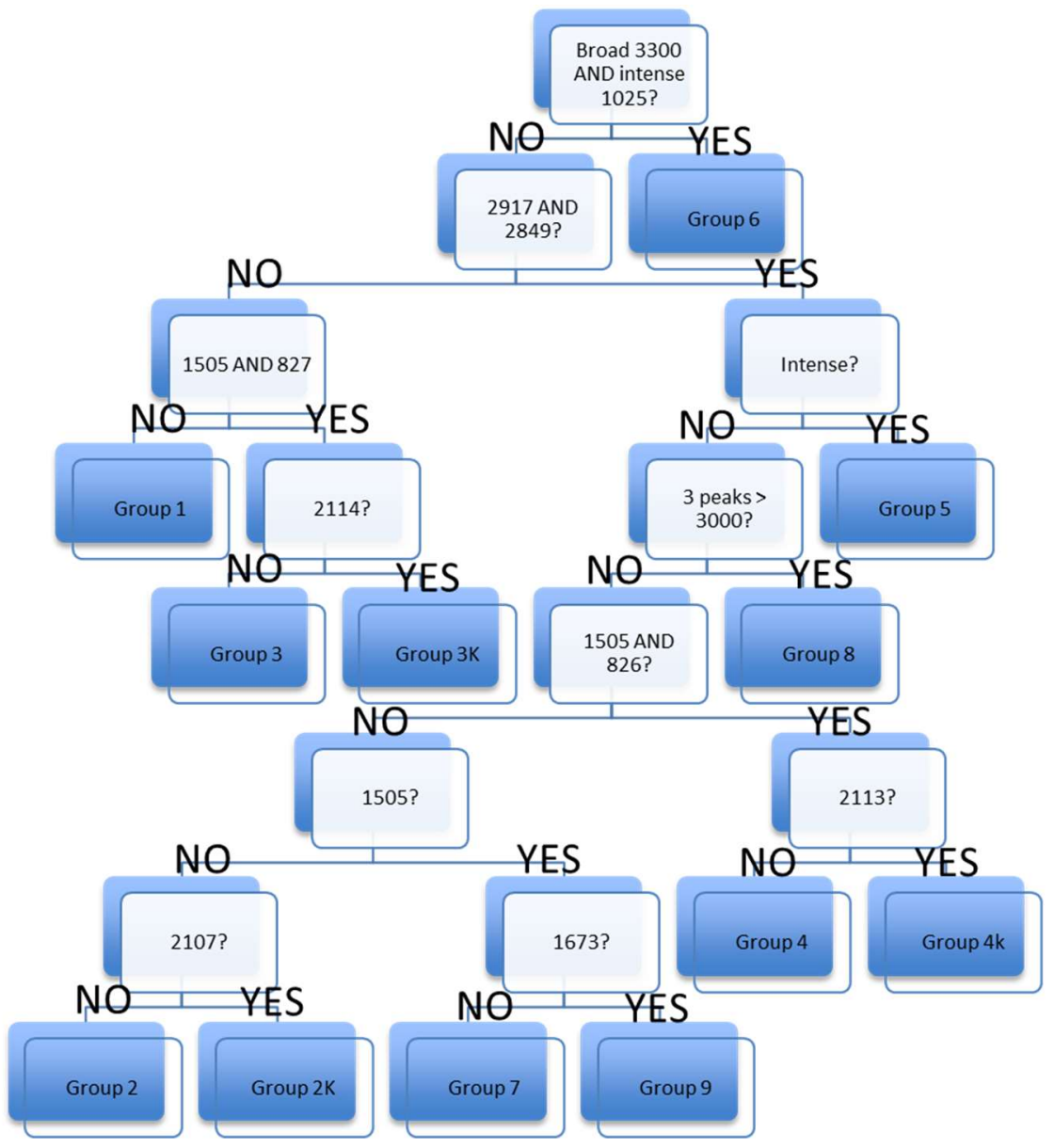

Figure 26- Decision tree for grouping of toners based on presence and absence of absorption bands in ATR-FTIR spectra. 
Table 10- Discrimination capability of ATR-FTIR for toners based on color

\begin{tabular}{|l|l|l|l|l|}
\hline \multirow{2}{*}{} & \multicolumn{4}{|l|}{ Toner Color } \\
\cline { 2 - 5 } & Black (K) & Cyan (C) & Magenta (M) & Yellow (Y) \\
\hline Number of Samples & 38 & 12 & 12 & 13 \\
\hline Total Comparisons & 703 & 66 & 66 & 78 \\
\hline Pairs Indistinguishable & 180 & 19 & 19 & 16 \\
\hline \% Discrimination & $74.4 \%$ & $71.2 \%$ & $71.2 \%$ & $79.5 \%$ \\
\hline
\end{tabular}

\subsubsection{Intaglio Results}

A strong cellulose peak and identical qualitative spectrum was observed for a majority of the samples. This peak is due to either the paper background contribution, in that the different banknotes are printed on the same paper type, and/or a cellulose resin that is present in the composition of the inks, as previously reported. Acquiring blank paper background spectra was not possible for the intaglio samples due to the layering of the inks on the paper, the small sample size, and the large sampling area of the ATR diamond crystal. When analyzing intaglio samples, the area sampled contained both ink and paper, and it was not possible to isolate the ink chemical signature from that of the paper substrate. Sixteen of the samples were differentiated into seven groups based, with samples in the same group originating from the same country. Due to the prevalence of the strong cellulose peak in a majority of samples ( 70 out of 86$)$ rendering them indistinguishable based on IR spectra alone, as illustrated in Figure 28, the discrimination percent for intaglio samples was $33.6 \%$ and the percent false inclusion of $66.4 \%$. 

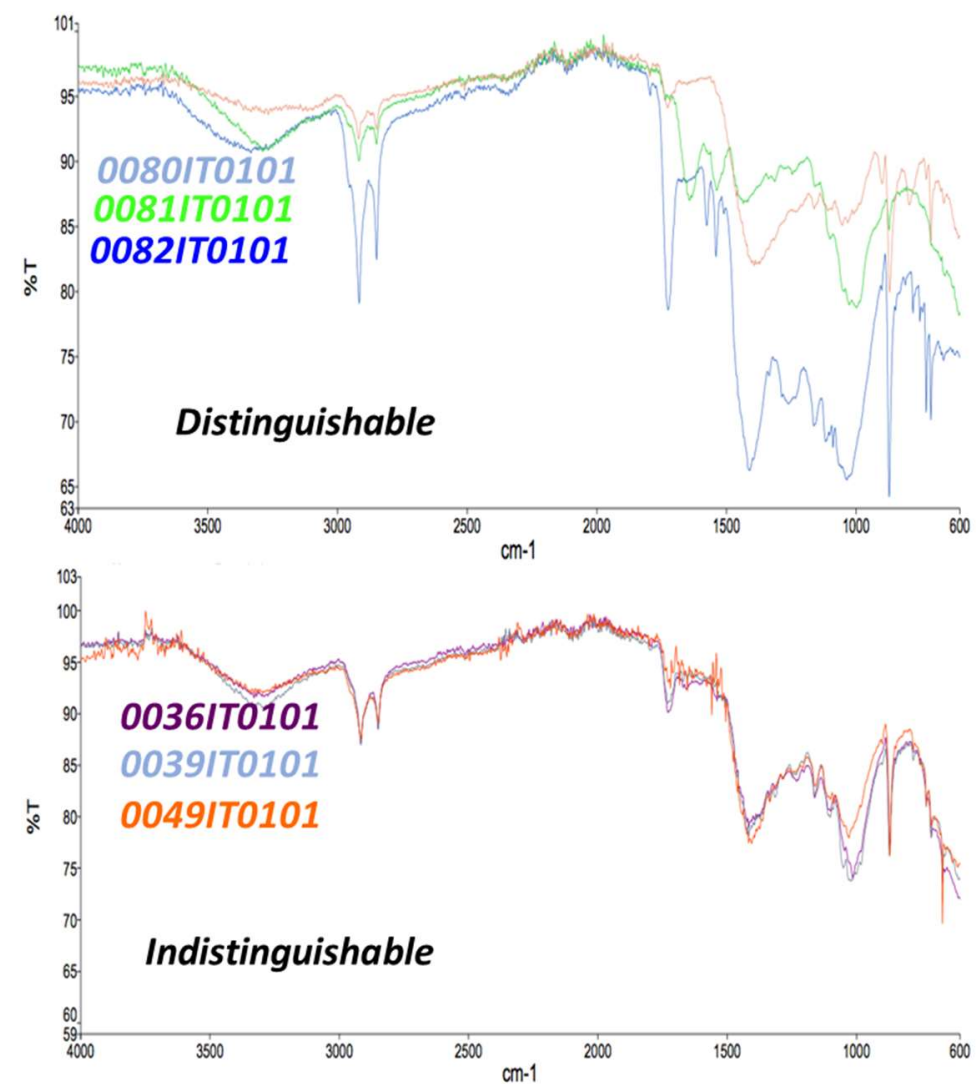

Figure 27. ATR-FTIR of intaglio inks illustrating limited discrimination capability. 


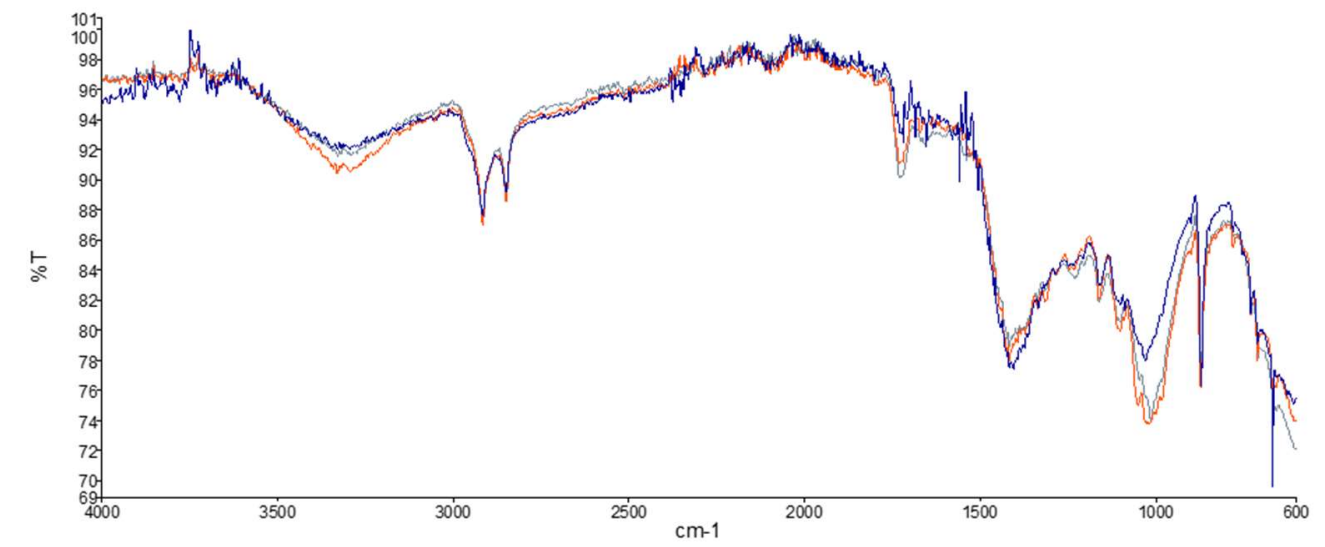

Figure 28- Intaglio samples from three different countries showing domination of cellulose peaks.

\subsubsection{Offset Results}

Due to the penetration depth of the ATR crystal and the offset ink into the surface of the paper substrate, the spectra obtained for the offset samples were identical to those of the blank paper on which the offset samples were printed/deposited. However, using the difference tool in the Spectrum software and subtracting the blank paper background spectrum allowed for the spectra of the offset ink to be obtained for those samples that were either printed or deposited. The samples that were portions of security documents produced spectra that were identical to the paper background, as is illustrated in Figure 29. This is due to the small area of ink printed on these samples and the large sampling area of the diamond crystal. The samples for which a spectrum was produced after background subtraction were discriminated by color. This provides evidence that the major component characterized via ATR-FTIR is the pigment or dye present in the composition of the ink. This allowed for discrimination of inks originating from the same printer or manufacturer but differing in color, even alternative colors such as orange 
and dark orange, as illustrated in Figure 30. For this reason, the ATR-FTIR analysis of offset inks provided the most comprehensive information for use in discriminating inks.

Out of 3081 possible comparison pairs, 227 were indistinguishable giving a discrimination percent of $92.6 \%$. The false inclusion percentage was $7.4 \%$.
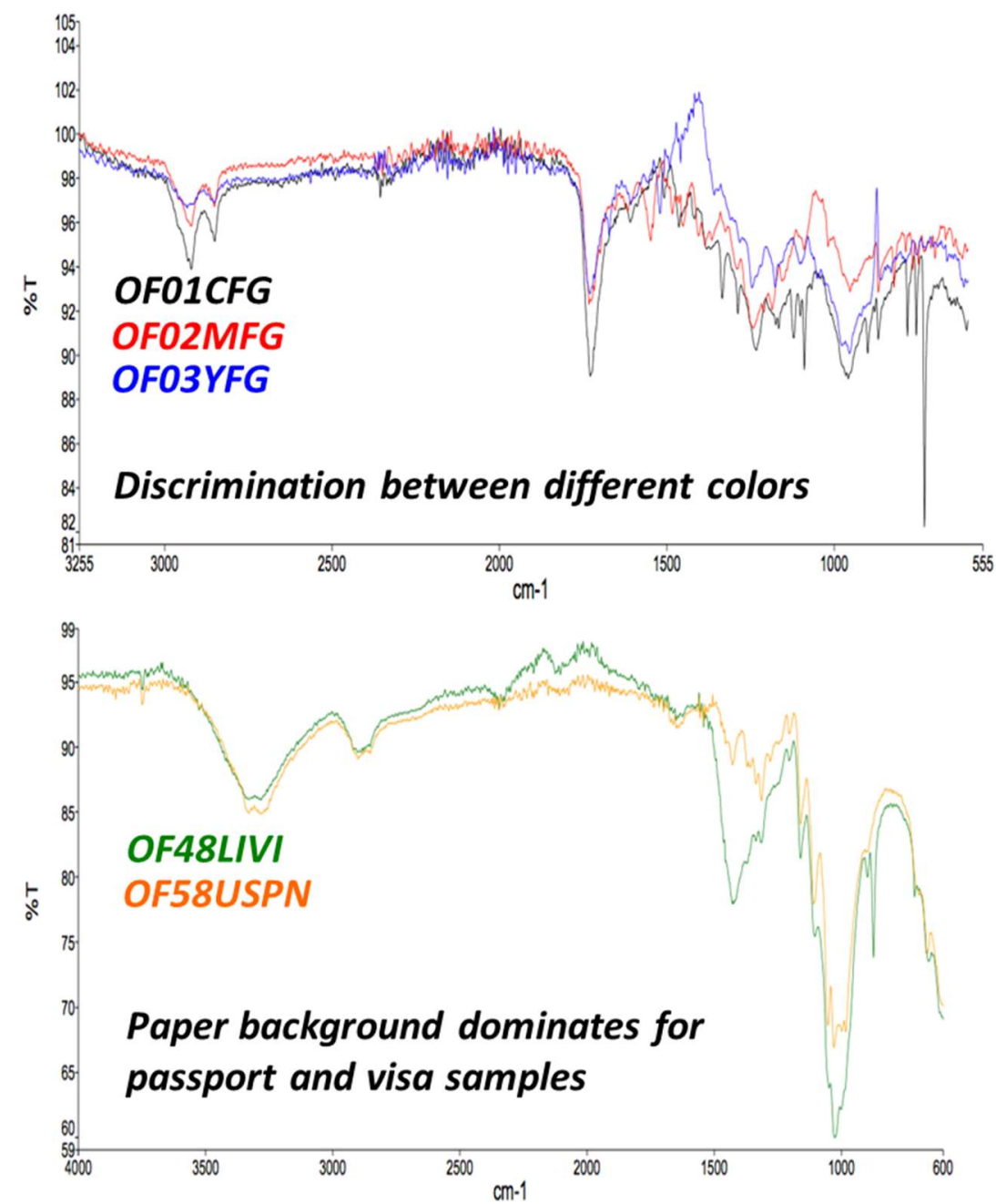

Figure 29. ATR-FTIR spectra of offset inks illustrating variability in sample type and information obtained for discrimination (top) samples of different colors from same manufacturer discriminated based on differences in ATR spectra and (bottom) lack of useful information for discrimination of offset samples from security documents due to domination of cellulose band 


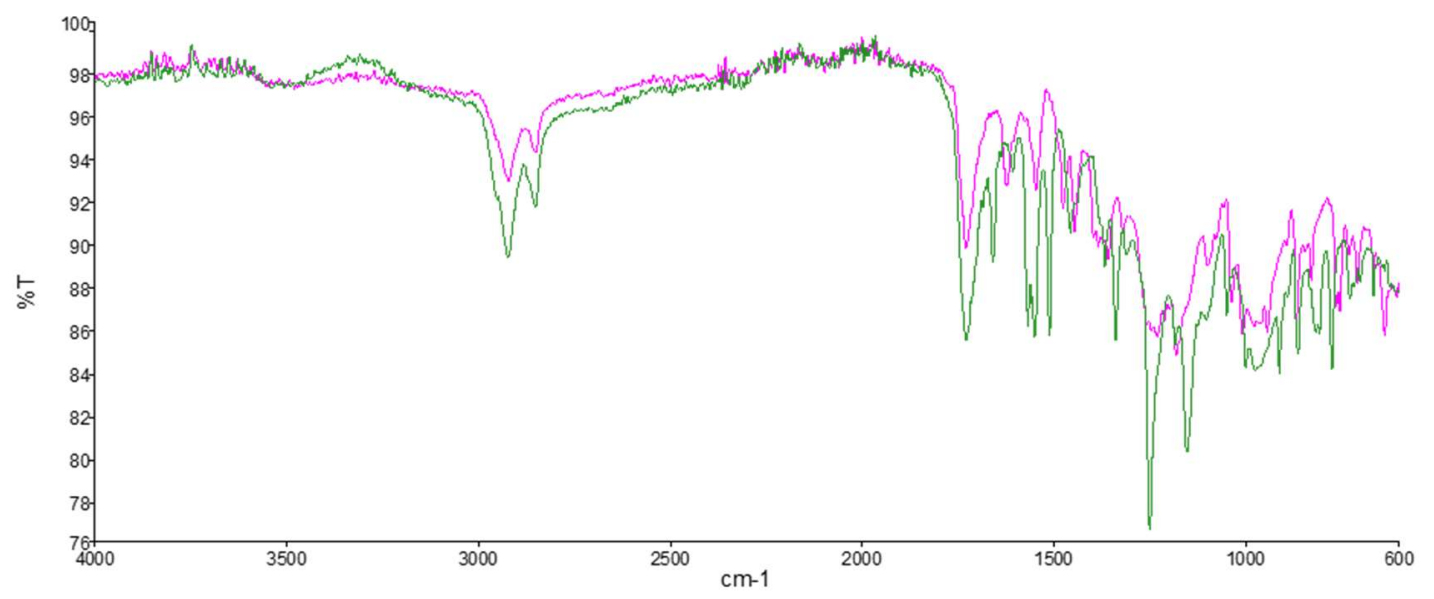

Figure 30- qualitative differences between orange and dark orange offset inks from same manufacturer

\subsection{Contamination Study}

A facet of the project involved determining whether handling of samples prior to analysis would interfere with the ability to associate common inks and discriminate inks. The worst case scenario would be that fingerprints and/or sweat deposited on ink samples as a result of handling would produce false exclusions of common inks that otherwise would be associated with one another. A number of printing samples were contaminated under the following conditions:

1) Controlled handling with minimum direct touching of the ink

2) Regular handing with bare hands and touched by multiple people

3) Handling with sweaty hands (hands wet with sweat after vigorous exercise

The sweat contaminated sample contained the most striking differences in terms of presence of additional absorption bands, most significantly the large $-\mathrm{OH}$ band present at 
$\sim 3500 \mathrm{~cm}^{-}$and additional absorption bands present in both the sweat and fingerprint contaminated samples between $\sim 1400-1700 \mathrm{~cm}^{-}$. These bands correspond to water content in the sample, and a protocol involving thoroughly drying samples prior to analysis could help prevent these contaminant peaks from being present in spectra.

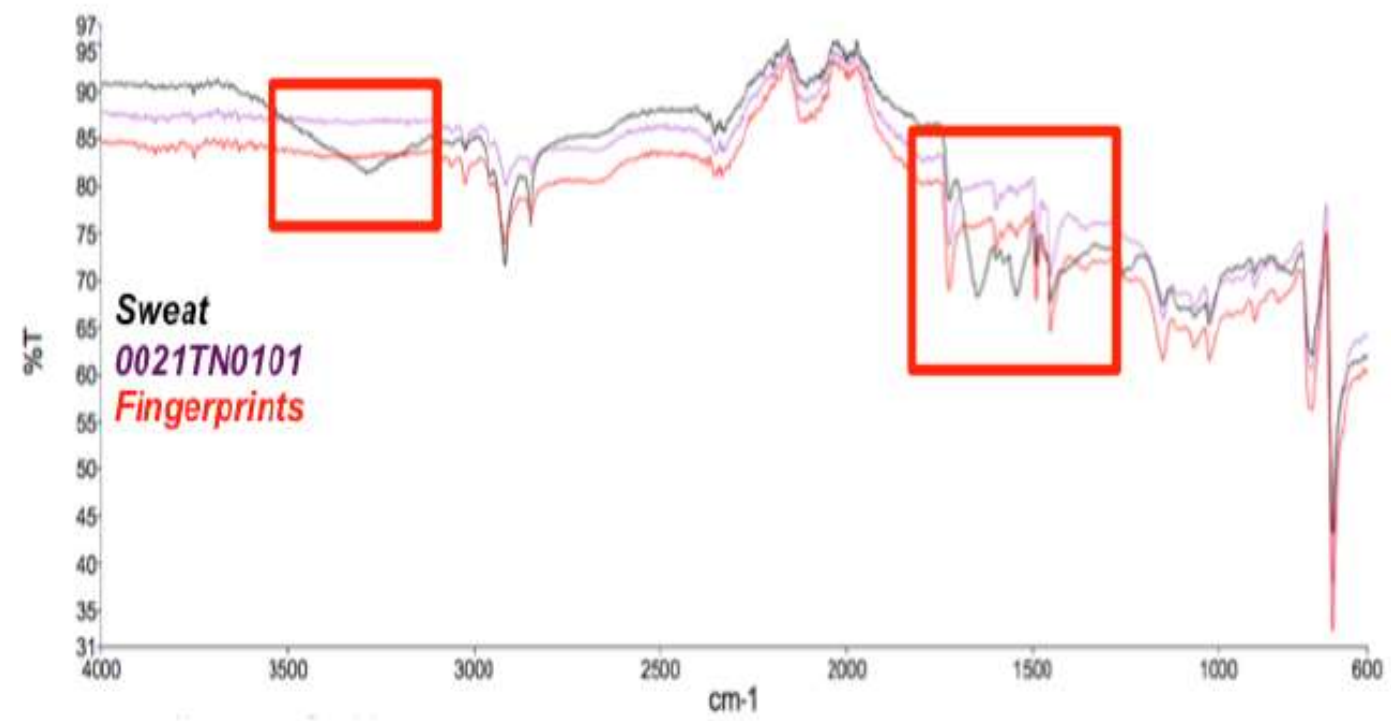

Figure 31- ATR-FTIR spectra of sample 0021TN0101 under different conditions: control, fingerprints, and sweat, with the most noticeable additional contaminant absorption bands present in the sweat sample

\subsection{Conclusion}

ATR-FTIR allows for the rapid, non-destructive, and highly reproducible analysis of printing inks on paper substrate with no sample preparation and provides varying discrimination capabilities based on composition of ink. A summary of the discrimination capability of ATR-FTIR based on ink type is illustrated in Table 11. 
ATR-FTIR analysis allows for the separation of samples into groups, with the ability to differentiate only those samples belonging to different groups. All samples belonging to the same group are identical in terms of peak shape and position. ATR-FTIR provides highest discrimination capability for offset inks due to the ability to subtract paper background and the high pigment composition of the inks. The characterization of toners by ATR-FTIR is based on the high polymeric content of the inks and thus allows for grouping based on chemical composition. The ATR-FTIR analysis of inkjet inks does not provide more information than can be obtained by visually inspecting the ink, due to the deep penetration of the ink into the paper substrate. ATR-FTIR provides the lowest discrimination capability of intaglio inks due to heterogeneity of ink deposition on paper substrate, high paper background contribution, and common cellulose-like resins present in different ink composition. Therefore, ATR-FTIR can be a useful tool for the classification of inks into groups, particularly for toner and offset inks. Though the purpose of ATR-FTIR to provide rapid, non-destructive analysis of inks on paper substrate, extraction of inks from paper substrate may provide more chemical information, while sacrificing the integrity of the overall ink or document. Extraction techniques may be useful for inkjet and intaglio inks in which no useful chemical information was obtained via the methodology set forth in this dissertation. 
Table 11. Summary of discrimination by ATR-FTIR based on ink type.

\begin{tabular}{|l|l|l|l|l|}
\hline & Inkjet & Toner & Intaglio & Offset \\
\hline \# samples & 78 & 76 & 86 & 79 \\
\hline \#samples from & $78(3003$ & $76(2850$ & $86(3655$ & $79(3081$ \\
different sources & comparison & comparison & comparison & comparison \\
pairs $)$ & pairs) & pairs $)$ & pairs) \\
\hline discrimination & of 3003$)$ & of 2850$)$ & of 3655$)$ & of 3081$)$ \\
\hline inclusions & of 3003$)$ & of 2850$)$ & of 3655$)$ & of 3081$)$ \\
\hline
\end{tabular}




\section{CHAPTER 5. ANALYSIS OF PRINTING INKS USING DART-MS}

Portions of this chapter were published in the Journal of Forensic Sciences, May 2016, Volume 61, Number 3, Pages 706-714 Copyright (C) John Wiley and Sons

\subsection{Method Development and Optimization}

The DART-MS analyses were conducted using a 6500 Q-TOF LC/MS (Agilent, Santa Clara, CA) coupled to a DART SVP (IonSense, Saugus, MA) ambient ionization source. DART ion source control was achieved through the DART SVP software (v 3.0.x). Mass spectra and Q-TOF data acquisition was achieved using MassHunter Workstation Software LC/MS Data Acquisition for the 6200 series TOF/6500 series QTOF (v B.05.00: Agilent, Santa Clara, CA). Analyses of spectra were carried out using MassHunter Workstation Software Qualitative Analysis (B.05.00). The optimum parameters for all analyses are included in Table 12 . The sample preparation and sampling procedure can be viewed in Figure 32.

Table 12- Optimized DART-MS Parameters

\begin{tabular}{|l|l|}
\hline DART SVP & 6500 Q-TOF LC/MS \\
\hline Positive Ionization Mode & Heater gas, He, $350{ }^{\circ} \mathrm{C}$ \\
\hline He gas temperature $350^{\circ} \mathrm{C}$ & Drying gas $0.2 \mathrm{~L} / \mathrm{min}$ \\
\hline & Fragmentor voltage, $175 \mathrm{~V}$ \\
\hline & Skimmer voltage, $65 \mathrm{~V}$ \\
\hline & Mass range $100-1000 \mathrm{amu}$ \\
\hline
\end{tabular}




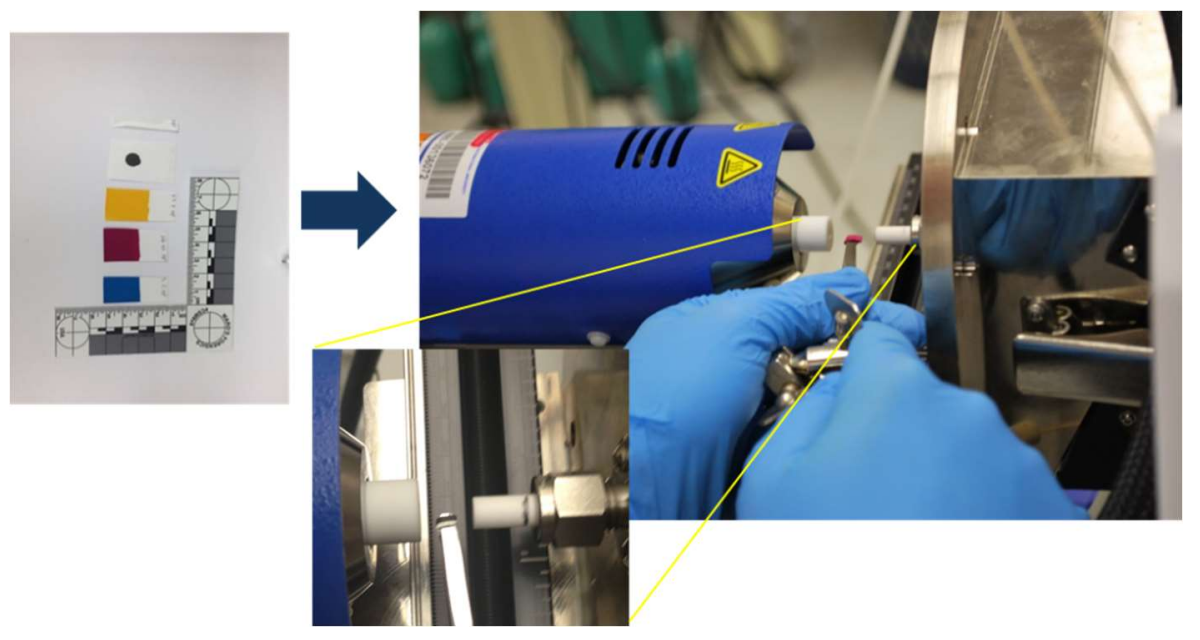

Figure 32- image of (left) preparation and size of ink samples for DART-MS analysis and (right) DART-MS sampling procedure for ink samples

A 5ppm solution of polyethylene glycol (PEG) 600 in 50:50 water:methanol was used as a daily performance standard and internal mass calibrant for the DART ionization source. For DART-MS analysis, samples were analyzed by cutting a $\sim 1 \times 10 \mathrm{~mm}$ rectangular section of the ink and wrapping the sample around a pair of tweezers. For each sample, mass spectra were recorded in the following sequence: air background, inkjet spectrum, and finally a polyethylene glycol 600 (PEG 600) reference standard to monitor the reproducibility of the DART ionization and MS acquisition. Six replicate measurements on different cuts of the sample were analyzed for each sample.

The method developed for the analysis of printing inks was adopted from Houlgrave et al. with minor alterations (70). Blank Whatman paper was analyzed prior to the analysis of inks on paper, and the spectrum produced was indistinguishable from the air background, providing evidence that Whatman paper does not interfere with the 
spectrum of ink. Inkjet inks were first analyzed to determine if PEG-like distributions were present as reported. Positive mode was chosen for the analysis of all inks due to the intensities of the peaks in negative mode being $>100$ times less intense than the spectra acquired in positive mode. The goal was to develop a single method applicable to the analysis of all ink types and the aforementioned parameters allowed for the successful acquisition of quality spectra for all ink types in this study. However, reproducibility of spectra acquired for inks varied based on sample type. This was due to the large area of the DART ionization stream and the heterogeneous distribution of this stream against the sampling surface of the ink. For some samples, mostly toners and offset inks, visible melting was observed as the ink sample passed through the DART stream. This is due to the low percent composition of volatile and semi-volatile components of these inks as compared to the inkjet inks, since toners are primarily composed of a heavy polymer resin. Therefore, up to six replicates taken from different cuts of the sample were analyzed for each of the ink samples to provide a more accurate depiction of the spread of the data. For data analysis purposes, though the mass resolution of the QTOF mass spectrometer allows for mass units to the thousandth place, it was noted that the variation in decimal places varied greatly between replicates. Therefore, the extracted data was treated to remove decimal places and round values at the same nominal mass unit, meaning the $\mathrm{m} / \mathrm{z}$ values ranged from $100-1000 \mathrm{~m} / \mathrm{z}$ in nominal units. 


\subsection{Results}

\subsubsection{Inkjet Results}

The most notable feature in the DART mass spectra of inkjets is the presence of multiple polymeric distributions characterized by a series of ions $44 \mathrm{~m} / \mathrm{z}$ units apart, as illustrated in Figure 33. These are due to combinations of PEG vehicles used in the formulation of inkjets with different average molecular weights, which have been identified previously in the analysis of inkjet inks. The polymeric vehicle content is then preferentially ionized by the DART ion source and a chemical profile is produced that can be used to associate common inks and discriminate different inks. Taking into account the variable intensity of individual ion peaks in replicate mass spectra of the same samples, the presence or lack thereof PEG distributions was the deciding factor in associating common inks and discriminating different inks. An example of two replicate measurements of the same inkjet and two spectra categorized as indistinguishable is illustrated in Figure 34. The mass spectra of inkjets allowed for the discrimination of inkjets from different brands, and also inkjets from different cartridges of the same brand, such as illustrated in Figure 35. However, inkjets of different colors originating from the same printer (CMYK) were not discriminated, due to similar polymer vehicle composition, thus providing evidence that the DART ionization source does not ionize the dye or pigment content of inkjets, which would alternatively allow for the discrimination of different color inks from the same printer. Out of 3003 comparison pairs, 2741 were correctly discriminated, giving a discrimination percent of $91.3 \%$ and a false inclusion rate of $8.7 \%$. 

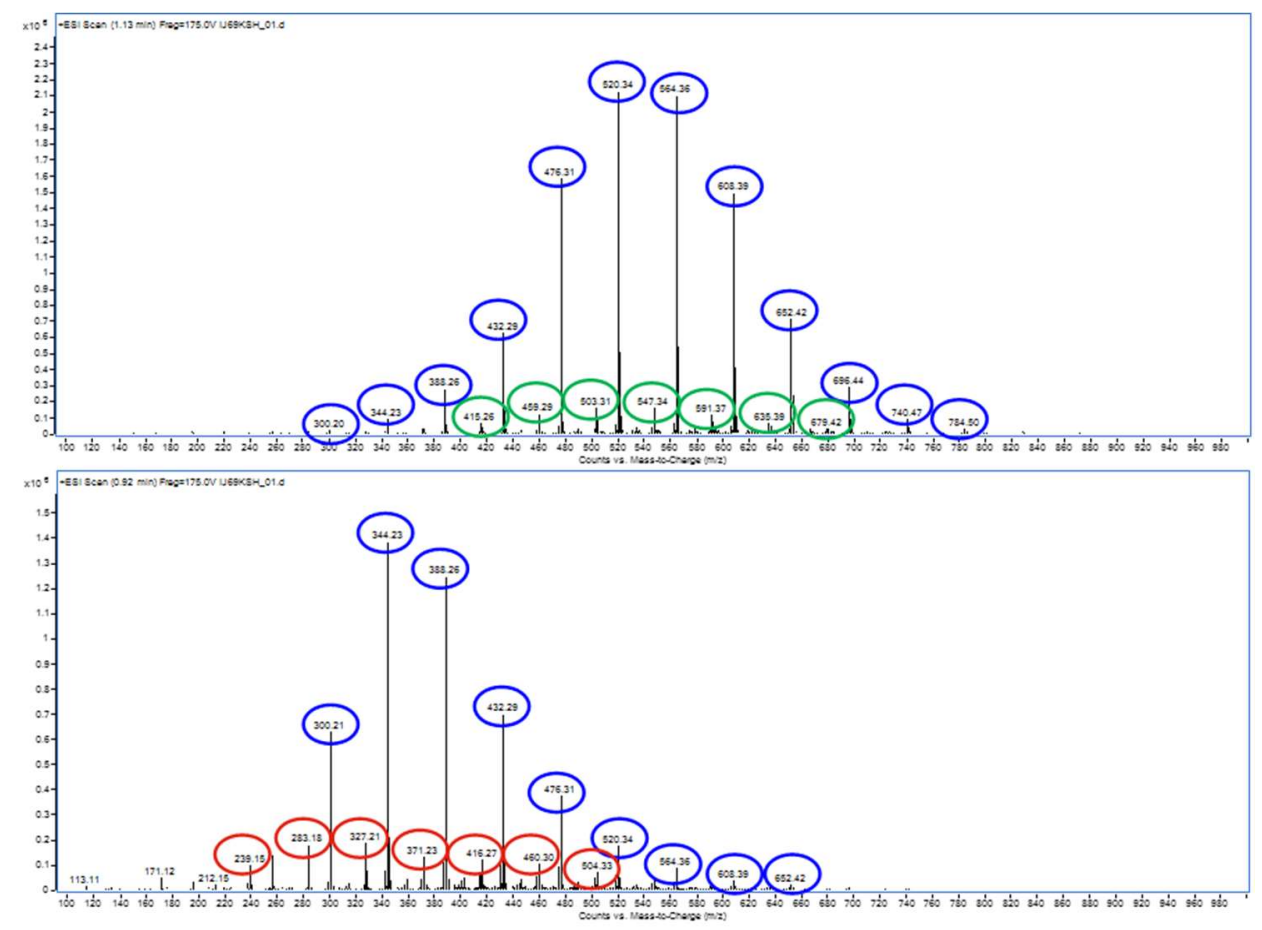

Figure 33- DART-MS spectra of PEG 600 internal standard (top) and inkjet sample (bottom)
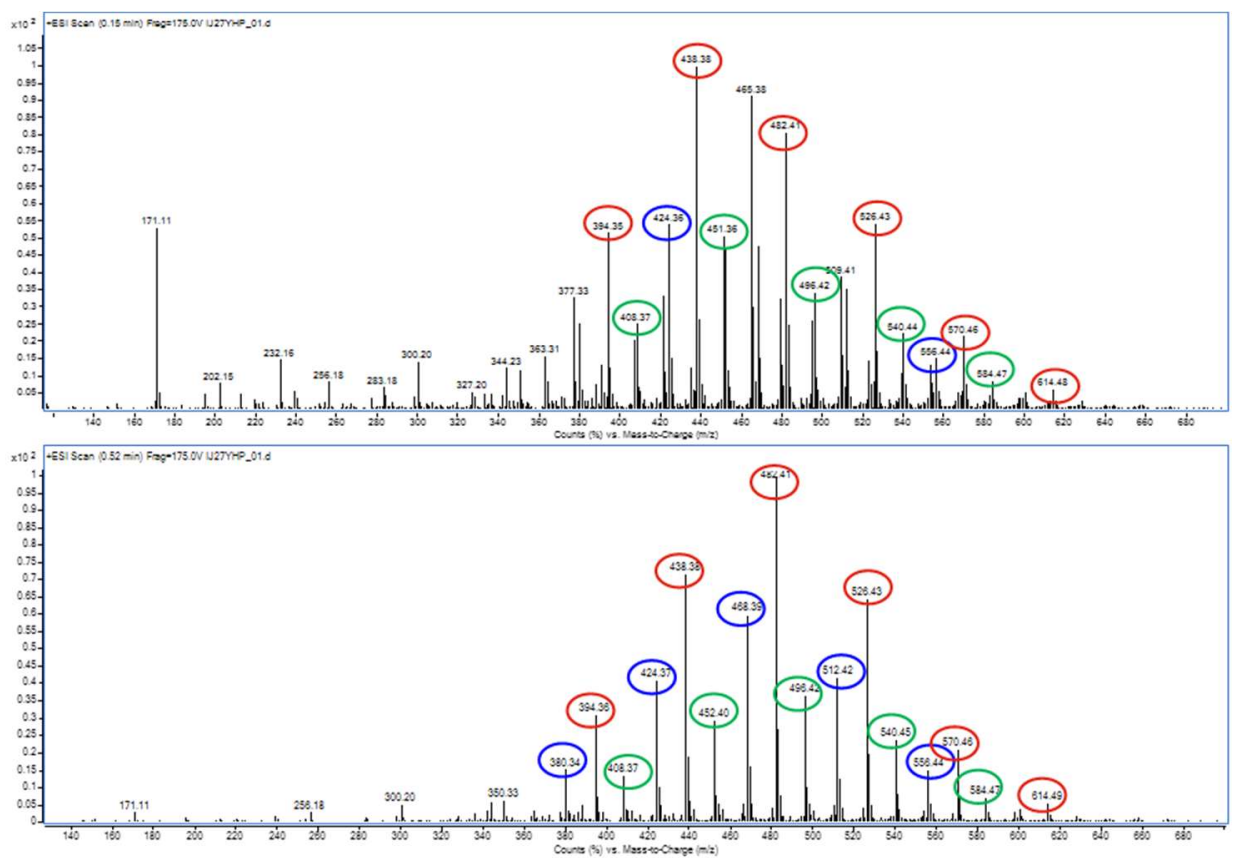

Figure 34- Inter-day reproducibility of inkjet sample and example of indistinguishable DART-MS spectra 

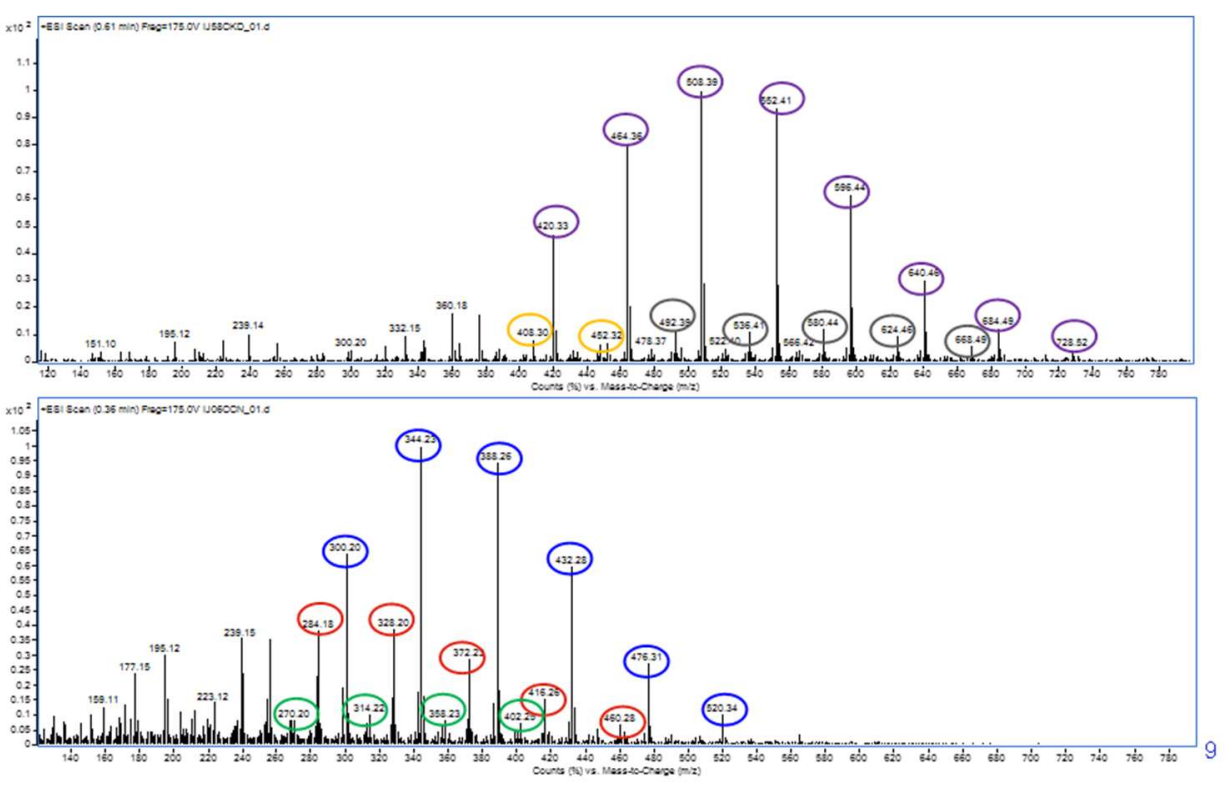

Figure 35- Two spectra of inkjets discriminated based on different combinations of PEG distributions present

\subsubsection{Toner Results}

The analysis of toners proved to be more difficult than that of inkjets. When many toner samples entered the DART ionization stream, visible melting was observed which caused a non-uniform acquisition of ions. For example, a flux of ions would be observed/detected once a toner sample entered the DART stream, but as visible melting occurred, the intensity of ions detected greatly diminished. The amount of melting that occurred also affected the reproducibility in the spectra obtained for the same sample. Therefore, great care was taken to remove the toners from the DART ionization stream when melting occurred. In the spectra of toner samples, some PEG distributions were observed, while polymeric distributions with ions $58 \mathrm{~m} / \mathrm{z}$ units apart were also observed. These polymeric ion peaks are characteristic of polypropylene glycol (PPG) fragments, which are known vehicle additives in toner inks. Other toner samples contained few ions, 
but were reproducible and used for discrimination purposes. Again, toners from different brands could be distinguished, as well as toners of the same brand from different cartridges. Due to a majority of the toner samples containing few diagnostic ions, the discrimination capability of DART-MS for toners was not as high as for inkjets. Out of 2850 comparison pairs, 2331 were discriminated, giving a discrimination power of $81.8 \%$ and false inclusion rate of $8.7 \%$.
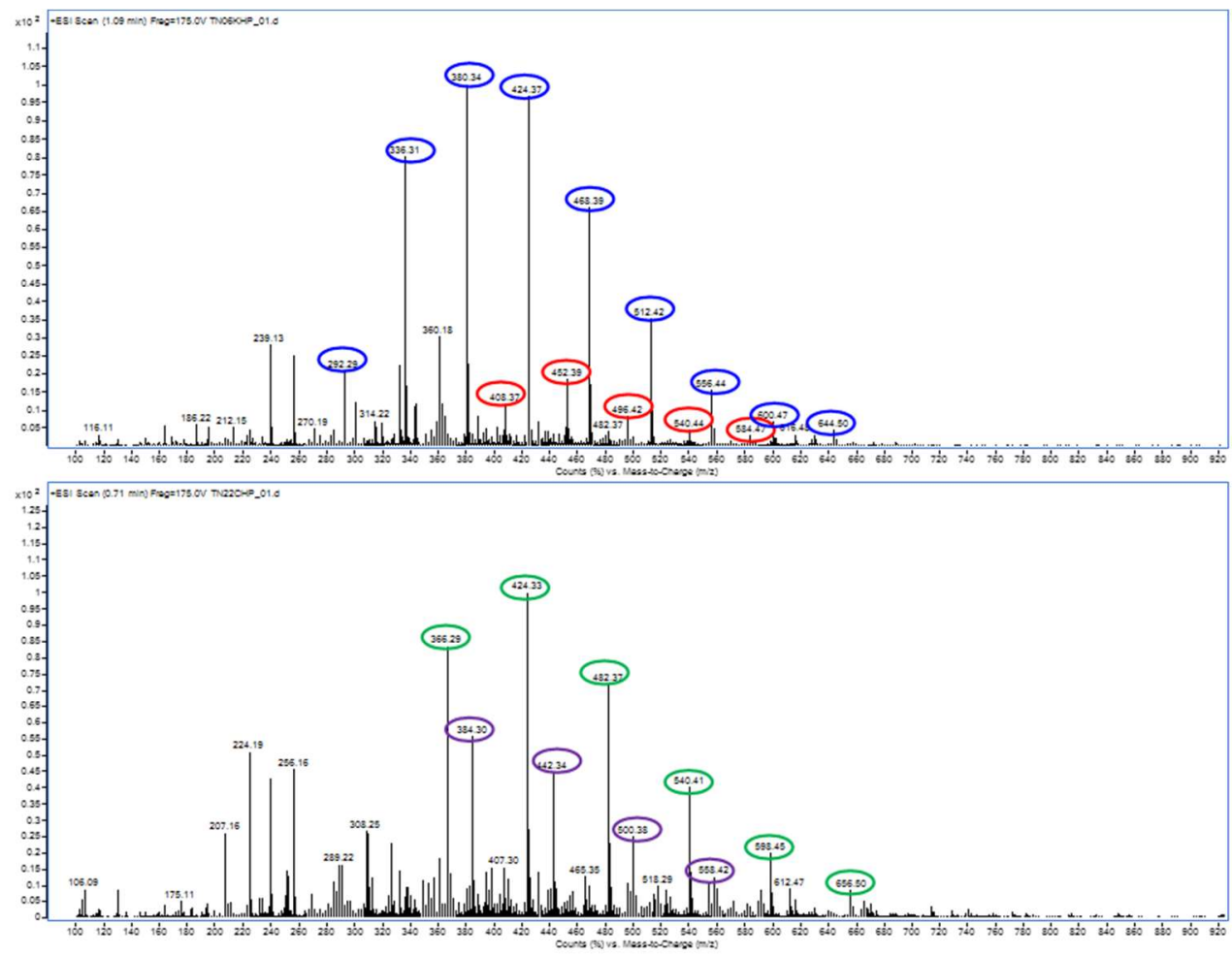

Figure 36- DART-MS Spectra of toner samples exhibiting PEG distributions (top) and PPG distributions (bottom) 


\subsubsection{Offset Results}

Two different classes of offset samples were analyzed: security documents and inks printed/deposited on paper. For the Lincoln Visa samples, PEG distributions were observed, similar to those found in the inkjet and toner samples. For offset samples of ink deposited on paper, melting was observed in many cases, affecting the reproducibility of the spectra obtained. However, portions of PEG distributions (44 m/z apart) were observed in a number of samples, but with fewer peaks and lower intensities than in the inkjet or toner samples. An example of each type of offset sample is illustrated in Figure 37. Furthermore, different colors of the inks originating from the same manufacturer or printer could not be discriminated based on the information given via DART-MS analysis. For offset samples, 1728 out of 3081 comparison pairs were discriminated, giving a discrimination power of $56.1 \%$ and false inclusion rate of $43.9 \%$. 

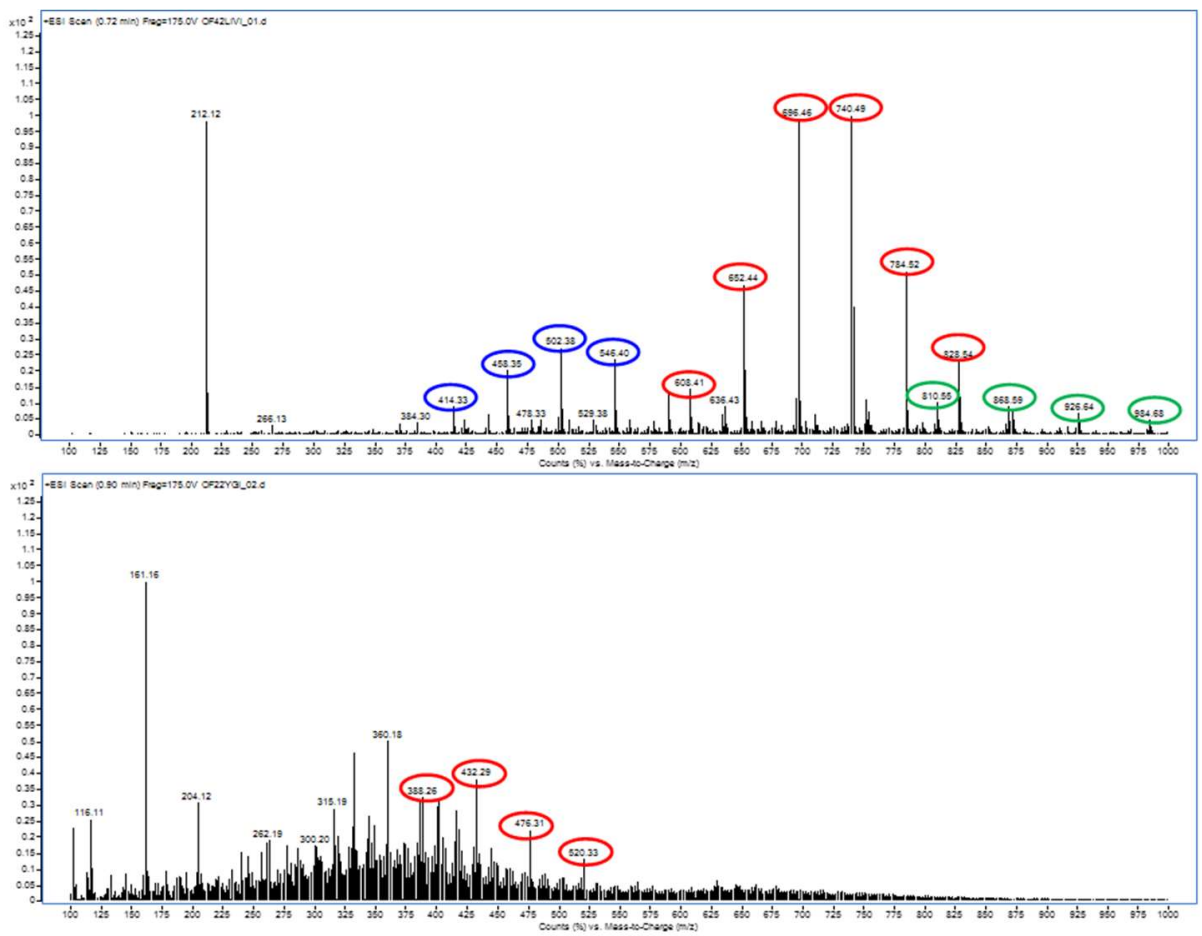

Figure 37- DART-MS spectra of offset samples containing portions of PEG distributions allowing for discrimination

\subsubsection{Intaglio Results}

The intaglio sample set consisted of banknotes and security documents which had previously been in circulation. Therefore, on a number of samples, contaminates were observed including cocaine. Due to the small sample size, heterogeneous deposition of ink on the sample, and the large DART ionization stream, reproducibility for the intaglio samples was poor. A peak at $391 \mathrm{~m} / \mathrm{z}$ was identified in a high number of samples, and is due to a common phthalate used as a plasticizer in many banknotes, as previously reported in the analysis of banknotes using ambient ionization techniques. Additionally, some samples contained PEG in their composition based on the observation of polymeric distributions $44 \mathrm{~m} / \mathrm{z}$ apart in the mass spectra. An example of each of these sample types 
is illustrated in Figure 38. Out of 3655 comparison pairs, 1776 were discriminated, for a discrimination power of $48.6 \%$ and false inclusion rate of $66.4 \%$.
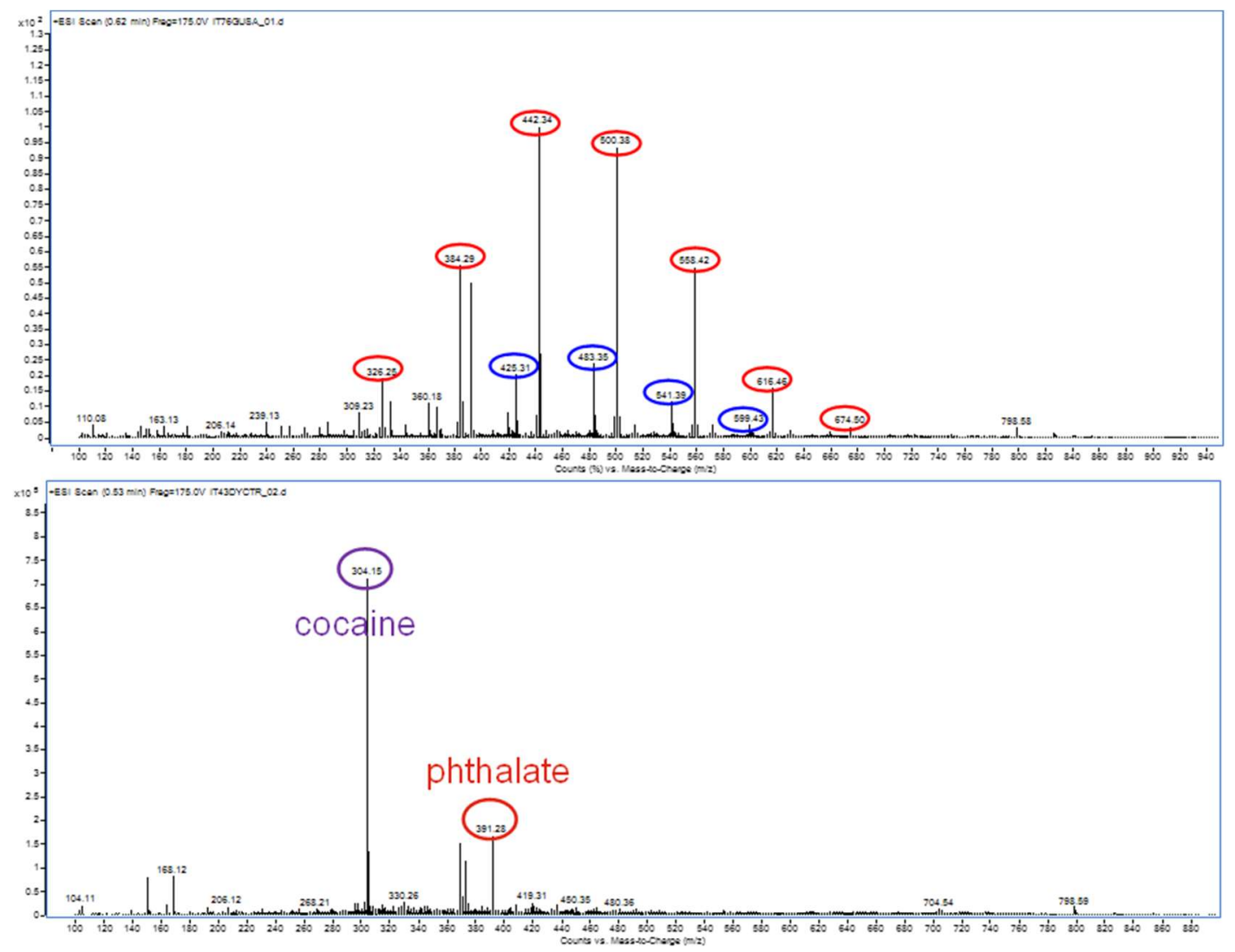

Figure 38- DART-MS Spectra of intaglio samples containing PEG distributions (top) and Cocaine contaminant and common phthalate (bottom) 
Table 13- Summary of DART-MS discrimination capability for each ink type

\begin{tabular}{|l|l|c|c|l|}
\hline & \multicolumn{1}{|c|}{ Inkjet } & Toner & Intaglio & \multicolumn{1}{|c|}{ Offset } \\
\hline \# samples & 78 & 76 & 86 & 79 \\
\hline $\begin{array}{l}\text { \#samples from } \\
\text { different sources }\end{array}$ & $\begin{array}{l}78(3003 \\
\text { comparison } \\
\text { pairs })\end{array}$ & $\begin{array}{c}76(2850 \\
\text { comparison } \\
\text { pairs })\end{array}$ & $\begin{array}{c}86(3655 \\
\text { comparison } \\
\text { pairs })\end{array}$ & $\begin{array}{l}79(3081 \\
\text { comparison } \\
\text { pairs })\end{array}$ \\
\hline $\begin{array}{l}\text { \% discrimination } \\
\text { inclusions }\end{array}$ & $\begin{array}{l}\text { 91.3\% (2741 } \\
\text { out of 3003) }\end{array}$ & $\begin{array}{c}81.8 \%(2331 \\
\text { out of } 2850)\end{array}$ & $\begin{array}{c}48.6 \%(1776 \text { out } \\
\text { of } 3655)\end{array}$ & $\begin{array}{l}56.1 \%(1728 \text { out } \\
\text { of } 3081)\end{array}$ \\
\hline
\end{tabular}

\subsection{Contamination Study}

A facet of the project involved determining whether handling of samples prior to analysis would interfere with the ability to associate common inks and discriminate inks. The worst case scenario would be that fingerprints and/or sweat deposited on ink samples as a result of handling would produce false exclusions of common inks that otherwise would be associated with one another. A number of printing samples were contaminated under the following conditions:

1) Controlled handling with minimum direct touching of the ink

2) Regular handing with bare hands and touched by multiple people

3) Handling with sweaty hands (hands wet with sweat after vigorous exercise 
When the contaminated samples were analyzed via DART-MS, samples with both fingerprints and sweat contained an additional peak at $\mathrm{m} / \mathrm{z} 206.14$ that was not present in the original control sample. However, this peak did not interfere or suppress the other ions present in the spectra that could be used for association and discrimination. These results are expected as external contaminants (such as cocaine in some intaglio samples) were observed in DART-MS spectra.

\subsection{Conclusion}

DART-MS allows for the characterization of the semi-volatile polymeric vehicle components of inkjet inks, allowing for the discrimination of inkjets originating from different cartridges of the same manufacturer. DART-MS also provides information regarding the plasticizer used in intaglio inks, as well as any light molecular weight polymeric vehicle that may be used in the formulation of the intaglio ink. DART-MS provides characterization of the PEG and PPG components of toner inks. DART-MS also provides limited information on the polymeric content of offset inks. DART-MS, which requires a small amount of sample, could be implemented in forensic document analysis for the association of common inks and discrimination of inks originating from different sources. Although an expensive combination, DART-Q-TOF-MS has found its way into the forensic laboratory as a useful tool for the rapid screening of drugs. The application being discussed here is an additional use for this analytical technique 

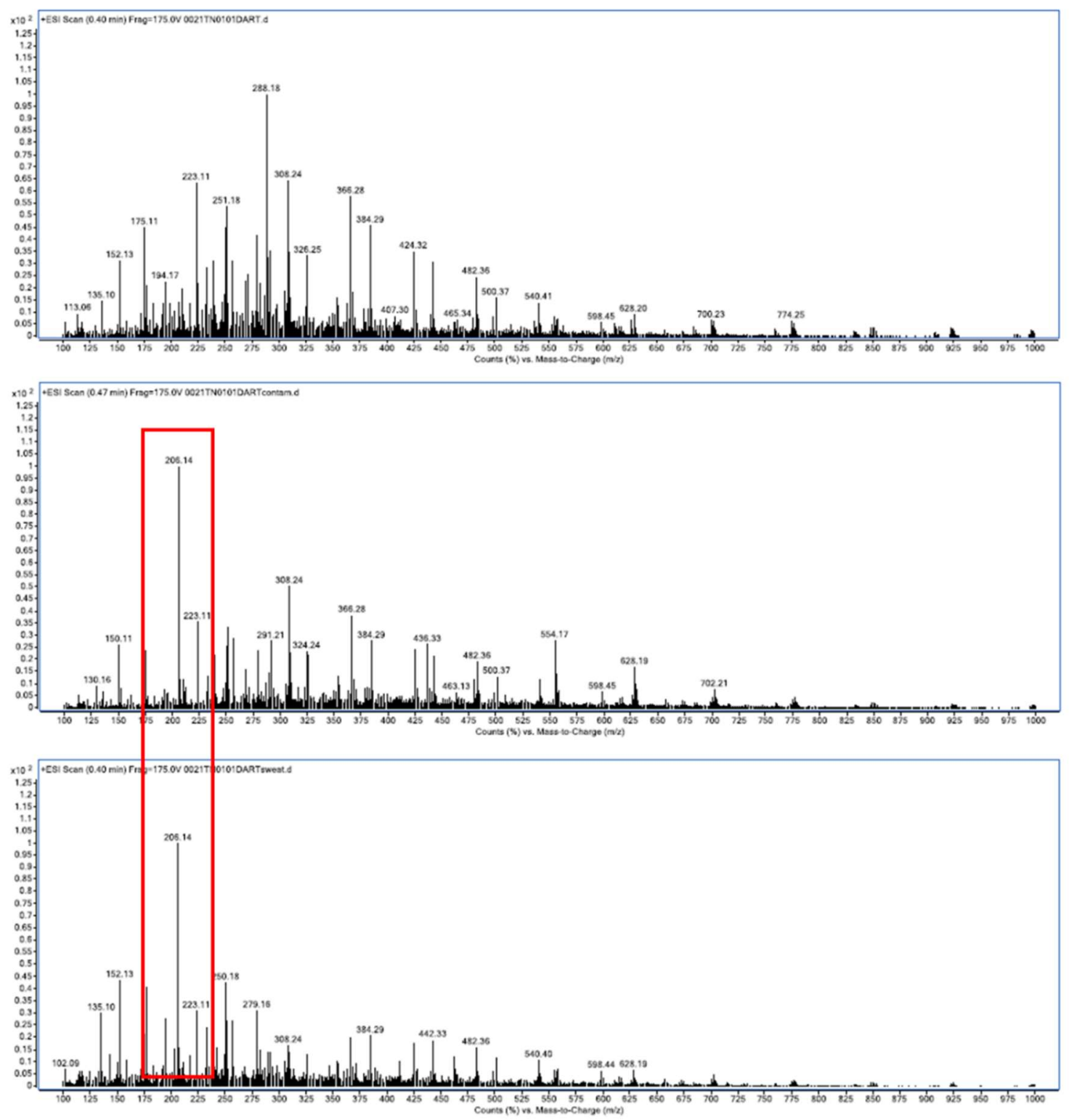

Figure 39- DART-MS spectra of 0021TN01 under different conditions: (top) no contamination, (middle) fingerprints, (bottom) sweat, showing the contaminant peak at $\mathrm{m} / \mathrm{z} 206.14$ present in fingerprint and sweat samples but absent from control 


\section{CHAPTER 6. ANALYSIS OF PRINTING INKS USING MALDI-MS}

\subsection{Method development and optimization}

The MALDI-MS analyses were conducted on a Voyager DE Pro TOF mass spectrometer (Applied Biosystems: Carlsbad, CA USA). Sample preparation involved cutting a $\sim 2 \times 2 \mathrm{~mm}$ portion of the ink on Whatman 42 paper (Whatman: Maidstone, UK) and attached to a 100 well stainless steel target (JBI Scientific: Huntsville, TX, USA). The matrix used was 9-aminoacridine (9AA: Aldrich: St. Louis, MO, USA) dissolved in $70 \%$ methanol:water $(5 \mathrm{mg} / \mathrm{mL})$. A $0.5 \mathrm{uL}$ aliquot of the matrix solution was spotted on top of the sample on the target. Instrumental parameters were as follows: $337 \mathrm{~nm}$ Nitrogen laser, $3 \mathrm{~ns}$ pulses, $2 \mathrm{~Hz}, 50$ shots per sample, negative and positive mode, mass range m/z 100-1000. Data Analysis was performed using Data Explorer TM software (v 4.0.0.0: Applied Biosystems, Carlsbad, CA, USA).

The goal of sample preparation for MALDI-MS analysis was to ensure that it was as minimally destructive and least time consuming as possible. Therefore, the method used to analyze inks on paper involved cutting a $\sim 1 \times 1 \mathrm{~mm}$ square of the paper with ink, cutting the same size square of $3 \mathrm{M}$ double-sided tape, and attaching to the MALDI target. If matrix was used in the analysis, $0.5 \mathrm{uL}$ of the solution was spotted on top of the sample and let dry for up to 10 minutes before introducing the plate to the mass spectrometer.

Method development was followed Soltzberg, Donnelly, and Heudt et al. (17, 75, 79). This study was the first to also include toner, offset, and intaglio printing inks as past work has focused on writing ink and inkjet printing inks exclusively. Acid Red 52 and Acid Blue 9, common dyes used in ink formulations were used as performance 
standards for the method. Heudt et al. also reported the analysis of the same dye and thus was used as a method development standard compared to results published in that article (79). Liquid inkjet inks that were available and also previously reported in Heudt and Donnelly et al. were also analyzed to provide proof of concept $(17,79)$. The next step involved analyzing the same inks on paper substrate to further prove the validity of the method. Subsequently, analyzing the same sample (Acid Red 52 and inkjet inks) with and without the addition of the matrix was evaluated. A comparison of Acid Red 52 with and without matrix can be seen in Figure 40.

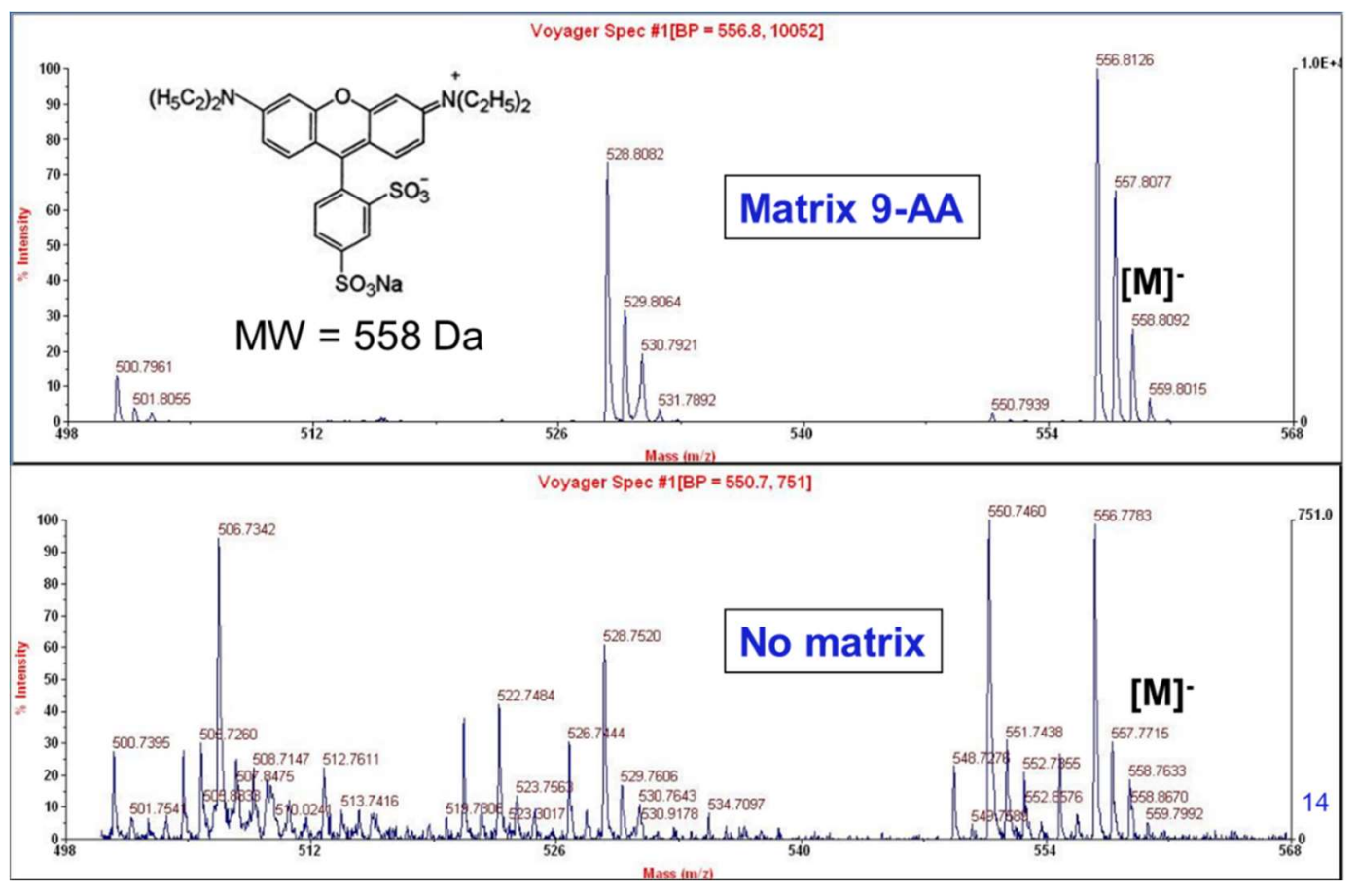

Figure 40- Comparison of MALDI-MS spectra of the same inkjet sample with (top) addition of matrix 9-aminoacridine and (bottom) with no matrix added

What is evidently observed between these two sample preparation methods is the result of a mass spectrum with much less noise and interference- that is to say, the mass spectrum of Acid Red 52 with the addition of the matrix contains solely molecular ions 
(and fragments) that can be attributed to the molecule itself, while the mass spectrum of Acid Red 52 with no matrix contains many more peaks, which can be the result of increased fragmentation and or interference from the paper substrate. Therefore, the process occurring of energy transfer from the laser to the matrix and then to the molecule itself, results in a much more efficient ionization process of the target molecule. This observation may also be the result of the adjustment to sample roughness, which has been reported to interfere in the acquisition of quality mass spectra in MALDI experiments of inks on paper substrates. Additionally, it has been reported that if colorant molecules contain multiple charged groups in the molecule, then the molecular ion will not be observed in a laser desorption experiment without the addition of a matrix, because a single charge is needed in the ion in order to be detected in mass spectrometry (77). Overall, it was determined that the implementation of the matrix is useful and results in higher quality spectra and much more efficient ionization process and therefore was used in all subsequent analyses of inks in this dissertation. The ability to analyze inks directly on a paper substrate was also realized after observing the mass spectra acquired of the same inkjet ink in pure liquid form and on paper, as illustrated in Figure 42. 


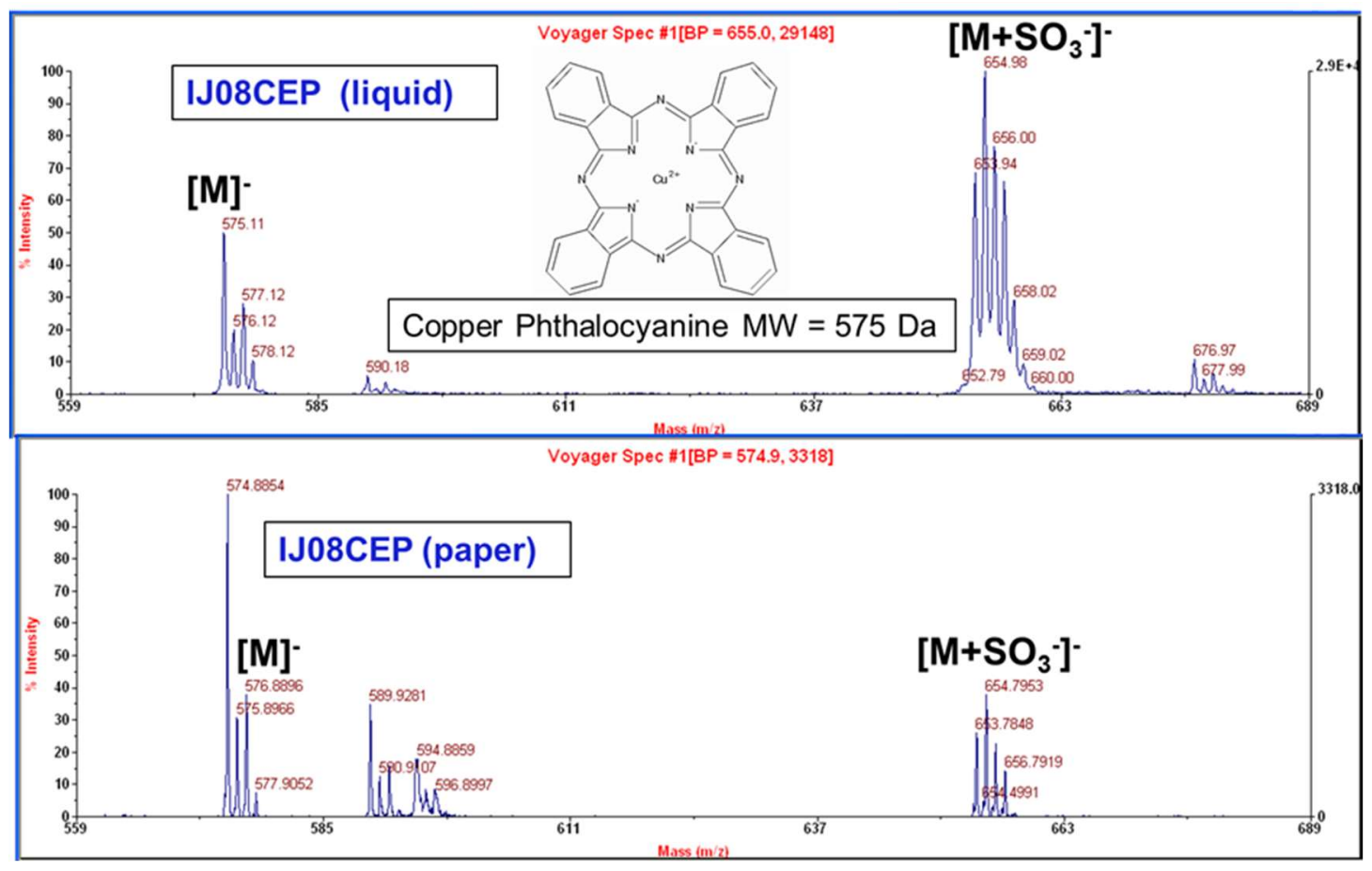

Figure 41- MALDI-MS spectra of the same inkjet sample (top) in pure liquid form and (bottom) on paper substrate

\subsection{Results}

As observed from the preliminary results and the literature on MALDI-MS of inks, the prominent feature of the inks characterized are the colorant dyes/pigments. In Figure 41 of sample IJ08CEP, the dominating molecular ions can be attributed to copper phthalocyanine, which is a commonly used pigment in blue and other inks. The organometallic pigment is highly insoluble and is not readily observed in LC-MS or DART-MS analyses of inks, and therefore MALDI-MS can provide complimentary information to other mass spectrometric methods, including those performed as a part of this dissertation, namely DART-MS. A comparison was also made between reflector and linear detection mode using the Voyager DE Pro. Reflector mode has a long ion path and 
utilizes a mirror, and results in increased resolution, while sacrificing sensitivity, which showed to produce better results in this study.

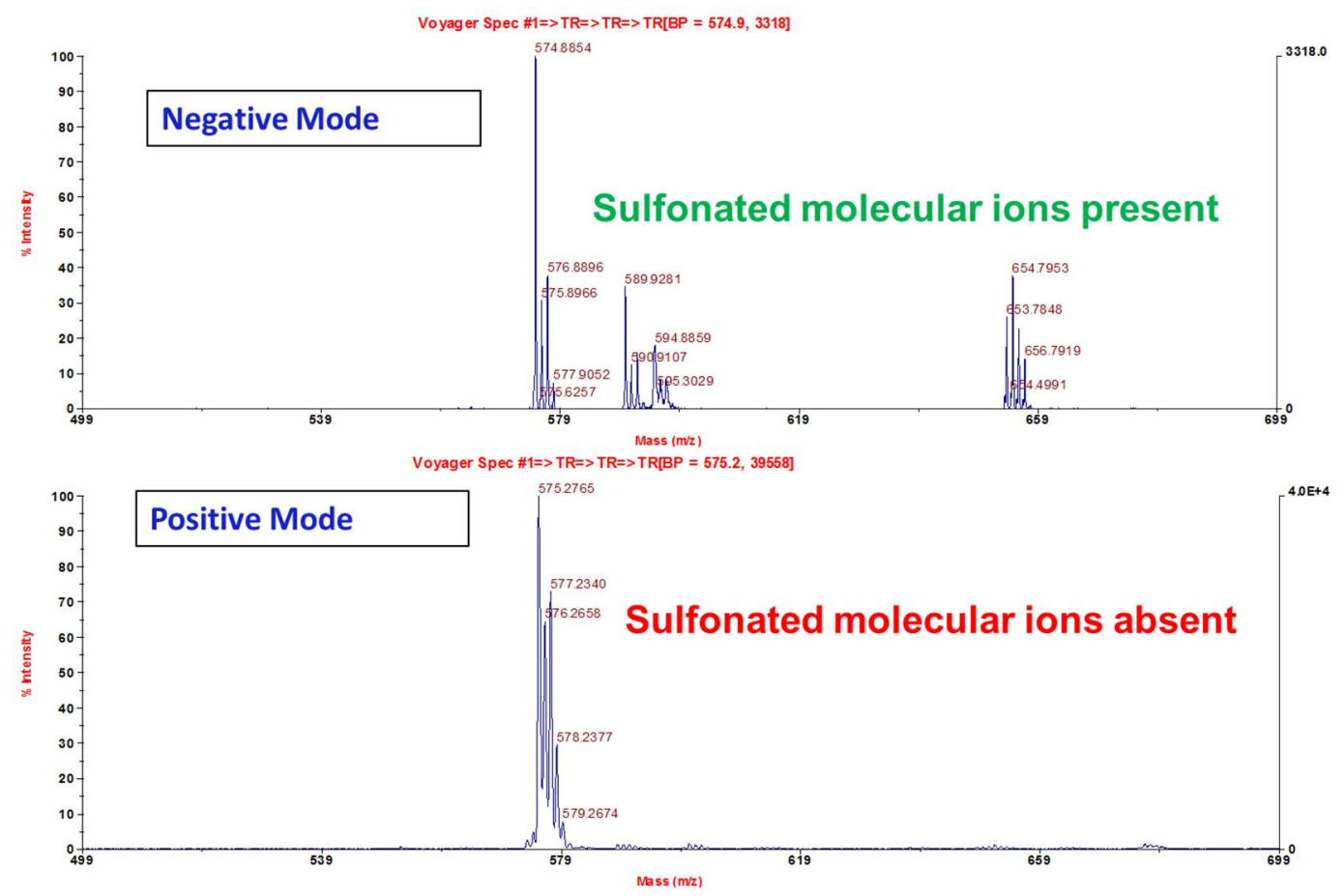

Figure 42- MALDI-MS spectra of same cyan inkjet sample in (top) negative mode containing sulfonated molecular ions and (bottom) in positive mode, where sulfonated molecular ions are absent

Both negative and positive mode were implemented for the ink samples and varying results were observed. For example, the sulfonated substitutions on copper phthalocyanine preferentially ionize in the negative polarity mode, and thus analyzing the same ink sample containing a sulfonic acid-substituted copper phthalocyanine in both positive and negative mode would result in different molecular species being observed, as seen in Figure 42. Thus, in the case of comparing two cyan inks which may be identical in positive mode, containing copper phthalocyanine, the same samples could then be 
analyzed in negative mode, and in the case that a different number of sulfonic acid groups were used in the formulation, the presence of these ions could be used as a point of distinction in the negative ion mode mass spectra.

Additionally, in positive ion mode, without matrix applied, polyethylene glycol (PEG) and polypropylene glycol fragments were observed in some offset and toner samples, adding to the results in DART-MS of the same samples. However, DART-MS is a much more efficient ionization source for the characterization of the semi-volatile polymeric components of printing inks than MALDI-MS.

The qualitative reproducibility of the method was also evaluated with both inter and intraday replicates of ink samples on paper being analyzed. Acid Red 52 was also used as a daily performance standard. Inter- and intra-day replicate mass spectra of toner sample TN22CHP can be seen in Figure 43 illustrating the reproducible characterization of the colorant molecular ions, in this case copper phthalocyanine. 


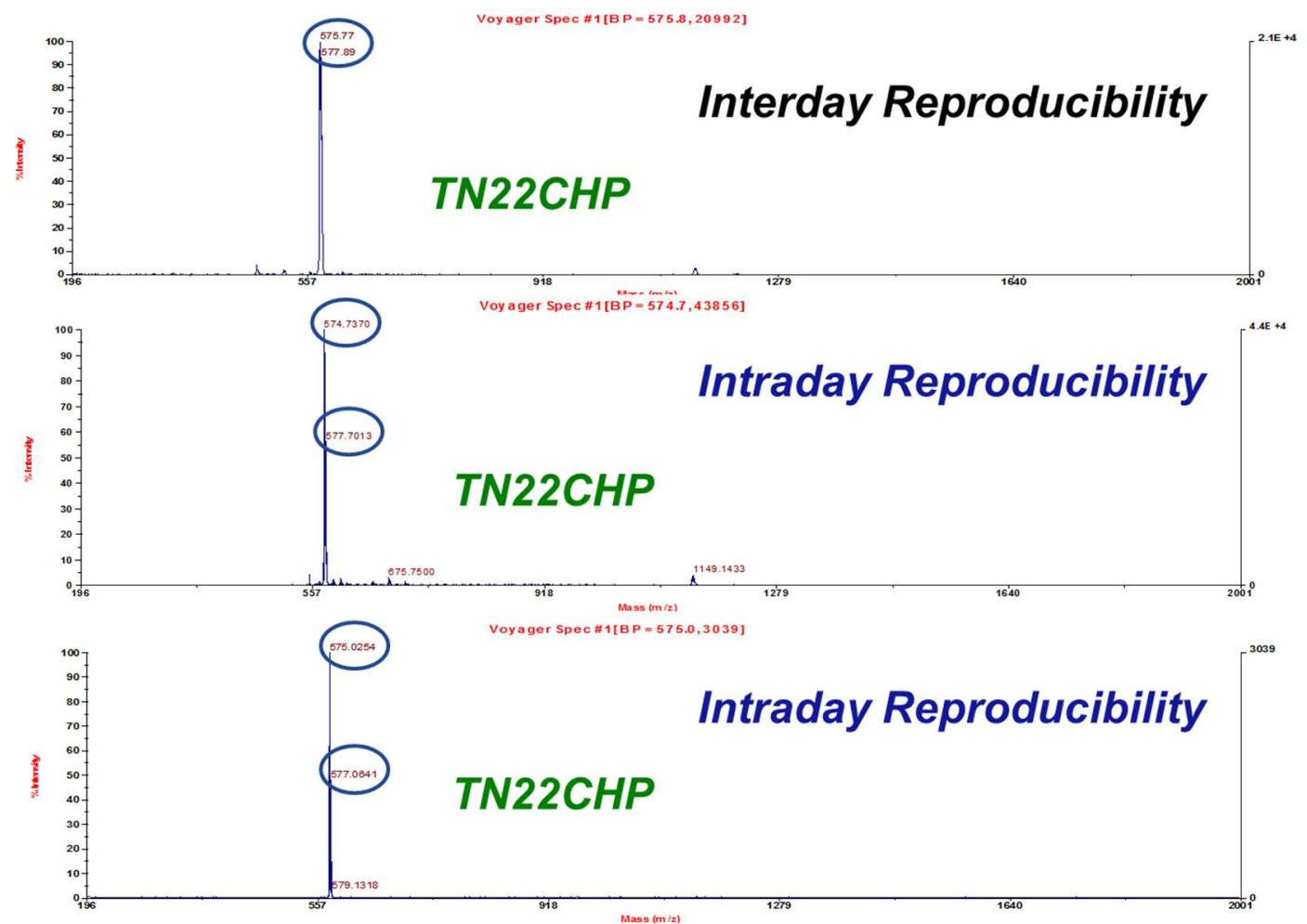

Figure 43- Replicate MALDI-MS spectra of the same toner sample (top) acquired on different days and (middle, bottom) on the same day

The small difference in $\mathrm{m} / \mathrm{z}$ in the thousandths place can be attributed to instrument drift, common in low resolution mass spectrometers such as this Voyager DE Pro. Laser energy is also a very important parameter to optimize as it was observed that different colorant molecules more efficiently ionize at differing laser energies.

Therefore, multiple replicate measurements of an ink surface at varying laser energies were completed to obtain optimized spectra dominated by molecular ions of colorant molecules. The number of shots fired per spectrum was another parameter that was evaluated to optimize the method. Since the deposition of ink on the paper substrate is not a homogeneous process, it is expected that the intensities, even relative intensities, of molecular ions will not be uniform as the laser is rastering across the sample area. Thus, 
there was no significant increase in quality of spectra as shots increased from 50 to 100 or more shots per sample. Therefore, it was determined that 50 shots per sample provides sufficient resolution for quality mass spectra of colorant molecules of printing inks on paper substrate.

The results for all ink types included mass spectra dominated by molecular ions that can be attributed to colorant dye and/or pigment molecules. As was completed with the other instrumental methodologies included in this dissertation, the percent discrimination was calculated for each ink class. However, for ink sample sets where the majority of samples were designated by the four primary printing ink colors CMYK, inks were differentiated by color, determined by the presence/absence of similar colorant molecules.

After application of the liquid matrix, temporary discoloration was observed, which reverted upon drying of the matrix. During analysis, target molecular ions were observed on the periphery of the sample, near the edges of the paper. This phenomenon could be a result of the spread of the liquid ink, which is imbedded in the paper substrate and would be slightly soluble in the matrix, and thus move upon addition of additional liquid. 


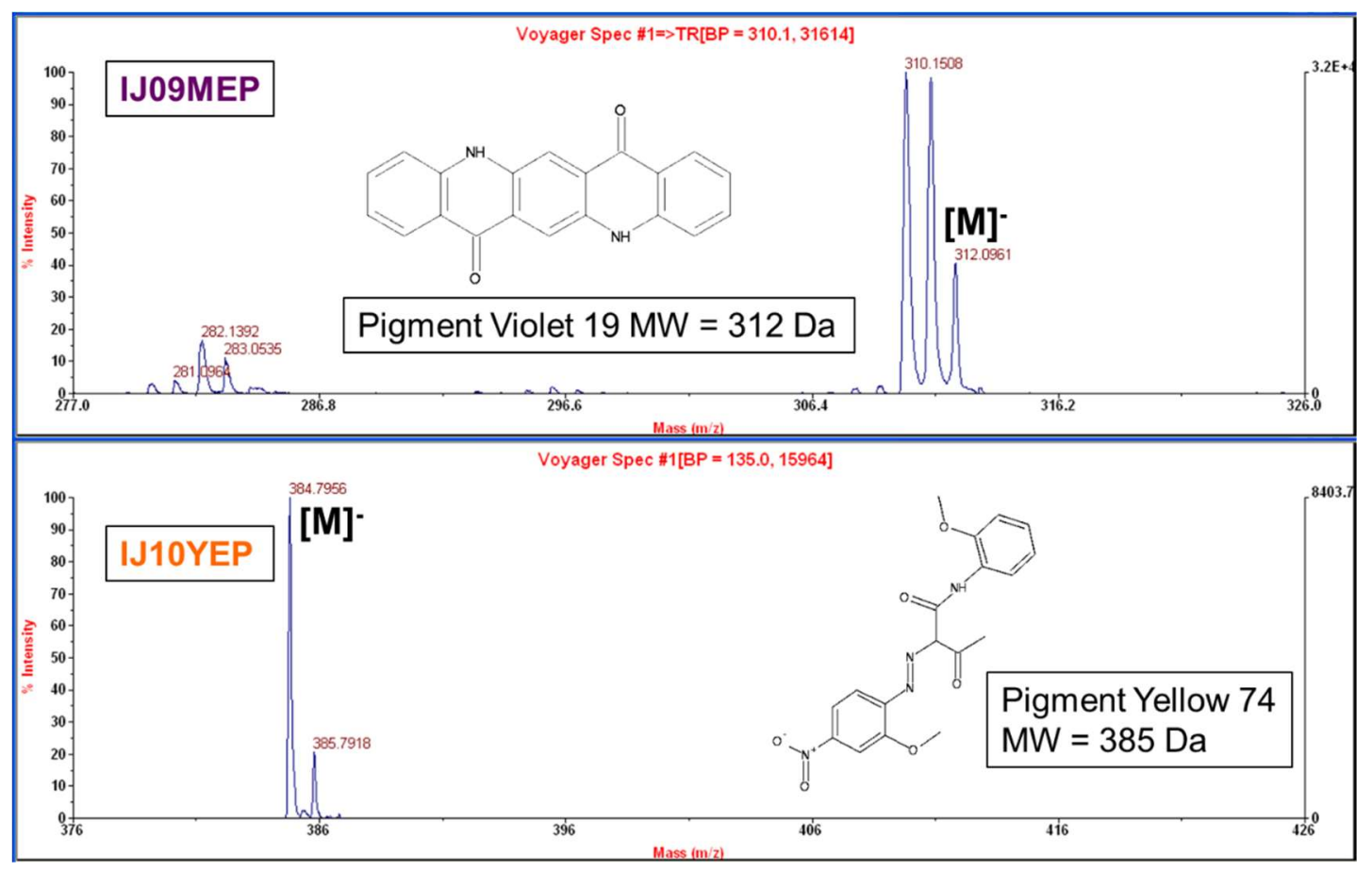

Figure 44- MALDI-MS spectra of two inkjet inks of different colors from the same printer cartridge showing different colorant molecular ions present (top) magenta and (bottom) yellow

Toner samples easily produced dominant molecular ions quickly upon contact with the laser, because the toner ink exists in a layer atop the paper substrate, and is insoluble to the addition of the liquid matrix.

Offset inks also ionized easily and efficiently, producing intensities well above those of inkjet inks, because of the insolubility of these inks and the layer formed atop the paper substrate. 

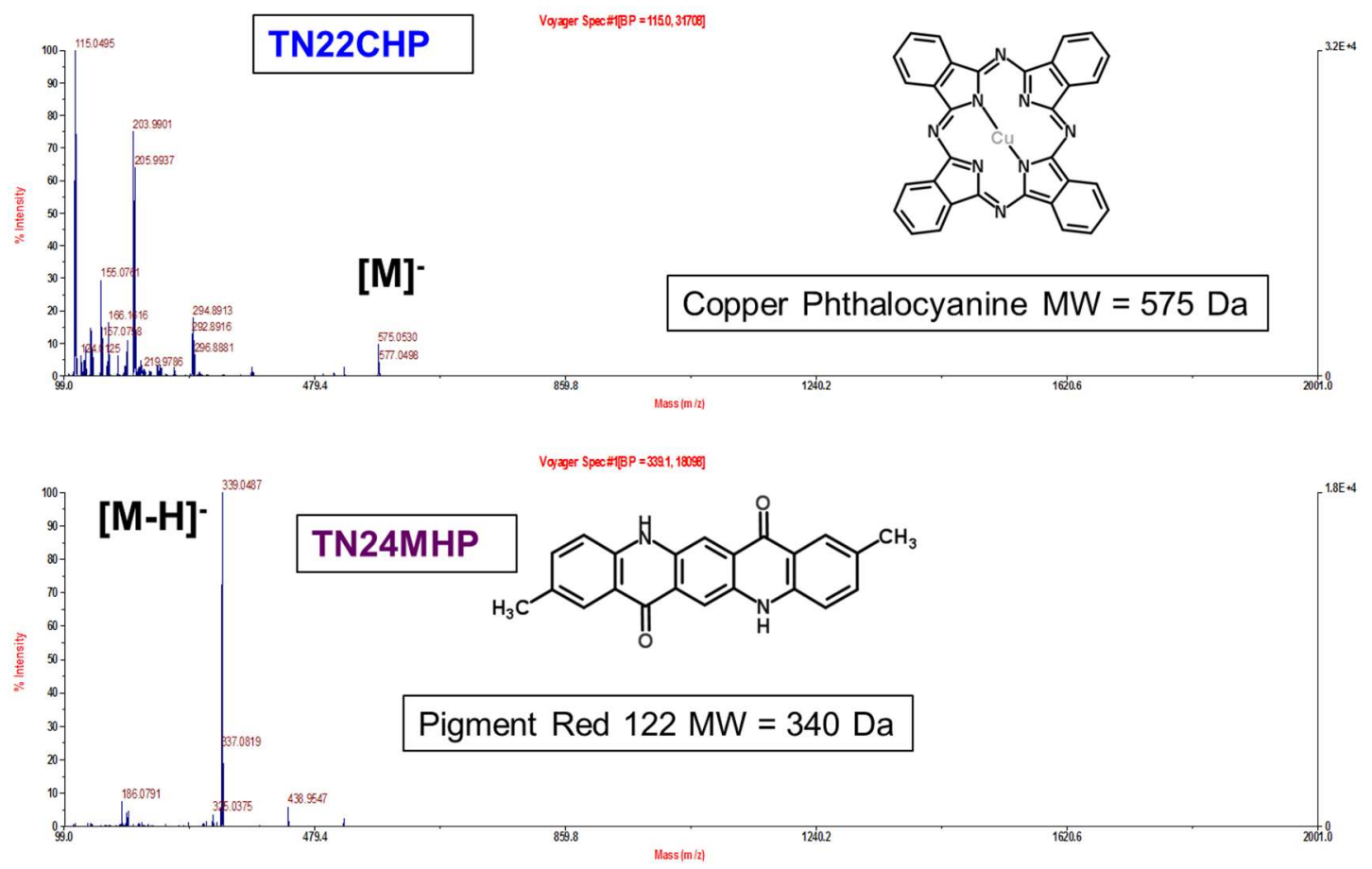

Figure 45- MALDI-MS spectra of two toner inks of different colors from the same printer cartridge showing different colorant molecular ions present (top) cyan and (bottom) magenta 

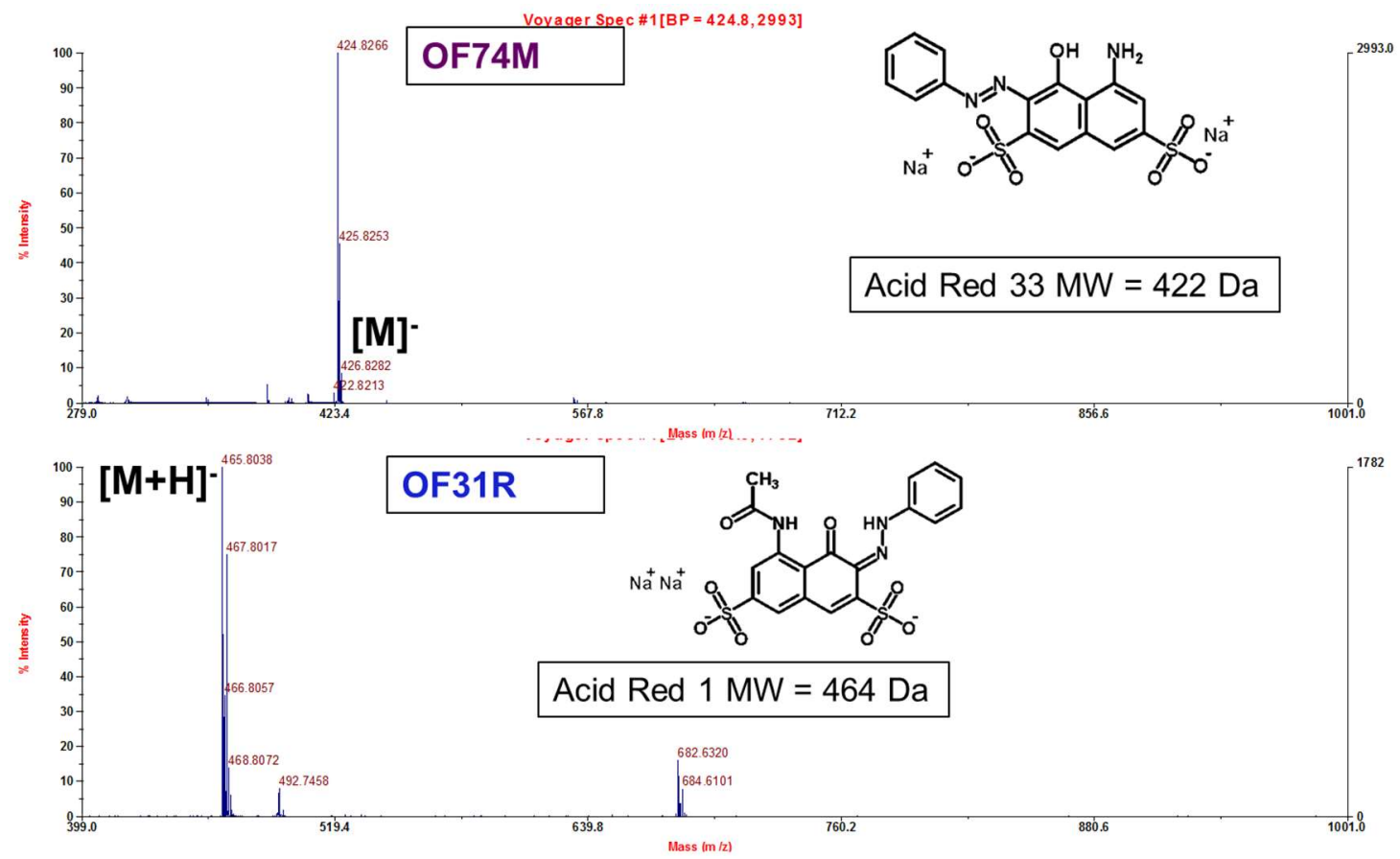

Figure 46- MALDI-MS spectra of two offset inks from the same manufacturer that are indistinguishable to the naked eye but contain different colorant molecules (top) magenta and (bottom) red

6.2.1 Comparison between Voyager DE PRO and Bruker AutoFlex II MALDI-TOF-MS

Another subset of inks was analyzed using a Bruker AutoFlex II MALDI-TOF-

MS. Sample preparation was similar with the exception of samples being affixed to an

ITO-coated (indium tin-oxide) glass slide (Bruker Daltonics, Bremen, Germany). All

analyses were conducted in negative mode and a mass spectrum dominated by a

molecular ion that could be attributed to a colorant molecule was acquired for all

samples. Negative mode calibration was achieved using Angiotensin II, 9-AA, and Acid

Red 52 at m/z 193.076, 501.079, 557.142, and 1044.527. Instrumental parameters were

as follows: $355 \mathrm{~nm}$ Nitrogen laser, 5-7ns pulses, $100 \mathrm{~Hz}, 400$ shots per sample, negative

mode, mass range m/z 100-1000. Imaging of each sample was also performed with a

minimum of 5 replicate spectra per sample spot. Intaglio inks were included in this 
subset. Results were similar and confirmed the MALDI-MS method to characterize the colorant component of printing inks. Data analysis was performed using mmass (v. 5.5.0: Martin Strohalm). A summary of the comparison between the discrimination capabilities of each of the instruments can be seen in Table 14. The Bruker AutoFlex II performed excellently and with improved mass accuracy over the Voyage De PRO, but still characterized the colorant molecules (Figure 47). All discrimination percent calculations were greater than $90 \%$. The discrimination percent calculation is biased towards the sample set, as most inks were differentiated based on color. However, in the case of some inks that are indistinguishable to the naked eye, such as sample OF74M, a magenta offset ink, and OF31R a red offset ink, which are both red inks, contain different colorant molecules and thus are able to be distinguished using MALDI-MS spectra.

\subsection{Conclusion}

Overall, MALDI-MS is a useful technique for the rapid characterization of colorant molecules from printing inks, directly on a paper surface with little sample preparation. Each of the four classes of printing inks was successfully characterized utilizing two different MALDI-MS instruments. Mass spectra containing molecular ions that correspond to colorant molecules/dyes/pigments were obtained for all samples analyzed. Though the method is destructive in that a piece of the ink must be physically removed from the sample/document, it requires a very small area, and thus is minimally destructive to the overall integrity of a document. The addition of a liquid matrix improves the output spectra, and is very reproducible in nature. Both positive and negative mode can provide complimentary results as certain colorant molecules preferentially ionize in one polarity over the other. MALDI-MS can be a very useful tool 
for the chemical analysis of printing inks, providing useful information for discrimination and association, and complimentary to other analytical techniques.

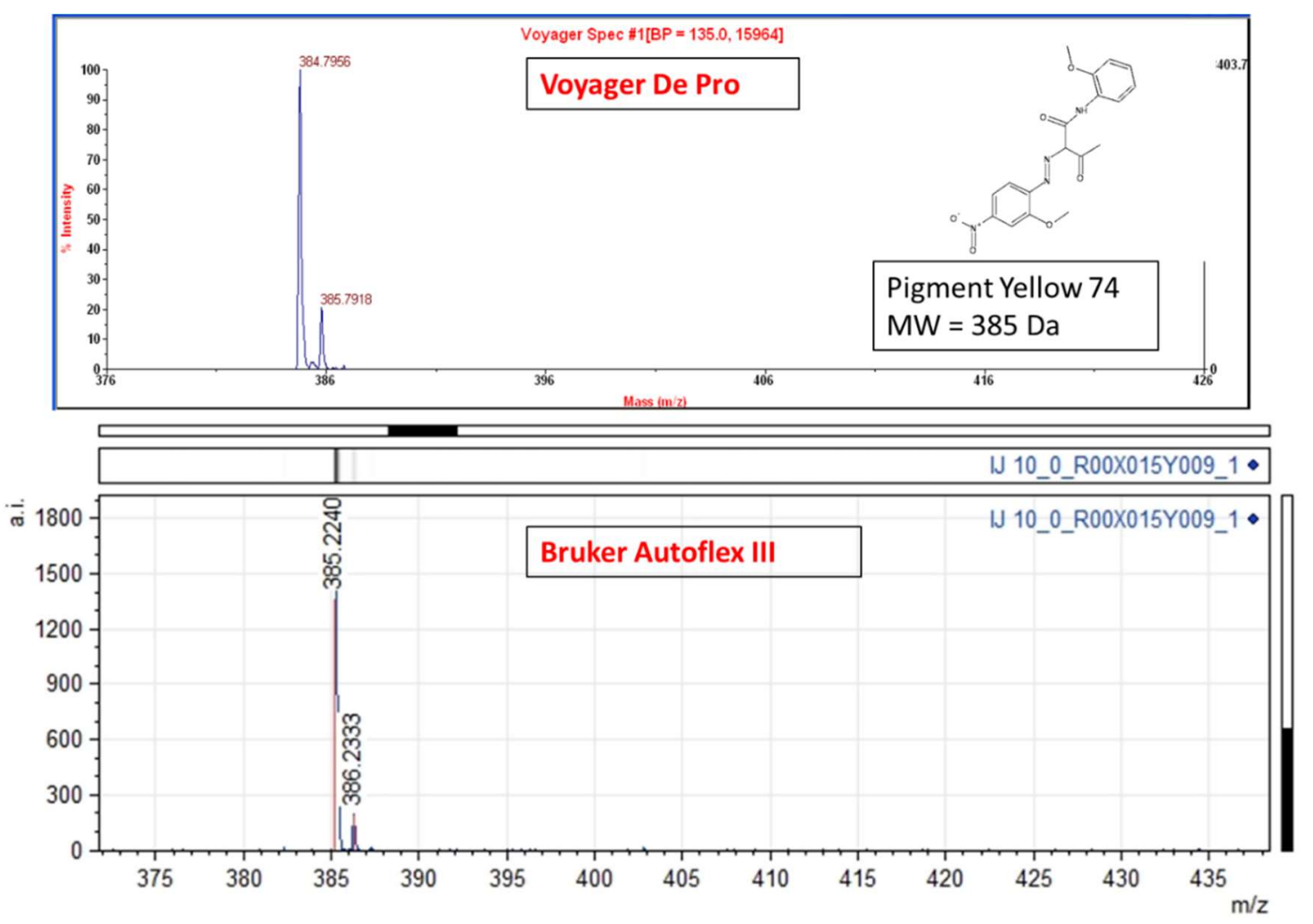

Figure 47- Instrumental comparison of same ink sample analyzed by (top) Voyager DE PRO and (bottom) Bruker Autoflex III exhibiting same molecular ions 
Table 14- Comparison of MALDI-MS discrimination capability of two different instruments Voyager DE PRO MALDI-TOF-MS and Bruker AutoFlex II MALDI-TOFMS, by ink type

\begin{tabular}{|c|c|c|c|c|}
\hline & Inkjet & & & \\
\hline Instrument & $\begin{array}{l}\text { Number of } \\
\text { Samples }\end{array}$ & $\begin{array}{l}\text { Comparison } \\
\text { Pairs }\end{array}$ & $\begin{array}{l}\text { Indistinguishable } \\
\text { Pairs }\end{array}$ & $\begin{array}{l}\% \\
\text { discriminated }\end{array}$ \\
\hline Voyager & 20 & 190 & 15 & 92 \\
\hline \multirow[t]{3}{*}{ Bruker } & 10 & 45 & 0 & 100 \\
\hline & \multicolumn{3}{|l|}{ Toner } & \\
\hline & $\begin{array}{l}\text { Number of } \\
\text { Samples }\end{array}$ & $\begin{array}{l}\text { Comparison } \\
\text { Pairs }\end{array}$ & $\begin{array}{l}\text { Indistinguishable } \\
\text { Pairs }\end{array}$ & $\begin{array}{l}\% \\
\text { discriminated }\end{array}$ \\
\hline Voyager & 28 & 378 & 34 & 91 \\
\hline \multirow[t]{3}{*}{ Bruker } & 10 & 45 & 4 & 91 \\
\hline & \multicolumn{3}{|l|}{ Offset } & \\
\hline & $\begin{array}{l}\text { Number of } \\
\text { Samples }\end{array}$ & $\begin{array}{l}\text { Comparison } \\
\text { Pairs }\end{array}$ & $\begin{array}{l}\text { Indistinguishable } \\
\text { Pairs }\end{array}$ & $\begin{array}{l}\% \\
\text { discriminated }\end{array}$ \\
\hline Voyager & 20 & 190 & 12 & 93 \\
\hline \multirow[t]{3}{*}{ Bruker } & 10 & 45 & 1 & 98 \\
\hline & \multicolumn{3}{|l|}{ Intaglio } & \\
\hline & $\begin{array}{l}\text { Number of } \\
\text { Samples }\end{array}$ & $\begin{array}{l}\text { Comparison } \\
\text { Pairs }\end{array}$ & $\begin{array}{l}\text { Indistinguishable } \\
\text { Pairs }\end{array}$ & $\begin{array}{l}\text { \% } \\
\text { discriminated }\end{array}$ \\
\hline \multicolumn{5}{|l|}{ Voyager } \\
\hline Bruker & 10 & 45 & 4 & 91 \\
\hline
\end{tabular}




\section{CHAPTER 7. PHYSICAL CHEMISTRY OF CROSSED-LINE INTERSECTIONS:}

\section{CHEMICAL ANALYSIS OF INK COMPONENTS}

\subsection{Research Motivation and Objectives}

In questioned document examination, it is useful to be able to determine the sequence of deposition of ink and/or markings on a substrate. This is most commonly explored in fraud investigations involving official documents, checks, or other documents of interest. Though optical examination and electron microscopy have been most widely applied, there is no universally accepted method to determine the sequence of ink deposition undisputedly (86). The composition of each component ink of a linecrossing and how the multiple inks interact with one another affect the ability to determine sequence of deposition (87). Additional techniques that have been applied to the analysis of line crossings with varying degrees of success including atomic force microscopy, attenuated total reflectance Fourier transform infrared spectral imaging, 3D laser profilometry, and scanning electron microscopy energy dispersive x-ray spectroscopy (SEM-EDX) $(86,88-90)$. The goal of this study was to determine if the method developed for MALDI-MS could be applicable to determining the sequence of deposition of ink in crossed-line intersections on a paper substrate. The second aspect of the study was to identify the luminescent compounds present in the composition of the inks. In addition to MALDI-MS, Thin Layer Chromatography (TLC), Liquid Chromatography Mass Spectrometry (LC-MS), Direct Analysis in Real Time Mass Spectrometry (DARTMS), and a Video Spectral Comparator (VSC) were used in the identification of luminescent compounds. 
7.2 Methods and Materials

\subsubsection{Sample Description}

This experiment involved two types of ink, a writing pen Pilot BPA-10F referred to as "writing instrument Y" and stamp ink Shachihata SGN-40 referred to as "writing instrument Z". All ink samples were prepared on Whatman 42 paper. For the pen ink, a number of strokes were written across the paper and for the stamp ink, a letter stamp was used to deposit the ink on the paper. Crossed-line intersections were prepared in two different ways: the first with the stamp ink deposited on the paper first, and then pen markings made on top of the stamp ink and secondly with pen markings made on the paper and stamp ink deposited on top of the pen markings. Photos of the samples are illustrated in Figure 48.
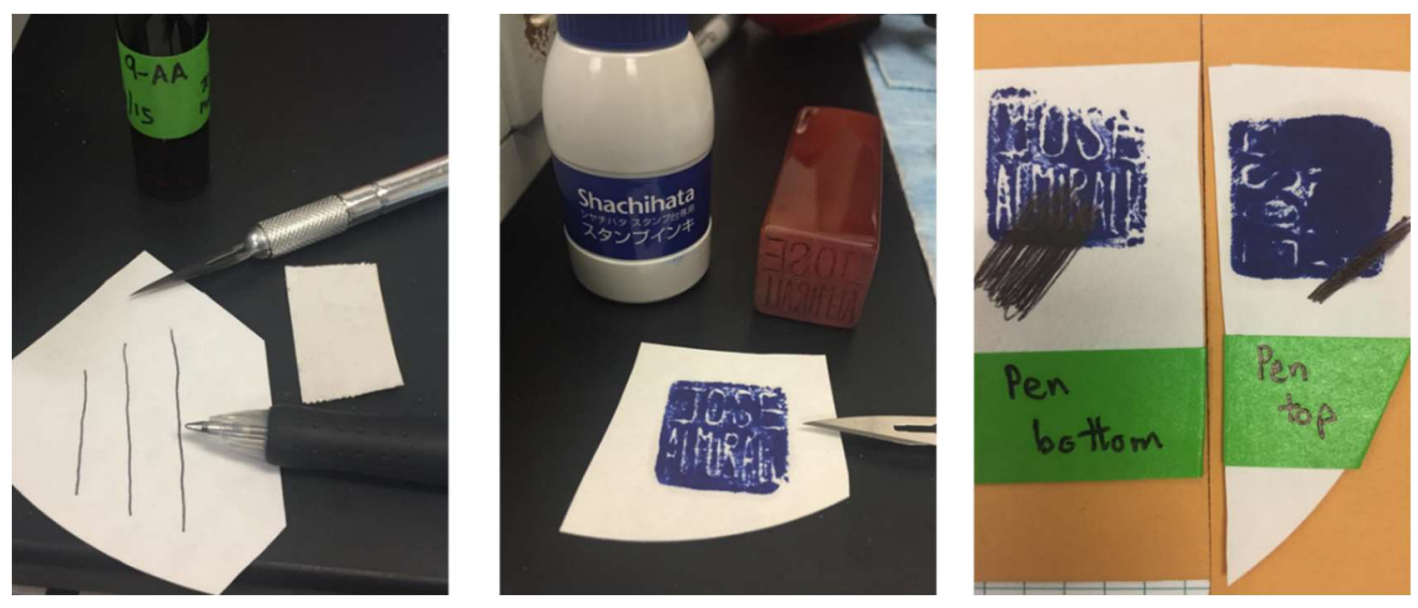

Figure 48- Photos of different ink samples (left) Instrument Y Pilot BPA-10F pen ink (middle) Instrument Z Shachihata SGN-40 stamp ink, and (right) crossed-line intersections of stamp and pen ink 


\subsubsection{Experimental Parameters}

MALDI-MS analyses were conducted on a Voyager DE Pro TOF mass spectrometer (Applied Biosystems: Carlsbad, CA USA). Sample preparation involved cutting a $\sim 2 \times 2 \mathrm{~mm}$ portion of the ink on whatman 42 paper (Whatman: Maidstone, UK) and attached to a 100 well stainless steel target (JBI Scientific: Huntsville, TX, USA). The matrix used was 9-aminoacridine (9AA: Aldrich: St. Louis, MO, USA) dissolved in $70 \%$ methanol:water $(5 \mathrm{mg} / \mathrm{mL}) .0 .5 \mathrm{uL}$ of the matrix solution was spotted on top of the sample on the target. Instrumental parameters were as follows: $337 \mathrm{~nm}$ Nitrogen laser, $3 \mathrm{~ns}$ pulses, $2 \mathrm{~Hz}, 50$ shots per sample, negative and positive mode, mass range $\mathrm{m} / \mathrm{z} 100$ 1000. Data Analysis was performed using Data Explorer TM software (v 4.0.0.0: Applied Biosystems, Carlsbad, CA, USA). Samples analyzed by MALDI-MS include writing instrument $\mathrm{Y}$, writing instrument $\mathrm{Z}$, and crossed-line intersections with writing instrument $\mathrm{Y}$ on top, and writing instrument $\mathrm{Y}$ on bottom.

The LC-MS analyses were conducted using a with a zorbax column coupled to a 6530 Q-TOF-MS (Agilent: Santa Clara, CA, USA). Chromatography parameters were as follows: $1.0 \mu \mathrm{L}$ injection volume, Tcolumn $=40{ }^{\circ} \mathrm{C}$, flow rate: $0.400 \mathrm{~mL} / \mathrm{min}$, eluent $\mathrm{A}$ water, $0.1 \% 5 \mathrm{mM}$ ammonium formate $\mathrm{pH} 4.0$, formic acid, eluent $\mathrm{B}$ ACN acetonitrile, 0.1 formic acid, program: start-5 min $95.00 \% \mathrm{~A}$ (water), 5.00\% $\mathrm{B}(\mathrm{ACN}), 25 \min 5.00 \%$ A (water), 95.00\% B (ACN), 30.0 min runtime total. Electrospray ionization and mass spectrometer parameters: heater gas at $350 \mathrm{C}$, drying gas flow at $7 \mathrm{~L} / \mathrm{min}$, nebulizer at 35 psig, sheath gas at $375 \mathrm{C}$, sheath gas flow at $11 \mathrm{~L} / \mathrm{min}$, cap voltage at $4000 \mathrm{~V}$, fragmentor voltage at $135 \mathrm{~V}$, skimmer voltage $65 \mathrm{~V}$, and mass range of 50-1000 amu. Mass Chromatogram, mass spectra, and data acquisition were achieved using MassHunter 
Workstation Software LC/MS Data Acquisition for the 6200 series TOF/6500 series QTOF (v B.05.00: Agilent: Santa Clara, CA, USA). Samples were extracted from paper with $0.1 \mathrm{~mL}$ methanol (HPLC grade, Thermo Fisher Scientific: Waltham, MA, USA). Samples analyzed include methanol blank, whatman paper blank, writing instrument Y extract diluted 1:10, and writing instrument $\mathrm{Z}$ extract.

The DART-MS analyses were conducted using a 6530 Q-TOF-MS (Agilent, Santa Clara, CA) coupled to a DART SVP (IonSense, Saugus, MA) ambient ionization source. The experimental parameters were as follows: positive ion mode with a DART helium gas at 350C, Q-TOF heater gas at 350C, drying gas flow at $0.2 \mathrm{~L} / \mathrm{min}$, fragmentor voltage of $175 \mathrm{~V}$, skimmer voltage $65 \mathrm{~V}$, and a mass range of 100-1000 amu. A 5ppm solution of polyethylene glycol 600 (Emerald Biosystems, Bainbridge Island, WA) in 50:50 water:methanol (Thermo Fisher Scientific, Waltham, MA) was used as a quality control standard and internal mass calibrant. DART ion source control was achieved using DART SVP software (v 3.0.x: IonSense, Saugus, MA). Mass spectra and data acquisition were achieved using MassHunter Workstation Software LC/MS Data Acquisition for the 6200 series TOF/6500 series Q-TOF (v B.05.00: Agilent, Santa Clara, CA). Samples were analyzed directly from paper substrate. Samples analyzed include paper blank, writing instrument $Y$, and writing instrument $Z$.

The TLC separation were performed using silica gel plates heated at $60 \mathrm{C}$ for 20 mins with mobile phase: ethyl acetate/ethanol/distilled water $(70: 35: 30, \mathrm{v} / \mathrm{v} / \mathrm{v})$. Ink was extracted from the paper using $0.1 \mathrm{~mL}$ pyridine and spotted using capillary tube $1.5-1.8 \mathrm{x}$ 90mm (Kimble Chase: Vineland, NJ, USA). VSC observations were made using the 
VSC-200 (Foster \& Freeman, UK) under spot light source (white light) with 440-580 nm filter. Samples separated via TLC include writing instrument Y, writing instrument z, paper blank, and pyridine blank.

\subsection{Results}

A colorless, therefore invisible migration band was observed at the interface of the paper and the visible inks when writing instruments $\mathrm{Y}$ and $\mathrm{Z}$ were viewed in the VSC under spot light source (480-620 nm filter), as illustrated in Figure 49. The spectra obtained of the pen molecular ions that correspond to multiple dyes present in the formulation of the ink (Figure 50and Figure 51). The series of molecular ions present in positive mode at $\mathrm{m} / \mathrm{z} 344,358$, and 372 correspond to methyl violet minus a chlorine atom and its degradation products, which preferentially ionize in the positive mode (91). It has also been reported that the $\mathrm{m} / \mathrm{z}$ values at 358 and 344 actually correspond to distinct derivatives of crystal violet with less than six methyl groups, with the $\mathrm{m} / \mathrm{z} 358$ containing five methyl groups and the $\mathrm{m} / \mathrm{z} 344$ containing four methyl groups (77). The intact molecule does not exist in ionized form in the mass spectrum, but the molecule plus a sodium molecule do form a molecular ion which is present at $\mathrm{m} / \mathrm{z} 429$. The presence of methyl violet was confirmed by analyzing an extract of the ink after separation by TLC via LC-MS, with the same ions present (Figure 55). In negative mode, the dominant ions present at $\mathrm{m} / \mathrm{z} 712$ correspond to Acid Violet 49, which is also present in the formulation of the pen ink, and preferentially ionizes in the negative mode. Acid Violet 49 is also present as a mixture with other dyes that are analogues of the molecule, substituted with additional sulfonated benzene groups (77). The ion at $\mathrm{m} / \mathrm{z} 925$ 
refers to an Acid Violet 49 analogue (structure seen in Figure 51) and is present in all replicate measurements of the pen ink in negative mode.

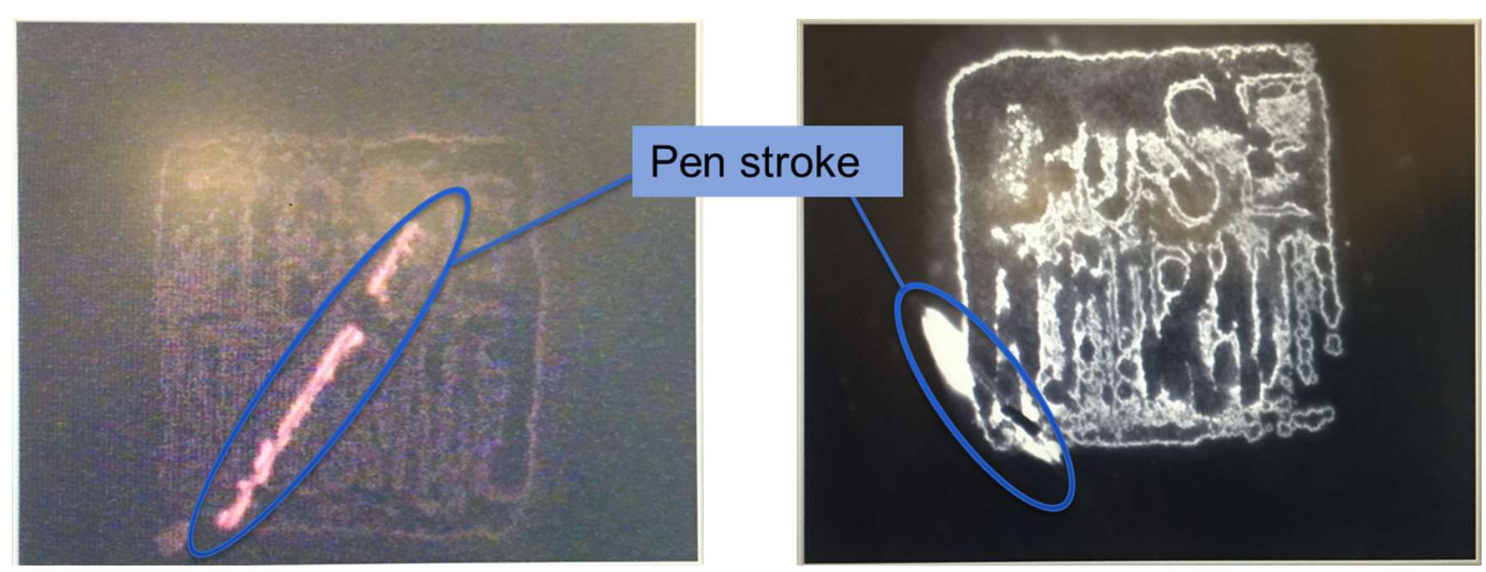

Figure 49- Cross-line intersections of writing instruments $\mathrm{Y}$ and $\mathrm{Z}$ visualized in VSC exhibiting invisible migration (colorless) under spot light source (480-620nm) (left) color, (right) black and white image.

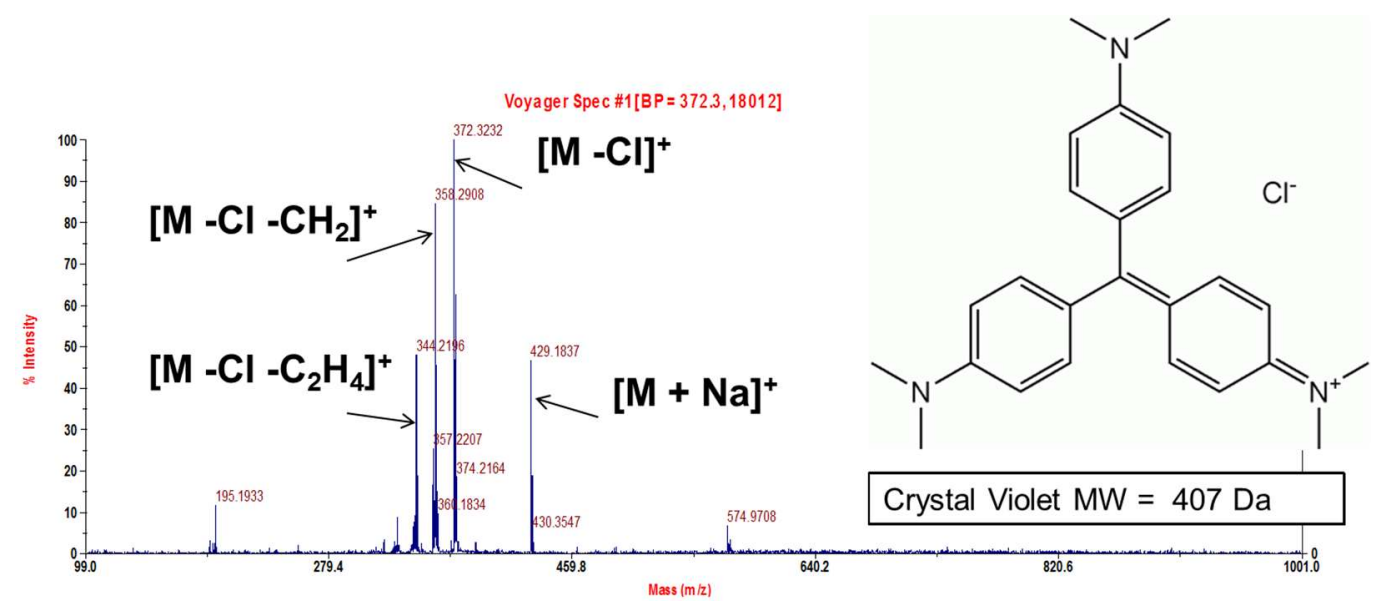

Figure 50- Positive mode MALDI-MS spectrum of pen ink Instrument $\mathrm{Y}$ containing Crystal Violet 


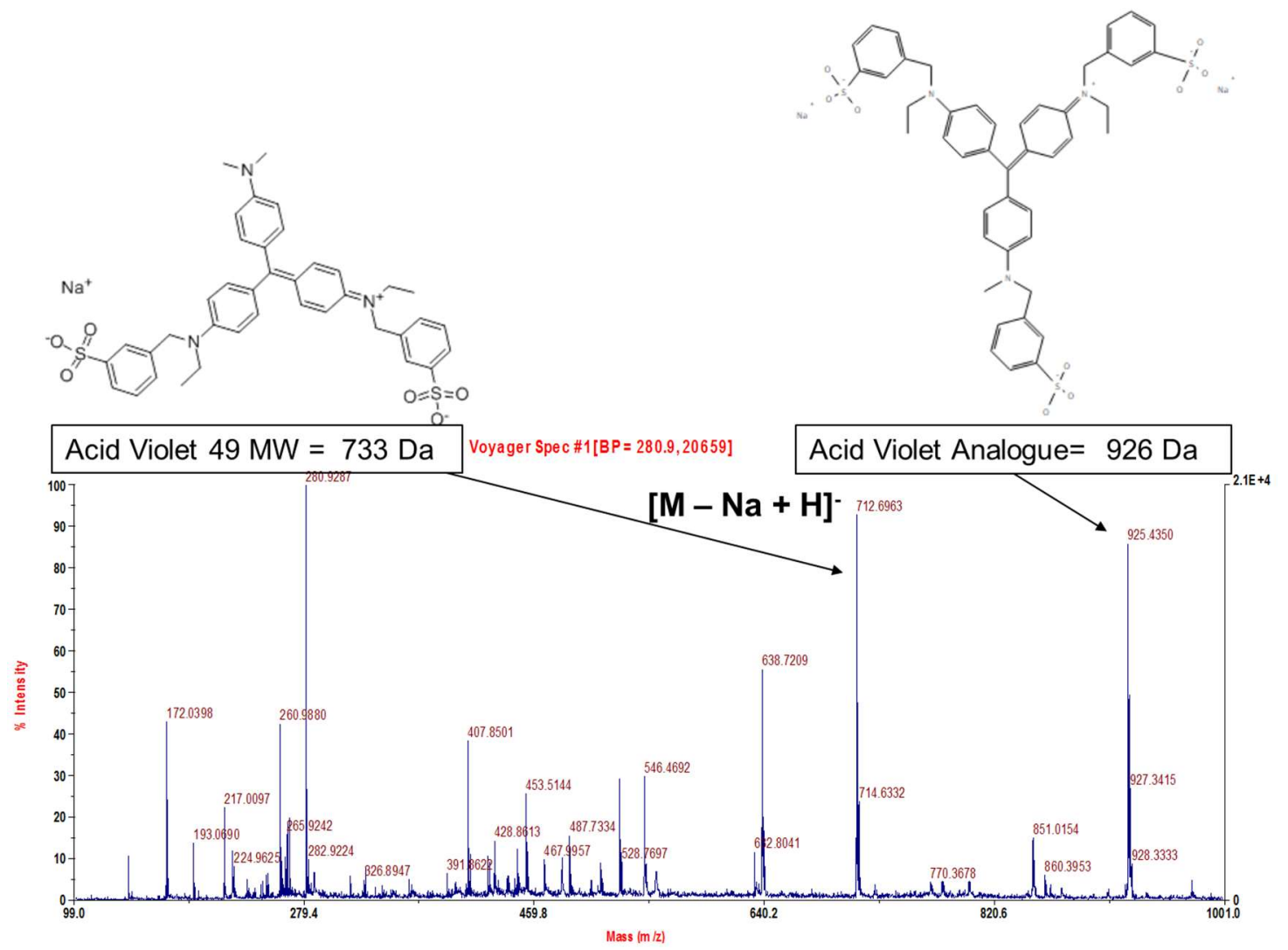

Figure 51- Negative mode MALDI-MS spectrum of pen ink Instrument Y containing Acid Violet 49

The positive and negative MALDI-MS spectra of writing instrument $\mathrm{Z}$ can be seen in Figure 52. In the positive ion spectra obtained of the stamp ink, the prominent ionic species present at $\mathrm{m} / \mathrm{z} 575$ corresponds to copper phthalocyanine. In the negative mode, the ions present at $\mathrm{m} / \mathrm{z} 653$ and 733 correspond to sulfonated copper phthalocyanine species, which are ionized preferentially in the negative mode, due to the anionic nature of the molecules. These molecular ions give insight into the presence of three distinct copper phthalocyanine pigments used in this ink formulation, one disulfonated pigment, one monosulfonated pigment, and one with no substitutions. 
Manufacturers often include these sulfonated pigments to increase solubility and thus can be used as a point of chemical characterization (17).

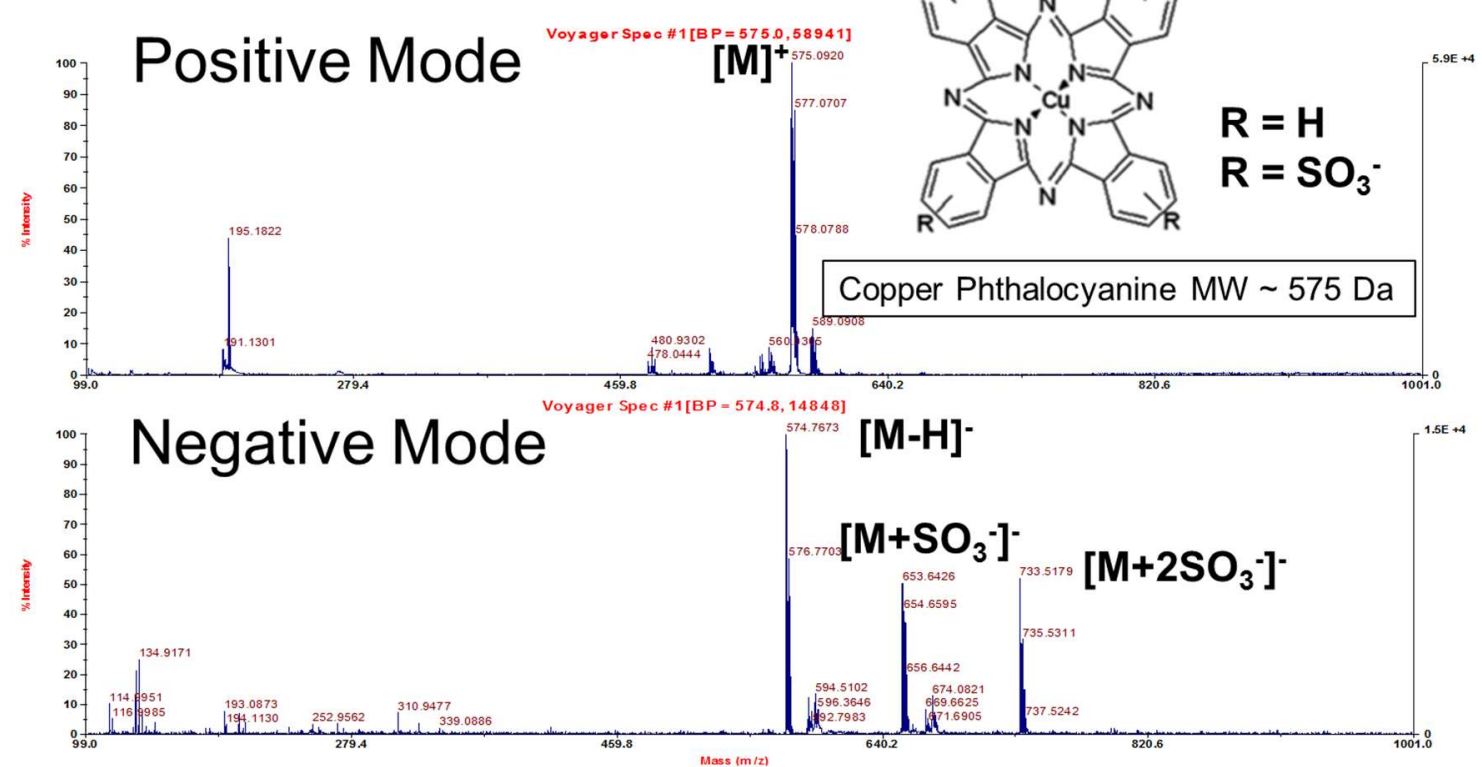

Figure 52- (top) Positive mode and (bottom) negative mode MALDI-MS spectra of stamp ink Instrument $\mathrm{Z}$ containing sulfonated Copper Phthalocyanine

The positive ion mode spectra of the crossed-line intersections (both with pen on bottom and on top of stamp ink) contained molecular ions corresponding to both the pen ink and stamp ink, with the series of $\mathrm{m} / \mathrm{z} 429,372,358,344$ originating from the methyl violet present in the pen ink instrument $\mathrm{Y}$, and the peak at $\mathrm{m} / \mathrm{z} 575$ originating from the copper phthalocyanine present in the stamp ink instrument Z (Figure 53) .

The negative ion mode spectra of the crossed-line intersections also contained molecular ions corresponding to both inks, with the molecular ions at m/z 925 and 712 originating from the acid violet 49 and analogue present in the pen ink instrument $\mathrm{Y}$ and 
the peak at 575 originating from the copper phthalocyanine present in the stamp ink instrument Z (Figure 54).
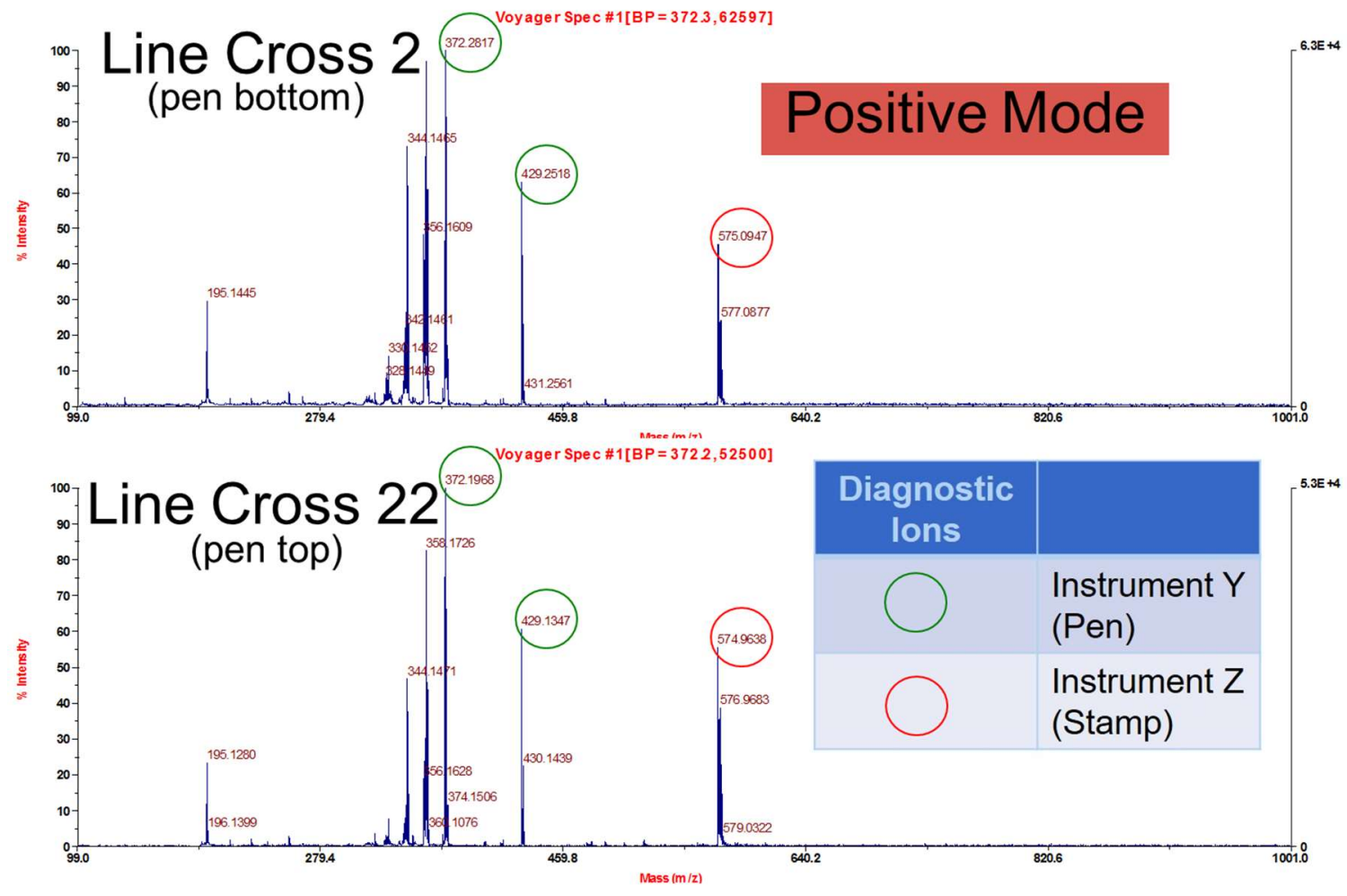

Figure 53-Positive mode MALDI-MS spectra of crossed-line intersections containing pen and stamp ink 


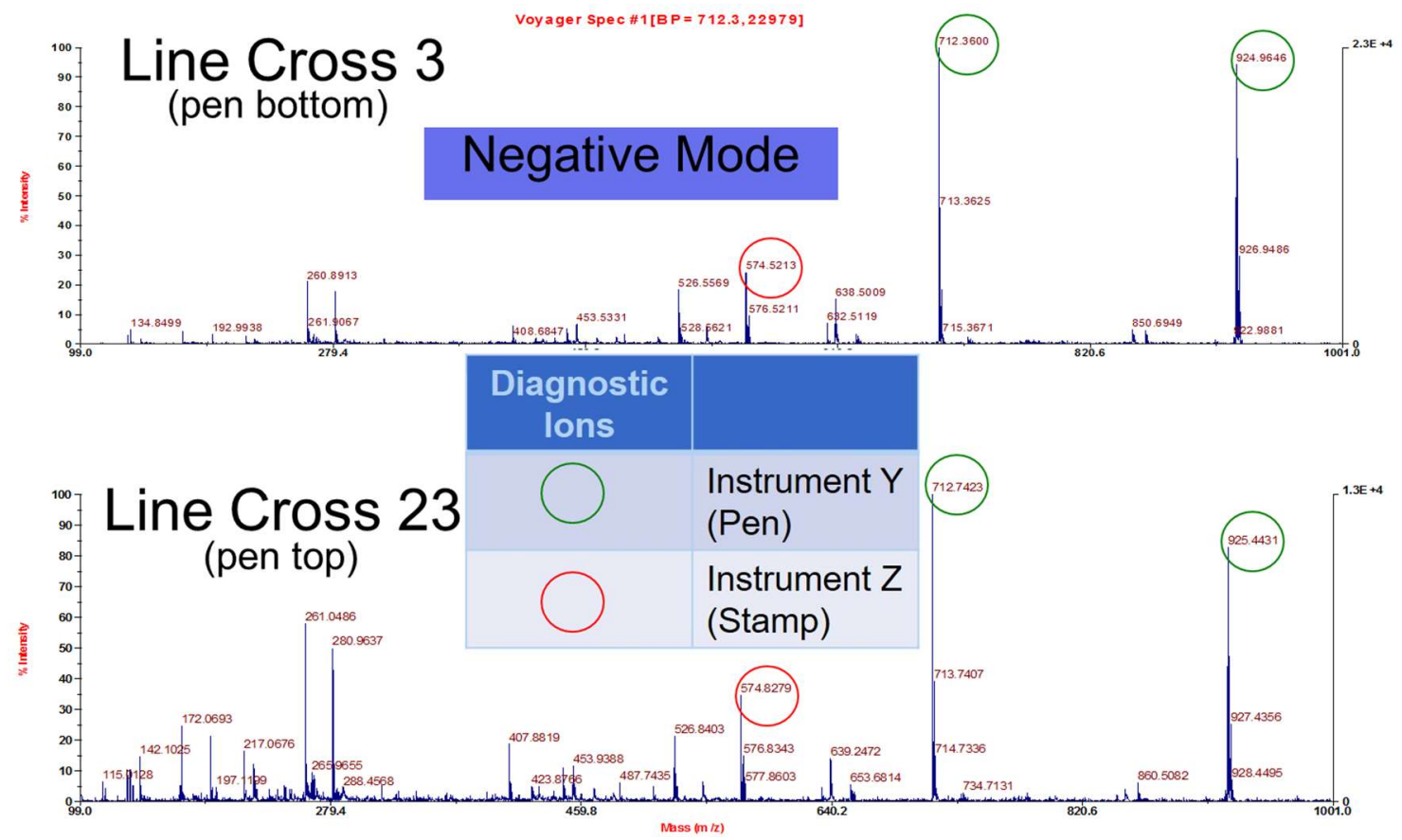

Figure 54- Negative mode MALDI-MS spectra of crossed-line intersections containing pen and stamp ink

The TLC analyses of writing instrument Y revealed the presence three fluorescent bands visible under spot light source and filter of 400-480 nm. The TLC of instrument Z did not reveal any separation or luminescent visualization. It was confirmed with LC-MS analyses that the fluorescent component of the pen ink is crystal violet, methyl violet, and tetramethyl pararosaniline with three distinct chromatographic peaks with mass spectra corresponding to ions with $\mathrm{m} / \mathrm{z} 372,358$, and 344 (Figure 55).

The DART-MS results did not characterize any colorant molecules, though revealed the presence of both polypropylene glycol (PPG) and polyethylene glycol (PEG) polymeric fragments in the pen ink, as seen in Figure 56. The direct DART-MS analysis of the luminescent bands for instrument $\mathrm{Y}$ did not contain any ions that did not come 
from the blank TLC plate. DART-MS analysis of writing instrument $Z$ also showed the presence of polymeric content. The LC-MS of writing instrument $\mathrm{Z}$ corroborated the presence of the liquid polymeric vehicle component.

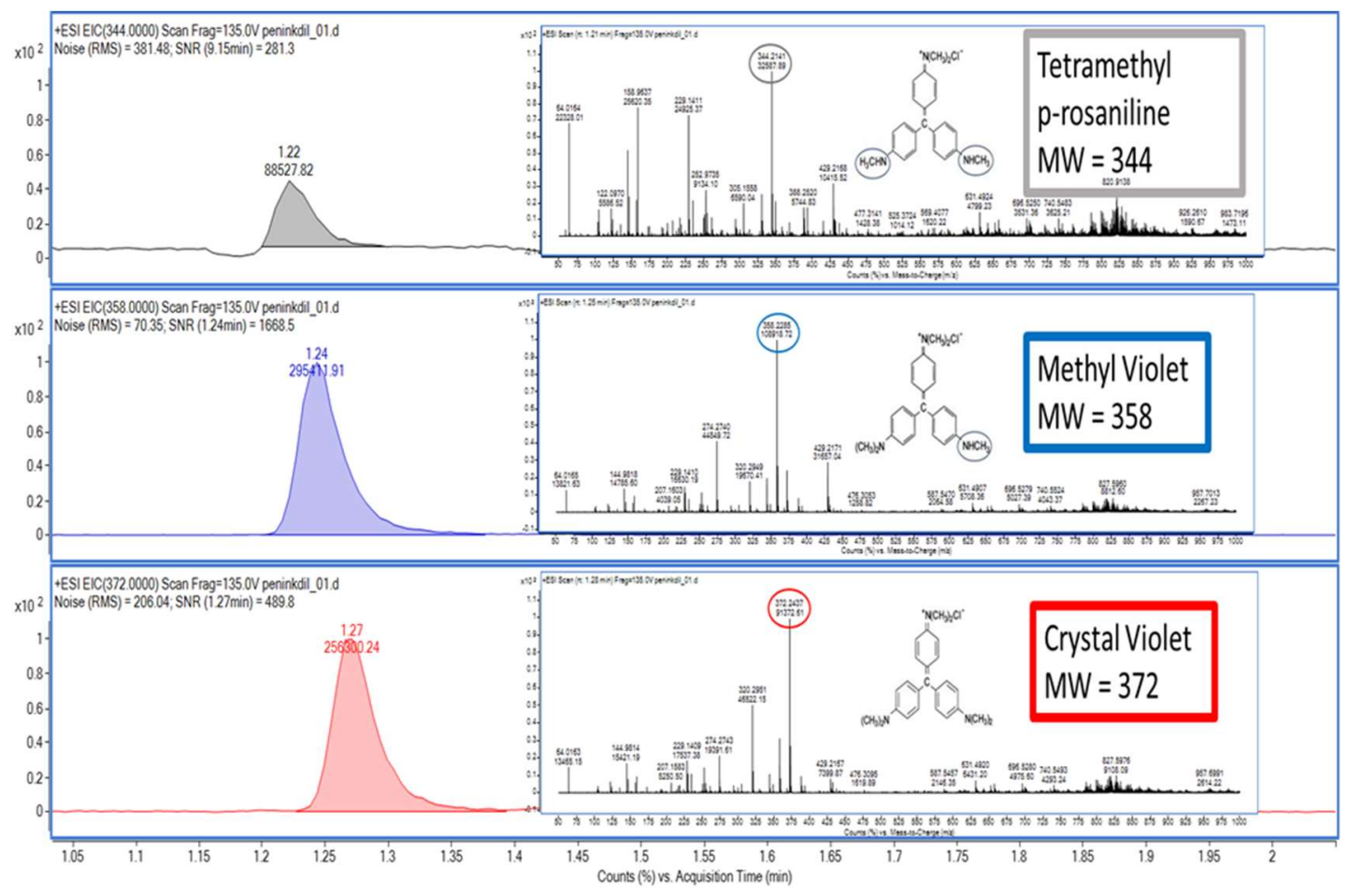

Figure 55- Liquid chromatogram and Positive mode LC-MS spectrum of writing instrument $Y$ pen ink exhibiting three distinct molecules tetramethyl p-rosaniline, methyl violet and crystal violet.

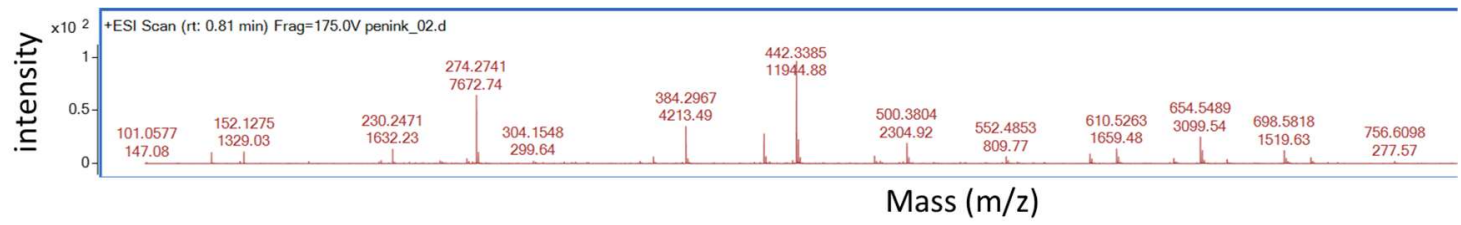

Figure 56- DART-MS spectrum of writing instrument $Y$ exhibiting series of mass fragments that correspond to polyethylene glycol (PEG) at $\mathrm{m} / \mathrm{z}$ 610, 654, 698 which are 44 units apart and polypropylene glycol (PPG) at $\mathrm{m} / \mathrm{z}$ 384, 442, 500 which are 58 units apart. 


\subsection{Conclusion}

While MALDI-MS analysis does not allow for the determination of sequence of crossed-line intersections, it does provide useful chemical information of inks in layers and mixtures on a paper substrate. Being able to characterize components of individual inks in a mixture still allows for useful conclusions to be made for the overall association of inks from common sources and discrimination of inks from different sources.

Additionally, MALDI-MS allows for the identification of inks mixtures on a document, which may be useful in tracing component inks back to the source. When inks interact in crossed-line intersections, invisible migration may occur, as illustrated in Figure 49. This migration is a result of the interaction of the liquid inks with one another, causing a solvation effect. This causes the luminescent compounds, in this case crystal violet and derivatives, to leach out of the ink marking. Once this occurs, the quenching effect of the non-luminescent black dye is inhibited, and the crystal violet dyes are able to luminesce. This seems like an invisible migration, but in fact, the concentration of the violet dyes is so low that the color is not visible to the naked eye. That being said, the identification of the luminescent compounds in these crossed-line intersections does not give insight as to the sequence of deposition of the inks, as this migratory effect occurs regardless of which ink is deposited first.

Since both the positive and negative mode analysis provide different yet complimentary chemical information, it is useful to analyze the crossed-line intersections in both positive and negative ion mode as well. In all spectra obtained, however, the samples with pen ink on bottom and stamp ink on top or vice-versa, there was no significant qualitative differences that could be used to determine sequence of deposition 
of the inks. However, since both component inks were successfully characterized even when deposited on top of one another in a mixture, this method can be applied when a mixture of inks requires characterization, since each individual ink component can be characterized via MALDI-MS.

In addition, the protocol described here allows for the identification of fluorescent components in inks. Dyes are aromatic, organic components that absorb electromagnetic radiation including visible light with wavelengths $350-700 \mathrm{~nm}$. Fluorescence generally refers to re emission in the visible region of the spectrum $400 \mathrm{~nm}$ $700 \mathrm{~nm}$, UV Fluorescence or UV excited visible fluorescence is referred to in ink analysis as infrared luminescence or visible - excited infrared luminescence. The properties of these molecules allows for visualization in the VSC under the spot light source.

While TLC allows for separation and in combination with the VSC visualization of individual luminescent components, LC-MS and MALDI-MS allows for characterization of the molecular properties of the luminescent components, which in this case was a fluorescent dye, crystal violet and demethylated derivatives methyl violet and trimethyl pararosaniline. An invisible migration band may be the result of and/or influenced by the chemistry of the paper (such as additives), the chemistry of the inks (such as solvents), the chemistry of the luminescent agent, and the stability of the components (solvent evaporation rate). The dyes themselves are not, in fact, colorless, but because they exist at such low concentrations, they are not visible to the naked eye. There was a series of demethylated compounds, including the mono- to pentademethylated derivatives of crystal violet, which correspond to the luminescent regions 
separated by TLC, which were invisible to the naked eye. While LC-MS is useful as a confirmatory technique after isolation of luminescent components utilizing TLC, MALDI-MS is a rapid technique for characterization of multiple dyes and/or pigments present in a mixture in the formulation of inks. In this study, crystal violet and degradation products methyl violet and trimethylpararosaniline, along with Acid Violet 49, and Copper phthalocyanine were characterized in the ink composition. These components of interest allow for association and discrimination of inks, and give insight into the composition of the inks that is useful in document examination and intelligence purposes. 


\section{CHAPTER 8. POSSIBLE ALTERATION OF A CHEMISTRY EXAM: A CASE STUDY USING DART-MS}

\subsection{Background and reasoning for chemical analysis}

The methods through which professors and teachers can track and stop plagiarism have also evolved, given the existence of tools such as turnitin.com and other software that provide a plagiarism probability score (92). However, there are cases of blatantly intentional plagiarism where professors may require more advanced means through which plagiarism can be positively identified. The chemical methods that document examiners apply to case work involving questioned and known documents may be useful in instances when perpetrators have intentionally altered a school assignment, such as an exam. One such recently evolved technique is Direct Analysis in Real Time Mass Spectrometry (DART-MS) which has seen great implementation in drug analysis, as well as other applications such as food testing and explosives monitoring, and more recently ink and paper analysis (65). DART-MS has shown to be a rapid, minimally destructive method for the analysis and differentiation of paper, writing inks, and printing inks due to its ability to characterize the semi-volatile components of inks, which can be useful for the association of inks from common sources and discrimination of inks from different sources $(67,69,70)$.

The case described here involves a professor who believed a student altered previously graded exams (that had been handed back to students), and brought the exams back to the professor stating the professor had logged the incorrect grades in his gradebook. The professor believed that after the exams had been handed back to the 
student, the student printed out unmarked copies of the exam, filled out the exam with correct answers, and regraded the exams with the same color pen that the professor had used, which resulted in the student having a higher grade than the professor had marked for the exam.

\subsection{Materials and Methods}

The professor submitted two exams from the student in question (exam 1 and exam 2) as well as exams collected from other students, which the professor was confident that he had graded. In figure 1, an exam from the student in question and an exam collected from another student can be seen. Each exam includes printing ink, pencil markings, and pen markings. The goal was to determine whether the printing inks and pen markings from the known exams could be associated with one another and also whether the questioned exam could be associated with or differentiated from the known exams.
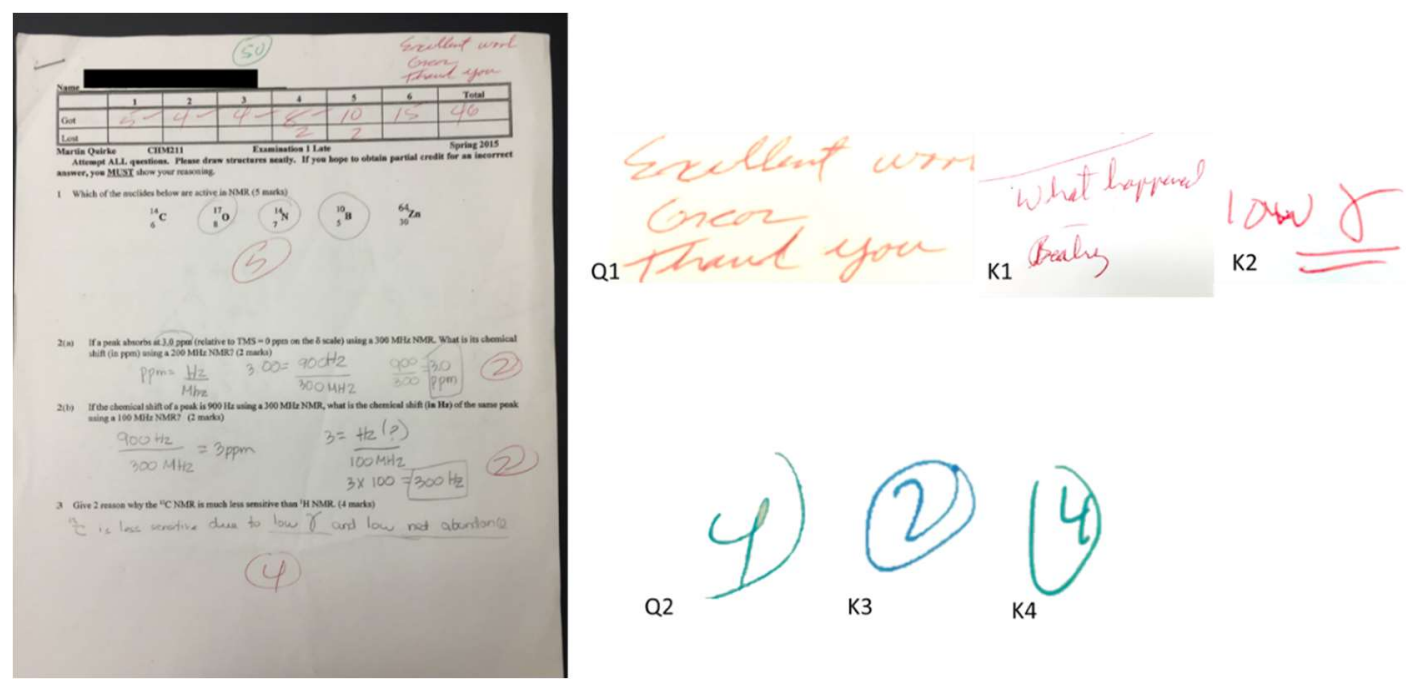

Q2

K3

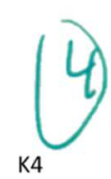

Figure 57- (left) image of questioned exam 1 and (right, top) red pen markings analyzed via DART-MS from exam 1 and (right, bottom) blue pen markings analyzed via DARTMS from exam 2 
8.2.1 Experimental method and sample description

Each document specimen was first examined visually using different light sources on the Visual Spectral Comparator (VSC 6000: Foster \& Freeman, Evesham, UK) to determine any fluorescent properties that may act as points of distinction. Each document specimen then underwent chemical analysis using DART-MS following the methodology derived from Williamson et al. It is noted that the visual integrity of the documents remained after analysis by DART-MS, meaning that the documents could still be examined visually following DART-MS analysis, and that the paper was not cut or destroyed. The samples included specimens from two different exams (exam 1 and exam 2), with two known exams for each (collected from other students) and one questioned exam for each. Exam 1 documents contained red pen markings and black printing ink and exam 2 contained blue pen markings and black printing ink. An explanation of how the documents are referred to can be seen below:

Exam 1 (Red pen ink, printing ink)

Questioned Document Q1

Known Document K1

Known Document K2

Exam 2 (blue pen ink, printing ink)

Questioned Document Q2

Known Document K3

Known Document K4 
The DART-MS analyses were conducted using a 6530 Q-TOF-MS (Agilent, Santa Clara, CA) coupled to a DART SVP (IonSense, Saugus, MA) ambient ionization source. The experimental parameters were as follows: positive ion mode with a DART helium gas at 350C, Q-TOF heater gas at 350C, drying gas flow at $0.2 \mathrm{~L} / \mathrm{min}$, fragmentor voltage of $175 \mathrm{~V}$, skimmer voltage $65 \mathrm{~V}$, and a mass range of 100-1000 amu. A 5ppm solution of polyethylene glycol 600 (Emerald Biosystems, Bainbridge Island, WA) in 50:50 water:methanol (Thermo Fisher Scientific, Waltham, MA) was used as a quality control standard and internal mass calibrant. DART ion source control was achieved using DART SVP software (v 3.0.x: IonSense, Saugus, MA). Mass spectra and data acquisition were achieved using MassHunter Workstation Software LC/MS Data Acquisition for the 6200 series TOF/6500 series Q-TOF (v B.05.00: Agilent, Santa Clara, CA).

Each data file was acquired in the following order: blank air background, specimen, PEG 600 standard. For each specimen, blank paper was also sampled in order to isolate the peaks in the acquired mass spectra due to ink. All mass spectra acquired were normalized to the sum of all peaks in the individual spectrum, so that all spectra between specimens were compared on the same scale. The air background and paper spectra were subtracted from each ink spectrum before comparison. Spectra were compared on a qualitative basis only. Diagnostic ions were chosen only if present in all replicate measurements of a specimen, were $>10 \%$ in relative abundance, and have been previously reported as known components of inks. On all specimens, 9 replicate measurements of the printing ink were taken on different physical locations on the paper. For Known “Control” Document Specimen K1, Known “Control” Document Specimen 
K2, and Questioned Document Specimen Q1, the red writing ink was analyzed 9 replicates each on different physical locations on the paper. For Known "Control" Document Specimen K3, Known "Control” Document Specimen K4, and Questioned Document Specimen Q2, the blue writing ink was analyzed 9 replicates each on different physical locations on the paper.

\subsection{Results}

After examination with the VSC, no useful points of comparison were observed. None of the printing inks from either questioned or known documents from exam 1 or 2 fluoresced, while all of the pen inks fluoresced. The DART-MS analysis of the printing ink from all samples (questioned, known, from exam 1 and 2) did not reveal any diagnostic ions that could be used as points of distinction.

The DART-MS results for the red pen markings from exam 1 and blue pen markings from exam 2 can be seen in figures 2 and 3. For exam 1, which contained red pen markings, all replicate analyses of the known documents $\mathrm{K} 1$ and $\mathrm{K} 2$ contained peaks at $\mathrm{m} / \mathrm{z} 213$, which corresponds to solvent orange 3 , a polar, semi-volatile dye used as a colorant in red pen inks (93). This molecular ion was not present in any of the replicate measurements of document Q1. However, all replicate measurements of document Q1 contained peaks at $\mathrm{m} / \mathrm{z} 268$, which corresponds to the ionic form of $\mathrm{C}_{18} \mathrm{H}_{24} \mathrm{~N}_{2}$, a common component reported in pen ink formulations (69). This molecular ion was not present in any of the replicates of K1 or K2. Since the peak present at m/z 443 which corresponds to the commonly used dye basic red 1 was observed in all documents $(\mathrm{Q} 1, \mathrm{~K} 1$, and $\mathrm{K} 2)$ 
from exam 1, it was not considered as a point of distinction between the questioned and known samples (93).

For exam 2, which contained blue pen markings, all replicate analyses of the known documents $\mathrm{K} 3$ and $\mathrm{K} 4$ contained peaks at $\mathrm{m} / \mathrm{z} 223$, which corresponds to diethyl phthalate, a common additive in writing inks (68). This molecular ion was not present in measurements of document Q2. However, all replicate measurements of document Q2 contained peaks at $\mathrm{m} / \mathrm{z} 367,388$, and 391 which correspond to dioctyl phthalate, a plasticizer reported in pen ink formulations. These peaks are not present in any of the replicates of documents $\mathrm{K} 3$ and $\mathrm{K} 4$.

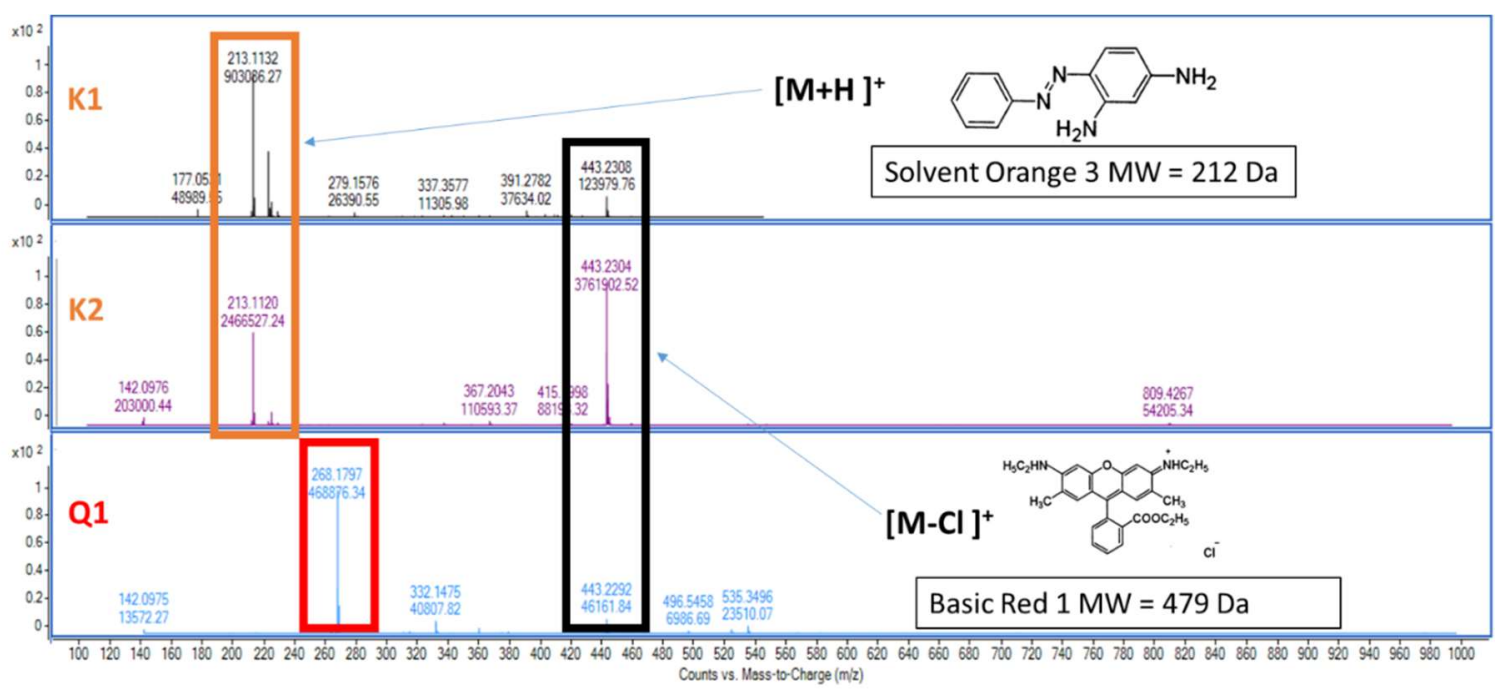

Figure 58- DART-MS spectra of red pen markings from Exam 1: (top) Known Document 1 K1, (middle) Known Document 2 K2, and (bottom) Questioned Document 1 (Q1)

Based on these diagnostic ions, a number of conclusions can be made regarding the association and discrimination of these exams. For exam 1, the red pen markings on document $\mathrm{K} 1$ and $\mathrm{K} 2$ are indistinguishable from one another and are distinguishable from the red pen markings on document Q1. 


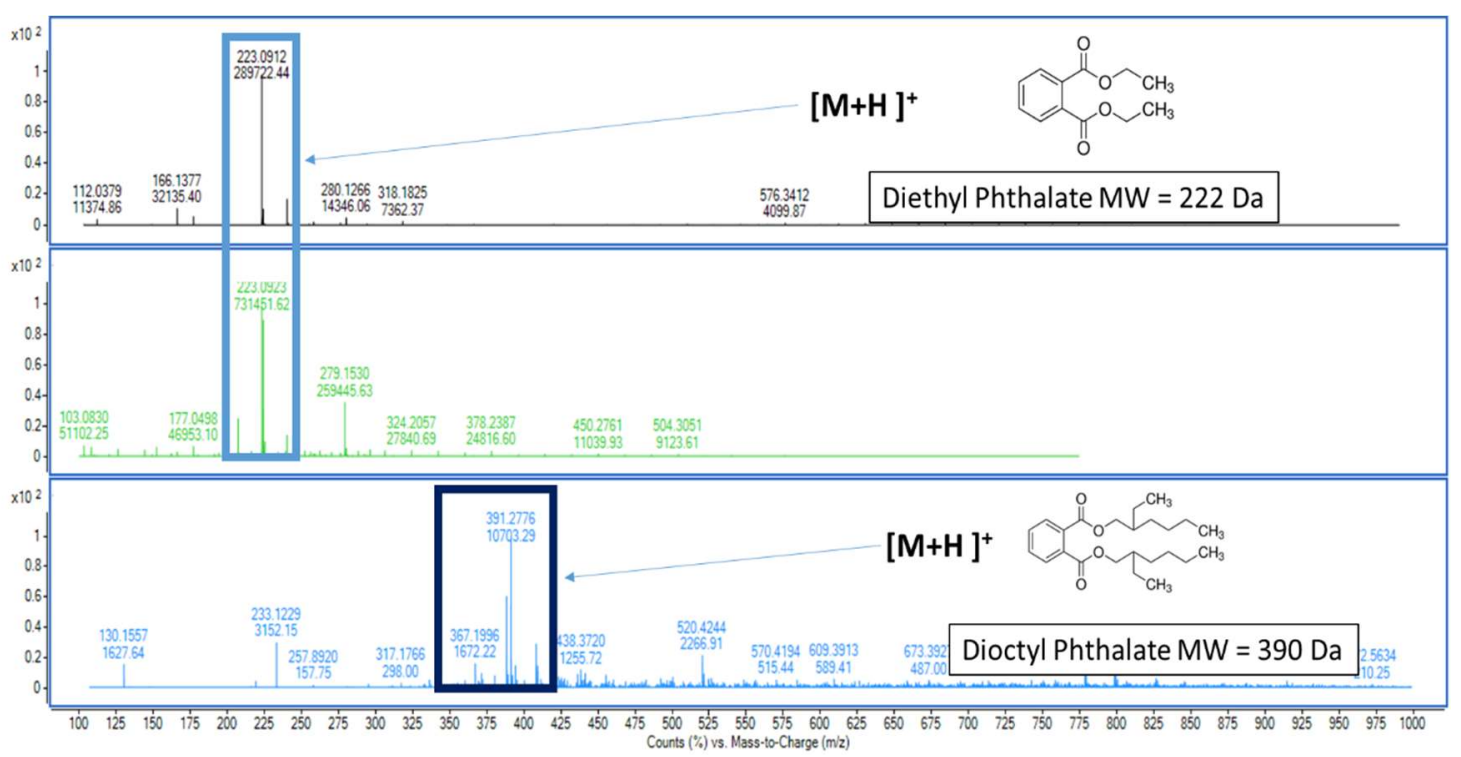

Figure 59- DART-MS spectra of blue pen markings from Exam 2: (top) Known Document 3 K3, (middle) Known Document 4 K4, and (bottom) Questioned Document 2 Q2

Similarly, for exam 2, the blue pen markings on document $\mathrm{K} 3$ and $\mathrm{K} 4$ are indistinguishable from one another and are distinguishable from the blue pen markings on document Q2. Therefore, it can be concluded that a different pen was used to make the red pen markings on document $\mathrm{Q} 1$ than on documents $\mathrm{K} 1$ and $\mathrm{K} 2$, and also that a different pen was used to make the blue pen markings on document Q2 than on documents $\mathrm{K} 3$ and $\mathrm{K} 4$.

\subsection{Conclusion}

These findings support the presumption by the professor that the questioned exams were marked with different pens than the known exams. As the professor holds that all exams were graded by the same pen, then these findings support the idea that the student in question altered the exams. 
Though the control sample set was extremely limited, the analyses performed illustrate the ability of DART-MS to produce spectra of inks that can be used for the association of inks originating from common sources and the differentiation of inks from different sources, in this case, two different pens.

This study illustrates the utility of DART-MS for the analysis of inks in questioned document analysis and how it can aid in intelligence gathering in investigations involving ink and document evidence. Overall, DART-MS is a rapid, visually non-destructive method for the analysis of inks on paper that can be useful in forensic settings and investigations involving questioned document examination. 


\section{CHAPTER 9. UTILITY OF COMBINING CHEMICAL METHODS FOR THE}

\section{ANALYSIS OF PRINTING INKS}

9.1 Combined ATR-FTIR and DART-MS analysis of printing inks

The analysis performed by ATR-FTIR and DART-MS provides complimentary qualitative organic chemical information that can be used in the association of common inks and discrimination of inks from different sources in varying degrees based on sample type. While ATR-FTIR is completely non-destructive to ink samples on paper, DART-MS is semi-destructive in that slight discoloration may occur, and the same exact sample spot cannot be analyzed more than once (due to desorption of ions from surface) but the overall visual integrity of samples is maintained following DART-MS analysis. Comparison of ATR-FTIR and DART-MS parameters can be seen in Table 16.

While ATR-FTIR provides chemical information based on bulk components, DART-MS characterizes the semi-volatile, low molecular weight, polymeric vehicle components of inks. ATR-FTIR is most useful in characterizing offset ink samples, based on the evidence that inks from the same manufacturer but of different colors can be discriminated, which would be useful in tracing an ink back to a source. ATR-FTIR is also useful in the classification of toner inks based on the combination of polymer resins used in the formulation of the ink. ATR-FTIR provides limited information for intaglio and inkjet inks. DART-MS, however, allows for the characterization of the semi-volatile polymeric vehicle components of inkjet inks, allowing for the discrimination of inkjets originating from different cartridges of the same manufacturer. DART-MS also provides information regarding the plasticizer used in intaglio inks, as well as any light molecular 
weight polymeric vehicle that may be used in the formulation of the intaglio ink. DARTMS provides characterization of the PEG and PPG components of toner inks, which compliments the polymer resin information provided by ATR-FTIR. DART-MS also provides limited information on the polymeric content of offset inks. Although an expensive combination, DART-Q-TOF-MS has found its way into the forensic laboratory as a useful tool for the rapid screening of drugs. The application being discussed here is an additional use for this analytical technique.

In conclusion, implementing a methodology of both analytical techniques in sequence provides improved discrimination capability over either technique alone, especially for toners and inkjet inks, as illustrated in Table 15. The combined discrimination capability of both techniques was determined to be $>96 \%$ for toners, $95 \%$ for inkjets, $>92 \%$ for offset, and $>54 \%$ for intaglio. Though not a facet of this research project, application of chemometric statistical analysis may provide improved association capabilities for the combined techniques. Together, a protocol involving first ATR-FTIR analysis, which is completely non-destructive and subsequently DART-MS, which requires a small amount of sample, could be implemented in forensic document analysis for the association of common inks and discrimination of inks originating from different sources. 
Table 15- Comparison of ATR-FTIR and DART-MS discrimination capabilities for each ink type

\begin{tabular}{|l|c|c|c|c|}
\hline & Inkjet & Toner & Offset & Intaglio \\
\hline $\begin{array}{l}\text { Samples from } \\
\text { different sources }\end{array}$ & 78 & 76 & 79 & 86 \\
\hline Comparison Pairs & 3003 & 2850 & 3081 & 3665 \\
\hline $\begin{array}{l}\text { \% discriminated by } \\
\text { ATR-FTIR }\end{array}$ & $\begin{array}{l}49.5(1485 \\
\text { out of } 3003)\end{array}$ & $\begin{array}{l}86.3(2459 \text { out } \\
\text { of } 2850)\end{array}$ & $\begin{array}{l}92.6(2854 \text { out } \\
\text { of } 3081)\end{array}$ & $\begin{array}{l}33.6(1187 \text { out } \\
\text { of 3655) }\end{array}$ \\
\hline $\begin{array}{l}\text { \% discriminated by } \\
\text { DART-MS }\end{array}$ & $\begin{array}{l}91.3(2741 \text { out } \\
\text { of 3003) }\end{array}$ & $\begin{array}{l}81.8(2331 \text { out } \\
\text { of 2850) }\end{array}$ & $\begin{array}{l}56.1(1728 \text { out } \\
\text { of } 3081)\end{array}$ & $\begin{array}{l}48.6(1776 \text { out } \\
\text { of 3655) }\end{array}$ \\
\hline $\begin{array}{l}\text { \% discriminated by } \\
\text { ATR-FTIR \& } \\
\text { DART-MS } \\
\text { Combined }\end{array}$ & $\begin{array}{l}\text { 95.0 (2853 out } \\
\text { of 3003) }\end{array}$ & $\begin{array}{l}96.8(2760 \text { out } \\
\text { of 2850) }\end{array}$ & $\begin{array}{l}92.7(2857 \text { out } \\
\text { of 3081) }\end{array}$ & $\begin{array}{l}54.2(1988 \text { out } \\
\text { of 3655) }\end{array}$ \\
\hline
\end{tabular}

Table 16- Comparison of ATR-FTIR and DART-MS analyses

\begin{tabular}{|l|l|l|}
\hline & ATR-FTIR & DART-MS \\
\hline Data Output & $\begin{array}{l}\text { IR Spectra (x-axis: } \\
\text { avenumber, y-axis: } \\
\% \text { transmittance) }\end{array}$ & $\begin{array}{l}\text { Mass Spectra (x-axis: m/z, } \\
\text { y-axis: intensity) }\end{array}$ \\
\hline Sample Penetration & Surface, $\sim<5 \mu \mathrm{m}$ & Surface \\
\hline Sampling Area & $2500 \mu \mathrm{m}^{2}$ & $7.5 \mathrm{~mm}^{2}$ \\
\hline Sample Destructiveness & None & $\begin{array}{l}\text { Moderate } \\
(\text { discoloration/melting) }\end{array}$ \\
\hline $\begin{array}{l}\text { Time of analysis per } \\
\text { replicate }\end{array}$ & 1 min & $3-5$ min \\
\hline
\end{tabular}




\subsection{Complementarity of DART-MS and MALDI-MS}

DART-MS is a promising technique for the analysis of printing inks directly on paper with minimal sample destruction. DART preferentially ionizes the semi-volatile polymeric vehicle content of printing inks, which include PEG and PPG-like distributions that can be used for the association of inks originating from the same printing source and for the reliable discrimination of inks originating from different sources. DART-MS is a rapid technique that allows for inks on paper to be analyzed with no prior sample preparation or pre-treatment. However, the ionization efficiency is highly temperature dependent, and thus can cause physical changes such as melting or evaporation of the sample to occur. Replicate measurements are also variable due to the analyses occurring in ambient conditions, and the sampling area is quite large $\left(\sim 7.5 \mathrm{~mm}^{2}\right)$, preventing useful spatial resolution of sample surfaces to be obtained.

Both DART-MS and MALDI-MS are surface desorption/ionization methods, and are considered soft ionization techniques due to the lack of fragmentation (as compared to traditional electron impact ionization methods) and production of $[\mathrm{M}+\mathrm{H}]$ molecular ions. Most significant to this dissertation is the ability of both methods to analyze inks directly from a paper substrate. The chemical information they provide is complimentary, and a protocol involving the analysis of the same sample by both DARTMS and MALDI-MS in succession would be useful in improved association and discrimination of printing inks in that both the semi-volatile polymeric content and colorant component of the same ink can be characterized (Figure 60). 
MALDI-MS is a destructive technique but requires a very small amount of sample and allows for analysis of printing inks directly on a paper substrate, characterizing the colorant pigment or dye component of the inks. It also has a very small sample spot size of $\sim 20 \mu \mathrm{m}^{2}$ which allows for precise spatial resolution of sample surfaces. However, MALDI-MS requires sample preparation in that ink samples must be cut from the original document/paper and affixed to the sampling tray. In addition, a liquid matrix is required for efficient ionization, and the laser power must be optimized for each sample on an individual basis. This information, together with the information obtained via DART-MS analysis allows for improved association and discrimination of inks. Both analytical techniques have various qualities that act either hinder or allow for robust analysis of printing inks directly on paper substrates, as illustrated in Figure 61. 


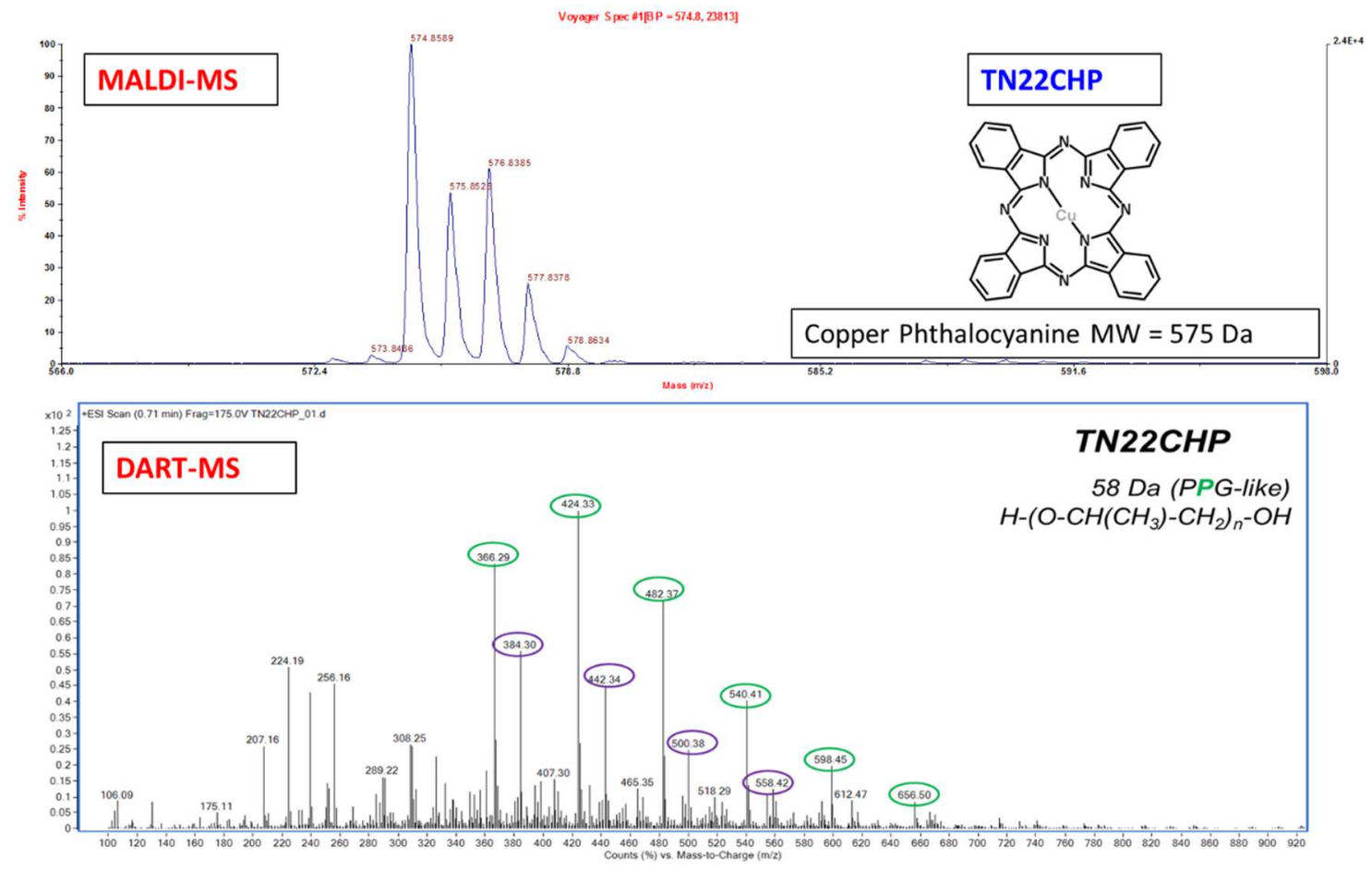

Figure 60- (top) MALDI-MS spectrum and (bottom) DART-MS spectrum of same toner ink sample illustrating complimentary information acquired via protocol including both analytical techniques

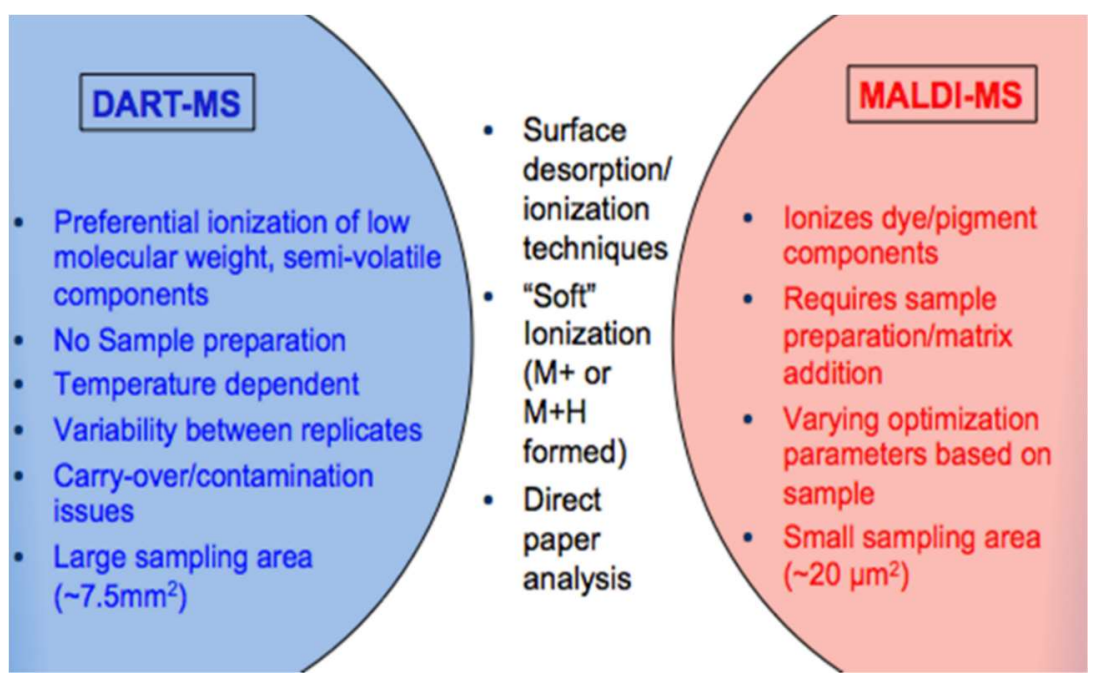

Figure 61- Comparison, similarities, and differences between DART-MS and MALDIMS, illustrating the complementarity of the two techniques 


\section{CHAPTER 10. DEVELOPMENT OF A SEARCHABLE DATABASE FOR THE}

\section{COMPARISON OF PRINTING INK EVIDENCE}

Portions of this chapter were published in the Journal of Forensic Sciences, May 2016, Volume 61, Number 3, Pages 715-724 Copyright (C) John Wiley and Sons

\subsection{Background and Research Motivation}

Many databases exist in the forensic sciences to compare profiles of unknown samples to those of a reference library such as PDQ for paint evidence, AFIS for fingerprints, IBIS for firearms, and CODIS for DNA profiles. Databases made up of chemical data are not widely used in the field of document examination due to the diversity of ink formulations, the ever changing nature of ink sources and raw materials, and the requirement that the analytical methodology producing the chemical profiles must be highly reproducible and repeatable. Neumann et al. developed a searchable database for the comparison and identification of writing inks using high performance thin layer chromatography (HPTLC) and demonstrated the necessity of standardizing data acquisition and an automated searching algorithm to effectively compare chemical profiles of inks (29). The database that was developed as a facet of this dissertation is the first time that a comprehensive searchable database has been developed for printing inks using such a large suite of chemical analytical techniques and data fusion algorithms.

The aim was to develop an automated identification system for printing inks fusing data outputs from five chemical analytical techniques: laser ablation inductively coupled plasma mass spectrometry (LA-ICP-MS), DART-MS, scanning electron microscopy energy dispersive spectroscopy (SEM-EDS), ATR-FTIR, and Py-GC/MS. This study combines the capabilities and advantages of the five aforementioned analytical methods 
to characterize both the inorganic and organic composition of four classes of printing inks: inkjets, toners, offset, and intaglio, with the ultimate goal of enhancing the ability to discriminate and characterize printing inks. This study also incorporates novel data fusion protocols in order to achieve the enhanced informing power of the data generated by the multiple methods.

The statistical methods used in the database are derived from partial least-squares discriminant analysis (PLSDA) algorithms, k-nearest neighbor (KNN) classification, and multisensory fusion. The PLSDA algorithm was included because it 1) has relatively few parameters or PLSDA components, 2) performs well, 3) is applicable to multiple sensor types/data outputs with minimal changes in preprocessing, 4) trains fast even with a large number of database entries, and 5) can quickly evaluate test samples (94). The KNN classification allows for comparison of test spectra with its closest neighbors, comparing the Euclidean distance between spectral outputs and assigns values for each spectrum between $0-1$, and mitigates any changes due to different experimental conditions (95). The data fusion component of the database allows for the combination of information from data output from multiple analytical techniques. Decisions as to association and discrimination of chemical profiles using data fusion from multiple techniques is often significantly improved when compared to using any one data output in isolation, since the experimental errors are independent of one another. The implementation of the suite of analytical techniques and ink database will advance the capabilities of forensic scientists to compare, associate, and/or eliminate chemical profiles of printing inks in an automated manner utilizing statistically sound algorithms. 


\subsection{Experimental Section}

Each ink sample was assigned a unique database file identification number using the following: 1) the first four digits represent the unique ID number for each of the four ink type subsets, 2) two letters that represent each ink type: IJ for inkjet, TN for toner, OF for offset, and IT for intaglio, 3) the subsequent two numbers represent the replicate number of the measurement of the same specimen sampled in a different location, 4) the next two numbers represent the printout number; if a sample printed from the same cartridge at a different time interval or a sample collected from the toner powder from different physical locations of the cartridge, 5) the final two numbers describe the analytical technique used to acquire the data file output, LA for LA-ICP-MS, DART for DART-MS, FTIR for ATR-FTIR, PY for Py-GC/MS, and SEM for SEM-EDS.

All data were acquired and exported to the database as .csv x-y plot files, where the $y$-axis is the normalized intensity and the $\mathrm{x}$-axis is the measured variable $(\mathrm{m} / \mathrm{z}$ for LAICP-MS and DART-MS, wavenumber (cm-) for ATR-FTIR, E for SEM-EDS, and time for Py-GC/MS). Data reduction was performed prior to transfer to the database to 1) remove instrumental and/or matrix interferences and 2) normalize the data for reproducibility. For DART-MS data, mass spectra intensitites were normalized so that the largest peak in each spectrum had a magnitude of one. The DART-MS data files were then treated using an in-house algorithm using SAS 9.3 (v.6.1.7601; SAS Institute., Cary, NC) to change mass units to nominal values $100-1000 \mathrm{~m} / \mathrm{z}$.

Data reduction and statistical analysis were performed using SYSTAT (v.9.0; SPSS Science, Chicago,IL), JMP (v.5.0.1; SAS Institute Inc., Cary, NC), Excel 2011 
(v.14.3.5; Microsoft Corp., Redmond, WA), Plot (v.0.997 Berlin, Germany), Mathematica (v. 5.2.0.0; Wolfram Mathematica, Champaign, IL, and various machine learning algorithms implemented and developed by CoVar Applied Technologies, Inc., using MATLAB (The MathWorks Inc., Natick, MA), and Pattern Recognition Toolbox (http://arxiv.org/abs/1406.5565).

The database software uses PLSDA algorithms for classification based on a reference and experiment (training/testing) database. The reference database contains the entries against which the experiment database will be compared, from which the PLSDA algorithm will develop the matching criteria. For example, if the goal is to classify a new or unknown ink, $\mathrm{X}$, as one of $\mathrm{n}$ different inks, the reference database will contain data outputs for each of the $\mathrm{n}$ inks being considered. The testing database will contain spectra collected from the new sample, $\mathrm{X}$, and the software can classify the ink $\mathrm{X}$ from one of the $\mathrm{n}$ inks. Each of the reference databases contains multiple inks from the same ink class (inkjet, toner, offset, intaglio), multiple replicates, and with various sensor types (LAICP-MS, SEM-EDS, ATR-FTIR, DART-MS). The software offers visualization to quickly asses the outputs from the PLSDA classification for a single testing sample, and provides a similarity score. The software also provides a visualization of the test spectra (as compared to the reference spectra) and gives an output list of the ten closest matches based on KNN classification.

\subsection{Results}

In order for the algorithm to function effectively, it was necessary to achieve the following, for each of the four ink class: 1) collect enough replicate measurements for 
each sample from each analytical technique ( $>3$ replicate measurements) and 2 ) collect enough data from enough samples ( $>4$ samples per ink class per analytical technique). Due to poor reproducibility of Py-GC/MS data, it was excluded from the database algorithm. The database currently contains 5469 data files, 4658 data files comprising the reference database originating from 319 different printing ink samples seen in Appendix I and 811 data files comprising the reference database from samples originating from duplicate control samples from each of the analytical techniques. A typical PLSDA output based on ATR-FTIR data can be seen in Figure 62, representing a test sample toner ink 57 and the PLSDA magnitudes (between -1,1) for each of the 76 reference toner inks. These outputs are not a probability, but a higher positive value indicates more confidence of class assignment (assignment of the test sample to a particular ink in the reference set). Therefore, based on Figure 62 the test ink is most likely to be ink 57 , more so than any of the other inks. 


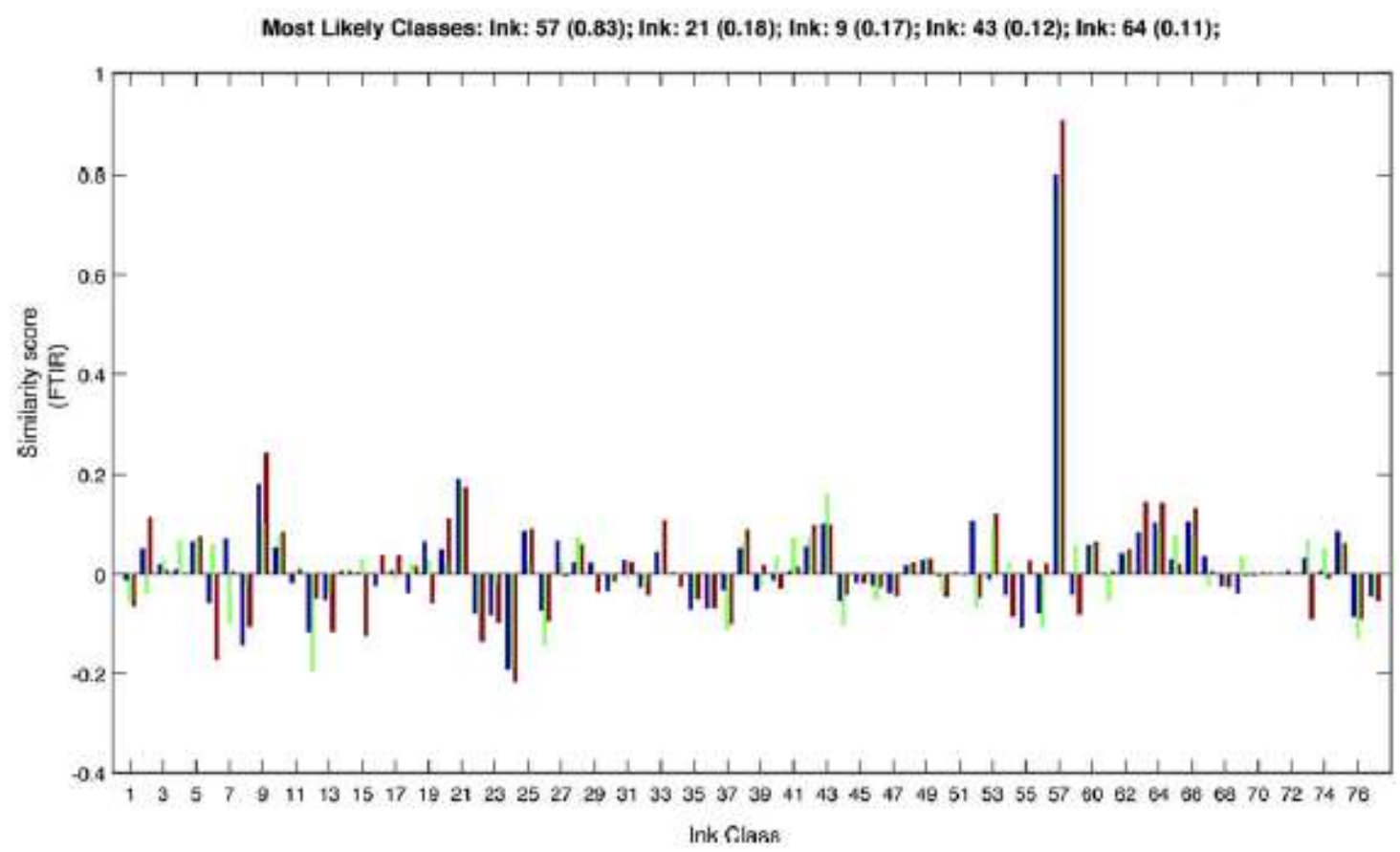

Figure 62- visualization of PLSDA output for ATR-FTIR data using a comparison sample as a duplicate toner ink (sample 57). The bars represent the PLSDA output magnitude for each replicate for each of the 76 inks in the reference database. The large similarity scores for sample 57 indicates the comparison sample (duplicate control) is correctly associated with the same sample in the reference database.

To test the overall reliability of the database, duplicate control test databases were classified using the algorithm. In order to have confidence in the utility of the database, it must be able to correctly classify previously unseen data to the correct class, meaning correctly classifying additional duplicate replicate measurements of an ink as the ink it belongs to. The control data were evaluated using three different statistical algorithms or match criteria: 1) spectral overlay, 2) PLSDA, and 3) KNN. The spectral overlay was conducted externally to the database by an analyst and acted as a point of reference to the performance of the database. The user interface and typical output for a database search can be seen in Figure 63. 
An ink was considered correctly classified if the correct duplicate was listed as one of the top five selections provided by the PLSDA algorithm. These match criteria were determined because in many cases, for inks with very similar chemical composition, the true ink may be listed as the second or third most likely ink by PLSDA. This is also true for outputs from ATR-FTIR in which inks of the same group (based on presence and absence of absorption bands) have identical ATR-FTIR output spectra. For KNN classification, a correct classification was determined if the duplicate was listed as any of the top ten nearest spectra. Table 17 summarizes the performance of the database for ATR-FTIR and DART-MS, assessing the correct classification of duplicate control outputs that were analyzed on different days and/or by different operators/instruments.

The results show that the database performs robust ink classification, dependent on the analytical technique, which mirrors the outcome of spectral overlay performed by analysts. The validation study of the database algorithms using double-blind searches of duplicate controls show that ATR-FTIR data searches result in $>90$ to $100 \%$ of duplicate pairs correctly associated for both toner and offset inks. The DART-MS data search results in $75-100 \%$ correct association of duplicate controls for all ink types. The less than $90 \%$ correct association is a result of the variation of replicate measurements from DART-MS, and resulted in inks from the same printer cartridge, but of different colors being incorrectly associated with one another, similar to the misclassification using spectral overlay. 


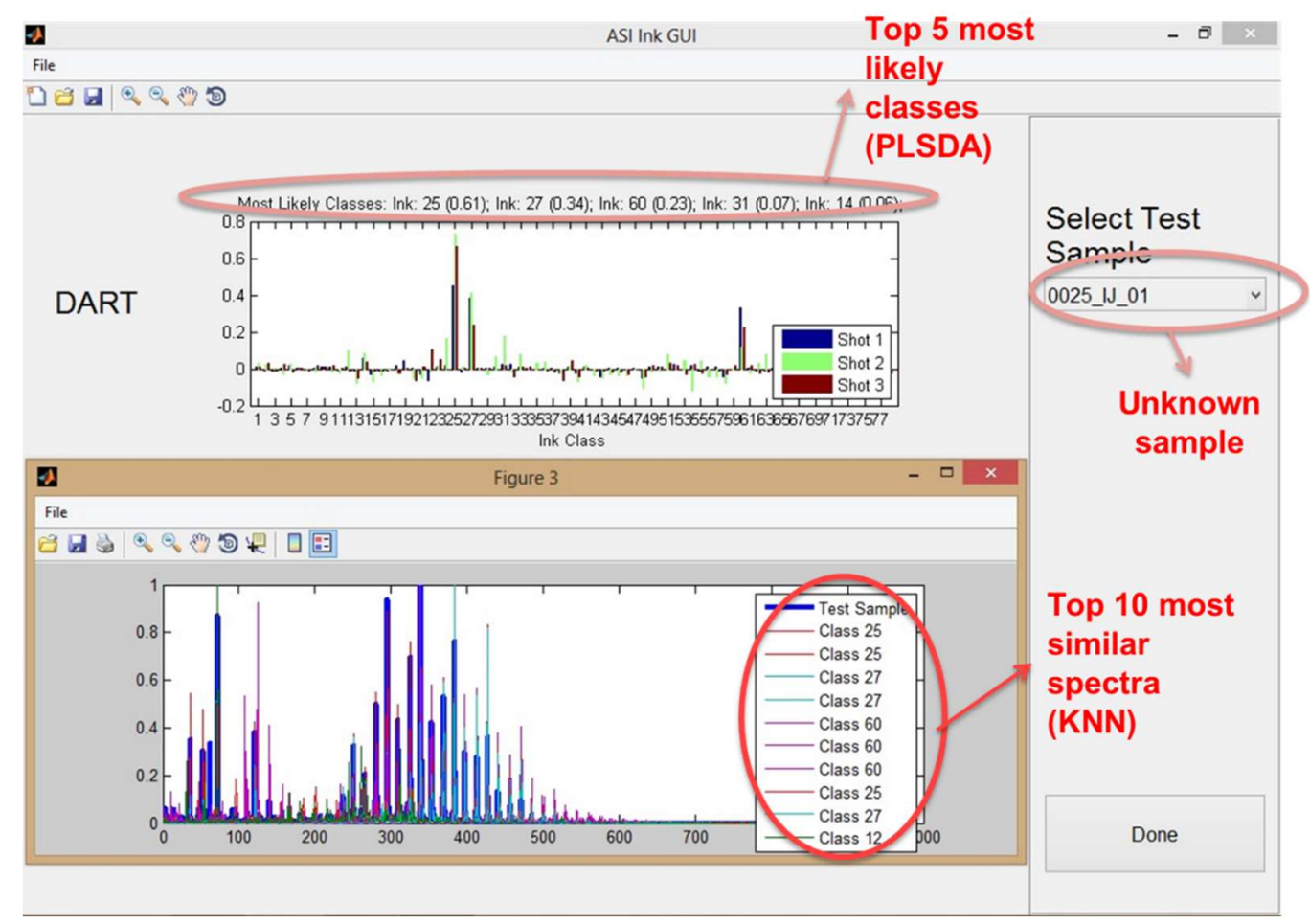

Figure 63- Database output for a comparison of DART-MS data for an inkjet sample against the reference databased illustrating the PLSDA top 5 most likely classes, the PLSDA visualization output, KNN spectral comparison, and the KNN top 10 most similar spectra

\subsection{Conclusion}

Overall, a printing ink chemical database and search software were successfully developed, utilizing and fusing the data output from multiple analytical techniques including ATR-FTIR and DART-MS. The database contains a fairly representative sample selected from various printing sources to account for global diversity. Though in the validation stage, as the database continues to be evaluated by more users, and more sample entries added, this will improve the overall performance and classification function of the database. The database is currently limited by the number of samples, the limited number of replicate per samples, and the variation in quality of data from each output. As the methodologies continue to be developed, as well as more data is 
generated, this will allow for more confidence in the match outputs for the database and allow it to become an effective tool in the association and discrimination of printing inks for uses in questioned document examination.

Table 17- Comparison of match criteria for ATR-FTIR and DART-MS for association of duplicate controls, using database algorithms

\begin{tabular}{|c|c|c|c|c|c|}
\hline & Match Criteria & Toner & Inkjet & Intaglio & Offset \\
\hline \multirow[t]{3}{*}{ ATR-FTIR } & Spectral & $\begin{array}{l}100 \% \text { ( } 20 \text { out } \\
\text { of } 20)\end{array}$ & & & $\begin{array}{l}100 \%(13 \\
\text { out of } 13)\end{array}$ \\
\hline & PLSDA (top 5) & $\begin{array}{l}100 \% \text { ( } 20 \text { out } \\
\text { of } 20)\end{array}$ & & & $\begin{array}{l}100 \%(13 \\
\text { out of } 13)\end{array}$ \\
\hline & $\begin{array}{l}\text { KNN (10 } \\
\text { Spectra) }\end{array}$ & $\begin{array}{l}100 \% \text { ( } 20 \text { out } \\
\text { of } 20)\end{array}$ & & & $\begin{array}{l}100 \%(13 \\
\text { out of } 13)\end{array}$ \\
\hline \multirow[t]{3}{*}{ DART-MS } & Spectral & $\begin{array}{l}100 \%(1 \text { out } \\
\text { of } 1)\end{array}$ & $\begin{array}{l}100 \%(4 \\
\text { out of } 4)\end{array}$ & $\begin{array}{l}100 \% \text { ( } 6 \text { out } \\
\text { of } 6)\end{array}$ & $\begin{array}{l}100 \% \text { (6 out } \\
\text { of } 6)\end{array}$ \\
\hline & PLSDA (top 5) & $\begin{array}{l}100 \%(1 \text { out } \\
\text { of } 1)\end{array}$ & $\begin{array}{l}100 \%(4 \\
\text { out of } 4)\end{array}$ & $\begin{array}{l}83 \%(5 \text { out } \\
\text { of } 6)\end{array}$ & $\begin{array}{l}83 \% \text { (5 out } \\
\text { of } 6)\end{array}$ \\
\hline & $\begin{array}{l}\text { KNN (10 } \\
\text { Spectra) }\end{array}$ & $\begin{array}{l}100 \%(1 \text { out } \\
\text { of } 1)\end{array}$ & $\begin{array}{l}100 \% 4 \text { out } \\
\text { of } 4)\end{array}$ & $\begin{array}{l}33 \%(2 \text { out } \\
\text { of } 6)\end{array}$ & $\begin{array}{l}67 \%(4 \text { out } \\
\text { of } 6)\end{array}$ \\
\hline
\end{tabular}




\section{CHAPTER 11. OVERALL CONCLUSIONS}

The forensic utility of each analytical technique to characterize the organic composition of printing inks was evaluated. It was determined that each of the analytical techniques included within the scope of this dissertation provide complimentary information that can be useful for the association of printing inks from common sources and discrimination of printing inks from different sources, to varying degrees.

The goal of the work included within this dissertation was to: 1) determine the utility of Py-GC/MS, ATR-FTIR, DART-MS, and MALDI-MS to characterize the organic composition of four classes of printing inks directly on a paper substrate: inkjet, toner, offset, and intaglio, 2) calculate the capability of each technique to discriminate inks from different sources, 3) determine the complementarity of implementing more than one of the aforementioned techniques in a protocol for the analysis of printing inks. A summary of the parameters, data output, and discrimination capability of each analytical technique can be seen in Table 18 .

Py-GC/MS, a mature technique for the analysis of printing inks, can be useful on a case-by-case basis for the individual analysis of printing inks, particularly toners. Its long analysis time, destructive nature, and poor reproducibility does not lend itself well to routine analysis of printing inks or the goals of the protocol developed as a part of this dissertation. For inkjet inks, a low pyrolysis temperature was used in order to prevent burning of the paper substrate, and in fact, instead of true pyrolysis, thermal desorption of the volatile components of the inks was performed. However, this method produced useful chemical information for ink samples manually deposited on paper and did not 
allow for characterization of printed inkjet samples. The effective analysis of toner ink samples by Py-GC/MS required the transfer of the toner ink to an aluminum foil substrate in order to avoid pyrograms dominated by peaks due to paper background contribution. The Py-GC/MS analysis of toner inks allowed for the characterization of the polymer content of the inks, due to observation of polymer pyrolysis breakdown products, or pyrolates. Overall, Py-GC/MS analysis allowed for a discrimination rate of $63.9 \%$ for toner inks. The Py-GC/MS analysis of offset and intaglio inks did not provide useful information due to inability to transfer samples to aluminum substrate, strong paper background contribution, and inability to determine in chromatographic peaks were due to ink or contaminants.

ATR-FTIR is another mature technique routinely implemented for the analysis of inks on paper. However, the work performed within this dissertation is the first to determine the performance of ATR-FTIR for the analysis of such a comprehensive collection of ink samples from four different classes. The ability of ATR-FTIR to produce useful chemical information is highly dependent on the manner through which the ink is deposited on the paper substrate due to the ATR beam penetrating below the surface of a sample $\sim 5 \mu \mathrm{m}$. Therefore, ATR-FTIR proved to be very useful in the analysis of both toner and offset ink samples, which form a layer above the surface of the paper substrate. ATR-FTIR characterizes the bulk molecular composition of substance, and therefore the molecules which make up the highest percent composition in a mixture will dominate the resultant FTIR spectra. In the case of toners, the bulk composition of this class of inks is made up of polymers and that is confirmed by ATR-FTIR analysis. 
The presence of absorption bands corresponding to polymers commonly found in toner inks such as polystyrene, acrylate, epoxy, and polyester was observed. With this information, the toner samples were able to be differentiated into groups based on presence and absence of absorption bands in the FTIR spectra, and thus were grouped based on the similarity in polymer composition. Since the colorant molecules in toner inks is a trace component, absorption bands due to these molecules were not observed. However, in offset inks, after subtraction of the blank paper background contribution, ATR-FTIR allowed for the discrimination of offset inks by color, even colors that are visually indistinguishable, such as red and magenta. This allows for the conclusion that the ATR-FTIR spectra of offset inks are dominated by absorption bands that correspond to the colorant molecules. The FTIR spectra of intaglio ink samples were dominated by absorption bands corresponding to cellulose or derivatives, due to paper background contribution and/or common cellulose components in the composition of the inks. The ATR-FTIR analysis of inkjet inks did not provide any useful information, as spectra acquired of the ink samples were identical to those of the blank paper background. This is due to the deep penetration of the inkjet ink into the paper fiber. Overall, ATR-FTIR allowed for a discrimination rate of $92.6 \%$ for offset and $86.3 \%$ for toner samples.

DART-MS is a relatively newly developed analytical technique, and only its application to the analysis of inkjet inks has been reported in the literature. Therefore, the analyses performed as a part of this dissertation would be the first to apply DARTMS to toner, offset, and intaglio inks. The biggest obstacle to overcome in developing a robust DART-MS method for the analysis of the four classes of printing inks directly on 
paper was optimizing the ionization temperature while limiting any physical changes, such as melting, that could destroy the sample and reduce the quality of the output mass spectra. DART-MS is most useful in desorbing and ionizing neutral, semi-volatile molecules that do not fragment or degrade upon being exposed to the DART gas stream. The ink component that fits this description is the vehicle/plasticizer/solvent polymer polyethylene and polypropylene glycol that is commonly found in printing ink formulation. Inkjet inks contain a higher percent composition of this component as compared to the other three ink classes, and thus the DART-MS of inkjets provided the most comprehensive information. Based on the presence and absence of differing polymeric fragments associated with polyethylene and polypropylene glycol molecules present in the inkjets, $91.3 \%$ of inkjet inks from different sources were correctly discriminated based on DART-MS spectra. Since toner, offset, and intaglio contain minimal semi-volatile polymeric components as compared to inkjet inks, DART-MS was less effective at discriminating inks from different sources. Overall, DART-MS analysis provided a discrimination rate of $81.8 \%$ for toners, $56.1 \%$ for offset, and $48.6 \%$ for intaglio ink samples.

A case study implementing DART-MS in a questioned document scenario was performed as a facet of this dissertation. It was shown that DART-MS allows for the association of inks from common sources and discrimination of inks from different sources present on documents in which the authenticity is questioned. Though a small case study, the investigation performed here shows great promise for the implementation 
of DART-MS in a protocol for the routine analysis of inks in questioned document examination.

MALDI-MS has been well documented as a valid method of analyzing inks directly from a paper substrate. MALDI-MS analyses have been limited to writing inks and inkjet printing inks, and thus the work performed as a part of this dissertation is the first time MALDI-MS has been applied to a comprehensive sample set of inkjet, toner, offset, and intaglio inks. It was determined that utilizing a liquid matrix prior to analysis improves the quality of MALDI-MS spectra and allows for a desorption and ionization of a wider variety of molecules, most significantly colorant molecules that exist in an anionic and/or cationic form in the ground state. The MALDI-MS method utilized as a part of this dissertation allowed for the direct analysis of inkjet, toner, offset, and intaglio ink samples directly on a paper substrate. Colorant molecules were successfully characterized for all of the inks analyzed as a part of the subset included in the MALDIMS study. Two different MALDI-MS instruments were utilized and it was shown that the method is applicable to the analysis of inks, regardless of the instrument. Overall, MALDI-MS allowed for $>90 \%$ discrimination of inks originating from different sources based on characterization of the colorant molecule used in the ink formulation.

The applicability of MALDI-MS to determine the sequence of deposition of inks in crossed-line intersections was also evaluated as a portion of this dissertation. Though the sequence of deposition was not able to be determined based on MALDI-MS analysis, the individual component inks of the crossed-line intersections, thus existing in a mixture, were able to be characterized and isolated. The application of MALDI-MS to inks in a 
mixture is otherwise unreported in the literature. Therefore, it was determined that MALDI-MS allows for the characterization of individual inks present in mixtures, which is useful in document examination for association of common inks and discrimination of inks from different sources.

The printing ink database developed as a part of this dissertation was the first of its kind to combine data output from multiple analytical techniques, including ATR-FTIR and DART-MS, and fusing these data to allow for improved association of unknown inks. The duplicate control studies performed served as a first step validation for the utility of this database to be implemented in forensic labs who can use the analytical protocols developed, and utilize the database as a means of comparison of unknown inks. The development of this database acts as a starting point, allowing for the addition of more ink samples to improve the overall utility as a forensic classification tool.

Another novel aspect of this dissertation is the combination of the various analytical techniques described here to obtain complimentary information for the improved association of common inks and discrimination of inks from different sources. It was shown that a protocol involving first ATR-FTIR and then subsequent DART-MS analysis resulted in $>96 \%$ discrimination for toner inks, $95 \%$ for inkjet inks, $>92 \%$ for offset inks, and $>54 \%$ for intaglio inks. The information that MALDI-MS analysis provides, complimentary to the information from the two aforementioned techniques, can improve association and discrimination of printing inks based on characterization of the colorant molecules present in ink formulations. Py-GC/MS is limitedly useful, but can provide beneficial information on the polymeric content of toner inks on a case by case 
basis. Overall, the work within this dissertation shows that the combination of analytical techniques Py-GC/MS, ATR-FTIR, DART-MS, and MALDI-MS can be implemented in a protocol for the analysis of printing inks from four classes (inkjet, toner, offset, and intaglio) to obtain information on the characterization of the organic chemical composition for association of common inks and discrimination of inks from different sources for implementation in document examination in forensic laboratories. The protocols developed here, along with the searchable ink library database, provide useful information in the area of ink analysis. 
Table 18-Comparison of analytical techniques included within this dissertation as well as discrimination capability for each ink class

\begin{tabular}{|c|c|c|c|c|}
\hline & ATR-FTIR & Py-GC/MS & DART-MS & MALDI-MS \\
\hline $\begin{array}{l}\text { Chemical } \\
\text { Information }\end{array}$ & $\begin{array}{l}\text { Polymers, } \\
\text { pigments }\end{array}$ & $\begin{array}{l}\text { Polymer } \\
\text { breakdown } \\
\text { products, } \\
\text { volatiles }\end{array}$ & $\begin{array}{l}\text { Semi-volatile } \\
\text { components, } \\
\text { solvent, } \\
\text { plasticizer }\end{array}$ & Pigment/dye \\
\hline $\begin{array}{l}\text { Sample } \\
\text { Penetration }\end{array}$ & $\begin{array}{l}\text { Surface, } \\
<5 \mu \mathrm{m}\end{array}$ & $\begin{array}{l}\text { Bulk, sample } \\
\text { consumed }\end{array}$ & Surface & Surface \\
\hline $\begin{array}{l}\text { Sampling } \\
\text { Area }\end{array}$ & $2500 \mu \mathrm{m}^{2}$ & $10 \mathrm{~mm}^{2}$ & $7.5 \mathrm{~mm}^{2}$ & $20 \mu \mathrm{m}^{2}$ \\
\hline Discrimination & & & & \\
\hline Inkjet $(n=78)$ & $49.5 \%$ & & $91.3 \%$ & $\begin{array}{l}\mathrm{n}=20,92.0 \% \\
\mathrm{n}=10,100 \%\end{array}$ \\
\hline Toner $(n=76)$ & $86.3 \%$ & $63.9 \%$ & $81.8 \%$ & $\begin{array}{l}\mathrm{n}=28,91.0 \% \\
\mathrm{n}=10,91.1 \%\end{array}$ \\
\hline Offset $(n=79)$ & $92.6 \%$ & & $56.1 \%$ & $\begin{array}{l}\mathrm{n}=20,93.0 \% \\
\mathrm{n}=10,97.7 \%\end{array}$ \\
\hline $\begin{array}{l}\text { Intaglio }(\mathrm{n}= \\
86)\end{array}$ & $33.6 \%$ & & $48.6 \%$ & $\mathrm{n}=10,91.1 \%$ \\
\hline
\end{tabular}




\section{REFERENCES}

1. Chaudhry P, Zimmerman A. The global growth of counterfeit trade. In: Springer; 2013. p. 7-31.

2. Williams MM, Anderson RG. Currency design in the united states and abroad: Counterfeit deterrence and visual accessibility. Review. 2007;89.

3. Counterfeit currency and security documents [Internet].; 2016. Available from: http://www.interpol.int/Crime-areas/Financial-crime/Counterfeit-currency-and-securitydocuments/Project-S-Print.

4. LaPorte GM, Stephens JC. Analysis techniques used for the forensic examination of writing and printing inks. In: Kobilinsky L, editor. John Wiley \& Sons; 2012.

5. LaPorte GM. Modern approaches to the forensic analysis of inkjet printing-physical and chemical examinations. J.Am.Soc.Question.Doc.Exam. 2004;7:22-35.

6. Carvalho DN. Forty centuries of ink: Or, A chronological narrative concerning ink and its backgrounds, introducing incidental observations and deductions, parallels of time and color phenomena, bibliography, chemistry, poetical effusions, citations, anecdotes and curiosa together with some evidence respecting the evanescent character of most inks of to-day and an epitome of chemico-legal ink. Banks law publishing Company; 1904.

7. Interpol. 17th international forensic science symposium: 2010-2013. 2013.

8. Council NR. Strengthening forensic science in the united states: A path forward. . 2009.

9. Report to the president: Forensic science in criminal courts: Ensuring scientific validity of feature-comparison methods. 2016.

10. Tebbett IR. Chromatographic analysis of inks for forensic science applications. Forensic Sci Rev. 1991;3(2):71-82.

11. Neumann C, Ramotowski R, Genessay T. Forensic examination of ink by highperformance thin layer chromatography--the united states secret service digital ink library. J Chromatogr A. 2011 May 13,;1218(19):2793-811.

12. Leach RH, Pierce RJ. The printing ink manual. 5th ed. The Netherlands: Springer; 1993.

13. Herbst W, Hunger K. Industrial organic pigments: Production, properties, applications.(VCH. 2004. 
14. Venkataraman K. The analytical chemistry of synthetic dyes. New York: Wiley; 1977.

15. Aginsky V. Forensic examination of "Slightly soluble" ink pigments using thin-layer chromatography. . 1993.

16. Santimauro JF. An introduction to copper phthalocyanine pigments. Dyestuffs. 1960;43:158-63.

17. Donnelly S, Marrero JE, Cornell T, Fowler K, Allison J. Analysis of pigmented inkjet printer inks and printed documents by laser desorption/mass spectrometry. J Forensic Sci. 2010 January;55(1):129-35.

18. Houlgrave S, LaPorte GM, Stephens JC. The use of filtered light for the evaluation of writing inks analyzed using thin layer chromatography. J Forensic Sci. 2011 May;56(3):778-82.

19. Horton R. Identifiability of the flatbed scanner and its products GraphicsFiles and printed results. The American Society of Questioned Document Examiners. 2000;3(1):41-5.

20. Chen H, Meng H, Cheng K. A survey of methods used for the identification and characterization of inks. Forensic Sci Int. 2002;1:1-14.

21. Bauer GT. The use of partially transparent plates to increase the contrast of images. Appl Opt. 1966;5(9):1361-4.

22. Kaur R, Saini K, Sood NC. Application of video spectral comparator (absorption spectra) for establishing the chronological order of intersecting printed strokes and writing pen strokes. Sci Justice. 2013 June;53(2):212-9.

23. Roux C, Novotny M, Evans I, Lennard C. A study to investigate the evidential value of blue and black ballpoint pen inks in australia. Forensic Sci Int. 1999;101:167-76.

24. Brunelle RL, Pro MJ. A systematic approach to ink identification. Journal of the Association of Official Analytical Chemists. 1972;55(4):823-6.

25. Sinor TW, Wilde JP, Everse KE, Menzel ER. Lasers and optical spectroscopy in questioned document examination. J Forensic Sci. 1986;31(3):825-39.

26. Cantu AA. Comments on the accelerated aging of ink. J Forensic Sci. 1988.

27. Sensi CA, Cantu AA. Infrared luminescence: Is it a valid method to differentiate among inks? J Forensic Sci. 1982;27(1):196-9. 
28. Cantu AA. Analytical methods for detecting fraudulent documents. Anal Chem. 1991;63(17):854A.

29. Neumann C, Margot P. New perspectives in the use of ink evidence in forensic science part II. development and testing of mathematical algorithms for the automatic comparison of ink samples analysed by HPTLC. Forensic Sci Int. 2009 March 10,;185(13):38-50.

30. Tholl J. Police. 1960.

31. Schwerin K. Journal of criminal law, criminology and police science. 1910-1960. A brief historical note. J Crim Law, Criminolog, and Pol Sci. 1960;51(1):4-6.

32. Poon NL, Ho SSH, Li CK. Differentiation of coloured inks of inkjet printer cartridges by thin layer chromatography and high performance liquid chromatography. Science \& Justice. 2005;45(4):187-94.

33. Ramotowski RS, Regen EM. Effect of electron beam irradiation on forensic evidence. 2. analysis of writing inks on porous surfaces. J Forensic Sci. 2007 May;52(3):604-9.

34. Pagano LW, Surrency MJ, Cantu AA. Inks: Forensic analysis by thin-layer (planar) chromatography. 2000.

35. Kelley JD, Cantu AA. Proposed standard methods for ink identification. J Assoc Offic Anal Chem. 1975;58(1):122-5.

36. ASTM. Standard guide for test methods for forensic writing ink comparison E1422.

37. Neumann C, Margot P. Considerations on the ASTM standards 1789-04 and 1422-05 on the forensic examination of ink. J Forensic Sci. 2010 September;55(5):1304-10.

38. Cantu AA. A sketch of analytical methods for document dating. part I. the static approach: Determining age independent analytical profiles. Int J Forensic Doc Exam. 1995;1(1):40-51.

39. Cantu AA, Crown DA, Brunelle RL. The parameters of ballpen ink examinations. J Forensic Sci. 1976;21(4):917-22.

40. Brunelle RL. Advances in the forensic analysis and dating of writing ink. Charles $\mathrm{C}$ Thomas; 2003.

41. Verma RS, Prasad KN, Misra GJ. Thin-layer chromatographic analysis of fibre-tip pen inks. Forensic Sci Int. 1979;13:65-70. 
42. Tappolet JA. The high-performance thin layer chromatography (HPTLC). its application to the examination of writing inks. Forensic Sci Int. 1983;22(2-3):99-109.

43. Blackledge RD, Iwan M. Differentiation between inks of the same brand by infrared luminescence photography of their thin-layer chromatograms. Forensic Sci Int. $1983 ; 21(2): 165-73$.

44. Ordidge M, Totty RN. The examination of ink writing on photographic paper. J Forensic Sci Soc. 1984;24(1):43-7.

45. Laporte GM, Arredondo MD, McConnell TS, Stephens JC, Cantu AA, Shaffer DK. An evaluation of matching unknown writing inks with the united states international ink library. J Forensic Sci. 2006 May;51(3):689-92.

46. Aginsky VN. Using TLC and GC-MS to determine whether inks came from the same manufacturing batch. . 2006.

47. Gallidabino M, Weyermann C, Marquis R. Differentiation of blue ballpoint pen inks by positive and negative mode LDI-MS. Forensic Sci Int. 2011 January 30,;204(1-3):16978.

48. Weyermann C, Kirsch D, Costa-Vera C, Spengler B. Photofading of ballpoint dyes studied on paper by LDI and MALDI MS. J Am Soc Mass Spectrom. 2006 March;17(3):297-306.

49. Levy EJ, Wampler TP. Applications of pyrolysis gas chromatography/mass spectrometry to toner materials from photocopiers. J Forensic Sci. 1986;31(1):258-71.

50. Merrill RA, Bartick EG, Mazzella WD. Studies of techniques for analysis of photocopy toners by IR. J Forensic Sci. 1996;41:264-71.

51. Egan WJ, Galipo RC, Kochanowski BK, Morgan SL, Bartick EG, Miller ML, et al. Forensic discrimination of photocopy and printer toners. III. multivariate statistics applied to scanning electron microscopy and pyrolysis gas chromatography/mass spectrometry. Anal Bioanal Chem. 2003 August;376(8):1286-97.

52. Mooney D, Zimmerman J, Kimmett MJ. Preliminary examination of machine copier toners by infrared spectrophotometry and pyrolysis gas chromatography. J Forensic Sci. 1986;31(2):489-93.

53. Partouche F, Espanet B, Villena C, Murie C. In: Forensic analysis of inkjet printings by pyrolysis GC/MS. Society for Imaging Science and Technology; 2005. p. 216-9.

54. Chiavari G, Montalbani S, Prati S, Keheyan Y, Baroni S. Application of analytical pyrolysis for the characterisation of old inks. J Anal Appl Pyrolysis. 2007;80(2):400-5. 
55. Keheyan Y, Eliazyan G, Engel P, Rittmeier B. Py/GC/MS characterisation of naturally and artificially aged inks and papers. J Anal Appl Pyrolysis. 2009;86(1):192-9.

56. Humecki H. In: Experiments in ballpoint ink aging using infrared spectroscopy. Proceedings of international symposium on non-handwriting aspects of questioned document examination; ; 1985. p. 131-5.

57. Bartick EG, Merrill RA. Analysis of ballpoint pen inks by diffuse reflectance infrared spectrometry. J Forensic Sci. 1992;37(2):528-41.

58. Fuller MP, Griffiths PR. Diffuse reflectance measurements by infrared fourier transform spectrometry. Anal Chem. 1978;50(13):1906-10.

59. Lennard CJ, Mazzella WD. A simple combined technique for the analysis of toners and adhesives. J Forensic Sci Soc. 1991.

60. Merrill RA, Bartick EG, Taylor JH, 3. Forensic discrimination of photocopy and printer toners I. the development of an infrared spectral library. Anal Bioanal Chem. 2003 August;376(8):1272-8.

61. Shaffer DK, Zlotnick JA. In: Forensic analysis and databasing of toners and inkjet inks used in the production of fraudulent documents. Society for Imaging Science and Technology; 2008. p. 777-80.

62. Assis AA, Barbosa MF, Nabais JV, Custódio AF, Tropecelo P. Diamond cell fourier transform infrared spectroscopy transmittance analysis of black toners on questioned documents. Forensic Sci Int. 2012;214(1):59-66.

63. Kivioja A, Hartus T, Vuorinen T, Gane P, Jaaskelainen AS. Use of total internal reflection raman (TIR) and attenuated total reflection infrared (ATR-IR) spectroscopy to analyze component separation in thin offset ink films after setting on coated paper surfaces. Appl Spectrosc. 2013 June;67(6):661-71.

64. Vila A, Ferrer N, Mantecón J, Bretón D, García JF. Development of a fast and nondestructive procedure for characterizing and distinguishing original and fake euro notes. Anal Chim Acta. 2006;559(2):257-63.

65. Chen H, Gamez G, Zenobi R. What can we learn from ambient ionization techniques? J Am Soc Mass Spectrom. 2009 November;20(11):1947-63.

66. Cody RB, Laramée J,A., Durst HD. Versatile new ion source for the analysis of materials in open air under ambient conditions. Anal Chem. 2005;77(8):2297-302.

67. Adams J. Analysis of printing and writing papers by using direct analysis in real time mass spectrometry. Int J Mass Spectrom. 2011;301(1-3):109-26. 
68. Jones RW, Cody RB, McClelland JF. Differentiating writing inks using direct analysis in real time mass spectrometry. J Forensic Sci. 2006 July;51(4):915-8.

69. Jones RW, McClelland JF. Analysis of writing inks on paper using direct analysis in real time mass spectrometry. Forensic Sci Int. 2013 September 10,;231(1-3):73-81.

70. Houlgrave S, LaPorte GM, Stephens JC, Wilson JL. The classification of inkjet inks using AccuTOF DART (direct analysis in real time) mass spectrometry--a preliminary study. J Forensic Sci. 2013 May;58(3):813-21.

71. Williamson R, Raeva A, Almirall JR. Characterization of printing inks using DARTQ-TOF-MS and attenuated total reflectance (ATR) FTIR. J Forensic Sci. 2016;61(3):70614.

72. Grim DM, Siegel J, Allison J. Evaluation of desorption/ionization mass spectrometric methods in the forensic applications of the analysis of inks on paper. J Forensic Sci. 2001;46(6):1411-20.

73. Siegel J, Allison J, Mohr D, Dunn J. The use of laser desorption/ionization mass spectrometry in the analysis of inks in questioned documents. Talanta. 2005 August $15, ; 67(2): 425-9$.

74. Shankai Z, Feng Z, Weide H, Zhongping Y, Hanhui W. Matrix-assisted laser desorption and fast-atom bombardment mass spectrometry of water-soluble phthalocyanines and their carboxyl derivatives. Rapid Comm Mass Spectrom. 1995;9(3):230-2.

75. Soltzberg LJ, Hagar A, Kridaratikorn S, Mattson A, Newman R. MALDI-TOF mass spectrometric identification of dyes and pigments. J Am Soc Mass Spectrom. 2007;18(11):2001-6.

76. Allison J. Ink analysis using UV laser desorption mass spectrometry. In: Blackledge RD, editor. Wiley \& Sons; 2007.

77. Dunn JD, Allison J. The detection of multiply charged dyes using matrix-assisted laser desorption/ionization mass spectrometry for the forensic examination of pen ink dyes directly from paper. J Forensic Sci. 2007 September;52(5):1205-11.

78. Matthews B, Walker GS, Kobus H, Pigou P, Bird C, Smith G. The analysis of dyes in ball point pen inks on single paper fibres using laser desorption ionisation time of flight mass spectrometry (LDI-TOFMS). Forensic Sci Int. 2011 June 15,;209(1-3):26.

79. Heudt L, Debois D, Zimmerman TA, Kohler L, Bano F, Partouche F, et al. Raman spectroscopy and laser desorption mass spectrometry for minimal destructive forensic 
analysis of black and color inkjet printed documents. Forensic Sci Int. 2012 June 10,;219(1-3):64-75.

80. Hanton SD. Mass spectrometry of polymers and polymer surfaces. Chem Rev. 2001;101(2):527-70.

81. Milosevic M. Internal reflection and ATR spectroscopy. 1. Aufl. ed. US: Wiley; 2012.

82. Chang WC, Huang LCL, Wang Y, Peng W, Chang HC, Hsu NY, et al. Matrixassisted laser desorption/ionization (MALDI) mechanism revisited. Anal Chim Acta. 2007;582(1):1-9.

83. Hoffmann Ed, Stroobant V. Mass spectrometry: Principles and applications. 1996.

84. Knochenmuss R. Ion formation mechanisms in UV-MALDI. Analyst. 2006;131(9):966-86.

85. Trejos T, Corzo R, Subedi K, Almirall J. Characterization of toners and inkjets by laser ablation spectrochemical methods and scanning electron microscopy-energy dispersive X-ray spectroscopy. Spectrochim Acta Part B: Atom Spectrosc. 2014;92:9-22.

86. Kasas S, Khanmy-Vital A, Dietler G. Examination of line crossings by atomic force microscopy. Forensic Sci Int. 2001;119:290-8.

87. Ozbek N, Braz A, López-López M, García-Ruiz C. A study to visualize and determine the sequencing of intersecting ink lines. Forensic Sci Int. 2014 Jan;234(C):3944.

88. Wang Y, Li B. Determination of the sequence of intersecting lines from laser toner and seal ink by fourier transform infrared microspectroscopy and scanning electron microscope / energy dispersive X-ray mapping. Sci Justice. 2012 June;52(2):112-8.

89. Spagnolo GS. Potentiality of 3D laser profilometry to determine the sequence of homogenous crossing lines on questioned documents. Forensic Sci Int. 2006 December $20 ; ; 164(2-3): 102-9$.

90. Bojko K, Roux C, Reedy BJ. An examination of the sequence of intersecting lines using attenuated total reflectance-fourier transform infrared spectral imaging. J Forensic Sci. 2008 November;53(6):1458-67.

91. Weyermann C, Marquis R, Mazzella W, Spengler B. Differentiation of blue ballpoint pen inks by laser desorption ionization mass spectrometry and high-performance thinlayer chromatography. J Forensic Sci. 2007 January;52(1):216-20. 
92. Bruton S, Childers D. The ethics and politics of policing plagiarism: A qualitative study of faculty views on student plagiarism and turnitin ${ }^{\circledR}$. Assess \& Eval Higher Ed. 2016;41(2):316-30.

93. Ng L, Brazeau L, Lafontaine P. Ballpoint pen inks: Characterization by positive and negative ion-electrospray ionization mass spectrometry for the forensic examination of writing inks. J Forensic Sci. 2002;47(6):1238-47.

94. Wold S, Sjstrm M, Eriksson L. PLS-regression: A basic tool of chemometrics. Chemometrics Intellig Lab Syst. 2001;58(2):109-30.

95. Wan KX, Vidavsky I, Gross ML. Comparing similar spectra: From similarity index to spectral contrast angle. J Am Soc Mass Spectrom. 2002;13(1):85-8. 


\section{APPENDICES}

Appendix 1- Description of printing ink samples analyzed in this dissertation

\begin{tabular}{|c|c|c|c|c|}
\hline Sample ID & Brand/Country & $\begin{array}{l}\text { Additional } \\
\text { Information }\end{array}$ & Color & Sample Form \\
\hline $\begin{array}{l}\text { IJ 01 K } \\
\text { BR }\end{array}$ & Brother & LC61BK & Black & $\begin{array}{l}\text { 1-layer printout, } \\
\text { Whatman } 42\end{array}$ \\
\hline $\begin{array}{l}\text { IJ 02 K } \\
\text { CN }\end{array}$ & Canon & 210 & Black & $\begin{array}{l}\text { manually deposited, } \\
\text { 1-layer printout, } \\
\text { Whatman } 42\end{array}$ \\
\hline $\begin{array}{l}\text { IJ 03 K } \\
\text { CN }\end{array}$ & Canon & 50 & Black & $\begin{array}{l}\text { cartridge, manually } \\
\text { deposited, Whatman } \\
42\end{array}$ \\
\hline $\begin{array}{l}\text { IJ 04 Y } \\
\text { CN }\end{array}$ & Canon & 51 & Yellow Tri-Color & $\begin{array}{l}\text { cartridge, manually } \\
\text { deposited, Whatman } \\
42\end{array}$ \\
\hline $\begin{array}{l}\text { IJ 05 M } \\
\text { CN }\end{array}$ & Canon & 51 & $\begin{array}{l}\text { Magenta Tri- } \\
\text { Color }\end{array}$ & $\begin{array}{l}\text { cartridge, manually } \\
\text { deposited, Whatman } \\
42\end{array}$ \\
\hline $\begin{array}{l}\text { IJ 06 C } \\
\text { CN }\end{array}$ & Canon & 51 & Cyan Tri-Color & $\begin{array}{l}\text { cartridge, manually } \\
\text { deposited, Whatman } \\
42\end{array}$ \\
\hline $\begin{array}{l}\text { IJ 07 K } \\
\text { EP }\end{array}$ & Epson & $676 \times 1$ & Black & $\begin{array}{l}\text { cartridge, liquid in } \\
\text { vial, manually } \\
\text { deposited, Whatman } \\
42\end{array}$ \\
\hline $\begin{array}{l}\text { IJ 08 C } \\
\text { EP }\end{array}$ & Epson & $676 \times 1$ & Cyan & $\begin{array}{l}\text { cartridge, liquid in } \\
\text { vial, manually } \\
\text { deposited, Whatman } \\
42\end{array}$ \\
\hline $\begin{array}{l}\text { IJ 09 M } \\
\text { EP }\end{array}$ & Epson & $676 x 1$ & Magenta & $\begin{array}{l}\text { cartridge, liquid in } \\
\text { vial, manually } \\
\text { deposited, Whatman } \\
42\end{array}$ \\
\hline $\begin{array}{l}\text { IJ } 10 \mathrm{Y} \\
\text { EP }\end{array}$ & Epson & $676 x 1$ & Yellow & $\begin{array}{l}\text { cartridge, liquid in } \\
\text { vial, manually } \\
\text { deposited, Whatman } \\
42\end{array}$ \\
\hline $\begin{array}{l}\text { IJ } 11 \mathrm{~K} \\
\text { EP }\end{array}$ & Epson & T032120 & Black & $\begin{array}{l}\text { cartridge, liquid in } \\
\text { vial, 1-layer printout, } \\
\text { Whatman } 42\end{array}$ \\
\hline
\end{tabular}




\begin{tabular}{|c|c|c|c|c|}
\hline Sample ID & Brand/Country & $\begin{array}{l}\text { Additional } \\
\text { Information }\end{array}$ & Color & Sample Form \\
\hline $\begin{array}{l}\text { IJ } 12 \text { K } \\
\text { HP }\end{array}$ & Hewlett Packard & 564 & Black & $\begin{array}{l}\text { 1-layer printout, } \\
\text { Whatman } 42\end{array}$ \\
\hline $\begin{array}{l}\text { IJ } 13 \mathrm{~K} \\
\text { HP }\end{array}$ & Hewlett Packard & 940 & Black & $\begin{array}{l}\text { 1-layer printout, } \\
\text { Whatman } 42\end{array}$ \\
\hline $\begin{array}{l}\text { IJ } 14 \text { K } \\
\text { HP }\end{array}$ & Hewlett Packard & 60 & Black & $\begin{array}{l}\text { 1-layer printout, } \\
\text { Whatman } 42\end{array}$ \\
\hline $\begin{array}{l}\text { IJ } 15 \mathrm{~K} \\
\text { HP }\end{array}$ & Hewlett Packard & $901 \times 1$ & Black & $\begin{array}{l}\text { 1-layer printout, } \\
\text { Whatman } 42\end{array}$ \\
\hline $\begin{array}{l}\text { IJ } 16 \mathrm{~K} \\
\text { HP }\end{array}$ & Hewlett Packard & 74 & Black & $\begin{array}{l}\text { 1-layer printout, } \\
\text { Whatman } 42\end{array}$ \\
\hline $\begin{array}{l}\text { IJ } 17 \mathrm{~K} \\
\text { HP }\end{array}$ & Hewlett Packard & 60 & Black & $\begin{array}{l}\text { 1-layer printout, } \\
\text { Whatman } 42\end{array}$ \\
\hline $\begin{array}{l}\text { IJ } 18 \mathrm{~K} \\
\text { HP }\end{array}$ & Hewlett Packard & 61 & Black & $\begin{array}{l}\text { 1-layer printout, } \\
\text { Whatman } 42\end{array}$ \\
\hline $\begin{array}{l}\text { IJ } 19 \mathrm{~K} \\
\text { HP }\end{array}$ & Hewlett Packard & $901 \times 1$ & Black & $\begin{array}{l}\text { 1-layer printout, } \\
\text { Whatman } 42\end{array}$ \\
\hline $\begin{array}{l}\text { IJ } 20 \mathrm{~K} \\
\text { HP }\end{array}$ & Hewlett Packard & $60 x 1$ & Black & $\begin{array}{l}\text { cartridge, liquid in } \\
\text { vial, 1-layer printout, } \\
\text { Whatman } 42\end{array}$ \\
\hline $\begin{array}{l}\text { IJ } 21 \mathrm{C} \\
\text { HP }\end{array}$ & Hewlett Packard & $60 x 1$ & Cyan Tri-Color & $\begin{array}{l}\text { cartridge, liquid in } \\
\text { vial, manually } \\
\text { deposited, 10-layer } \\
\text { printout, Whatman } 42\end{array}$ \\
\hline $\begin{array}{l}\text { IJ 22 M } \\
\text { HP }\end{array}$ & Hewlett Packard & $60 \times 1$ & $\begin{array}{l}\text { Magenta Tri- } \\
\text { Color }\end{array}$ & $\begin{array}{l}\text { cartridge, liquid in } \\
\text { vial, manually } \\
\text { deposited, 10-layer } \\
\text { printout, Whatman } 42\end{array}$ \\
\hline $\begin{array}{l}\text { IJ } 23 \text { Y } \\
\text { HP }\end{array}$ & Hewlett Packard & $60 \times 1$ & Yellow Tri-Color & $\begin{array}{l}\text { cartridge, liquid in } \\
\text { vial, manually } \\
\text { deposited, 10-layer } \\
\text { printout, Whatman } 42\end{array}$ \\
\hline $\begin{array}{l}\text { IJ } 24 \text { K } \\
\text { HP }\end{array}$ & Hewlett Packard & 45 & Black & $\begin{array}{l}\text { cartridge, manually } \\
\text { deposited, Whatman } \\
42\end{array}$ \\
\hline $\begin{array}{l}\text { IJ } 25 \text { C } \\
\text { HP }\end{array}$ & Hewlett Packard & 78 & Cyan Tri-Color & $\begin{array}{l}\text { cartridge, manually } \\
\text { deposited, Whatman } \\
42\end{array}$ \\
\hline
\end{tabular}




\begin{tabular}{|c|c|c|c|c|}
\hline Sample ID & Brand/Country & $\begin{array}{l}\text { Additional } \\
\text { Information }\end{array}$ & Color & Sample Form \\
\hline $\begin{array}{l}\text { IJ 26 M } \\
\text { HP }\end{array}$ & Hewlett Packard & 78 & $\begin{array}{l}\text { Magenta Tri- } \\
\text { Color }\end{array}$ & $\begin{array}{l}\text { cartridge, manually } \\
\text { deposited, Whatman } \\
42\end{array}$ \\
\hline $\begin{array}{l}\text { IJ } 27 \text { Y } \\
\text { HP }\end{array}$ & Hewlett Packard & 78 & Yellow Tri-Color & $\begin{array}{l}\text { cartridge, manually } \\
\text { deposited, Whatman } \\
42\end{array}$ \\
\hline $\begin{array}{l}\text { IJ } 28 \mathrm{~K} \\
\text { LX }\end{array}$ & Lexmark & 28 & Black & $\begin{array}{l}\text { manually deposited, } \\
\text { 1-layer printout, } \\
\text { Whatman } 42\end{array}$ \\
\hline $\begin{array}{l}\text { IJ } 29 \mathrm{~K} \\
\text { LX }\end{array}$ & Lexmark & $44 \times 1$ & Black & $\begin{array}{l}\text { cartridge, manually } \\
\text { deposited (sponge), } \\
\text { Whatman } 42\end{array}$ \\
\hline $\begin{array}{l}\text { IJ 30 C } \\
\text { LX }\end{array}$ & Lexmark & $43 x 1$ & Cyan Tri-Color & $\begin{array}{l}\text { cartridge, manually } \\
\text { deposited (sponge), } \\
\text { Whatman } 42\end{array}$ \\
\hline $\begin{array}{l}\text { IJ } 31 \text { M } \\
\text { LX }\end{array}$ & Lexmark & $43 \times 1$ & $\begin{array}{l}\text { Magenta Tri- } \\
\text { Color }\end{array}$ & $\begin{array}{l}\text { cartridge, manually } \\
\text { deposited (sponge), } \\
\text { Whatman } 42\end{array}$ \\
\hline $\begin{array}{l}\text { IJ 32 Y } \\
\text { LX }\end{array}$ & Lexmark & $43 \times 1$ & Yellow Tri-Color & $\begin{array}{l}\text { cartridge, manually } \\
\text { deposited (sponge), } \\
\text { Whatman } 42\end{array}$ \\
\hline $\begin{array}{l}\text { IJ 33 K } \\
\text { LX }\end{array}$ & Lexmark & 17 & Black & $\begin{array}{l}\text { cartridge, manually } \\
\text { deposited, Whatman } \\
42\end{array}$ \\
\hline $\begin{array}{l}\text { IJ 34 C } \\
\text { LX }\end{array}$ & Lexmark & 27 & Cyan Tri-Color & $\begin{array}{l}\text { cartridge, manually } \\
\text { deposited, Whatman } \\
42\end{array}$ \\
\hline $\begin{array}{l}\text { IJ 35 M } \\
\text { LX }\end{array}$ & Lexmark & 27 & $\begin{array}{l}\text { Magenta Tri- } \\
\text { Color }\end{array}$ & $\begin{array}{l}\text { cartridge, manually } \\
\text { deposited, Whatman } \\
42\end{array}$ \\
\hline $\begin{array}{l}\text { IJ 36 Y } \\
\text { LX }\end{array}$ & Lexmark & 27 & Yellow Tri-Color & $\begin{array}{l}\text { cartridge, 1-layer } \\
\text { printout, Whatman } 42\end{array}$ \\
\hline $\begin{array}{l}\text { IJ 37 K } \\
\text { CN }\end{array}$ & Canon & $210 \mathrm{XL}$ & Black & $\begin{array}{l}\text { cartridge, liquid in } \\
\text { vial, manually } \\
\text { deposited, Whatman } \\
42\end{array}$ \\
\hline $\begin{array}{l}\text { IJ } 38 \text { LM } \\
\text { HP }\end{array}$ & Hewlett Packard & 81 & Light Magenta & $\begin{array}{l}\text { cartridge, liquid in } \\
\text { vial, manually }\end{array}$ \\
\hline
\end{tabular}




\begin{tabular}{|c|c|c|c|c|}
\hline Sample ID & Brand/Country & $\begin{array}{l}\text { Additional } \\
\text { Information }\end{array}$ & Color & Sample Form \\
\hline & & & & $\begin{array}{l}\text { deposited, 10-layer } \\
\text { printout, Whatman } 42\end{array}$ \\
\hline $\begin{array}{l}\text { IJ 39 M } \\
\text { HP }\end{array}$ & Hewlett Packard & 80 & Magenta & $\begin{array}{l}\text { cartridge, liquid in } \\
\text { vial, manually } \\
\text { deposited, Whatman } \\
42\end{array}$ \\
\hline $\begin{array}{l}\text { IJ } 40 \mathrm{C} \\
\text { HP }\end{array}$ & Hewlett Packard & 80 & Cyan & $\begin{array}{l}\text { cartridge, liquid in } \\
\text { vial, manually } \\
\text { deposited, Whatman } \\
42\end{array}$ \\
\hline $\begin{array}{l}\text { IJ } 41 \mathrm{~K} \\
\text { HP }\end{array}$ & Hewlett Packard & 80 & Black & $\begin{array}{l}\text { cartridge, liquid in } \\
\text { vial, manually } \\
\text { deposited, Whatman } \\
42\end{array}$ \\
\hline $\begin{array}{l}\text { IJ } 42 \text { C } \\
\text { OL }\end{array}$ & Olivetti & N/A & Cyan & $\begin{array}{l}\text { manually deposited, } \\
\text { not Whatman } 42\end{array}$ \\
\hline $\begin{array}{l}\text { IJ } 43 \mathrm{M} \\
\text { OL }\end{array}$ & Olivetti & N/A & Magenta & $\begin{array}{l}\text { manually deposited, } \\
\text { not Whatman } 42\end{array}$ \\
\hline $\begin{array}{l}\text { IJ } 44 \text { Y } \\
\text { OL }\end{array}$ & Olivetti & $\mathrm{N} / \mathrm{A}$ & Yellow & $\begin{array}{l}\text { manually deposited, } \\
\text { not Whatman } 42\end{array}$ \\
\hline $\begin{array}{l}\text { IJ 45 C } \\
\text { HP }\end{array}$ & Hewlett Packard & 940XL & Cyan & $\begin{array}{l}\text { cartridge, manually } \\
\text { deposited, Whatman } \\
42\end{array}$ \\
\hline $\begin{array}{l}\text { IJ } 46 \text { M } \\
\text { HP }\end{array}$ & Hewlett Packard & 940XL & Magenta & $\begin{array}{l}\text { cartridge, manually } \\
\text { deposited, Whatman } \\
42\end{array}$ \\
\hline $\begin{array}{l}\text { IJ } 47 \mathrm{~K} \\
\text { HP }\end{array}$ & Hewlett Packard & 940XL & Black & $\begin{array}{l}\text { cartridge, manually } \\
\text { deposited, Whatman } \\
42\end{array}$ \\
\hline $\begin{array}{l}\text { IJ } 48 \mathrm{~K} \\
\text { BR }\end{array}$ & Brother & LC79BK & Black & $\begin{array}{l}\text { cartridge, liquid in } \\
\text { vial, manually } \\
\text { deposited, Whatman } \\
42\end{array}$ \\
\hline $\begin{array}{l}\text { IJ } 49 \text { K } \\
\text { SH }\end{array}$ & Sharp & UX-C80B & Black & $\begin{array}{l}\text { cartridge, liquid in } \\
\text { vial, manually } \\
\text { deposited, Whatman } \\
42\end{array}$ \\
\hline
\end{tabular}




\begin{tabular}{|c|c|c|c|c|}
\hline Sample ID & Brand/Country & $\begin{array}{l}\text { Additional } \\
\text { Information }\end{array}$ & Color & Sample Form \\
\hline $\begin{array}{l}\text { IJ 50 K } \\
\text { SH }\end{array}$ & Sharp & UX-C70B & Black & $\begin{array}{l}\text { cartridge, liquid in } \\
\text { vial, } 10 \text {-layer printout, } \\
\text { Whatman } 42\end{array}$ \\
\hline $\begin{array}{l}\text { IJ 51 K } \\
\text { CN }\end{array}$ & Canon & 7 & Black & $\begin{array}{l}\text { cartridge, liquid in } \\
\text { vial, 3-layer printout, } \\
\text { Whatman } 42\end{array}$ \\
\hline $\begin{array}{l}\text { IJ } 52 \mathrm{~K} \\
\text { CN }\end{array}$ & Canon & 9 & Black & $\begin{array}{l}\text { cartridge, liquid in } \\
\text { vial, manually } \\
\text { deposited, Whatman } \\
42\end{array}$ \\
\hline $\begin{array}{l}\text { IJ } 53 \text { C } \\
\text { CN }\end{array}$ & Canon & 9 & Cyan & $\begin{array}{l}\text { cartridge, liquid in } \\
\text { vial, manually } \\
\text { deposited, Whatman } \\
42\end{array}$ \\
\hline $\begin{array}{l}\text { IJ } 54 \text { M } \\
\text { CN }\end{array}$ & Canon & 9 & Magenta & $\begin{array}{l}\text { cartridge, liquid in } \\
\text { vial, manually } \\
\text { deposited, Whatman } \\
42\end{array}$ \\
\hline $\begin{array}{l}\text { IJ } 55 \mathrm{Y} \\
\text { CN }\end{array}$ & Canon & 9 & Yellow & $\begin{array}{l}\text { cartridge, liquid in } \\
\text { vial, manually } \\
\text { deposited, Whatman } \\
42\end{array}$ \\
\hline $\begin{array}{l}\text { IJ } 56 \mathrm{~K} \\
\text { KD }\end{array}$ & Kodak & $10 \mathrm{~B}$ & Black & $\begin{array}{l}\text { cartridge, liquid in } \\
\text { vial, manually } \\
\text { deposited, Whatman } \\
42\end{array}$ \\
\hline $\begin{array}{l}\text { IJ } 57 \mathrm{~K} \\
\text { KD }\end{array}$ & Kodak & 30 & Black & $\begin{array}{l}\text { cartridge, liquid in } \\
\text { vial, 10-layer printout } \\
\text { (copied), Whatman } 42\end{array}$ \\
\hline $\begin{array}{l}\text { IJ } 58 \mathrm{C} \\
\text { KD }\end{array}$ & Kodak & 30 & Cyan Tri-Color & $\begin{array}{l}\text { cartridge, liquid in } \\
\text { vial, manually } \\
\text { deposited, Whatman } \\
42\end{array}$ \\
\hline $\begin{array}{l}\text { IJ 59 M } \\
\text { KD }\end{array}$ & Kodak & 30 & $\begin{array}{l}\text { Magenta Tri- } \\
\text { Color }\end{array}$ & $\begin{array}{l}\text { cartridge, liquid in } \\
\text { vial, manually } \\
\text { deposited, Whatman } \\
42\end{array}$ \\
\hline $\begin{array}{l}\text { IJ } 60 \mathrm{Y} \\
\text { KD }\end{array}$ & Kodak & 30 & Yellow Tri-Color & $\begin{array}{l}\text { cartridge, liquid in } \\
\text { vial, manually }\end{array}$ \\
\hline
\end{tabular}




\begin{tabular}{|c|c|c|c|c|}
\hline Sample ID & Brand/Country & $\begin{array}{l}\text { Additional } \\
\text { Information }\end{array}$ & Color & Sample Form \\
\hline & & & & $\begin{array}{l}\text { deposited, Whatman } \\
42\end{array}$ \\
\hline $\begin{array}{l}\text { IJ } 61 \mathrm{~K} \\
\text { EP }\end{array}$ & Epson & T034120 & Black & $\begin{array}{l}\text { cartridge, liquid in } \\
\text { vial, manually } \\
\text { deposited, Whatman } \\
42\end{array}$ \\
\hline $\begin{array}{l}\text { IJ } 62 \text { LC } \\
\text { EP }\end{array}$ & Epson & T033520 & Light Cyan & $\begin{array}{l}\text { cartridge, liquid in } \\
\text { vial, manually } \\
\text { deposited, Whatman } \\
42\end{array}$ \\
\hline $\begin{array}{l}\text { IJ } 63 \mathrm{M} \\
\text { EP }\end{array}$ & Epson & T033320 & Magenta & $\begin{array}{l}\text { cartridge, liquid in } \\
\text { vial, manually } \\
\text { deposited, Whatman } \\
42\end{array}$ \\
\hline $\begin{array}{l}\text { IJ } 64 \mathrm{Y} \\
\text { EP }\end{array}$ & Epson & T034420 & Yellow & $\begin{array}{l}\text { cartridge, liquid in } \\
\text { vial, manually } \\
\text { deposited, Whatman } \\
42\end{array}$ \\
\hline $\begin{array}{l}\text { IJ } 65 \text { Y } \\
\text { BR }\end{array}$ & Brother & LC25Y & Yellow & $\begin{array}{l}\text { cartridge, liquid in } \\
\text { vial, manually } \\
\text { deposited, Whatman } \\
42\end{array}$ \\
\hline $\begin{array}{l}\text { IJ } 66 \text { C } \\
\text { BR }\end{array}$ & Brother & LC25C & Cyan & $\begin{array}{l}\text { cartridge, liquid in } \\
\text { vial, manually } \\
\text { deposited, Whatman } \\
42\end{array}$ \\
\hline $\begin{array}{l}\text { IJ 67 M } \\
\text { BR }\end{array}$ & Brother & LC25M & Magenta & $\begin{array}{l}\text { cartridge, liquid in } \\
\text { vial, manually } \\
\text { deposited, Whatman } \\
42\end{array}$ \\
\hline $\begin{array}{l}\text { IJ } 68 \mathrm{~K} \\
\text { BR }\end{array}$ & Brother & LC71BK & Black & $\begin{array}{l}\text { cartridge, liquid in } \\
\text { vial, manually } \\
\text { deposited, Whatman } \\
42\end{array}$ \\
\hline $\begin{array}{l}\text { IJ } 69 \text { K } \\
\text { SH }\end{array}$ & Sharp & AJ-C50B & Black & $\begin{array}{l}\text { cartridge, liquid in } \\
\text { vial, manually } \\
\text { deposited, Whatman } \\
42\end{array}$ \\
\hline
\end{tabular}




\begin{tabular}{|c|c|c|c|c|}
\hline Sample ID & Brand/Country & $\begin{array}{l}\text { Additional } \\
\text { Information }\end{array}$ & Color & Sample Form \\
\hline $\begin{array}{l}\text { IJ } 70 \text { C } \\
\text { SH }\end{array}$ & Sharp & AJ-C50C & Cyan Tri-Color & $\begin{array}{l}\text { cartridge, manually } \\
\text { deposited (sponge), } \\
\text { Whatman } 42\end{array}$ \\
\hline $\begin{array}{l}\text { IJ } 71 \mathrm{Y} \\
\text { SH }\end{array}$ & Sharp & AJ-C50C & Yellow Tri-Color & $\begin{array}{l}\text { cartridge, manually } \\
\text { deposited (sponge), } \\
\text { Whatman } 42\end{array}$ \\
\hline $\begin{array}{l}\text { IJ } 72 \text { M } \\
\text { SH }\end{array}$ & Sharp & AJ-C50C & $\begin{array}{l}\text { Magenta Tri- } \\
\text { Color }\end{array}$ & $\begin{array}{l}\text { cartridge, manually } \\
\text { deposited (sponge), } \\
\text { Whatman } 42\end{array}$ \\
\hline $\begin{array}{l}\text { IJ } 73 \mathrm{~K} \\
\text { DL }\end{array}$ & $\overline{\text { Dell }}$ & 9 & Black & $\begin{array}{l}\text { cartridge, liquid in } \\
\text { vial, manually } \\
\text { deposited, Whatman } \\
42\end{array}$ \\
\hline $\begin{array}{l}\text { IJ } 74 \text { K } \\
\text { DL }\end{array}$ & Dell & 21 & Black & $\begin{array}{l}\text { cartridge, liquid in } \\
\text { vial, manually } \\
\text { deposited, Whatman } \\
42\end{array}$ \\
\hline $\begin{array}{l}\text { IJ } 75 \text { C } \\
\text { DL }\end{array}$ & Dell & 5 & Cyan Tri-Color & $\begin{array}{l}\text { cartridge, liquid in } \\
\text { vial, manually } \\
\text { deposited, Whatman } \\
42\end{array}$ \\
\hline $\begin{array}{l}\text { IJ } 76 \text { Y } \\
\text { DL }\end{array}$ & Dell & 5 & Yellow Tri-Color & $\begin{array}{l}\text { cartridge, liquid in } \\
\text { vial, manually } \\
\text { deposited, Whatman } \\
42\end{array}$ \\
\hline $\begin{array}{l}\text { IJ } 77 \mathrm{M} \\
\text { DL }\end{array}$ & $\overline{\text { Dell }}$ & 5 & $\begin{array}{l}\text { Magenta Tri- } \\
\text { Color }\end{array}$ & $\begin{array}{l}\text { cartridge, liquid in } \\
\text { vial, manually } \\
\text { deposited, Whatman } \\
42\end{array}$ \\
\hline $\begin{array}{l}\text { IJ } 78 \text { LC } \\
\text { HP }\end{array}$ & Hewlett Packard & 81 & Light Cyan & $\begin{array}{l}\text { cartridge, liquid in } \\
\text { vial, manually } \\
\text { deposited, Whatman } \\
42\end{array}$ \\
\hline $\begin{array}{c}\text { TN 01 K } \\
\text { BR }\end{array}$ & Brother & TN-360 & Black & $\begin{array}{l}\text { 1-layer printout, } \\
\text { Whatman } 42\end{array}$ \\
\hline $\begin{array}{l}\text { TN 02 K } \\
\text { HPCN }\end{array}$ & $\begin{array}{l}\text { HB (HP/Canon) } \\
\text { "Hummingbird" }\end{array}$ & $\mathrm{N} / \mathrm{A}$ & Black & $\begin{array}{c}\text { powder in vial, } \\
\text { manually deposited, } \\
\text { Whatman } 42\end{array}$ \\
\hline
\end{tabular}




\begin{tabular}{|c|c|c|c|c|}
\hline Sample ID & Brand/Country & $\begin{array}{l}\text { Additional } \\
\text { Information }\end{array}$ & Color & Sample Form \\
\hline $\begin{array}{l}\text { TN 03 C } \\
\text { HPCN }\end{array}$ & $\begin{array}{l}\text { HB (HP/Canon) } \\
\text { "Hummingbird" }\end{array}$ & $\overline{\mathrm{N} / \mathrm{A}}$ & Cyan & $\begin{array}{c}\text { powder in vial, } \\
\text { manually deposited, } \\
\text { Whatman } 42\end{array}$ \\
\hline $\begin{array}{c}\text { TN } 04 \text { M } \\
\text { HPCN }\end{array}$ & $\begin{array}{l}\text { HB (HP/Canon) } \\
\text { "Hummingbird" }\end{array}$ & $\mathrm{N} / \mathrm{A}$ & Magenta & $\begin{array}{c}\text { powder in vial, } \\
\text { manually deposited, } \\
\text { Whatman } 42\end{array}$ \\
\hline $\begin{array}{l}\text { TN 05 Y } \\
\text { HPCN }\end{array}$ & $\begin{array}{l}\text { HB (HP/Canon) } \\
\text { "Hummingbird" }\end{array}$ & $\mathrm{N} / \mathrm{A}$ & Yellow & $\begin{array}{c}\text { powder in vial, } \\
\text { manually deposited, } \\
\text { Whatman } 42\end{array}$ \\
\hline $\begin{array}{c}\text { TN 06 K } \\
\text { HP }\end{array}$ & Hewlett Packard & $124 \mathrm{~A}$ & Black & $\begin{array}{c}\text { cartridge, manually } \\
\text { deposited, Whatman } \\
42\end{array}$ \\
\hline $\begin{array}{c}\text { TN } 07 \mathrm{~K} \\
\text { HP }\end{array}$ & Hewlett Packard & $124 \mathrm{~A}$ & Black & $\begin{array}{c}\text { cartridge, manually } \\
\text { deposited, Whatman } \\
42\end{array}$ \\
\hline $\begin{array}{c}\text { TN } 08 \mathrm{~K} \\
\text { HP }\end{array}$ & Hewlett Packard & $124 \mathrm{~A}$ & Black & $\begin{array}{c}\text { cartridge, manually } \\
\text { deposited, Whatman } \\
42\end{array}$ \\
\hline $\begin{array}{c}\text { TN 09 K } \\
\text { HP }\end{array}$ & Hewlett Packard & $05 \mathrm{~A}$ & Black & $\begin{array}{c}\text { cartridge, manually } \\
\text { deposited, Whatman } \\
42\end{array}$ \\
\hline $\begin{array}{c}\text { TN } 10 \mathrm{~K} \\
\text { HP }\end{array}$ & Hewlett Packard & $125 \mathrm{~A}$ & Black & $\begin{array}{c}\text { cartridge, manually } \\
\text { deposited, Whatman } \\
42\end{array}$ \\
\hline $\begin{array}{c}\text { TN } 11 \mathrm{~K} \\
\text { HP }\end{array}$ & Hewlett Packard & $304 \mathrm{~A}$ & Black & $\begin{array}{l}\text { 1-layer printout, } \\
\text { Whatman } 42\end{array}$ \\
\hline $\begin{array}{c}\text { TN } 12 \mathrm{~K} \\
\text { HP }\end{array}$ & Hewlett Packard & $05 \mathrm{X}$ & Black & $\begin{array}{l}\text { 1-layer printout, } \\
\text { Whatman } 42\end{array}$ \\
\hline $\begin{array}{c}\text { TN } 13 \mathrm{~K} \\
\text { HP }\end{array}$ & Hewlett Packard & $05 \mathrm{~A}$ & Black & $\begin{array}{l}\text { 1-layer printout, } \\
\text { Whatman } 42\end{array}$ \\
\hline $\begin{array}{c}\text { TN } 14 \mathrm{~K} \\
\text { HP }\end{array}$ & Hewlett Packard & $11 \mathrm{~A}$ & Black & $\begin{array}{l}\text { 1-layer printout, } \\
\text { Whatman } 42\end{array}$ \\
\hline $\begin{array}{c}\text { TN } 15 \mathrm{~K} \\
\text { HP }\end{array}$ & Hewlett Packard & $55 \mathrm{~A}$ & Black & $\begin{array}{l}\text { 1-layer printout, } \\
\text { Whatman } 42\end{array}$ \\
\hline $\begin{array}{c}\text { TN } 16 \mathrm{~K} \\
\text { HP }\end{array}$ & Hewlett Packard & $55 \mathrm{~A}$ & Black & $\begin{array}{c}\text { 1-layer printout, } \\
\text { Whatman } 42\end{array}$ \\
\hline
\end{tabular}




\begin{tabular}{|c|c|c|c|c|}
\hline Sample ID & Brand/Country & $\begin{array}{l}\text { Additional } \\
\text { Information }\end{array}$ & Color & Sample Form \\
\hline $\begin{array}{c}\text { TN } 17 \mathrm{~K} \\
\text { HP }\end{array}$ & Hewlett Packard & $55 \mathrm{~A}$ & Black & $\begin{array}{l}\text { 1-layer printout, } \\
\text { Whatman } 42\end{array}$ \\
\hline $\begin{array}{c}\text { TN } 18 \mathrm{~K} \\
\text { HP }\end{array}$ & Hewlett Packard & $11 \mathrm{~A}$ & Black & $\begin{array}{l}\text { 1-layer printout, } \\
\text { Whatman } 42\end{array}$ \\
\hline $\begin{array}{c}\text { TN 19 K } \\
\text { HP }\end{array}$ & Hewlett Packard & $05 \mathrm{X}$ & Black & $\begin{array}{l}\text { 1-layer printout, } \\
\text { Whatman } 42\end{array}$ \\
\hline $\begin{array}{c}\text { TN 20 K } \\
\text { HP }\end{array}$ & Hewlett Packard & $12 \mathrm{~A}$ & Black & $\begin{array}{l}\text { 1-layer printout, } \\
\text { Whatman } 42\end{array}$ \\
\hline $\begin{array}{c}\text { TN } 21 \mathrm{~K} \\
\text { HP }\end{array}$ & Hewlett Packard & $305 \mathrm{~A}$ & Black & $\begin{array}{c}\text { cartridge, powder, } \\
\text { manually deposited, } 1 \\
\& \text { 10-layer printout, } \\
\text { Whatman } 42\end{array}$ \\
\hline $\begin{array}{c}\text { TN 22 C } \\
\text { HP }\end{array}$ & Hewlett Packard & $125 \mathrm{~A}$ & Cyan & $\begin{array}{c}\text { cartridge, powder, } \\
\text { manually deposited, } 1 \\
\& \text { 10-layer printout, } \\
\text { Whatman } 42\end{array}$ \\
\hline $\begin{array}{c}\text { TN 23 C } \\
\text { HP }\end{array}$ & Hewlett Packard & $305 \mathrm{~A}$ & Cyan & $\begin{array}{c}\text { cartridge, powder, } \\
\text { manually deposited, } 1 \\
\& \text { 10-layer printout, } \\
\text { Whatman } 42\end{array}$ \\
\hline $\begin{array}{c}\text { TN } 24 \text { M } \\
\text { HP }\end{array}$ & Hewlett Packard & $125 \mathrm{~A}$ & Magenta & $\begin{array}{l}\text { cartridge, powder, } \\
\text { manually deposited, } \\
\text { Whatman } 42\end{array}$ \\
\hline $\begin{array}{c}\text { TN } 25 \mathrm{M} \\
\text { HP }\end{array}$ & Hewlett Packard & $305 \mathrm{~A}$ & Magenta & $\begin{array}{c}\text { cartridge, powder, } \\
\text { manually deposited, } \\
\text { Whatman } 42\end{array}$ \\
\hline $\begin{array}{c}\text { TN 26 Y } \\
\text { HP }\end{array}$ & Hewlett Packard & $125 \mathrm{~A}$ & Yellow & $\begin{array}{c}\text { cartridge, powder, } \\
\text { manually deposited, } \\
\text { Whatman } 42\end{array}$ \\
\hline $\begin{array}{c}\text { TN } 27 \text { Y } \\
\text { HP }\end{array}$ & Hewlett Packard & $305 \mathrm{~A}$ & Yellow & $\begin{array}{l}\text { cartridge, powder, } \\
\text { manually deposited, } \\
\text { Whatman } 42\end{array}$ \\
\hline $\begin{array}{l}\text { TN } 28 \mathrm{~K} \\
\text { IMX }\end{array}$ & IMEX 2300 & $\overline{\mathrm{N} / \mathrm{A}}$ & Black & $\begin{array}{c}\text { powder in vial, } \\
\text { manually deposited, } \\
\text { Whatman } 42\end{array}$ \\
\hline $\begin{array}{c}\text { TN } 29 \text { C } \\
\text { IMX }\end{array}$ & IMEX 2300 & N/A & Cyan & $\begin{array}{c}\text { powder in vial, } \\
\text { manually deposited, } \\
\text { Whatman } 42\end{array}$ \\
\hline
\end{tabular}




\begin{tabular}{|c|c|c|c|c|}
\hline Sample ID & Brand/Country & $\begin{array}{l}\text { Additional } \\
\text { Information }\end{array}$ & Color & Sample Form \\
\hline $\begin{array}{l}\text { TN 30 M } \\
\text { IMX }\end{array}$ & IMEX 2300 & $\overline{\mathrm{N} / \mathrm{A}}$ & Magenta & $\begin{array}{c}\text { powder in vial, } \\
\text { manually deposited, } \\
\text { Whatman } 42\end{array}$ \\
\hline $\begin{array}{l}\text { TN } 31 \text { Y } \\
\text { IMX }\end{array}$ & IMEX 2300 & $\mathrm{~N} / \mathrm{A}$ & Yellow & $\begin{array}{c}\text { powder in vial, } \\
\text { manually deposited, } \\
\text { Whatman } 42\end{array}$ \\
\hline $\begin{array}{c}\text { TN 32 K } \\
\text { KN }\end{array}$ & KM2300 Konica & N/A & Black & $\begin{array}{c}\text { powder in vial, } \\
\text { manually deposited, } \\
\text { Whatman } 42\end{array}$ \\
\hline $\begin{array}{c}\text { TN 33 C } \\
\text { KN }\end{array}$ & KM2300 Konica & $\overline{\mathrm{N} / \mathrm{A}}$ & Cyan & $\begin{array}{c}\text { powder in vial, } \\
\text { manually deposited, } \\
\text { Whatman } 42\end{array}$ \\
\hline $\begin{array}{c}\text { TN } 34 \text { M } \\
\text { KN }\end{array}$ & KM2300 Konica & N/A & Magenta & $\begin{array}{c}\text { powder in vial, } \\
\text { manually deposited, } \\
\text { Whatman } 42\end{array}$ \\
\hline $\begin{array}{c}\text { TN 35 Y } \\
\text { KN }\end{array}$ & KM2300 Konica & N/A & Yellow & $\begin{array}{c}\text { powder in vial, } \\
\text { manually deposited, } \\
\text { Whatman } 42\end{array}$ \\
\hline $\begin{array}{c}\text { TN 36 K } \\
\text { OD }\end{array}$ & Office Depot & N/A & Black & $\begin{array}{l}\text { 1-layer printout, } \\
\text { Whatman } 42\end{array}$ \\
\hline $\begin{array}{c}\text { TN } 37 \mathrm{~K} \\
\text { OKI }\end{array}$ & OKI & 43381904 & Black & $\begin{array}{c}\text { cartridge, manually } \\
\text { deposited, 1-layer } \\
\text { printout, Whatman } 42\end{array}$ \\
\hline $\begin{array}{c}\text { TN } 38 \text { K } \\
\text { OKI }\end{array}$ & OKI & 43381904 & Black & $\begin{array}{c}\text { manually deposited, } 1 \\
\& \text { 10-layer printout, } \\
\text { Whatman } 42\end{array}$ \\
\hline $\begin{array}{c}\text { TN 39 C } \\
\text { OKI }\end{array}$ & OKI & 43381904 & Cyan & $\begin{array}{c}\text { cartridge, powder, } \\
\text { manually deposited, } \\
\text { Whatman } 42\end{array}$ \\
\hline $\begin{array}{c}\text { TN } 40 \mathrm{M} \\
\text { OKI }\end{array}$ & OKI & 43381904 & Magenta & $\begin{array}{c}\text { cartridge, powder, } \\
\text { manually deposited, } \\
\text { Whatman } 42\end{array}$ \\
\hline $\begin{array}{c}\text { TN } 41 \text { Y } \\
\text { OKI }\end{array}$ & $\overline{\mathrm{OKI}}$ & 43381904 & Yellow & $\begin{array}{c}\text { cartridge, powder, } \\
\text { manually deposited, } \\
\text { Whatman } 42\end{array}$ \\
\hline $\begin{array}{l}\text { TN } 42 \mathrm{~K} \\
\text { XR }\end{array}$ & X6200 Xerox & N/A & Black & $\begin{array}{c}\text { powder in vial, } \\
\text { manually deposited, } \\
\text { Whatman } 42\end{array}$ \\
\hline
\end{tabular}




\begin{tabular}{|c|c|c|c|c|}
\hline Sample ID & Brand/Country & $\begin{array}{l}\text { Additional } \\
\text { Information }\end{array}$ & Color & Sample Form \\
\hline $\begin{array}{c}\text { TN 43 C } \\
\text { XR }\end{array}$ & X6200 Xerox & $\mathrm{N} / \mathrm{A}$ & Cyan & $\begin{array}{c}\text { powder in vial, } \\
\text { manually deposited, } \\
\text { Whatman } 42\end{array}$ \\
\hline $\begin{array}{c}\text { TN } 44 \text { M } \\
\text { XR }\end{array}$ & X6200 Xerox & $\mathrm{N} / \mathrm{A}$ & Magenta & $\begin{array}{c}\text { powder in vial, } \\
\text { manually deposited, } \\
\text { Whatman } 42\end{array}$ \\
\hline $\begin{array}{c}\text { TN } 45 Y \\
\text { XR }\end{array}$ & X6200 Xerox & $\mathrm{N} / \mathrm{A}$ & Yellow & $\begin{array}{c}\text { powder in vial, } \\
\text { manually deposited, } \\
\text { Whatman } 42\end{array}$ \\
\hline $\begin{array}{c}\text { TN } 46 \mathrm{~K} \\
\text { XK }\end{array}$ & XeiKon & $\mathrm{N} / \mathrm{A}$ & Black & $\begin{array}{c}\text { powder in vial, } \\
\text { manually deposited, } \\
\text { Whatman } 42\end{array}$ \\
\hline $\begin{array}{c}\text { TN } 47 \text { C } \\
\text { XK }\end{array}$ & XeiKon & $\mathrm{N} / \mathrm{A}$ & Cyan & $\begin{array}{c}\text { powder in vial, } \\
\text { manually deposited, } \\
\text { Whatman } 42\end{array}$ \\
\hline $\begin{array}{l}\text { TN } 48 \mathrm{M} \\
\text { XK }\end{array}$ & XeiKon & $\mathrm{N} / \mathrm{A}$ & Magenta & $\begin{array}{c}\text { powder in vial, } \\
\text { manually deposited, } \\
\text { Whatman } 42\end{array}$ \\
\hline $\begin{array}{c}\text { TN 49Y } \\
\text { XK }\end{array}$ & XeiKon & $\mathrm{N} / \mathrm{A}$ & Yellow & $\begin{array}{c}\text { powder in vial, } \\
\text { manually deposited, } \\
\text { Whatman } 42\end{array}$ \\
\hline $\begin{array}{c}\text { TN 50 K } \\
\text { BR }\end{array}$ & Brother & TN-420 & Black & $\begin{array}{c}1 \& \text { 10-layer printout, } \\
\text { Whatman } 42\end{array}$ \\
\hline $\begin{array}{c}\text { TN } 51 \mathrm{~K} \\
\text { XR }\end{array}$ & Xerox & $857 \mathrm{X}$ & Black & $\begin{array}{c}1 \& \text { 3-layer printout, } \\
\text { Whatman } 42\end{array}$ \\
\hline $\begin{array}{c}\text { TN } 52 \mathrm{~K} \\
\text { RC }\end{array}$ & $\mathrm{RICOH}$ & $1357 \mathrm{EX}$ & Black & $\begin{array}{l}\text { cartridge, powder, } \\
\text { manually deposited, } \\
\text { Whatman } 42\end{array}$ \\
\hline $\begin{array}{c}\text { TN } 53 \mathrm{~K} \\
\text { RC }\end{array}$ & RICOH & $1357 \mathrm{EX}$ & Black & $\begin{array}{c}\text { cartridge, powder, } \\
\text { manually deposited, } \\
\text { Whatman } 42\end{array}$ \\
\hline $\begin{array}{c}\text { TN } 54 \mathrm{~K} \\
\text { HP }\end{array}$ & Hewlett Packard & $305 \mathrm{~A}$ & Black & $\begin{array}{l}\text { cartridge, powder, } \\
\text { manually deposited, } \\
\text { Whatman } 42\end{array}$ \\
\hline $\begin{array}{c}\text { TN } 55 \mathrm{Y} \\
\text { HP }\end{array}$ & Hewlett Packard & $304 \mathrm{~A}$ & Yellow & $\begin{array}{l}\text { cartridge, powder, } \\
\text { manually deposited, } \\
\text { Whatman } 42\end{array}$ \\
\hline
\end{tabular}




\begin{tabular}{|c|c|c|c|c|}
\hline Sample ID & Brand/Country & $\begin{array}{l}\text { Additional } \\
\text { Information }\end{array}$ & Color & Sample Form \\
\hline $\begin{array}{c}\text { TN } 56 \mathrm{~K} \\
\text { HP }\end{array}$ & Hewlett Packard & $304 \mathrm{~A}$ & Black & $\begin{array}{l}\text { cartridge, powder, } \\
\text { manually deposited, } \\
\text { Whatman } 42\end{array}$ \\
\hline $\begin{array}{c}\text { TN } 57 \mathrm{~K} \\
\text { TS }\end{array}$ & Toshiba & $\begin{array}{c}\text { T-7200 } \\
\text { estudio853 }\end{array}$ & Black & $\begin{array}{l}1 \& 10 \text {-layer printout } \\
\text { (copied), Whatman } 42\end{array}$ \\
\hline $\begin{array}{c}\text { TN } 58 \mathrm{~K} \\
\text { CN }\end{array}$ & Canon & LC120/720 & Black & $\begin{array}{c}\text { cartridge, powder, } \\
\text { manually deposited, } \\
\text { Whatman } 42\end{array}$ \\
\hline $\begin{array}{c}\text { TN } 60 \mathrm{~K} \\
\text { CN }\end{array}$ & Canon & $\begin{array}{c}\text { GPR-32 } \\
\text { printer }\end{array}$ & Black & $\begin{array}{c}\text { powder, manually } \\
\text { deposited, Whatman } \\
42\end{array}$ \\
\hline $\begin{array}{l}\text { TN } 61 \text { Y } \\
\text { OKI }\end{array}$ & OKI & 430668 & Yellow & $\begin{array}{c}\text { cartridge, powder, } \\
\text { manually deposited, } \\
\text { Whatman } 42\end{array}$ \\
\hline $\begin{array}{c}\text { TN } 62 \text { K } \\
\text { CN }\end{array}$ & Canon & CLC1100 & Black & $\begin{array}{l}\text { cartridge, powder, } \\
\text { manually deposited, } \\
\text { Whatman } 42\end{array}$ \\
\hline $\begin{array}{c}\text { TN } 63 \text { C } \\
\text { CN }\end{array}$ & Canon & 116 & Cyan & $\begin{array}{l}\text { cartridge, powder, } \\
\text { manually deposited, } \\
\text { Whatman } 42\end{array}$ \\
\hline $\begin{array}{c}\text { TN 64 M } \\
\text { CN }\end{array}$ & Canon & 116 & Magenta & $\begin{array}{l}\text { cartridge, powder, } \\
\text { manually deposited, } \\
\text { Whatman } 42\end{array}$ \\
\hline $\begin{array}{c}\text { TN } 65 \mathrm{Y} \\
\text { CN }\end{array}$ & Canon & 116 & Yellow & $\begin{array}{l}\text { cartridge, powder, } \\
\text { manually deposited, } \\
\text { Whatman } 42\end{array}$ \\
\hline $\begin{array}{c}\text { TN } 66 ~ K \\
\text { DL }\end{array}$ & Dell & J9833 & Black & $\begin{array}{l}\text { cartridge, powder, } \\
\text { manually deposited, } \\
\text { Whatman } 42\end{array}$ \\
\hline $\begin{array}{c}\text { TN } 67 \text { C } \\
\text { DL }\end{array}$ & Dell & C5GC3 & Cyan & $\begin{array}{l}\text { cartridge, powder, } \\
\text { manually deposited, } \\
\text { Whatman } 42\end{array}$ \\
\hline $\begin{array}{c}\text { TN } 68 \mathrm{M} \\
\text { DL }\end{array}$ & Dell & XMX5D & Magenta & $\begin{array}{l}\text { cartridge, powder, } \\
\text { manually deposited, } \\
\text { Whatman } 42\end{array}$ \\
\hline $\begin{array}{c}\text { TN } 69 \text { K } \\
\text { PN }\end{array}$ & Panasonic & KX-FA83 & Black & $\begin{array}{l}\text { cartridge, powder, } \\
\text { manually deposited, } \\
\text { Whatman } 42\end{array}$ \\
\hline
\end{tabular}




\begin{tabular}{|c|c|c|c|c|}
\hline Sample ID & Brand/Country & $\begin{array}{l}\text { Additional } \\
\text { Information }\end{array}$ & Color & Sample Form \\
\hline $\begin{array}{c}\text { TN 70 C } \\
\text { RC }\end{array}$ & $\overline{\mathrm{RICOH}}$ & GC $21 \mathrm{C}$ & Cyan & $\begin{array}{l}\text { cartridge, liquid, } \\
\text { manually deposited, } \\
\text { Whatman } 42\end{array}$ \\
\hline $\begin{array}{c}\text { TN } 71 \mathrm{M} \\
\text { RC }\end{array}$ & $\overline{\mathrm{RICOH}}$ & GC 21M & Magenta & $\begin{array}{c}\text { cartridge, liquid, } \\
\text { manually deposited, } \\
\text { Whatman } 42\end{array}$ \\
\hline $\begin{array}{c}\text { TN } 72 \mathrm{Y} \\
\text { RC }\end{array}$ & $\overline{\mathrm{RICOH}}$ & GC 21Y & Yellow & $\begin{array}{c}\text { cartridge, liquid, } \\
\text { manually deposited, } \\
\text { Whatman } 42\end{array}$ \\
\hline $\begin{array}{c}\text { TN } 73 \text { K } \\
\text { SM }\end{array}$ & Samsung & K409 & Black & $\begin{array}{c}\text { cartridge, powder, } \\
\text { manually deposited, } \\
\text { Whatman } 42\end{array}$ \\
\hline $\begin{array}{c}\text { TN } 74 \text { C } \\
\text { SM }\end{array}$ & Samsung & $\mathrm{C} 407$ & Cyan & $\begin{array}{c}\text { cartridge, powder, } \\
\text { manually deposited, } \\
\text { Whatman } 42\end{array}$ \\
\hline $\begin{array}{c}\text { TN } 75 M \\
\text { SM }\end{array}$ & Samsung & M407 & Magenta & $\begin{array}{c}\text { cartridge, powder, } \\
\text { manually deposited, } \\
\text { Whatman } 42\end{array}$ \\
\hline $\begin{array}{c}\text { TN } 76 \mathrm{Y} \\
\text { SM }\end{array}$ & Samsung & Y409 & Yellow & $\begin{array}{c}\text { cartridge, powder, } \\
\text { manually deposited, } \\
\text { Whatman } 42\end{array}$ \\
\hline $\begin{array}{c}\text { TN } 77 \mathrm{~K} \\
\text { SH }\end{array}$ & Sharp & AL-110TD & Black & $\begin{array}{c}\text { cartridge, powder, } \\
\text { manually deposited, } \\
\text { Whatman } 42\end{array}$ \\
\hline $\begin{array}{c}\text { IT 01 DG } \\
\text { UZB }\end{array}$ & Uzbekistan & 1000 & Dark Green & 2001 \\
\hline $\begin{array}{c}\text { IT 02 BR } \\
\text { NEP }\end{array}$ & Nepal & 5 & Brown & 2009 \\
\hline $\begin{array}{c}\text { IT } 03 \text { DB } \\
\text { HAI }\end{array}$ & Haiti & 100 & Dark Blue & 2004 \\
\hline $\begin{array}{c}\text { IT 04 DG } \\
\text { ARG }\end{array}$ & Argentina & 5 & Dark Green & 1997 \\
\hline $\begin{array}{c}\text { IT 05 AQ } \\
\text { BAR }\end{array}$ & Barbados & 2 & Aqua & 2007 \\
\hline $\begin{array}{c}\text { IT 06 DM } \\
\text { BAR }\end{array}$ & Barbados & 2 & Dark Magenta & 2007 \\
\hline
\end{tabular}




\begin{tabular}{|c|c|c|c|c|}
\hline Sample ID & Brand/Country & $\begin{array}{l}\text { Additional } \\
\text { Information }\end{array}$ & Color & Sample Form \\
\hline $\begin{array}{c}\text { IT } 07 \text { DB } \\
\text { BAR }\end{array}$ & Barbados & 2 & Dark Blue & 2007 \\
\hline $\begin{array}{c}\text { IT 08 DB } \\
\text { BAR }\end{array}$ & Barbados & 2 & Dark Blue & 2007 \\
\hline $\begin{array}{c}\text { IT } 09 \mathrm{~K} \\
\text { UKR }\end{array}$ & Ukraine & 10 & Black & 2011 \\
\hline $\begin{array}{c}\text { IT 10 R } \\
\text { UKR }\end{array}$ & Ukraine & 10 & Red & 2011 \\
\hline $\begin{array}{l}\text { IT } 11 \text { GL } \\
\text { UKR }\end{array}$ & Ukraine & 10 & Gold & 2011 \\
\hline $\begin{array}{c}\text { IT } 12 \mathrm{~K} \\
\text { RUS }\end{array}$ & Russia & 50 & Black & 1997 \\
\hline $\begin{array}{c}\text { IT } 13 \mathrm{~K} \\
\text { RUS }\end{array}$ & Russia & 50 & Black & 1997 \\
\hline $\begin{array}{c}\text { IT } 14 \text { BR } \\
\text { RUS }\end{array}$ & Russia & 100 & Brown & 1997 \\
\hline $\begin{array}{c}\text { IT 15 BR } \\
\text { RUS }\end{array}$ & Russia & 100 & Brown & 1997 \\
\hline $\begin{array}{c}\text { IT } 16 \text { DB } \\
\text { CAN }\end{array}$ & Canada & 5 & Dark Blue & 2006 \\
\hline $\begin{array}{c}\text { IT } 17 \text { DB } \\
\text { CAN }\end{array}$ & Canada & 5 & Dark Blue & 2006 \\
\hline $\begin{array}{c}\text { IT } 18 \text { B } \\
\text { KOR }\end{array}$ & Korea (South) & 1000 & Blue & 2007 \\
\hline $\begin{array}{c}\text { IT } 19 \text { PR } \\
\text { KOR }\end{array}$ & Korea (South) & 1000 & Purple & 2007 \\
\hline $\begin{array}{c}\text { IT } 20 \text { PR } \\
\text { KOR }\end{array}$ & Korea (South) & 1000 & Purple & 2007 \\
\hline $\begin{array}{c}\text { IT } 21 \mathrm{DB} \\
\text { GUA }\end{array}$ & Guatemala & 5 & Dark Blue & 2008 \\
\hline $\begin{array}{c}\text { IT } 22 \text { DB } \\
\text { GUA }\end{array}$ & Guatemala & 5 & Dark Blue & 2008 \\
\hline $\begin{array}{c}\text { IT } 23 \text { DB } \\
\text { GUA }\end{array}$ & Guatemala & 5 & Dark Blue & 2008 \\
\hline
\end{tabular}




\begin{tabular}{|c|c|c|c|c|}
\hline Sample ID & Brand/Country & $\begin{array}{l}\text { Additional } \\
\text { Information }\end{array}$ & Color & Sample Form \\
\hline $\begin{array}{c}\text { IT 24 B } \\
\text { UKR }\end{array}$ & Ukraine & 5 & Blue & 2005 \\
\hline $\begin{array}{c}\text { IT } 25 \text { BR } \\
\text { UKR }\end{array}$ & Ukraine & 2 & Brown & 2011 \\
\hline $\begin{array}{c}\text { IT } 26 \text { G } \\
\text { CHI }\end{array}$ & China & 1 & Green & 1999 \\
\hline $\begin{array}{c}\text { IT } 27 \text { R } \\
\text { HON }\end{array}$ & Honduras & 1 & Red & 2006 \\
\hline $\begin{array}{c}\text { IT } 28 \text { R } \\
\text { PER }\end{array}$ & Peru & 10 & Red & 2009 \\
\hline $\begin{array}{c}\text { IT } 29 \text { G } \\
\text { PER }\end{array}$ & Peru & 10 & Green & 2009 \\
\hline $\begin{array}{c}\text { IT } 30 \text { G } \\
\text { PER }\end{array}$ & Peru & 10 & Green & 2009 \\
\hline $\begin{array}{c}\text { IT } 310 \\
\text { PER }\end{array}$ & Peru & 10 & Orange & 2009 \\
\hline $\begin{array}{c}\text { IT 32 R } \\
\text { TRI }\end{array}$ & Trinidad and Tobago & 1 & Red & 2006 \\
\hline $\begin{array}{c}\text { IT } 33 \text { MA } \\
\text { TRI }\end{array}$ & Trinidad and Tobago & 1 & Maroon & 2006 \\
\hline $\begin{array}{c}\text { IT } 34 \text { G } \\
\text { EUR }\end{array}$ & Europe (Italy) & 5 & Green & 2002 \\
\hline $\begin{array}{c}\text { IT } 35 \text { BR } \\
\text { EUR }\end{array}$ & Europe (Italy) & 5 & Brown & 2002 \\
\hline $\begin{array}{c}\text { IT } 36 \text { BR } \\
\text { EUR }\end{array}$ & Europe (Italy) & 5 & Brown & 2002 \\
\hline $\begin{array}{c}\text { IT } 37 \text { R } \\
\text { CUB }\end{array}$ & Cuba & 3 & Red & 2006 \\
\hline $\begin{array}{c}\text { IT } 38 \mathrm{G} \\
\text { CUB }\end{array}$ & Cuba & 3 & Green & 2006 \\
\hline $\begin{array}{c}\text { IT } 39 \text { DG } \\
\text { CTR }\end{array}$ & Costa Rica & 10000 & Dark Green & 2009 \\
\hline $\begin{array}{c}\text { IT } 40 \mathrm{G} \\
\text { CTR }\end{array}$ & Costa Rica & 10000 & Green & 2009 \\
\hline
\end{tabular}




\begin{tabular}{|c|c|c|c|c|}
\hline Sample ID & Brand/Country & $\begin{array}{l}\text { Additional } \\
\text { Information }\end{array}$ & Color & Sample Form \\
\hline $\begin{array}{c}\text { IT } 41 \mathrm{G} \\
\text { CTR }\end{array}$ & Costa Rica & 10000 & Green & 2009 \\
\hline $\begin{array}{c}\text { IT } 42 \text { G } \\
\text { CTR }\end{array}$ & Costa Rica & 10000 & Green & 2009 \\
\hline $\begin{array}{c}\text { IT } 43 \text { DY } \\
\text { CTR }\end{array}$ & Costa Rica & 5000 & Dark Yellow & 2009 \\
\hline $\begin{array}{c}\text { IT } 44 \text { MA } \\
\text { CTR }\end{array}$ & Costa Rica & 5000 & Maroon & 2009 \\
\hline $\begin{array}{c}\text { IT } 45 \text { Y } \\
\text { CTR }\end{array}$ & Costa Rica & 5000 & Yellow & 2009 \\
\hline $\begin{array}{c}\text { IT } 46 \text { DY } \\
\text { CTR }\end{array}$ & Costa Rica & 5000 & Dark Yellow & 2009 \\
\hline $\begin{array}{c}\text { IT } 47 \text { G } \\
\text { CAY }\end{array}$ & Cayman Islands & 5 & Green & 1996 \\
\hline $\begin{array}{c}\text { IT } 48 \text { BR } \\
\text { UAE }\end{array}$ & United Arab Emirates & 5 & Brown & 2009 \\
\hline $\begin{array}{c}\text { IT } 49 \text { AQ } \\
\text { TUN }\end{array}$ & Tunisia & 10 & Aqua & 1994 \\
\hline $\begin{array}{c}\text { IT } 50 \text { DB } \\
\text { TUN }\end{array}$ & Tunisia & 10 & Dark Blue & 1994 \\
\hline $\begin{array}{c}\text { IT } 51 \text { DB } \\
\text { TUN }\end{array}$ & Tunisia & 10 & Dark Blue & 1994 \\
\hline $\begin{array}{c}\text { IT } 52 \mathrm{~K} \\
\text { TRI }\end{array}$ & Trinidad and Tobago & 10 & Black & Unknown \\
\hline $\begin{array}{c}\text { IT } 53 \text { BR } \\
\text { NZE }\end{array}$ & New Zealand & 5 & Brownish-orange & Unknown \\
\hline $\begin{array}{c}\text { IT } 54 \mathrm{~K} \\
\text { RIT }\end{array}$ & N/A & $\mathrm{N} / \mathrm{A}$ & Black & N/A \\
\hline $\begin{array}{c}\text { IT } 55 \mathrm{G} \\
\text { RIT }\end{array}$ & $\mathrm{N} / \mathrm{A}$ & $\mathrm{N} / \mathrm{A}$ & Green & N/A \\
\hline $\begin{array}{c}\text { IT } 56 \text { B } \\
\text { LIVI }\end{array}$ & $\mathrm{N} / \mathrm{A}$ & $\mathrm{N} / \mathrm{A}$ & Blue & N/A \\
\hline $\begin{array}{c}\text { IT } 57 \mathrm{R} \\
\text { LIVI }\end{array}$ & $\mathrm{N} / \mathrm{A}$ & $\mathrm{N} / \mathrm{A}$ & Red & $\mathrm{N} / \mathrm{A}$ \\
\hline
\end{tabular}




\begin{tabular}{|c|c|c|c|c|}
\hline Sample ID & Brand/Country & $\begin{array}{l}\text { Additional } \\
\text { Information }\end{array}$ & Color & Sample Form \\
\hline $\begin{array}{c}\text { IT } 58 \text { GL } \\
\text { LIVI }\end{array}$ & N/A & N/A & Gold & $\mathrm{N} / \mathrm{A}$ \\
\hline $\begin{array}{c}\text { IT } 59 \text { G } \\
\text { CZE }\end{array}$ & Czech Republic & 100 & Green & 1997 \\
\hline $\begin{array}{c}\text { IT } 60 \mathrm{~K} \\
\text { JAM }\end{array}$ & Jamaica & 500 & Black & 2012 \\
\hline $\begin{array}{c}\text { IT } 61 \text { MA } \\
\text { JAM }\end{array}$ & Jamaica & 500 & Maroon & 2012 \\
\hline $\begin{array}{c}\text { IT 62 BR } \\
\text { JAM }\end{array}$ & Jamaica & 500 & Brown & 2012 \\
\hline $\begin{array}{c}\text { IT 63 B } \\
\text { NZE }\end{array}$ & New Zealand & 10 & Blue & Unknown \\
\hline $\begin{array}{c}\text { IT } 64 \text { B } \\
\text { NZE }\end{array}$ & New Zealand & 10 & Blue & Unknown \\
\hline $\begin{array}{c}\text { IT } 65 \text { G } \\
\text { NZE }\end{array}$ & New Zealand & 20 & Green & Unknown \\
\hline $\begin{array}{c}\text { IT 66 B } \\
\text { CTR }\end{array}$ & Costa Rica & 2000 & Blue & 2009 \\
\hline $\begin{array}{c}\text { IT } 67 \text { B } \\
\text { CTR }\end{array}$ & Costa Rica & 2000 & Blue & 2009 \\
\hline $\begin{array}{c}\text { IT } 68 \mathrm{LB} \\
\text { CTR }\end{array}$ & Costa Rica & 2000 & Light Blue & 2009 \\
\hline $\begin{array}{c}\text { IT 69 B } \\
\text { CTR }\end{array}$ & Costa Rica & 2000 & Blue & 2009 \\
\hline $\begin{array}{c}\text { IT } 70 \text { PR } \\
\text { CHI }\end{array}$ & China & 5 & Purple & 2005 \\
\hline $\begin{array}{c}\text { IT } 71 \mathrm{~K} \\
\text { CHI }\end{array}$ & China & 10 & Black & 2005 \\
\hline $\begin{array}{c}\text { IT } 72 \mathrm{G} \\
\text { EUR }\end{array}$ & Europe (Italy) & 5 & Green & 2013 \\
\hline $\begin{array}{c}\text { IT } 73 \text { G } \\
\text { EUR }\end{array}$ & Europe (Italy) & 5 & Green & 2013 \\
\hline $\begin{array}{c}\text { IT } 74 \text { G } \\
\text { EUR }\end{array}$ & Europe (Italy) & 5 & Green & 2013 \\
\hline
\end{tabular}




\begin{tabular}{|c|c|c|c|c|}
\hline Sample ID & Brand/Country & $\begin{array}{l}\text { Additional } \\
\text { Information }\end{array}$ & Color & Sample Form \\
\hline $\begin{array}{c}\text { IT } 75 \mathrm{~K} \\
\text { USA }\end{array}$ & United States & 1 & Black & 2006 \\
\hline $\begin{array}{c}\text { IT } 76 \text { G } \\
\text { USA }\end{array}$ & United States & 1 & Green & 2006 \\
\hline $\begin{array}{c}\text { IT } 77 \mathrm{~K} \\
\text { USA }\end{array}$ & United States & 5 & Black & 2006 \\
\hline $\begin{array}{c}\text { IT } 78 \text { G } \\
\text { USA }\end{array}$ & United States & 5 & Green & 2006 \\
\hline $\begin{array}{c}\text { IT } 79 \mathrm{~K} \\
\text { USA }\end{array}$ & United States & Unknown & Black & Unknown \\
\hline $\begin{array}{c}\text { IT } 80 \text { G } \\
\text { USA }\end{array}$ & United States & Unknown & Green & Unknown \\
\hline $\begin{array}{c}\text { IT } 81 \text { PR } \\
\text { NEP }\end{array}$ & Nepal & 5 & Purple & 2009 \\
\hline $\begin{array}{c}\text { IT } 82 \text { DB } \\
\text { HAI }\end{array}$ & Haiti & 100 & Dark Blue & 2004 \\
\hline $\begin{array}{c}\text { IT 83 B } \\
\text { RUS }\end{array}$ & Russia & 50 & Blue & 1997 \\
\hline $\begin{array}{c}\text { IT } 84 \text { BR } \\
\text { RUS }\end{array}$ & Russia & 100 & Brown & 1997 \\
\hline $\begin{array}{c}\text { IT 85 B } \\
\text { KOR }\end{array}$ & Korea (South) & 1000 & Blue & 2007 \\
\hline $\begin{array}{c}\text { IT } 86 \text { R } \\
\text { CAY }\end{array}$ & Cayman Islands & 5 & Red & 1996 \\
\hline $\begin{array}{c}\text { OF 01 C } \\
\text { FG }\end{array}$ & Flint Group & & Cyan & 5 discs, 2 paper \\
\hline $\begin{array}{c}\text { OF 02 M } \\
\text { FG }\end{array}$ & Flint Group & & Magenta & 4 discs, 2 paper \\
\hline $\begin{array}{c}\text { OF 03 Y } \\
\text { FG }\end{array}$ & Flint Group & & Yellow & 4 discs, 2 paper \\
\hline $\begin{array}{c}\text { OF 04 K } \\
\text { FG }\end{array}$ & Flint Group & & Black & 5 discs, 3 paper \\
\hline $\begin{array}{c}\text { OF 05 B } \\
\text { ECK }\end{array}$ & Eckart & & Brown & 6 discs, 2 paper \\
\hline
\end{tabular}




\begin{tabular}{|c|c|c|c|c|}
\hline Sample ID & Brand/Country & \begin{tabular}{|l|} 
Additional \\
Information
\end{tabular} & Color & Sample Form \\
\hline $\begin{array}{c}\text { OF 06 LY } \\
\text { FG }\end{array}$ & Flint Group & & Light Yellow & 5 discs, 1 paper \\
\hline $\begin{array}{c}\text { OF 07 DC } \\
\text { FG }\end{array}$ & Flint Group & & Dark Cyan & 4 discs, 2 paper \\
\hline $\begin{array}{c}\text { OF 08 C } \\
\text { DG }\end{array}$ & DayGlo & & Cyan & 5 discs, 2 paper \\
\hline $\begin{array}{c}\text { OF 09 K } \\
\text { TI }\end{array}$ & Toyo Ink & & Black & 4 discs, 2 paper \\
\hline $\begin{array}{c}\text { OF 10 C } \\
\text { TI }\end{array}$ & Toyo Ink & & Cyan & 4 discs, 2 paper \\
\hline $\begin{array}{c}\text { OF } 11 \mathrm{M} \\
\text { TI }\end{array}$ & Toyo Ink & & Magenta & 4 discs, 2 paper \\
\hline $\begin{array}{c}\text { OF } 12 \mathrm{Y} \\
\text { TI }\end{array}$ & Toyo Ink & & Yellow & 4 discs, 2 paper \\
\hline $\begin{array}{c}\text { OF } 13 \mathrm{~K} \\
\text { SC }\end{array}$ & Sun Chemical & & Black & 4 discs, 2 paper \\
\hline $\begin{array}{c}\text { OF } 14 \mathrm{C} \\
\text { SC }\end{array}$ & Sun Chemical & & Cyan & 5 discs, 2 paper \\
\hline $\begin{array}{c}\text { OF } 15 \mathrm{Y} \\
\text { SC }\end{array}$ & Sun Chemical & & Yellow & 4 discs, 2 paper \\
\hline $\begin{array}{c}\text { OF } 16 \mathrm{M} \\
\text { SC }\end{array}$ & Sun Chemical & & Magenta & 6 discs, 2 paper \\
\hline $\begin{array}{c}\text { OF } 17 \mathrm{~K} \\
\text { SC }\end{array}$ & Sun Chemical & & Black & 4 discs, 2 paper \\
\hline $\begin{array}{c}\text { OF } 18 \mathrm{C} \\
\text { SC }\end{array}$ & Sun Chemical & & Cyan & 4 discs, 2 paper \\
\hline $\begin{array}{c}\text { OF } 19 \mathrm{M} \\
\text { SC }\end{array}$ & Sun Chemical & & Magenta & 4 discs, 2 paper \\
\hline $\begin{array}{c}\text { OF } 20 \mathrm{Y} \\
\text { SC }\end{array}$ & Sun Chemical & & Yellow & 4 discs, 2 paper \\
\hline $\begin{array}{c}\text { OF } 21 \mathrm{~K} \\
\text { GI }\end{array}$ & Graphic Ink Co. & & Black & 4 discs, 2 paper \\
\hline $\begin{array}{c}\text { OF 22 Y } \\
\text { GI }\end{array}$ & Graphic Ink Co. & & Yellow & 4 discs, 2 paper \\
\hline
\end{tabular}




\begin{tabular}{|c|c|c|c|c|}
\hline Sample ID & Brand/Country & \begin{tabular}{|l|} 
Additional \\
Information
\end{tabular} & Color & Sample Form \\
\hline $\begin{array}{c}\text { OF } 23 \mathrm{M} \\
\text { GI }\end{array}$ & Graphic Ink Co. & & Magenta & 4 discs, 2 paper \\
\hline $\begin{array}{c}\text { OF } 24 \text { DC } \\
\text { GI }\end{array}$ & Graphic Ink Co. & & Dark Cyan & 4 discs, 2 paper \\
\hline $\begin{array}{c}\text { OF } 25 \text { C } \\
\text { GI }\end{array}$ & Graphic Ink Co. & & Cyan & 4 discs, 2 paper \\
\hline $\begin{array}{c}\text { OF } 26 \text { LY } \\
\text { GI }\end{array}$ & Graphic Ink Co. & & Light Yellow & 4 discs, 2 paper \\
\hline $\begin{array}{c}\text { OF } 27 \text { Y } \\
\text { GI }\end{array}$ & Graphic Ink Co. & & Yellow & 4 discs, 2 paper \\
\hline $\begin{array}{c}\text { OF } 28 \text { DO } \\
\text { GI }\end{array}$ & Graphic Ink Co. & & Dark Orange & 4 discs, 2 paper \\
\hline $\begin{array}{c}\text { OF } 29 \text { DO } \\
\text { GI }\end{array}$ & Graphic Ink Co. & & Dark Orange & 4 discs, 2 paper \\
\hline $\begin{array}{c}\text { OF 30 O } \\
\text { GI }\end{array}$ & Graphic Ink Co. & & Orange & 4 discs, 2 paper \\
\hline $\begin{array}{c}\text { OF 31 R } \\
\text { GI }\end{array}$ & Graphic Ink Co. & & Red & 4 discs, 2 paper \\
\hline $\begin{array}{c}\text { OF 32 R } \\
\text { GI }\end{array}$ & Graphic Ink Co. & & Red & 4 discs, 2 paper \\
\hline $\begin{array}{c}\text { OF } 33 \text { DP } \\
\text { GI }\end{array}$ & Graphic Ink Co. & & Dark Pink & 4 discs, 2 paper \\
\hline $\begin{array}{c}\text { OF } 34 \text { DP } \\
\text { GI }\end{array}$ & Graphic Ink Co. & & Dark Pink & 4 discs, 2 paper \\
\hline $\begin{array}{c}\text { OF } 35 \text { PR } \\
\text { GI }\end{array}$ & Graphic Ink Co. & & Purple & 4 discs, 2 paper \\
\hline $\begin{array}{c}\text { OF 36 } \\
\text { DPR GI }\end{array}$ & Graphic Ink Co. & & Dark Purple & 5 discs, 2 paper \\
\hline $\begin{array}{c}\text { OF 37 } \\
\text { DPR GI }\end{array}$ & Graphic Ink Co. & & Dark Purple & 4 discs, 2 paper \\
\hline $\begin{array}{c}\text { OF } 38 \text { DC } \\
\text { GI }\end{array}$ & Graphic Ink Co. & & Dark Cyan & 4 discs, 2 paper \\
\hline $\begin{array}{c}\text { OF } 39 \text { G } \\
\text { GI }\end{array}$ & Graphic Ink Co. & & Green & 4 discs, 2 paper \\
\hline
\end{tabular}




\begin{tabular}{|c|c|c|c|c|}
\hline Sample ID & Brand/Country & $\begin{array}{l}\text { Additional } \\
\text { Information }\end{array}$ & Color & Sample Form \\
\hline $\begin{array}{c}\text { OF } 40 \\
\text { RIT }\end{array}$ & N/A & & Black & 3 pieces \\
\hline $\begin{array}{l}\text { OF } 41 \\
\text { LIVI }\end{array}$ & $\mathrm{N} / \mathrm{A}$ & & Green & 3 pieces \\
\hline $\begin{array}{l}\text { OF } 42 \\
\text { LIVI }\end{array}$ & N/A & & Pink/Peach & 3 pieces \\
\hline $\begin{array}{l}\text { OF } 43 \\
\text { LIVI }\end{array}$ & $\mathrm{N} / \mathrm{A}$ & & $\begin{array}{c}\text { Blue \& Orange } \\
\text { Stripes }\end{array}$ & 3 pieces \\
\hline $\begin{array}{l}\text { OF } 44 \\
\text { LIVI }\end{array}$ & N/A & & Red & 3 pieces \\
\hline $\begin{array}{l}\text { OF 45 } \\
\text { LIVI }\end{array}$ & $\mathrm{N} / \mathrm{A}$ & & Blue & 3 pieces \\
\hline $\begin{array}{l}\text { OF } 46 \\
\text { LIVI }\end{array}$ & N/A & & Bronze & 3 pieces \\
\hline $\begin{array}{l}\text { OF } 47 \\
\text { LIVI }\end{array}$ & N/A & & Green & 3 pieces \\
\hline $\begin{array}{l}\text { OF } 48 \\
\text { LIVI }\end{array}$ & N/A & & Brown/Orange & 3 pieces \\
\hline $\begin{array}{l}\text { OF } 49 \\
\text { USPB }\end{array}$ & $\mathrm{N} / \mathrm{A}$ & & $\begin{array}{c}\text { Blue/Pink/Orange } \\
\text { Lines }\end{array}$ & 3 pieces \\
\hline $\begin{array}{l}\text { OF 50 } \\
\text { USPB }\end{array}$ & N/A & & Orange Stripes & 3 pieces \\
\hline $\begin{array}{l}\text { OF } 51 \\
\text { USPB }\end{array}$ & N/A & & Red & 3 pieces \\
\hline $\begin{array}{l}\text { OF } 52 \\
\text { USPB }\end{array}$ & N/A & & $\begin{array}{l}\text { Blue (solid blue } \\
\text { side with white } \\
\text { circles) }\end{array}$ & 3 pieces \\
\hline $\begin{array}{l}\text { OF } 53 \\
\text { USPB }\end{array}$ & N/A & & Red & 3 pieces \\
\hline $\begin{array}{l}\text { OF } 54 \\
\text { USPB }\end{array}$ & N/A & & Red & 3 pieces \\
\hline $\begin{array}{l}\text { OF } 55 \\
\text { USPB }\end{array}$ & N/A & & Blue & 3 pieces \\
\hline $\begin{array}{l}\text { OF } 56 \\
\text { USPN }\end{array}$ & N/A & & Yellow & 3 pieces \\
\hline
\end{tabular}




\begin{tabular}{|c|c|c|c|c|}
\hline Sample ID & Brand/Country & \begin{tabular}{|l|} 
Additional \\
Information
\end{tabular} & Color & Sample Form \\
\hline $\begin{array}{l}\text { OF } 57 \\
\text { USPN }\end{array}$ & N/A & & Black & 3 pieces \\
\hline $\begin{array}{l}\text { OF } 58 \\
\text { USPN }\end{array}$ & $\mathrm{N} / \mathrm{A}$ & & Light Blue & 3 pieces \\
\hline $\begin{array}{l}\text { OF } 59 \\
\text { USPN }\end{array}$ & N/A & & Black & 3 pieces \\
\hline $\begin{array}{l}\text { OF 60 } \\
\text { USPN }\end{array}$ & $\mathrm{N} / \mathrm{A}$ & & Red & 3 pieces \\
\hline $\begin{array}{l}\text { OF } 61 \\
\text { USPN }\end{array}$ & N/A & & Blue & 3 pieces \\
\hline $\begin{array}{l}\text { OF } 62 \\
\text { USPN }\end{array}$ & $\mathrm{N} / \mathrm{A}$ & & Black & 3 pieces \\
\hline $\begin{array}{l}\text { OF } 63 \\
\text { USPN }\end{array}$ & $\mathrm{N} / \mathrm{A}$ & & Dark Blue & 3 pieces \\
\hline $\begin{array}{c}\text { OF } 64 \mathrm{~K} \\
\text { UB }\end{array}$ & Unibrilliant (Germany) & & Black & Paste \\
\hline $\begin{array}{c}\text { OF 65 C } \\
\text { UB }\end{array}$ & Unibrilliant (Germany) & & Cyan & Paste \\
\hline $\begin{array}{c}\text { OF } 66 \mathrm{M} \\
\text { UB }\end{array}$ & Unibrilliant (Germany) & & Magenta & Paste \\
\hline $\begin{array}{c}\text { OF } 67 \mathrm{Y} \\
\text { UB }\end{array}$ & Unibrilliant (Germany) & & Yellow & Paste \\
\hline $\begin{array}{c}\text { OF } 68 \mathrm{~K} \\
\text { SC }\end{array}$ & Sun Chemical & & Black & Paste \\
\hline $\begin{array}{c}\text { OF } 69 \text { C } \\
\text { SC }\end{array}$ & Sun Chemical & & Cyan & Paste \\
\hline $\begin{array}{c}\text { OF } 70 \mathrm{M} \\
\text { SC }\end{array}$ & Sun Chemical & & Magenta & Paste \\
\hline $\begin{array}{c}\text { OF } 71 \mathrm{Y} \\
\text { SC }\end{array}$ & Sun Chemical & & Yellow & Paste \\
\hline $\begin{array}{c}\text { OF } 72 \mathrm{~K} \\
\text { SC }\end{array}$ & Sun Chemical & & Black & Paste \\
\hline $\begin{array}{c}\text { OF } 73 \mathrm{C} \\
\text { SC }\end{array}$ & Sun Chemical & & Cyan & Paste \\
\hline
\end{tabular}




\begin{tabular}{|c|c|c|c|c|}
\hline Sample ID & Brand/Country & $\begin{array}{l}\text { Additional } \\
\text { Information }\end{array}$ & Color & Sample Form \\
\hline $\begin{array}{c}\text { OF 74 M } \\
\text { SC }\end{array}$ & Sun Chemical & & Magenta & Paste \\
\hline $\begin{array}{c}\text { OF 75 Y } \\
\text { SC }\end{array}$ & Sun Chemical & & Yellow & Paste \\
\hline $\begin{array}{c}\text { OF 76 K } \\
\text { SC }\end{array}$ & Sun Chemical & & Black & Paste \\
\hline $\begin{array}{c}\text { OF 77 C } \\
\text { SC }\end{array}$ & Sun Chemical & & Cyan & Paste \\
\hline $\begin{array}{c}\text { OF 78 M } \\
\text { SC }\end{array}$ & Sun Chemical & & Magenta & Paste \\
\hline $\begin{array}{c}\text { OF 79 Y } \\
\text { SC }\end{array}$ & Sun Chemical & & Yellow & Paste \\
\hline
\end{tabular}


VITA

\section{RHETT WILLIAMSON}

Born, Somers Point, New Jersey

2008-2012

B.S., Chemistry

The College of New Jersey

Ewing, New Jersey

$2012-2016$

Doctoral Candidate

Florida International University

Miami, Florida

2015

Best Student Poster Presentation

ASMS Sanibel Conference

Clearwater Beach, Florida

2015

Southern Regional Finalist

CSGS 3 Minute Thesis (3MT) Competition

New Orleans, LA

2016

Dissertation Year Fellowship

Florida International University

Miami, Florida

\section{PUBLICATIONS AND PRESENTATIONS}

Williamson, R., Raeva, A., \& Almirall, J. R. (2016). Characterization of Printing Inks Using DART-Q-TOF-MS and Attenuated Total Reflectance (ATR) FTIR. Journal of Forensic Sciences, 61(3), 706-714.

Trejos, T., Torrione, P., Corzo, R., Raeva, A., Subedi, K., Williamson, R., ... \& Almirall, J. (2016). A novel forensic tool for the characterization and comparison of printing ink evidence: development and evaluation of a searchable database using data fusion of spectrochemical methods. Journal of Forensic Sciences, 61(3), 715-724.

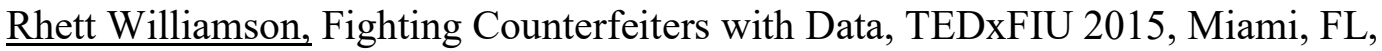
November 2015 
Rhett Williamson and José R. Almirall, MALDI-MS as a tool for the characterization of inks in forensic document analysis, FACSS SciX, Providence, RI, September 2015

Rhett Williamson and José R. Almirall, Characterization of Printing Inks using DARTMS and MALDI-MS for uses in Forensic Document Analysis, ASMS Sanibel Conference, Clearwater Beach, FL, January 2015

Rhett Williamson and José R. Almirall, Characterization and Discrimination of Printing Inks for uses in Forensic Document Analysis, FACSS SciX, Reno, NV, September 2014

Rhett Williamson and José R. Almirall, Characterization and Discrimination of Printing Inks using DART-MS, Py-GC/MS, and ATR-FTIR for Forensic Document Analysis, AAFS $66^{\text {th }}$ Annual Meeting, Seattle, WA, February 2014

Rhett Williamson and John Allison, A Survey of Methods in Latent Fingerprint Development, Northeast Regional Honors Council Conference, Baltimore, MD, April 2012 